\title{
Palaeomagnetic secular variation \\ recorded by lavas from the \\ Taupo Volcanic Zone, \\ New Zealand
}

by

\section{Annika Greve}

\author{
A thesis \\ submitted to the Victoria University of \\ Wellington in fulfilment of the requirements for \\ the degree of Doctor of Philosophy \\ in Geophysics \\ Victoria University of Wellington
}




\begin{abstract}
In order to understand the origin, temporal behaviour and spatial characteristics of Earth's magnetic field, globally distributed records of the palaeomagnetic direction and absolute palaeointensity are required. However a paucity of data from the southern hemisphere significantly limits the resolution of global field models, particularly on short time-scales.

In this thesis new, high quality palaeomagnetic data from volcanic materials sampled within the Taupo Volcanic Zone, New Zealand are presented, with a focus on the Tongariro and Okataina Volcanic Centre.

New palaeomagnetic directions were obtained from 19 andesitic or rhyolitic lavas, of which 10 also produced successful palaeointensity results. Palaeointensity experiments were conducted using a combination of traditional Thellier-type thermal, and microwave techniques. Detailed magneto-mineralogical investigations carried out alongside these experiments helped to characterise the primary remanence carriers and to justify the reliability of the results.

The study also revises the age controls and results from earlier palaeomagnetic studies on Holocene volcanic materials from the area. All new or revised data are summarized into a new data compilation for New Zealand, which includes 24 directions and ten palaeointensities dated between $1886 \mathrm{AD}$ and 15,000 yrs BP.

The new directional data reproduces the features of the most recently published continuous record from Lake Mavora (Fiordland, New Zealand), although with directions ranging in their extremes from $321^{\circ}$ (west) to $26^{\circ}$ (east) declination and -82 to $-49^{\circ}$ in inclination, the discrete dataset describes somewhat larger amplitude swings.
\end{abstract}


With few exceptions, the new palaeointensity dataset describes a steady increase in the palaeointensity throughout the Holocene, from $37.0 \pm 5.7 \mu \mathrm{T}$ obtained from a pre- $8 \mathrm{ka}$ lava to $70.6 \pm 4.1 \mu \mathrm{T}$ from the youngest $(\leq 500 \mathrm{yrs} \mathrm{BP}$ ) flows sampled. A similar trend is also predicted by the latest global field model pfm9k. Furthermore, the data falls within the range of palaeointensity variation suggested by the Mavora record. The dataset roughly agrees with a global VADM reconstruction in the early Holocene ( $>$ 5000 yrs BP), but yields values significantly above the global trend in the late Holocene $(<1000$ yrs BP) which supports the presence of significant non-dipolar components over the SW Pacific region in the time period, visible in global field models and from continuous PSV records.

A comparison of the directional records with the Mavora Curve provided refinement of age estimates of five lava flows from the Tongariro Volcanic Centre, from uncertainties in the range of 2-3000 years. The new palaeomagnetic emplacement age estimates for these flows have age brackets as short as 500 years and thus highlight different phases of the young cone building eruptive activity on Ruapehu volcano. 


\section{Acknowledgements}

First of all I would like to thank my primary supervisor Gillian Turner for the support and encouragement all the way along.

To John Gamble who always had an open ear for my questions and his support in particular during the last six months of "PhD rollercoaster". To my co- $\mathrm{PhD}$ student Rimpy Kinger and the rest of the research group including Eva Sutter and Elizabeth Cairns for the social times and providing "moral" support. I'm grateful to the palaeomagnetic research group at the University of Liverpool, for being welcoming, letting me use their facilities, the advice in setting up experiments and fruitful discussions; including Andreas Nilsson, Mimi Hill, Andy Biggins, Laura Artal-Roberts, Megan Hammond, John Shaw and Andy Roberts. To Emma Hodgson in particular for the many hours invested into teaching me how to run palaeointensity experiments and to operate the microwave system and giving me a place to stay.

To Chris Conway, Dougal Townsend and Graham Leonard for collaborating during the Ruapehu sampling campaign. Stewart Bush for the preparation of polished thin sections and Ian Shipper for teaching me how to use the electron microprobe.

Thank you to Group B during the 2013 Summer School for Rock Magnetism, led by Dario Bilardello, including Maggie Avery, Emma Hodgson, Timothy O'Brien, and Sara Satolli and the rest of the team at the Institute for Rock Magnetism.

I'm in debt to a large number of field assistants, including Andreas Nilsson, Emma Hodgson, Michael \& Tim Sherry, Russel Bicknell, Ben Hines, Pia Skorstengaard, Achim Gäthke, Rick Zwaan, Klemenz Ilse, my parents Carmen and Ulf. Robyn Vasco, who helped during fieldwork, sample preparation and 
palaeomagnetic experiments during a summer internship in 2014. To the Sherry \& Goodwin family, who adopted me as one of their own and gave me a home far away from home. My family, in particular my parents Carmen and Ulf, and grandfather Horst for their ongoing encouragement and financial support. Antje Müller, for all the sailing adventures and competing with me during the South Pacific Javelin championships in Perth in early 2016, and filling me with energy to complete my thesis.

To Tim Sherry, my partner and skiff crew, who has been by my side all the way along, through many up and downs! Thank you to Katie Collins, Tim Sherry and Elisa Piispa for proof reading and constructive comments on the draft chapters.

This study was largely funded by a Royal Society Marsden fund. Early financial support was also provided by a scholarship by the German Academic Exchange Service (DAAD), who also funded Robyn Vasco's summer research experience in 2014. 


\section{Table of Contents}

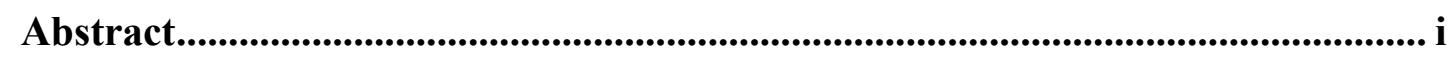

Acknowledgements .............................................................................................. iii

Table of Contents .........................................................................................................

List of Figures........................................................................................................................... $x$

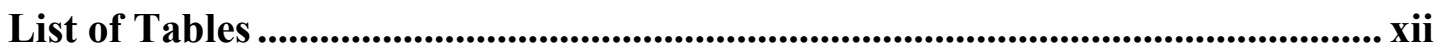

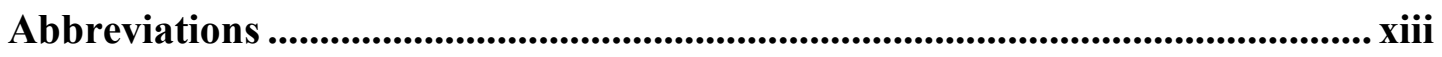

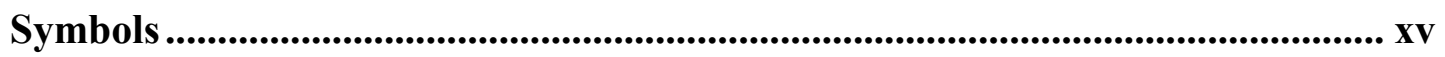

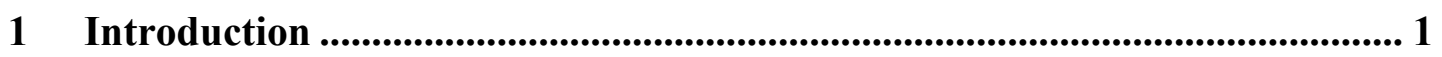

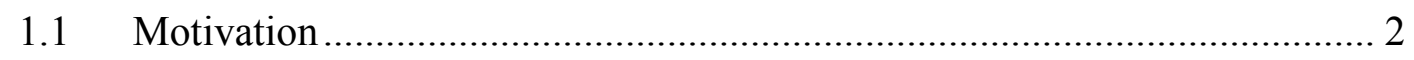

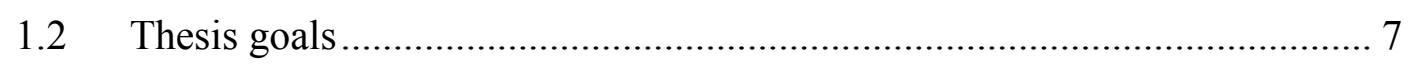

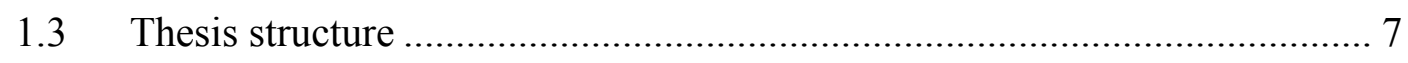

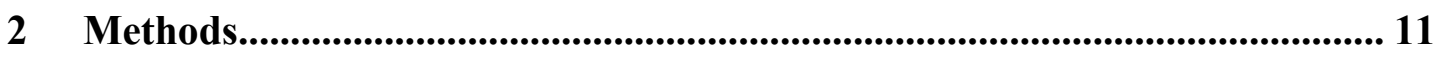

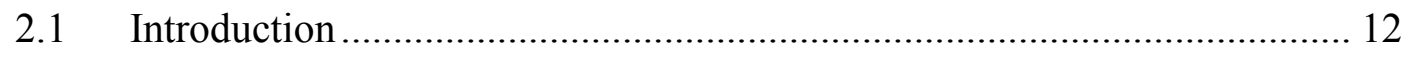

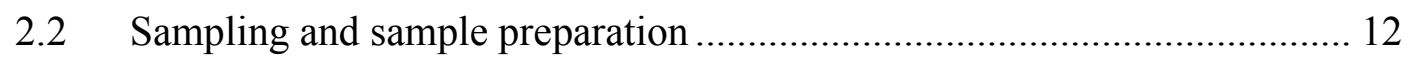

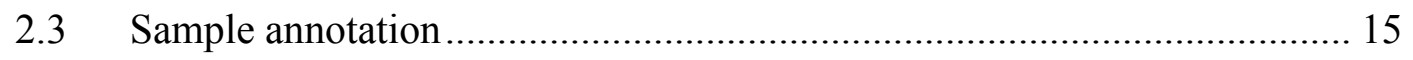

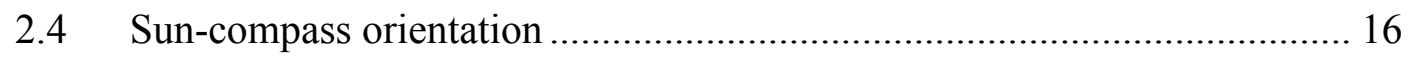

$2.5 \quad$ Rock magnetic investigation ........................................................... 17

2.5.1 Isothermal remanent magnetisation (IRM) and backfield experiments18

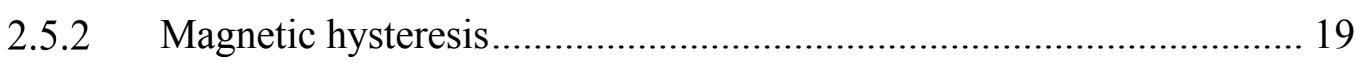

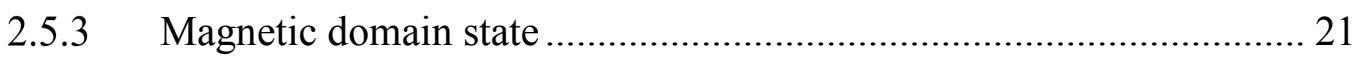

2.5.4 Thermomagnetic experiments..................................................... 22

2.6 Imaging methods and quantitative analysis ......................................... 24

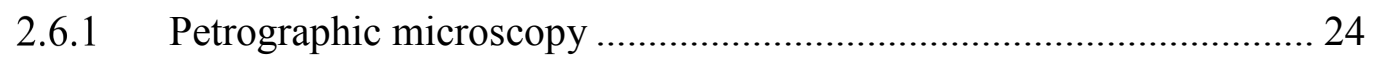

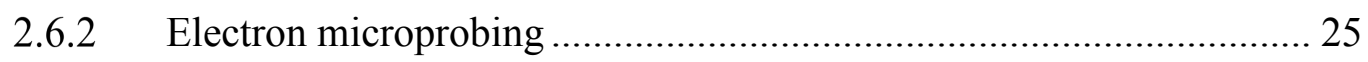

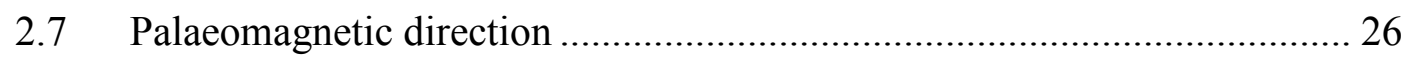

2.7.1 Progressive demagnetisation techniques ......................................... 26

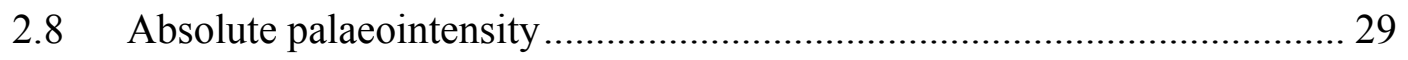




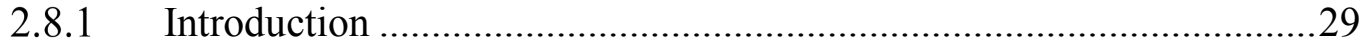

2.8.2 Concept and palaeointensity protocols .............................................29

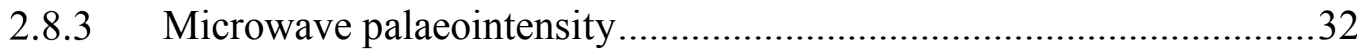

\section{Secular variation and new palaeomagnetic age constraints on lava flows}

from the Tongariro Volcanic Centre, New Zealand................................................35

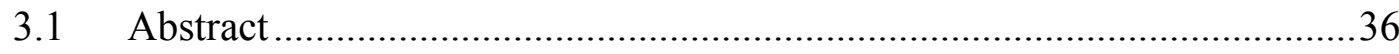

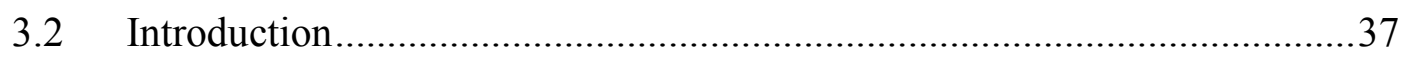

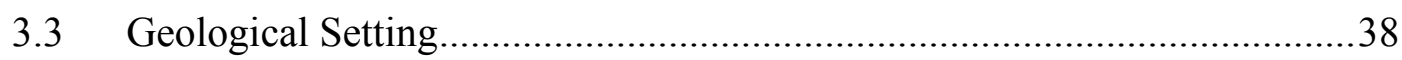

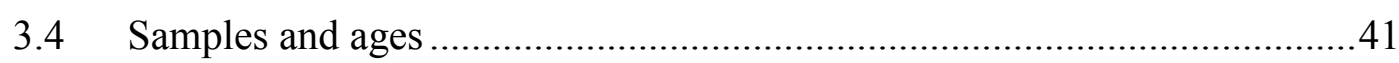

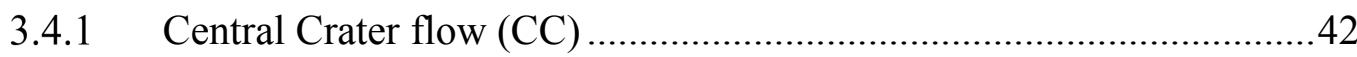

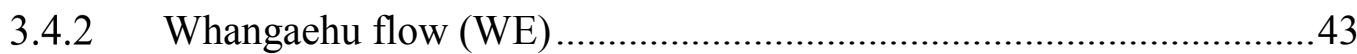

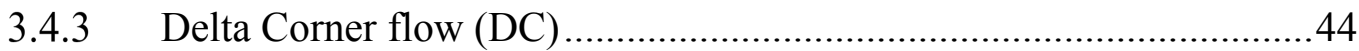

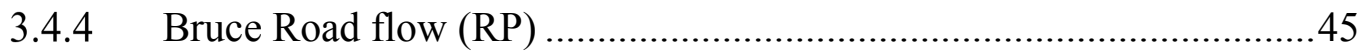

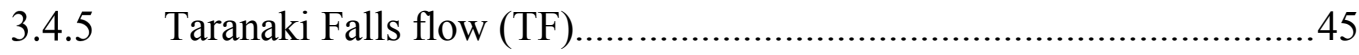

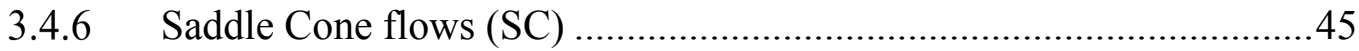

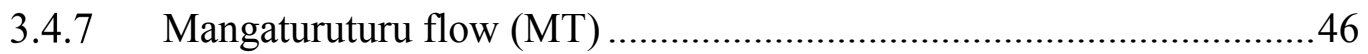

3.4.8 Whakapapaiti A-C flows (WPA, WPB, WPC) ...................................46

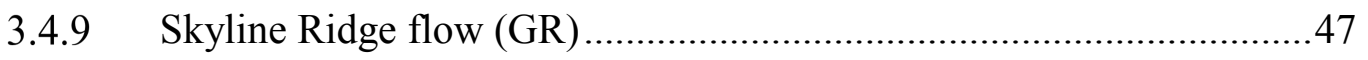

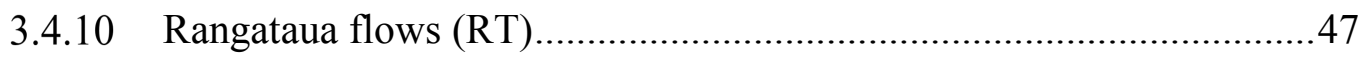

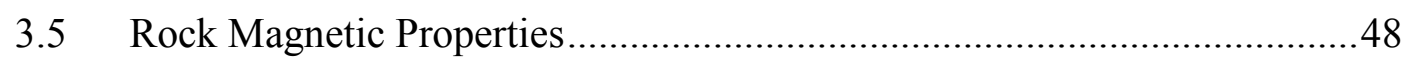

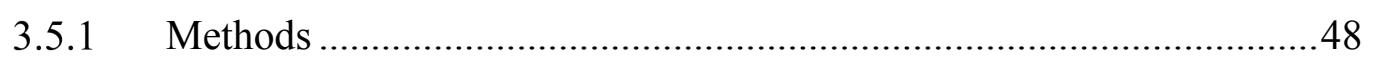

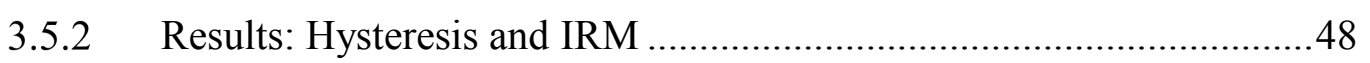

3.5.3 Results: Thermomagnetic experiments .............................................49

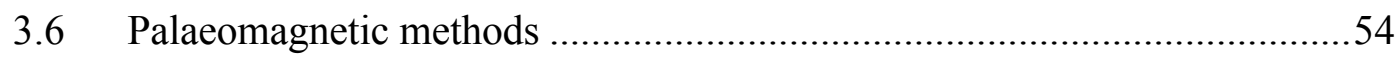

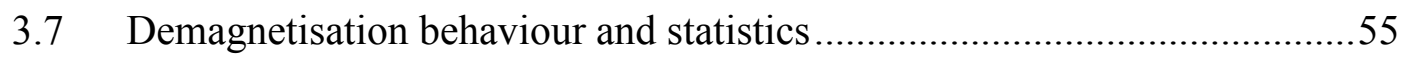

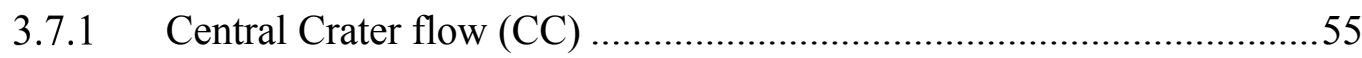

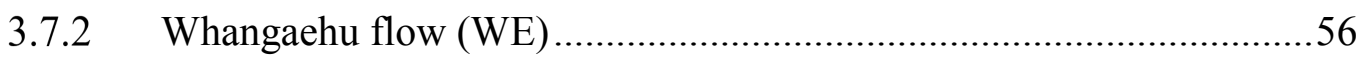

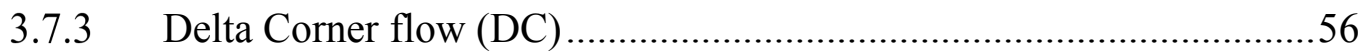

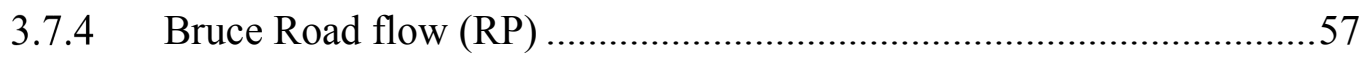

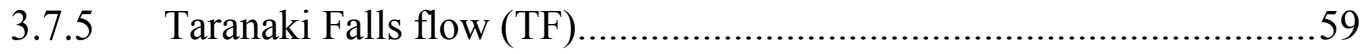

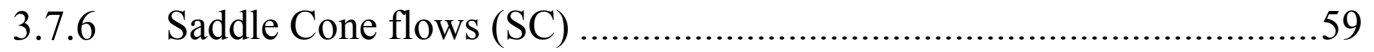

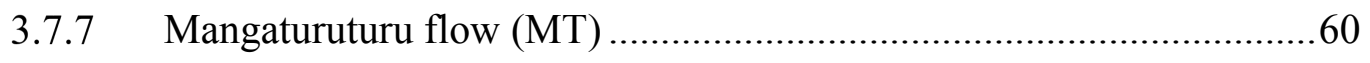

3.7.8 Whakapapapaiti A - C flows (WPA, WPB, WPC) ............................60 


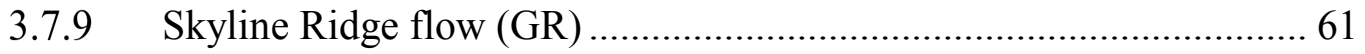

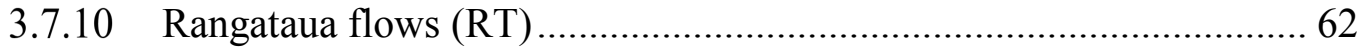

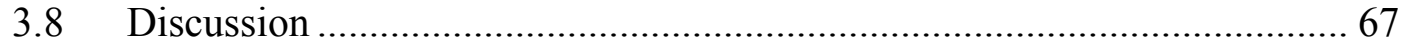

3.8.1 Accuracy and precision of the palaeomagnetic data.......................... 67

3.8.2 Comparison with previous New Zealand PSV studies ....................... 69

3.8.3 Palaeomagnetic refinement of the age-control on flows younger than

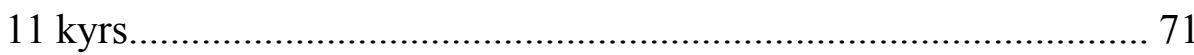

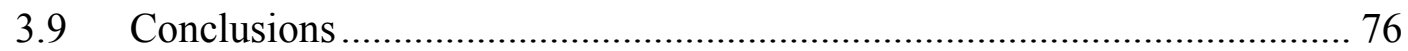

4 Rock magnetic characterization and palaeointensities of Holocene lava flows from the Tongariro Volcanic Centre, New Zealand.................................. 77

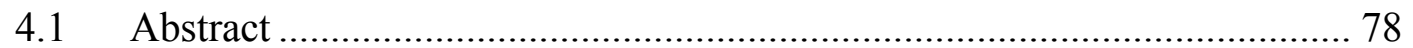

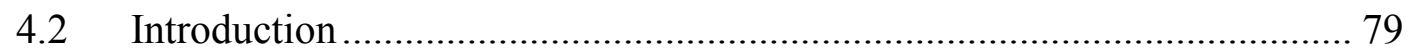

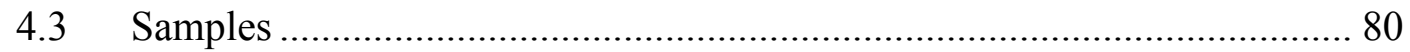

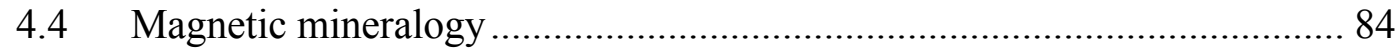

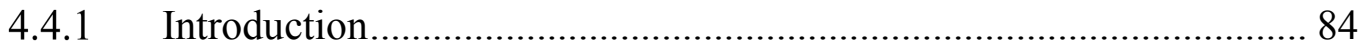

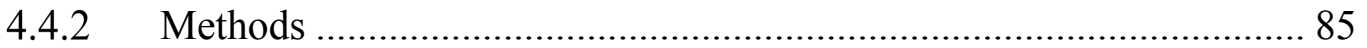

4.4.3 Petrographic description (microscopy and BSE imaging)................. 86

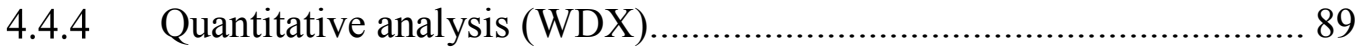

4.4.5 Rock and thermomagnetic behaviour ............................................. 90

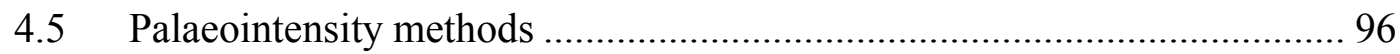

4.5.1 Thermal (double-heating) palaeointensity method ............................ 96

4.5.2 Microwave palaeointensity method .................................................. 97

4.5.3 Selection criteria and calculation of flow mean palaeointensities ....... 98

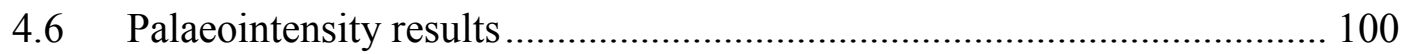

4.6.1 Central Crater flow (CC) ........................................................... 100

4.6.2 Whangaehu flow (WE) .............................................................. 102

4.6.3 Delta Corner flow (DC) ............................................................... 104

4.6.4 Bruce Road flow (RP) ................................................................ 105

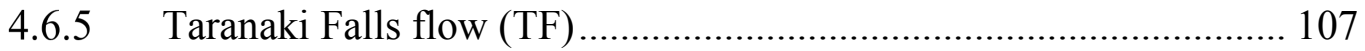

4.6.6 Mangaturuturu flow (MT) …..................................................... 108

4.6.7 Whakapapaiti A flow (WPA) and Skyline Ridge flow (GR)........... 110

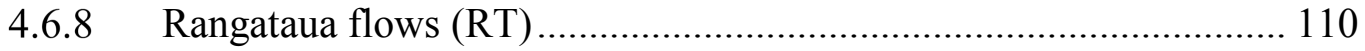

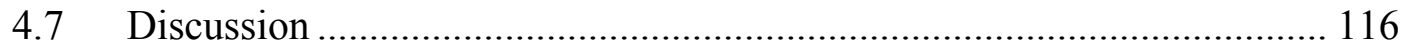


4.7.1 Palaeointensity success rates and data quality .................................116

4.7.2 Origins of data scatter and experimental failure................................119

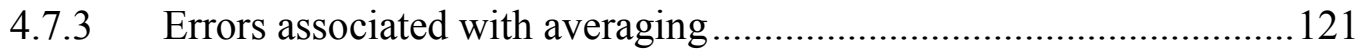

4.7.4 Comparison with previous datasets from New Zealand .....................122

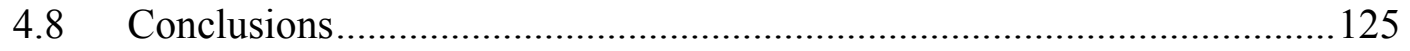

\section{Palaeosecular variation studies of rhyolitic lavas from the Taupo Volcanic}

Zone, New Zealand: revision and new data ......................................................127

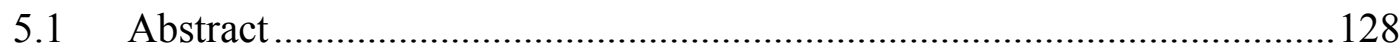

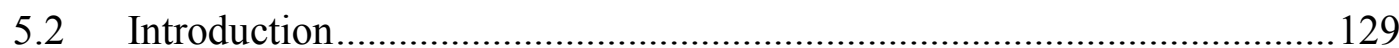

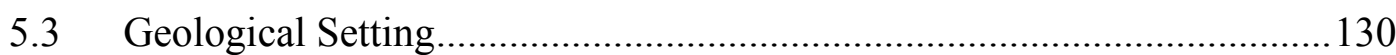

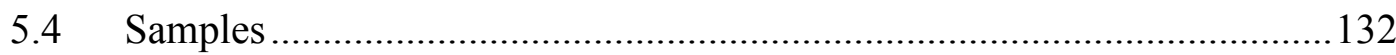

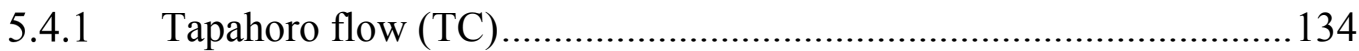

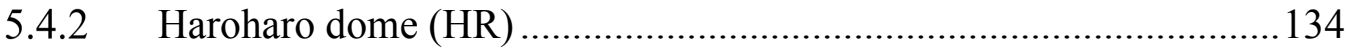

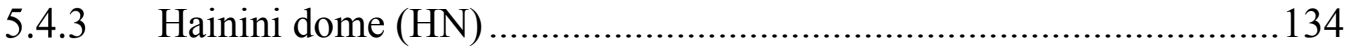

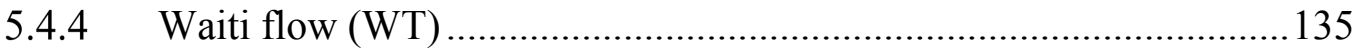

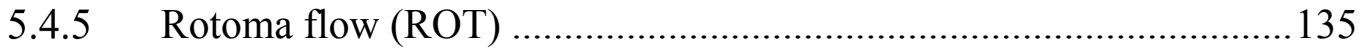

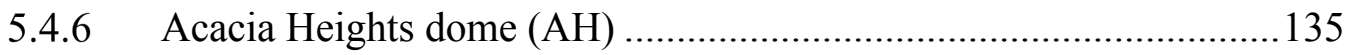

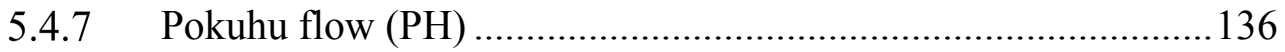

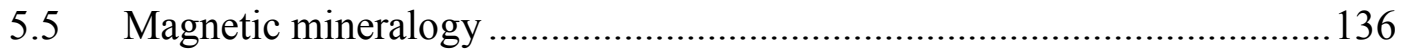

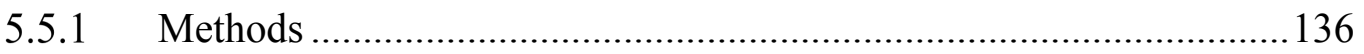

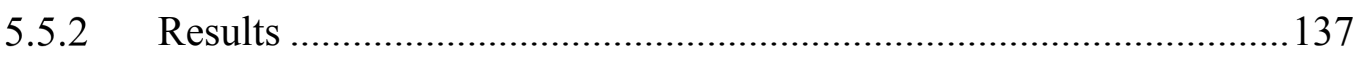

5.6 Demagnetisation methods and site averaging...................................... 143

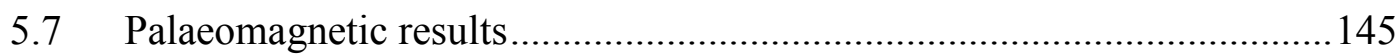

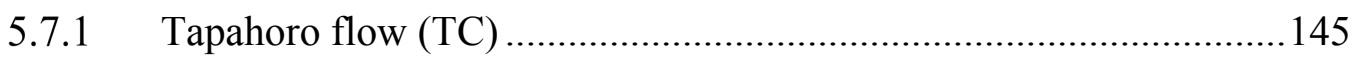

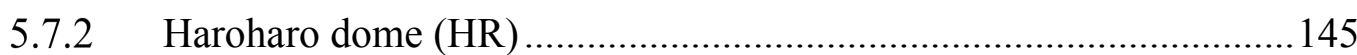

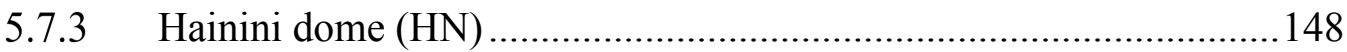

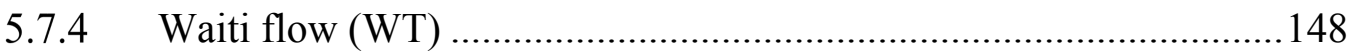

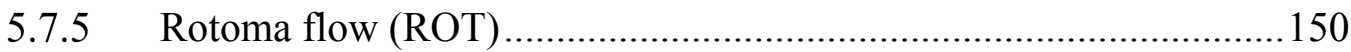

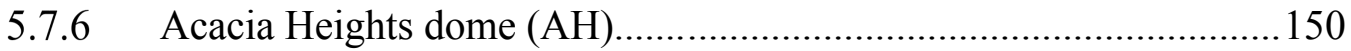

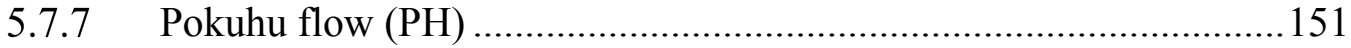

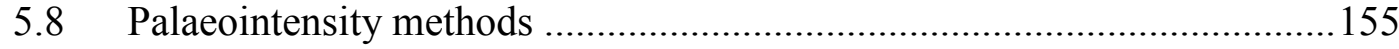

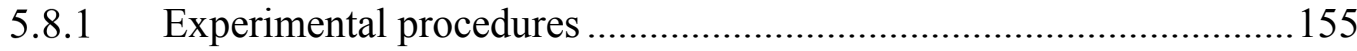

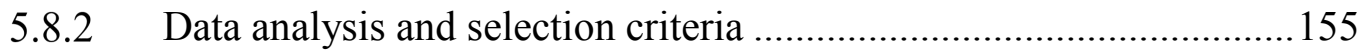




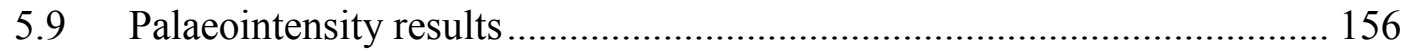

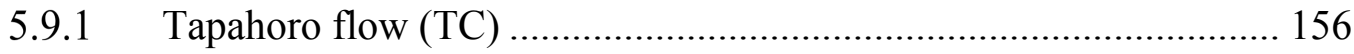

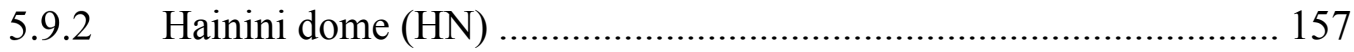

5.9.3 Acacia Heights dome (AH) …………………………………...... 157

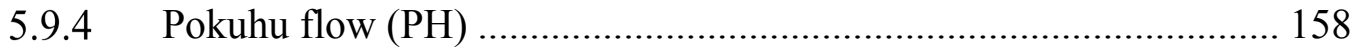

5.10 Discussion: Data quality and comparison with previous results................ 164

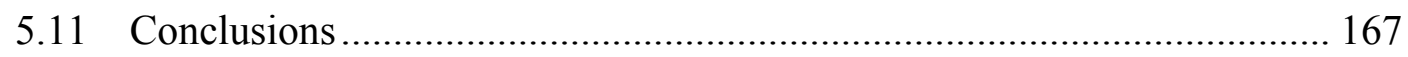

6 Discussion and Future Work ............................................................................ 169

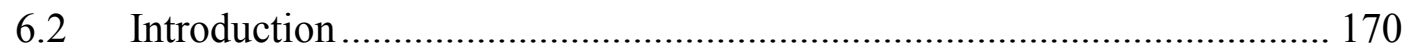

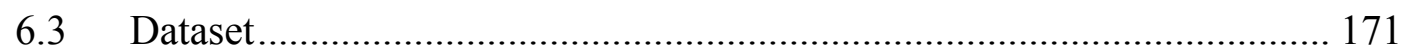

6.4 Addressing ages and age uncertainties................................................. 172

6.5 Integration with regional datasets and global field model ' $\mathrm{pfm} 9 \mathrm{k}$ ' .......... 178

6.5.1 Comparison to the Lake Mavora PSV record (11,250 yrs BP - present)

6.5.2 Scaling of the amplitudes of the Lake Mavora PSV record ............... 186

6.5.3 The Lake Pounui record (2400 yrs BP - 250 yrs BP?)....................... 189

6.5.4 Effects of the new data on global field model 'pfm9k.1a' ................ 193

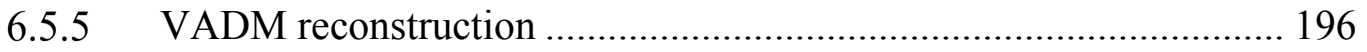

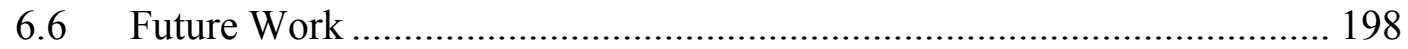

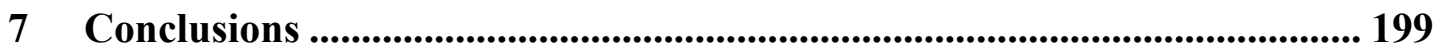

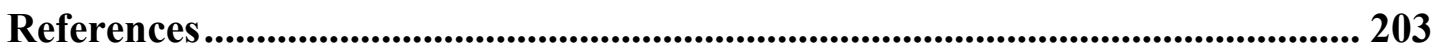

All supplementary materials is provided in electronic form. A list of the relevant electronic appendices is given on each chapter heading page. 


\section{List of Figures}

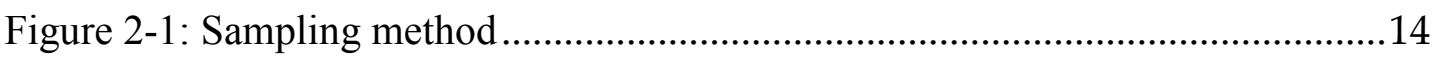

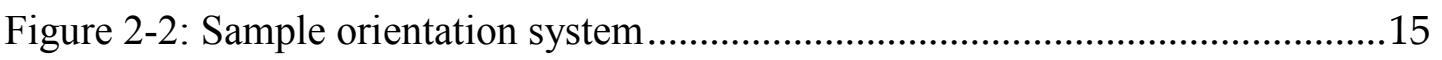

Figure 2-3: Representative IRM and backfield curves ............................................19

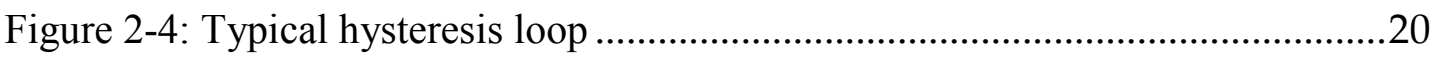

Figure 2-5: Representative thermomagnetic curves .................................................23

Figure 2-6: Representative vector component diagrams ......................................28

Figure 2-7: Representative Arai plot from a Thellier experiment ..............................31

Figure 3-1: Digital topographic map of Ruapehu Volcano ........................................40

Figure 3-2: Sampling scheme on two lava flows ...................................................4

Figure 3-3: Day plot, representative hysteresis and thermomagnetic curves............53

Figure 3-4: Representative vector component, $\mathrm{M} / \mathrm{M}_{0}$, and stereo-plots....................63

Figure 3-5: Representative vector component, $\mathrm{M} / \mathrm{M}_{0}$, and stereo-plots....................64

Figure 3-6: Equal angle (Wulff) projections of the directions of TgVC lavas............68

Figure 3-7: Comparison of the new palaeomagnetic data (TgVC) ...........................71

Figure 3-8: Examples of palaeomagnetic dating results on lavas from the TgVC .....75

Figure 4-1: Digital topographic map of Ruapehu Volcano ....................................... 82

Figure 4-2: Photomicrographs of a porphyritic pyroxene andesite ..........................87

Figure 4-3: Representative back scattered electron (BSE) photomicrographs...........88

Figure 4-4: Reflected light microscopic images of two opaque grains ......................89

Figure 4-5: Iron oxide ternary diagrams showing ulvospinel and ilmenite................90

Figure 4-6: Representative IRM and backfield coercivity curves...........................93

Figure 4-7: Hysteresis properties of TgVC samples .................................................93

Figure 4-8: "Type 1" thermomagnetic curves ..........................................................94

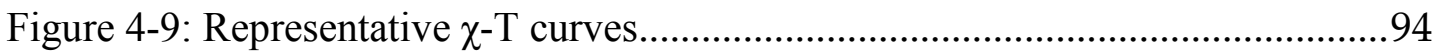

Figure 4-10: Representative rock magnetic and palaeointensity results, CC ...........102

Figure 4-11: Representative trockmagnetic and palaeointensity results, WE...........104 
Figure 4-12: Representative rock magnetic and palaeointensity results, DC .......... 105

Figure 4-13: Representative rock magnetic and palaeointensity results, RP.......... 106

Figure 4-14: Representative rock magnetic and palaeointensity results, TF ............. 108

Figure 4-15: Representative rock magnetic and palaeointensity results, MT.......... 109

Figure 4-16: Representative rockmagnetic and rejected microwave

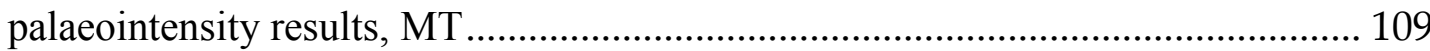

Figure 4-17: Representative rock magnetic and palaeointensity results, RT .......... 111

Figure 4-18: Distribution of the successful palaeointensity results ....................... 118

Figure 4-19: Records of palaeomagnetic declination, inclination and intensity...... 124

Figure 5-1: Map of the main young volcanic centres in New Zealand.................... 133

Figure 5-2: Typical IRM acquisition and backfield curves .................................. 139

Figure 5-3: Hysteresis properties of the rhyolitic lavas.......................................... 140

Figure 5-4: Representative thermomagnetic curves for the rhyolitic lavas ............ 141

Figure 5-5: Typical sample behaviour during susceptibility checks ..................... 142

Figure 5-6: Representative vector component and corresponding M/Mo plots ....... 147

Figure 5-7: Representative Zijderveld, stereoplot and M/M $\mathrm{M}_{0}$ plots ....................... 149

Figure 5-8: Representative Zijderveld and M/Mo plots from Pokuhu lava flow ..... 152

Figure 5-9: Equal angle (Wulff) projections of rhyolitic lavas from the TVZ ........ 153

Figure 5-10: Representative Arai plots and corresponding vector component plots161

Figure 5-11: Palaeosecular variation described by the rhyolitic lavas ................... 166

Figure 6-1: Distribution of the Lake Mavora PSV data........................................... 179

Figure 6-2: Palaeosecular variation in New Zealand over the last 15,000 years..... 185

Figure 6-3: Distribution of the palaeomagnetic directions .................................... 188

Figure 6-4: Calibrated age model for the Pounui record ........................................ 191

Figure 6-5: Comparison between the Lake Mavora and Pounui PSV curves......... 192

Figure 6-6: Declination, inclination and intensity records for $39.2^{\circ} \mathrm{S}, 175.5^{\circ} \mathrm{E}$

calculated from the global field model pfm9k.1a ................................................... 195

Figure 6-7: VADM's calculated from all intensity data from NZ volcanics and Pacific Island pottery 197 


\section{List of Tables}

Table 3-1: Description and independent age information, $\mathrm{TgVC}$ lavas ....................42

Table 3-2: Summary of the directional results from the TgVC by site and flow .......65

Table 4-1: Summary of the Holocene lava flows from the TgVC ...........................83

Table 4-2: Quantitative ulvospinel $\left(\mathrm{X}_{\mathrm{usp}}\right)$ component and expected $\mathrm{T}_{\mathrm{c}} \ldots \ldots \ldots \ldots \ldots \ldots . . . . . . . . .95$

Table 4-3: Thermomagnetic curve characteristics, TgVC lavas..............................95

Table 4-4: Accepted palaeointensity results from the TgVC ..................................112

Table 5-1: Rock magnetic properties extracted from IRM acquisition, backfield,

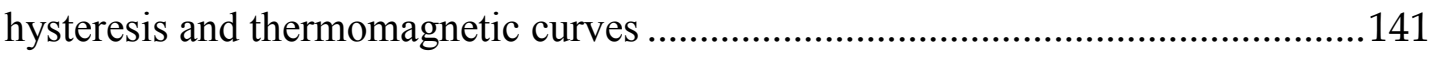

Table 5-2: Summary of all TVZ sites and units sampled in this study ...................154

Table 5-3: Selected palaeointensity results from the TVZ ......................................162

Table 6-1: Compilation of Holocene $(<15 \mathrm{ka}$ ) records of palaeomagnetic directions and intensity from New Zealand volcanic rocks. 176 


\section{Abbreviations}

AD

$\mathrm{AF}$

AMS

yrs BP

BSE

cal. yrs

CALS10K

ChRM

CRM

Dec

EDX

FMR

FORC

GAD

IGRF

IRM

Inc

$\mathrm{Ka}$

Kyrs

MAD

MD

MPMS

NRM

NSPSV10K

OVC

PDF

pfm9k

pmag
Anno Domini

alternating field

anisotropy of magnetic susceptibility

years before $1950 \mathrm{AD}$

backscattered electrons

calendar years

world field model for the last $10 \mathrm{ka}$

characteristic remanent magnetisation

chemical remanent magnetisation

magnetic declination

energy dispersive $\mathrm{x}$-ray spectrometry

ferromagnetic resonance

First Order Reversal Curves

geocentric axial dipole

International Geomagnetic Reference Field

isothermal remanent magnetisation

magnetic inclination

kilo annum before present

kilo annum before present

maximum angular deviation

multi domain

Magnetic Properties Measurement System

natural remanent magnetisation

NZ PSV Master Curve for the last 10, 000 years

Okataina Volcanic Centre

probability density function

most recent world field model for the last $10 \mathrm{ka}$

palaeomagnetic 
PSD

PSV

pTRM

SD

SE

SW Pacific

$\mathrm{TgVC}$

TRM

TVC

TVZ

VADM

VDM

VFSM

VFTB

VGP

VRM

VSM

WDX pseudo-single domain

palaeosecular variation

partial thermoremanent magnetisation

single domain

secondary electrons

south west pacific

Tongariro Volcanic Centre

thermoremanent magnetisation

Taupo Volcanic Centre

Taupo Volcanic Zone

virtual axial dipole moment

virtual dipole moment

Variable Frequency Susceptibility Meter

Variable Field Translation Balance

virtual geomagnetic dipole

viscous remanent magnetisation

Vibrating Sample Magnetometer

wavelength dispersive $\mathrm{x}$-ray spectrometry 


\section{Symbols}

$\alpha$

$\alpha 95$

$\mathrm{B}_{\mathrm{c}}$

$\mathrm{B}_{\mathrm{cr}}$

$\mathrm{d}(\mathrm{CK})$

d(pal)

$d(t)$

$\mathrm{dt}^{*}$

f

$\mathrm{M}_{\mathrm{r}}$

$\mathrm{M}_{\mathrm{rs}}$

$\theta$

$\theta 63$

$\theta 95$

$\theta_{\mathrm{m}}$

q

ß

$\mathrm{T}_{\mathrm{b}}$

$\mathrm{T}_{\mathrm{c}}$

$\mathrm{T}_{\mathrm{M}} \mathrm{RM}$

$\mathrm{T}_{\mathrm{ub}}$

angular difference between the anchored and free floating fit angular $95 \%$ confidence limit on the mean of a Fisher distribution magnetic coercivity (in T)

coercivity of remanence (in T)

normalized pTRM check error

normalized cumultative pTRM check error

normalized tail check error

normalized tail check error including angular criterion

fraction of the NRM

remanent magnetisation (in $\mathrm{Am}^{2} \mathrm{~kg}^{-1}$ )

saturation remanent magnetisation (in $\mathrm{Am}^{2} \mathrm{~kg}^{-1}$ )

co-latitude

angle containing $63 \%$ of all directions

angle containing $95 \%$ of all directions

magnetic co-latitude

quality factor (Arai plot)

quality of the slope of the best-fit line in an Arai plot

blocking temperature (in ${ }^{\circ} \mathrm{C}$ )

Curie temperature $\left(\right.$ in $\left.{ }^{\circ} \mathrm{C}\right)$

microwave induced remanent magnetisation

unblocking temperature $\left(\right.$ in $\left.{ }^{\circ} \mathrm{C}\right)$ 


\section{Chapter One}

Introduction 


\subsection{Motivation}

In contrast to all other terrestrial planets within the solar system, the Earth generates a largely dipolar and strong magnetic field. This effectively shields us and our planet's atmosphere and surface from harmful solar radiation, a stream of charged particles emitted from the sun. However, the Earth's magnetic field is subject to changes throughout time. Periodic field fluctuations ranging from years to millennia are called secular variation or palaeosecular variation (PSV) when referring to changes that predate direct magnetic observations. The most extreme phenomenon experienced by the Earth's magnetic field is the magnetic polarity reversal, which occurs in undefined intervals between thousands and millions of years. Shorter lived events that involve a sudden decrease in the magnetic field intensity and rapid movement of the poles to lower latitudes are called geomagnetic excursions - the last excursion occurred 33,000 years ago (Roberts, 2008). Over the last 150 years, observatories around the world have recorded a significant decrease in the global dipole moment and triggered a discussion around whether a reversal is imminent (e.g. Constable and Korte, 2006; Olson, 2002). Such a reversal or extremes of secular variation could have dramatic effects on our modern lifestyle. Knowledge about the field's evolution will help place recent or historic field variations in a long term and geological context and to predict the geomagnetic field's future behaviour. The creation of a detailed record of field variations throughout the last 15,000 years in New Zealand is the major aim of this thesis.

The magnetic field is a vector field. At any point on Earth's surface, it has a specific direction and intensity. The field direction is commonly described by two angles. The magnetic declination is the angle measured between geographic north and the horizontal component of the field direction, in easterly direction, and needs to be accurately known in order to navigate using a magnetic compass. The inclination is the angle of the vector below the horizontal plane. Averaged over long time-scales the geomagnetic field appears to be centred about a geocentric axial dipole (GAD). Currently the best fitting geocentric diople is tilted by $9.7^{\circ}$ with respect to the Earth's rotation axis, with its poles, the "geomagnetic poles" at $80.65^{\circ} \mathrm{N} / \mathrm{S}$ 
respectively (Thébault et al., 2015). More detailed approximations also describe the presence of a notable non-dipolar field. Because of the latter, secular variation is not coherent over long distances, although at nearby locations it follows similar patterns (for example compare Turner et al, 2015b and Turner and Lillis, 1994). Even on short time-scales secular variation is apparent, for instance, since the first observations of magnetic declination in New Zealand were recorded by Abel Tasman in 1642, the direction measured in the northernmost tip of New Zealand has migrated from approximately $8^{\circ}$ to $20^{\circ}$ easterly declination (Thébault et al., 2015; Van Bemmelen, 1898).

The main source of Earth's magnetic field lies within the fluid, iron-rich outer core of the planet, where convection in combination with Earth's rotation drives a self-sustaining magneto hydrodynamic process - the geodynamo. Numerical simulations of such a dynamo (e.g. Glatzmaier and Roberts, 1995) have reproduced typical features of the Earth's magnetic field i.e. the dipolar nature, secular variation, excursions and polarity reversals. To improve such simulations, we require datasets and models that describe the field evolution in the past. Global palaeomagnetic datasets are compiled in a number of databases such as MagIC (http://earthref.org/ MAGIC/) (Constable et al., 2006), GEOMAGIA50 (http://geomagia.gfzpotsdam.de/) (Brown et al., 2015; Donadini et al., 2006; Korhonen et al., 2008) and Pint (http://earth.liv.ac.uk/pint/) (Biggin et al., 2009; Biggin et al., 2010). Spherical harmonic models that approximate the global field have been created for various timeframes and datasets: a) Present day observational data is used to calculate the International Geomagnetic Reference Field (e.g. Finlay et al., 2010; Thébault et al., 2015), b) historical observations were compiled into the gufm model by Jackson et al. (2000) and c) Holocene palaeomagnetic records were assembled into a series of models such CALS3k for the last 3000 years (CALS3k) (Korte et al., 2009) and CALS10k for the last 10,000 years (Korte et al., 2011), the latter being recently modified into model pfm $9 k$ by Nilsson et al. (2014). The models of the present day and historical field are constrained by data from modern observatories and satellites or other historical observations. To go further back in time we need to study the magnetic remanence recorded within fired 
archaeological artefacts or natural materials such as rocks and sediments. Lava flows, for instance, acquire a thermoremanent magnetisation (TRM) upon cooling through the Curie temperature of the constituent ferro-/ferrimagnetic minerals and provide instantaneous records of the palaeomagnetic direction and absolute intensity. The palaeointensity and direction extracted is essential for the calibration of continuous PSV records from sediments, which provide relative estimates of the palaeointensity only, often suffer a depositional inclination error and are subject to amplitude smoothing. Vice-versa, the ages of the lavas can be refined by comparison of their palaeomagnetic information with the continuous records (Lanos, 2004; Pavón-Carrasco et al., 2011; Speranza et al., 2008). Similar processes and methods apply for fired archaeological materials. While archaeomagnetic datasets are restricted to times of human settlement, which in New Zealand reaches back to $\sim 700$ yrs BP, dated lavas provide records throughout the volcanic history of an area and hence in the range of thousands of years.

In the southwest Pacific region Earth's magnetic field displays several interesting features. Its proximity to the magnetic South Pole, the point on Earth's surface where the field is vertical, places it into the vicinity of highly dynamic patches of intensive magnetic flux. These are distributed about the northern and southern hemisphere and have not yet been fully explained (Constable et al., 2000; Korte and Holme, 2010). In addition, statistical studies of PSV throughout the last 5 millennia have revealed a very low level of secular variation across the Pacific (e.g. Johnson and Constable, 1998; Walker and Backus, 1996). Records of Holocene PSV are required to re-construct the evolution of both features, however all current global models and datasets suffer from a paucity of data from the southern hemisphere and the South West Pacific in particular. For instance, until recently only one continuous record spanning the last 2500 years was available from New Zealand (Turner and Lillis, 1994) and few more records from Australia (Barton and Mc Elhinny, 1982; Constable and Mc Elhinny, 1985). During recent efforts to better constrain Holocene PSV in the region, archaeomagnetic data have become available on Pacific island pottery (Stark et al., 2010) and New Zealand 
hangi stones (Kinger, in prep). In addition Turner et al. (2015b) published a new lake sediment record from the South Island in New Zealand, spanning the last $11.5 \mathrm{ka}$, and efforts to construct a PSV mast $\mathrm{r}$ curve for New Zealand are under way (Turner et al., 2015a). Age control has been a limiting factor during previous PSV studies on volcanic materials in New Zealand. Early palaeomagnetic studies, carried out at a time or in an area where no or little age information on volcanic materials was available, approached secular variation from a statistical perspective (Cox, 1969; Tanaka et al., 1997). Other studies were carried out with the purpose to date or provide chronological constraints on the sampled materials by comparison with PSV reconstructions (Downey et al., 1994; Robertson, 1986) or in older lava sequences with periods of reversed polarity (Tanaka et al., 1996). The establishment of eruptive stratigraphies for the main rhyolitic volcanic centres in New Zealand (Froggatt and Lowe, 1990; Nairn, 2002; Wilson, 1993) and radiometric dating of andesites from the Tongario Volcanic Centre (Conway et al., 2016; Gamble et al., 2003; Hobden et al., 1996) allowed the production of the first temporally defined discrete datasets (Tanaka et al., 1994; Tanaka et al., 2009), and enabled comparison with continuous datasets or PSV data from elsewhere (e.g. Turner and Lillis, 1994). Palaeomagnetic data was also obtained during studies that were carried out with the aim to constraint emplacement temperatures of volcaniclastic materials (McClelland and Erwin, 2003; McClelland et al., 2004). However the distribution of palaeomagnetic data is still sparse and many of the associated age controls have since been revised (e.g. Lowe et al., 2013). Consequently the available datasets require critical re-assessment.

Absolute palaeointensity data is urgently required to constrain the new lacustrine records and to reconstruct fluctuations in the global dipole strength throughout time. However to date only four absolute palaeointensity estimates on volcanic products were published for the last 15,000 years of secular variation in New Zealand (Tanaka et al., 1994; 1997; 2009). Absolute palaeointensity studies require ideal sample material, i.e remanence carriers need to be single domain grains and thermally stable, a requirement that is difficult to satisfy (Biggin et al., 
2007), and this is probably the source for low success rates found during previous studies (e.g. Tanaka et al., 2009).

New radiometric and other age controls have become available during an ongoing, multidisciplinary research programme on the geological and geochemical evolution of the Tongariro Volcanic Centre (TgVC) in the central North Island, New Zealand (e.g. Conway et al., 2016; Eaves, 2015; Gamble et al., 2003; Tost and Cronin, 2015; Townsend et al., in prep). For the first time, the glacio-volcanic history of Ruapehu volcano was approached as well, with a focus on the last glaciation preceding the Holocene (Eaves, 2015). Radiometric dating of young lava flows is difficult due to the long half-life of ${ }^{40} \mathrm{Ar}$, the low potassium content of the rock samples, and accordingly, the eruption ages provided have uncertainties in the range of several thousands of years. However, the location of the lava flows within known glacial moraines, together with stratigraphic relationships of chosen samples, have enhanced confidence in the ages provided (Conway et al., 2016). An additional refinement of some ages can be achieved using palaeomagnetic correlation techniques (e.g. Lanos, 2004).

This research programme, and also a recent revision on the tephra stratigraphy of eruptive episodes in the wider North Island (e.g. Lowe et al., 2013) have provided the necessary framework for the palaeomagnetic study on Holocene volcanic rocks presented in this thesis. 


\subsection{Thesis goals}

This thesis has three major goals:

1) To built a sequence of discrete palaeomagnetic secular variation records from young volcanic rocks from the Taupo Volcanic Zone in New Zealand, with a focus on the Tongariro Volcanic Centre.

2) To review previously published discrete PSV data from the region and integrate all datasets with continuous records of palaeomagnetic direction and relative intensity from lake sediments (Turner and Lillis, 1994; Turner et al., 2015b) and global field models (e.g. Nilsson et al., 2014). This will integrate with the on-going development of a PSV Master Curve from New Zealand (Turner et al., 2015a).

3) To refine some of the independent radiometric or stratigraphic ages on lava flows by comparison of our new palaeomagnetic data with existing, well dated records.

\subsection{Thesis structure}

This thesis is presented in seven chapters, including three chapters that are specifically written for publication in international journals.

Chapter 3 is based on a manuscript that has been accepted for publication in the "Geophysical Journal International". Chapters 4 and 5 cover specific themes of the research programme and will be edited for publication in due course. In all cases, the contributions of individual authors, the respective journals and a list of relevant appendices are stated at the beginning of each chapter. Additional chapters that introduce context and the applied methodology are provided. Some overlap, in particular within the introductory, geological settings and methods sections was unavoidable. Such overlap is in particular present between chapters 3 and 4 . Both chapters are based on results from a sampling campaign from the $\mathrm{TgVC}$, and geological setting, rock magnetic findings and site descriptions detailed in chapter 3 are represented in tabular form in chapter 4. 
Chapter 1 (this chapter) provides an introduction and overview of the main aims of this thesis.

Chapter 2 outlines the palaeomagnetic and rock magnetic methods used in this study. It introduces the sampling procedures and sample orientation in the field and the subsequent preparation in the laboratory. The methods used for palaeomagnetic demagnetisation and intensity experiments, as well as rock magnetic analysis is explained.

Chapter 3 is a study on the palaeomagnetic directions recorded by lavas from the Tongariro Volcanic Centre (TgVC). The geological setting and the sampled flows and sites are introduced. An overview of the rock magnetic behaviour is given to the extent required for the interpretation of the palaeomagnetic (directional) data. Subsequently the behaviour during demagnetisation experiments and the following statistical data treatment are described in detail. The new data is compared to a recently published continuous PSV curve for New Zealand (Turner et al., 2015b). A comparison is also used to refine the age controls on five of the sampled flows and thus provides constraints on the eruptive history of the volcanoes of the $\mathrm{TgVC}$.

Chapter 4 is a comprehensive palaeointensity study on the lavas introduced in chapter 3. The results of both thermal and microwave palaeointensity experiments are presented together with a detailed investigation of the magneto-mineralogical composition and properties of the samples. The final discussion is two-fold: The new palaeointensity data is discussed in the context of global and regional field-models, and the difficulties arising during thermal and microwave palaeointensity experiments are drawn out in the context of rock magnetic properties and the oxidation state of the iron-titanium-oxides for individual sampling sites.

Chapter 5 presents new palaeomagnetic results from a selection of Holocene rhyolitic lava flows and domes from the Taupo Volcanic Zone, with a focus on the Okataina Volcanic Centre. Palaeomagnetic data on some of the lavas sampled was previously published in two studies by Tanaka et al. (1994; 2009). The differences and similarities between the original and the new data are discussed. 
Chapter 6 presents a compilation and critical evaluation of all palaeomagnetic datasets on Holocene volcanic materials from New Zealand. The revised data is integrated with the new data from this thesis and compared to sedimentary records from Lake Mavora in Fiordland, NZ (Turner et al., 2015b), Lake Pounui in the southern North Island, NZ (Turner and Lillis, 1994), and a reconstruction of the variation in Earth's virtual axial dipole moment (VADM) by Knudsen et al. (2008). The effect of the new data on the most recent field model pfm $9 k$ (Nilsson et al., 2014) is demonstrated.

Chapter 7 summarizes the main findings of this thesis. 


\section{Chapter Two}

\section{Methods}

Relevant appendices (electronic):

a) Sun-compass programme and representative in- and output files. File suncompass-README.txt contains user information and an explanation of the program.

Path: Suncompass/ suncompass-README.txt and associated files

b) Comparison between the new sun-compass program and an online calculator provided by the US National Oceanic and Atmospheric Administration. The azimuth of the sun was calculated for 30 random locations, time and dates between the years 2011 and 2015 (file format: *.xlxs)

Path: Suncompass/ Suncompass-comparison.xlsx 


\subsection{Introduction}

This chapter gives an overview of the palaeomagnetic and rock magnetic methods used, including the sample collection in the field. The data analysis and selection criteria applied to the palaeomagnetic data are detailed in chapters 3 to 5. A full description of the physical background to palaeomagnetic and rock magnetic techniques is beyond the scope of this thesis. Suitable introductory texts are Tauxe (2015) and Butler (1998). Dunlop and Özdemir (1997) provide a detailed treatment of the rock magnetic theory.

For summaries of different Thellier-type palaeointensity methods and the corresponding data analysis please refer to Tauxe and Yamazaki (2007) and Leonhardt et al. (2004a). Background to the theory, development and application of the microwave method are given in Hill and Shaw (1999) and Suttie et al. (2010) and references therein.

\subsection{Sampling and sample preparation}

The primary aim of this thesis was to extract reliable palaeomagnetic directions and intensities from the natural remanent magnetisation (NRM) recorded in lava flows and domes from the Taupo Volcanic Zone. It was therefore important to collect accurately oriented samples. Each lava flow or dome was sampled in at least three sites, accessibility permitting. At every site $4-10$ cores with $2.5 \mathrm{~cm}$ diameter and $6-12 \mathrm{~cm}$ length were drilled using a petrol driven and water cooled rock-drill. To reduce the environmental impact remote locations were chosen and outcrops were usually drilled at a maximum of one hand-length above the ground. All cores were given a specimen internal coordinate system and oriented using magnetic and sun-compass bearings wherever possible prior to removal from the outcrop.

The specimen internal coordinate system applied in this study corresponds to a standard Cartesian system, the $\mathrm{z}$ axis pointing along the core-axis, the $\mathrm{y}$ axis corresponding to the horizontal in right handed direction and $\mathrm{x}$ pointing vertical to $\mathrm{z}$ and y along the upper face of the cores (Figure 2-1c). In order to reference the sample 
coordinate system to geographic coordinates, we determined the plunge of the core axis $(\mathrm{z})$ beneath the horizontal and the magnetic azimuth, which is the angle between $\mathrm{y}$ and magnetic north. Sun-compass orientations were determined using a separate orientation device and will be described in detail in section 2.4. After removal the $\mathrm{z}$ axis, pointing along the core and tick marks in y direction were marked on each sample (Figure 2-2). Magnetic compass bearings were corrected for the local declination using the field predictions made by the 2010 International Geomagnetic Reference Field (IGRF) (IGRF calculator: http://www.ngdc.noaa.gov/geomag-web/). Note that after this correction, the orientations calculated from magnetic compass bearings sometimes differed by up to $10^{\circ}$ from the sun-compass orientations (section 2.4), which suggests the presence of some small scale anomalies in the magnetic field. Hence when no sun was available we placed the gnomom used for the sun-compass orientation on the orientation device and took a bearing of the sample orientation from a distance between 5 to $10 \mathrm{~m}$. This helped to verify correct orientation of the samples.

At sites that were too remote to drill samples, or if additional sample material was required, we marked the geological strike and dip on the flat surface of block samples and removed them from the outcrop by hand. They were later drilled in the laboratory using a vertical drill press. All samples were cut into $2.5 \mathrm{~cm}$ long cylindrical specimens, and the $\mathrm{x}$-axis marked on the outside surface of each specimen. Full sized specimens were used for thermal and alternating field demagnetisation and Thellier-type intensity experiments while core-ends were either crushed for rock magnetic experimentation or prepared for microwave palaeointensity experiments.

Microwave experiments require mini-samples of $\sim 2-3 \mathrm{~mm}$ length and $5 \mathrm{~mm}$ diameter. In general I drilled 5-10 long cores from each specimen and cut these into multiple sub-specimens. Individual sub-specimens were trimmed carefully to provide a smooth surface for the vacuum holder system.

After preparation all specimens were stored in zero-field shielding until all palaeomagnetic measurements were completed. 

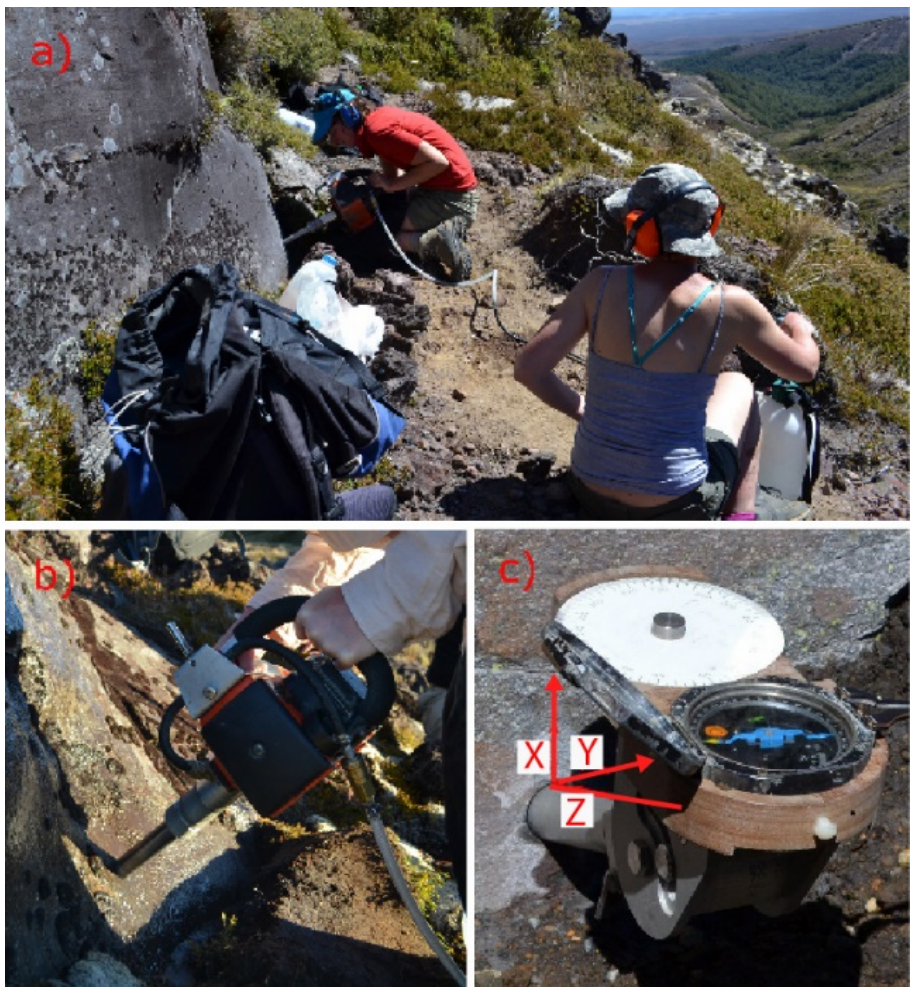

Figure 2-1: Sampling method: a) Author coring an andesitic lava flow on the left and assistant operating pressure sprayer to enable cooling water flow. b) close-up shot drilling. A petrol driven drill with a diamond bit of $2.5 \mathrm{~cm}$ diameter is used to core the rock. c) Orienting of a drilled sample prior to removal from the bedrock, the sample coordinate system is indicated in red. Plunge (angle between $\mathrm{z}$ and horizontal) and azimuth (angle between magnetic north and y) are measured using an inclinometer, sun- and magnetic compass. 


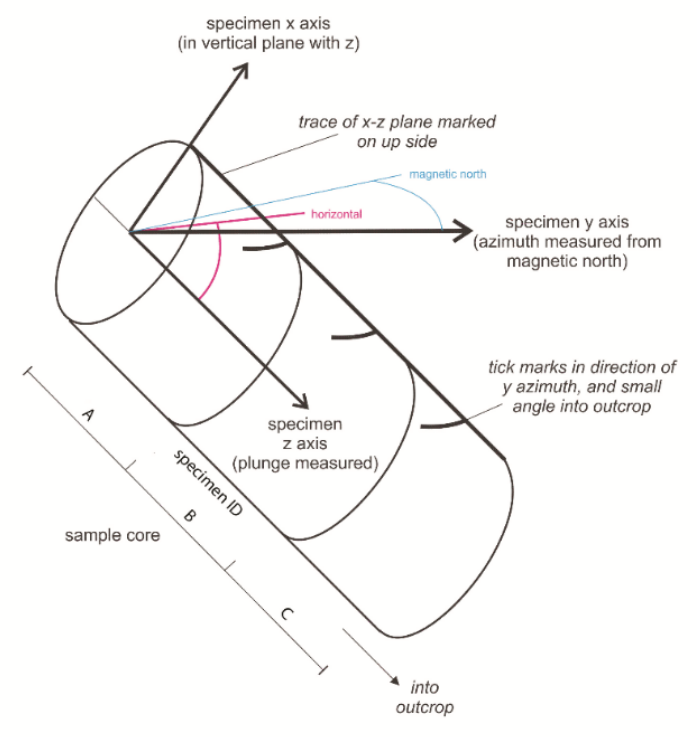

Figure 2-2: Sample orientation system applied to all core-samples in this thesis. Figure modified from Cairns (2014). At some sites we collected oriented hand samples, cores were drilled out of the latter and adjusted to the same coordinate system.

\subsection{Sample annotation}

Throughout this thesis, sample sites are annotated following the system XXyy.n, where ' $\mathrm{XX}$ ' is the abbreviation chosen for each flow/unit sampled and ' $\mathrm{y}$ ' the site numbering. ' $n$ ' corresponds to the ID of a sub-site, if applicable. For example site SC01.1 corresponds to subsite 1 from site 01 at Saddle Cone lava flow. Specimens are labelled in the format XX-zzN-n for cored and XX-zzH-iiN.n for hand samples. ' $z z$ ' is the individual core-number counted, starting from 01 for each individual unit. $\mathrm{N}$ is an alphabetical character between $\mathrm{A}$ and $\mathrm{D}$ and deciphers the specimen ID, starting with 'A' from the outermost end of each core/sample. Another number ' $\mathrm{n}$ ' is added when specimens are further subdivided into multiple samples, for example for microwave or rock magnetic experiments (example: Specimen ID CC12A-1 corresponds to sub-specimen 1 from the outermost specimen from core/sample 12, sampled from Central Crater flow). Hand samples require an additional numeral, to accommodate the fact that more than one core was drilled from each sample. Here ' $z z$ ' corresponds to the number of the hand samples taken from a flow and 'ii' to the i'th core removed from one hand sample. 


\subsection{Sun-compass orientation}

Rather than referencing to magnetic north, orientation data obtained using the suncompass is referenced directly to geographic coordinates. The advantage is that local anomalies in the Earth's magnetic field cannot induce an error in the measured orientation. Sun-compass orientation requires accurate determination of the angle between the shadow thrown by a gnomon located on the origin/centre of an orientation disc and the y axis of the specimen coordinate system. In addition the exact position of the sun needs to be known, which is calculated from an accurate record of the time and geographic positon where the measurement was taken.

All relevant calculations were conducted using a Matlab programme, written following the steps outlined in Tauxe (2015), which is based on the recommendations of the 1996 Astronomical Almanac. The programme consists of two Matlab scripts: the function 'suncompass.m' calculates the local declination of the sun (angle between geographic north and the position of the sun) and subsequently the (solar) azimuth or orientation of the sample. This function needs to be included in the path of the Matlab environment. 'Input.m' imports an orientation file including the sampling information, coordinates, local time and the compass declination for all cores sampled per day and creates an output text file including sample orientation calculated using the suncompass in comparison to the orientation obtained by magnetic compass bearings and all other sampling information. Matlab codes, representative in-and output files and all other information required are displayed in the appendices.

To verify the correct operation of the sun-compass it was compared to an online sun calculator provided by the US National Oceanic and Atmospheric Administration (http://www.esrl.noaa.gov/gmd/grad/solcalc/). The azimuthal position of the sun (angle between geographic north and the position of the sun) was calculated for thirty randomly assigned locations on Earth and times between the years 2013 and 2015. The mean difference between the provided Matlab script and NOAA's online calculator was $5^{*} 10^{-4 \circ}$ and the standard deviation was $0.048^{\circ}$ (see appendix). Such difference could be attributed to rounding errors and is insignificant for the purpose of this study. 


\subsection{Rock magnetic investigation}

Beside the thermal history of a rock, the rock magnetic properties and mineralogy influence the stability of the natural remanent magnetisation (NRM) carried by a rock sample and are hence invaluable in the interpretation of palaeomagnetic data and design of experimental procedures.

The majority of the rock magnetic experiments for this study were conducted using the Variable Field Translation Balance (VFTB) and the AGICO Kappa Bridge at the Geomagnetism Laboratory of the University of Liverpool. VFTB experiments included the measurement of isothermal remanent magnetisation (IRM) acquisition, backfield curves, hysteresis and thermomagnetic curves. Additional temperaturesusceptibility ( $\chi$ vs. T) curves were measured using the Kappa Bridge in a reaction neutral Ar atmosphere. All heating experiments were carried out to a peak temperature of ca. $700^{\circ} \mathrm{C}$ with a heating rate of ca. $30^{\circ} \mathrm{C} / \mathrm{min}$ and subsequent cooling. The peak field applied during in-field measurements (hysteresis, IRM, backfield and thermomagnetic curves) was $800 \mathrm{mT}$. All VFTB data were analysed using Leonhardt's (2006) software RockMag Analyser 1.0 and susceptibility data from the Kappa Bridge using Curveval (Chadima and Hrouda, 2012).

Following the first palaeomagnetic fieldwork season in 2013, a small number of preliminary rock magnetic experiments were carried out as a group project during the 2013 Summer School for Rock Magnetism, held at the Institute for Rock Magnetism in Minneapolis, Minnesota. The experiments carried out included hysteresis experiments, using a Princeton Vibrating Sample Magnetometer (VSM), Anisotropy of Magnetic Susceptibility (AMS) experiments using an AGICO Kappa Bridge, amplitude and frequency dependent magnetic susceptibility using a Magnon Variable Frequency Susceptibility Meter, alternating field demagnetisation using a $2 G$-squid magnetometer with in-line alternating field demagnetisation coils, and low temperature thermomagnetic experiments using two Magnetic Properties Measurement System (MPMS) instruments. The data from these experiments provided a first impression 
of the rock magnetic properties of the samples, however for consistency they were not included in this thesis and are therefore not discussed further.

\subsubsection{Isothermal remanent magnetisation (IRM) and backfield experiments}

Ferro-/ferrimagnetic material can acquire a remanent magnetisation without heating when exposed to a field higher than the room temperature coercivity $\left(\mathrm{B}_{\mathrm{c}}\right)$ of the constituent grains. While the ambient Earth magnetic field is approximately three orders of magnitude smaller than the coercivity of, for example magnetite, a lightning strike can induce a field strong enough to re-magnetise rocks in the field. In the laboratory we can use IRM acquisition as a tool to rapidly investigate magnetic coercivity, remanence and saturation magnetisation by exposing a sample to a strong external magnetic field that is increased incrementally, and measuring the magnetic remanence $\left(\mathrm{M}_{\mathrm{r}}\right)$ after each treatment step. Upon saturation the IRM acquisition curve flattens out, and the remanence saturation magnetisation $\left(\mathrm{M}_{\mathrm{rs}}\right)$ can be extracted (Figure 2-3). $\mathrm{M}_{\mathrm{rs}}$ and the applied field required to saturate a sample are related to the magnetic mineralogy.

In most experimental procedures IRM measurements are followed by backfield measurements, during which the experimental procedure is repeated in a field of opposite direction. Starting at saturated state, an antiparallel field of strength $B_{c r}$ is required to reduce the remanence back to zero (Figure 2-3). $\mathrm{B}_{\mathrm{cr}}$ is also called the coercivity of remanence. 


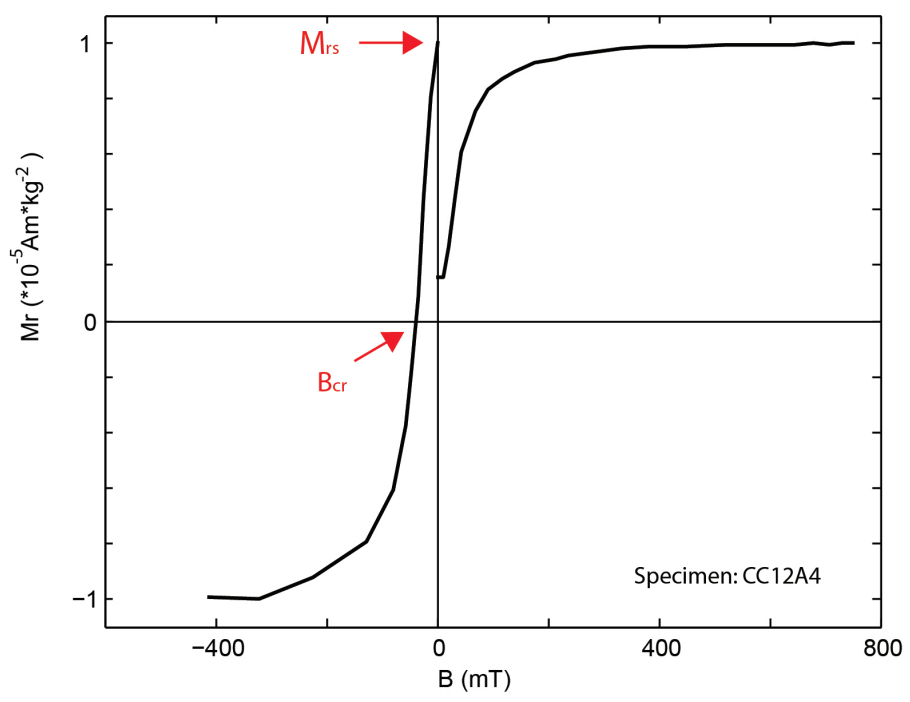

Figure 2-3: Representative IRM and backfield curves measured using a Variable Field Translation Balance with a peak field of ca. $700 \mathrm{mT}$ at the University of Liverpool. $\mathrm{M}_{\mathrm{rs}}$ and $\mathrm{B}_{\mathrm{cr}}$ can be read from the graph as shown.

\subsubsection{Magnetic hysteresis}

During hysteresis experiments a sample is exposed to a strong magnetic field that is increased from zero to a strong field $\mathrm{B}_{\max }$, followed by a decrease to zero and reapplication of a field in the reverse direction. Subsequently the field is decreased to zero and increased to $B_{\max }$ again. In contrast to IRM experiments, during hysteresis experiments the magnetic moment is measured continuously during application of the field and it thus measures ferri-/ferromagnetic remanence carriers as well as diamagnetic, paramagnetic and/or superparamagnetic particles. Ferri-/ferromagnetic behaviour produces a hysteresis loop, characterised by its opening, which is defined by the magnetic coercivity $B_{c}$, and the saturation magnetisation $M_{s} . B_{c}$ can be read of the intersection of the descending and ascending hysteresis curves with the B-axis (Figure 2-4). Paramagnetic behaviour produces a linear increase of the magnetisation with applied field. Diamagnetism is negative and in the presence of ferri/ferromagnetic and paramagnetic particles is negligible, superparamagnetism produces a similar effect to the ferri/ferromagnetic particles but with an infinitely small coercivity. 
Volcanic rocks usually contain an assemblage of grains that behave differently to each other. The dashed plot shown in Figure 2-4 displays the measured hysteresis loop for a basaltic sample from the Tongariro Volcanic Centre. The contributions of the two major effects, the ferri-/ferromagnetic and paramagnetic effects can clearly be observed. The paramagnetic contribution is in particular visible in the linear slope within the upper closed parts of the hysteresis loop. This component is usually not of major interest for palaeomagnetic studies and its contribution is removed by subtracting a slope fit to the linear part of each loop. Subsequently, a number of parameters can be extracted that are dependent on magnetic mineralogy and grain size (section 2.5.3, Figure 2-4): Besides $B_{c}$ and $M_{s}$, the remanent magnetisation $M_{r s}$ is the remanence retained by a sample after removal of the field and corresponds to the saturation remanence measured during IRM experiments. Besides the parameters extracted additional information, for example about mixtures between superparamagnetic and ferri-/ferromagnetic grains, can be obtained from the overall shape of a loop. For a detailed description please refer to Tauxe et al. (1996).

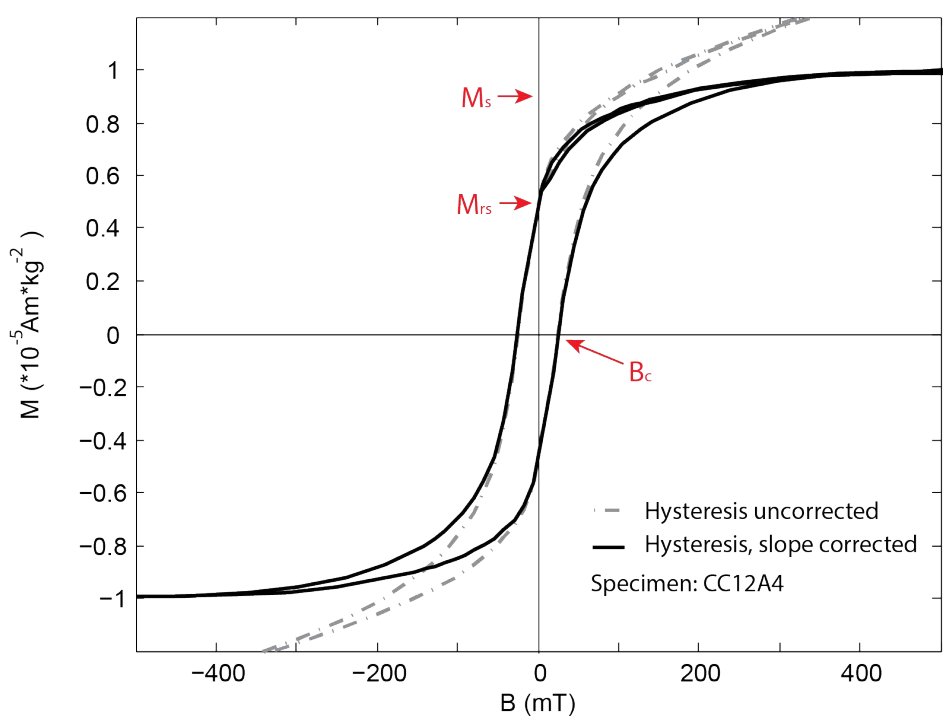

Figure 2-4: Typical hysteresis loop measured using a Vibrating Field Translation Balance and a peak field of ca. $700 \mathrm{mT}$ at the University of Liverpool. Dashed line: hysteresis loop prior to the paramagnetic slope correction and solid line after correction. Important parameters can be read from the graph as indicated. 


\subsubsection{Magnetic domain state}

The magnetic domain state is primarily defined by grainsize. Knowledge of the latter is essential for sample selection and interpretation of palaeomagnetic data: In contrast to single domain (SD) grains, multi domain (MD) grains react to an applied field by domain wall movement rather than magnetic moment flipping (Levi, 1977; Néel, 1955). Domain wall nucleation requires a lower energy, and MD grains thus exhibit relatively low coercvity and unstable remanence. The width and steepness of hysteresis loops and backfield curves and hence the ratios $\mathrm{M}_{\mathrm{rs}} / \mathrm{M}_{\mathrm{s}}$ and $\mathrm{B}_{\mathrm{cr}} / \mathrm{B}_{\mathrm{c}}$ are related to the magnetic domain state (Dunlop and Özdemir, 1997). Throughout this thesis I display plots of the two ratios for each hysteresis loop against each other, a diagram first suggested by Day et al. (1977). Day et al. (1977) subdivided the diagram into sections for single-domain (high $\mathrm{M}_{\mathrm{rs}} / \mathrm{M}_{\mathrm{s}}$, low $\mathrm{B}_{\mathrm{cr}} / \mathrm{B}_{\mathrm{c}}$ ), pseudo-single-domain (PSD) (intermediate values) and multi-domain (MD) grains (low $\mathrm{M}_{\mathrm{r} s} / \mathrm{M}_{\mathrm{s}}$, high $\mathrm{B}_{\mathrm{cr}} / \mathrm{B}_{\mathrm{c}}$ ). The original boundaries between the individual behaviour types were revised based on theoretical considerations by Dunlop (2002): SD magnetite or titanomagnetites exhibit the ratios $\mathrm{M}_{\mathrm{rs}} / \mathrm{M}_{\mathrm{s}}>0.5$ and $\mathrm{B}_{\mathrm{cr}} / \mathrm{B}_{\mathrm{c}}<2$, to qualify as predominantly $\mathrm{MD}$ a lower ratio $\mathrm{M}_{\mathrm{rs}} / \mathrm{M}_{\mathrm{s}}<0.02$ and a higher ratio $\mathrm{B}_{\mathrm{cr}} / \mathrm{B}_{\mathrm{c}}>5$ are required. Dunlop (2002) also showed that mixtures between $\mathrm{SD}$ and $\mathrm{MD}$ grains, often found in natural samples, plot within the PSD section of the diagram along near hyperbolic curves. Throughout this thesis I display Day-diagrams including Dunlop's (2002) boundaries and representative mixing curves. The reader is advised that while these boundaries and mixing curves provide a reference frame, the exact grain size distribution cannot solely be defined from this diagram.

If adequate instrumentation is available, the measurement of First Order Reversal Curves (FORC) may reveal further information about individual coercivity populations and magnetic interaction within a sample (e.g. Roberts, 2000). These experiments involve repeated measurement of hysteresis loops from a variable starting field but have not been carried out in this study. 


\subsubsection{Thermomagnetic experiments}

Temperature dependent investigation of the rock magnetic properties of a sample provides an aid in the identification of magnetic minerals and their composition by targeting transition temperatures such as the Curie or Néel temperatures and crystallographic transitions such as the isotropic point and Verwey transition for magnetite. Information about the blocking temperature distribution and effects of thermal alteration can be identified by repeated heating experiments.

In this thesis high temperature (room temperature up to $700^{\circ} \mathrm{C}$ ) experiments were carried out only, targeting the Curie temperatures $\left(\mathrm{T}_{\mathrm{c}}\right)$ of the main remanence carriers. To compare, saturation magnetisation with temperature $\left(M_{S}\right.$ vs. T) curves were measured using a VFTB, and susceptibility with temperature ( $\chi$ vs. T) curves on sister samples using an $A G I C O$ Kappa Bridge. In these experiments $\mathrm{M}_{\mathrm{s}}$ or $\chi$ are measured continuously during heating up to $700^{\circ} \mathrm{C}$ and subsequent cooling cycles. At $\mathrm{T}_{\mathrm{c}}$ ferro/ferrimagnetic particles undergo a change to paramagnetic behaviour which results in sharp drops in the $\mathrm{M}_{\mathrm{s}}$ vs. $\mathrm{T}$ curves and $\chi$ vs. $\mathrm{T}$ curves. Reversibility of heating and cooling curves shows whether the magnetic minerals are thermally stable.

In addition to single heating and cooling curves, a selection of samples was also subjected to repeated heating $\chi$ vs. T experiments with the aim of identifying the onset temperature of thermal alteration. These experiments included heating samples to stepwise higher temperatures and subsequent cooling during the measurement of susceptibility curves.

Curie points were estimated from $\mathrm{M}_{\mathrm{s}} \mathrm{vs}$. T graphs using the second derivative approach (Tauxe, 1998) and picked from $\chi$ vs. T curves at the onset temperature of linearity in $1 / \chi$, which, following the Curie-Weiss law corresponds to paramagnetic behaviour (Petrovskȳ and Kapicka, 2006) (Figure 2-5). It is noteworthy however that neither method works well in estimating the lower Curie temperature(s) in samples carrying more than one ferrimagnetic phase. In $\mathrm{M}_{\mathrm{s}}$ vs. T curves such lower Curie temperatures are often not expressed well, while application of the $1 / \chi$ method to $\chi$ vs. T data presupposes that above the $T_{c}$ behaviour is purely paramagnetic, which is not true if there is another higher Curie temperature. In addition, thermally induced magneto- 
mineral alteration can cause sharp drops in $\mathrm{M}_{\mathrm{s}}$ and/or $\chi$ that may be misinterpreted as Curie temperature.

Ms vs. T

a)

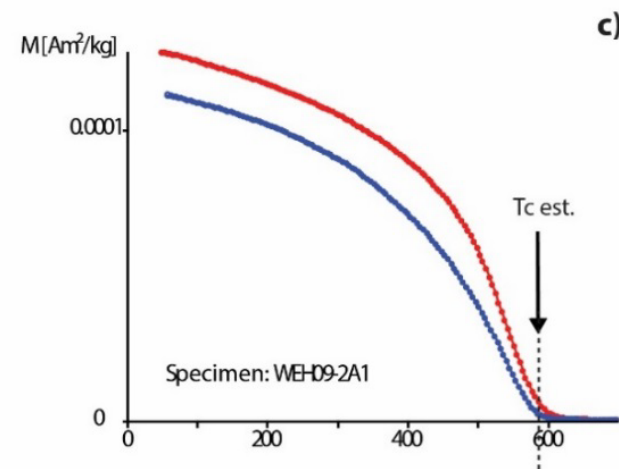

b)

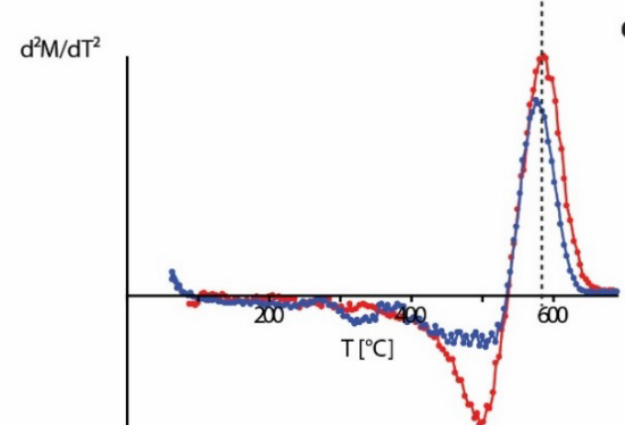

$X$ vs. T

c)

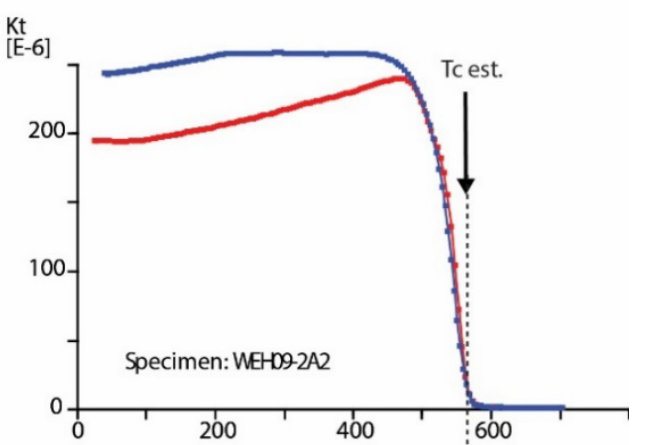

d)

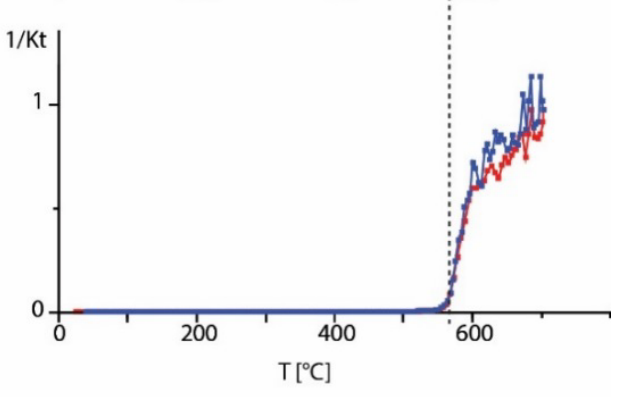

Figure 2-5: Representative thermomagnetic curves on sister specimens from Whangaehu flow. The Curie points, estimated using the methods discussed in the text are indicated. Figures (a) and (b) illustrate the estimation of $T_{c}\left(T_{c}\right.$ est.) from the peak of the second derivative of $M_{s} v s . T$, (c) and (d) illustrate the estimation of $\mathrm{T}_{\mathrm{c}}$ from the onset of linearity in $1 / \chi$ vs. $\mathrm{T}$. Red: heating cycles, blue: cooling cycles. 


\subsection{Imaging methods and quantitative analysis}

The rock magnetic experimentation discussed above reveals a variety of information about the type, magnetic behaviour and thermal stability of the carriers of magnetic remanence and other magnetic minerals in a sample. However, it is difficult to identify secondary mineral phases, formed for example by low temperature or deuteric oxidation solely based on the rock magnetic results. Imaging methods allow rapid petrographic description and identification of different mineral phases. However the threshold grainsize needed to record a magnetic remanence is usually below the resolution of optical methods. For instance a SD magnetite has a maximum size of $0.3 \mu \mathrm{m}$ (Dunlop and Özdemir, 1997) and best results can be achieved by combining both techniques.

In this study I conducted detailed petrographic imaging on samples from the Tongariro Volcanic Centre (TgVC) using a Olympus BX51 polarisation microscope with a maximum magnification of 400x under reflected and transmitted light at the School of Geography, Environment and Earth Sciences at Victoria University of Wellington. Additional electron microprobing was subsequently carried out on a selection of samples using a JEOL JXA-8230 electron microprobe. Polished thin sections, required for both methods, were kindly produced by Stewart Bush at the School of Earth Sciences, Victoria University of Wellington. Prior to microprobing the thin sections were carbon coated to increase the electrical conductivity.

\subsubsection{Petrographic microscopy}

Polarisation microscopy uses the variation in the optical properties of different crystal structures under plain polarised and cross polarised transmitted light for mineral identification and allows instantaneous petrographic description of the main rockforming minerals and texture. Spinel and orthorhombic phases, found in this study are opaque and were therefore analysed under reflected rather than transmitted light. Mineral identification under reflected light is primarily based on observations such as shape and the reflectivity of the minerals examined. The main magnetic mineral phases identified during petrographic analysis in this study were intergrown phases of the 
cubic-centred titanomagnetites and rhombohedral hemo-ilmenites (refer to chapter 4 for details). Titanomagnetites are isotropic, and in contrast the rhombohedral phases show low bireflectance. The rhombohedral phases could therefore be distinguished from the cubic minerals under plane polarized light - the amount of light absorbed within the rhombohedral crystal structure and hence the shading of the grain changes with the orientation of its optical axes in the path of the light, which can be adjusted by rotation of the objective table.

\subsubsection{Electron microprobing}

Rather than relying on the transmitted or reflecting properties of light, during microprobing samples are subjected to a focussed scanning electron beam and detailed imaging is possible from the emission of backscattered electrons (BSE) and secondary electrons (SE), while quantitative geochemical analysis can be done using energy dispersive x-ray spectroscopy (EDX) or wavelength dispersive spectroscopy (WDX). In this study I used BSE imaging in combination with EDX for first identification of oxide mineral phases. BSE imaging is based on the backscattering properties of the probed grains, the number of backscattered electrons is linked to the atomic mass of the elements the electron beam collides with. Iron and titanium are of higher atomic mass than the constituents of most rock forming minerals and stand out as bright spots in a BSE image. By adjusting the brightness and contrast of the image sufficienty, resolution can be achieved for imaging of exsolution textures between (titano)magnetites and (hemo)ilmenites in grains sized $>5 \mu \mathrm{m}$. In such images, the (hemo)-ilmenites appear darker due to the lower atomic mass of titanium than that of iron. EDX analysis measures the characteristic spectra from $\mathrm{x}$-rays diffracted from different elements at a spot probed and helps to rapidly identify mineral phases. The composition of a selected number of iron-titanium oxides was quantitatively determined using WDX analysis. The latter method is based on the same principle as EDX, however by isolating between the characteristic wavelengths it detects one predefined element at a time and allows more precise calibration and determination of compositions. But it requires prior selection of synthetic crystals that have 
specific lattice parameters for the diffraction of the wavelengths of interest. The electron microprobe at Victoria University is equipped with five wavelength dispersive $\mathrm{x}$-ray spectrometers, which permits quantitative analysis of up to 10 preselected elements within the same experimental run. Beam current and diameter can be adjusted to the target properties. Careful calibration with synthetic crystals or natural materials of known composition is a prerequisite. Details of the calibration procedure and beam properties applied in this study are given in chapter 4 .

\subsection{Palaeomagnetic direction}

\subsubsection{Progressive demagnetisation techniques}

Progressive demagnetisation techniques are used to remove viscous overprints from the natural remanent magnetisation (NRM), and to identify and separate different components of magnetisation. Following Néel's (1955) theory, we assume that a rock sample consist of a finite number of grains with different blocking temperature and coercivity. Secondary heating events to temperatures below the Curie point may results in overprinting of the grain fraction within a sample with blocking temperatures $\left(\mathrm{T}_{\mathrm{b}}\right)$ lower than the secondary temperature reached. The procedure consists of stepwise demagnetisation of an oriented sample to successively higher levels while measuring the NRM remaining after each step. If the NRM contains both primary and secondary components the effect of the primary magnetisation will become larger with progressive demagnetisation level. Magnetisation direction and intensity after each treatment step are commonly displayed in vector component/Zijderveld plots (Zijderveld, 1967) (Figure 2-6), which display the horizontal (E-W) and vertical (N/ up-down) vector components in one diagram. Unless there is other reason to believe so (e.g. the sample moved during cooling), the most stable characteristic remanence $(\mathrm{ChRM})$ direction usually corresponds to the linear component found at high temperature. Besides the determination of palaeomagnetic directions, the method therefore also provides information about the thermal history of each site, blocking temperature or coercivity distribution of the magnetic minerals in each lava flow (Butler, 1998). In thermal demagnetisation samples are heated and cooled in zero-field 
and subsequently measured. A more rapid approach used is alternating field (AF) demagnetisation. Here samples are exposed to an alternating field, the amplitude of which is smoothly decreased from a preselected peak value to zero. This results in a randomisation of the magnetic moments with coercivities lower than the peak field. AF treatment is applied to all three orthogonal axes of a sample.

Thermal demagnetisation experiments were carried out at Victoria University of Wellington and the geomagnetism laboratory, University of Liverpool. Heating cycles were usually carried out over 30 minute time-periods up to a maximum temperature of $600^{\circ} \mathrm{C}$. To detect the influence of mineral-alteration, thermal demagnetisation experiments were accompanied by susceptibility checks after each heating step. AF demagnetisation was conducted on a selected number of specimens using Molspin AF demagnetiser with a maximum peak field of $100 \mathrm{mT}$. Remanences were measured using either an AGICO JR6 at the University of Liverpool or a JR6A at Victoria University of Wellington, which have a maximum sensitivity of $1 * 10^{-6} \mathrm{~A} /$ m. ChRM directions were selected for all specimens from the most reliable directional by Principal Component Analysis (PCA) using AGICO's software, Remasoft 3.0 (Chadima and Hrouda, 2006; Kirschvink, 1980). The software also allows the user to switch between the specimen coordinate system $(\mathrm{X}, \mathrm{Y}, \mathrm{Z})$ and the geographic reference frame (N/S, E/W. up/down). Site and flow average directions and associated $95 \%$ confidence cones $(\alpha 95)$ were calculated following the procedures outlined for statistics of spherical distributions of directions by Fisher (1953). 
a)

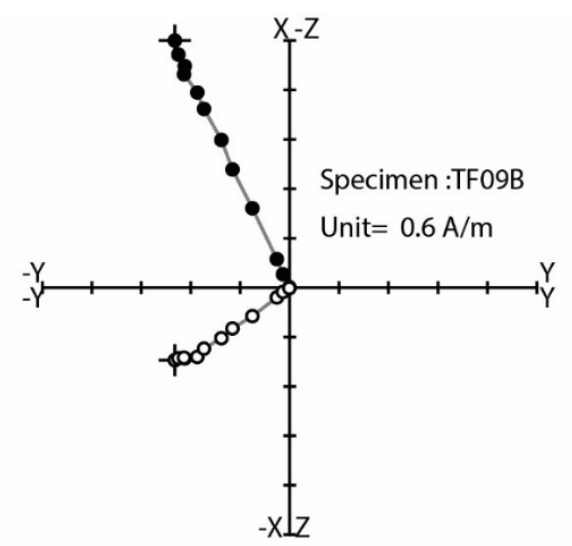

c)

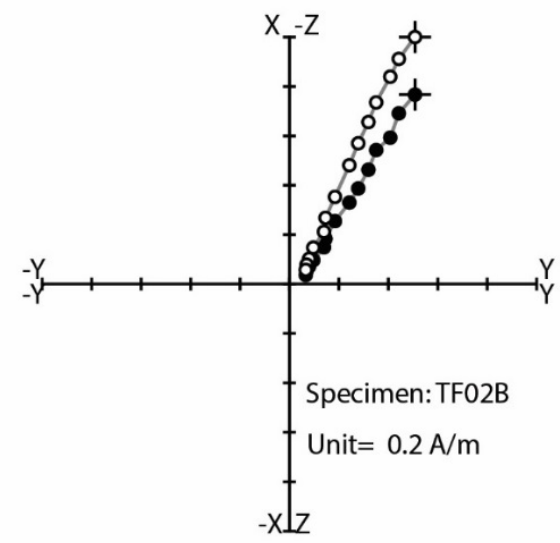

- Horizontal o Vertical b)

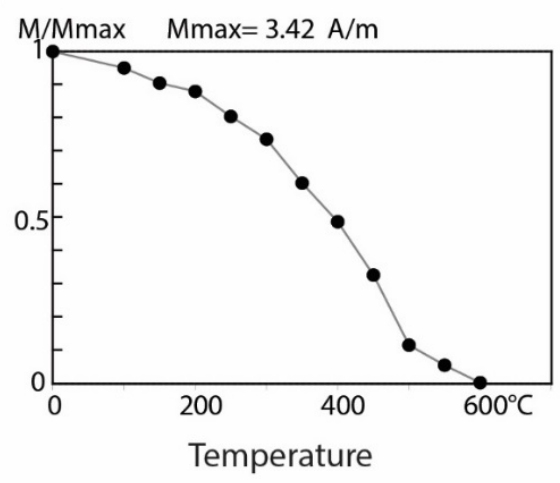

d)

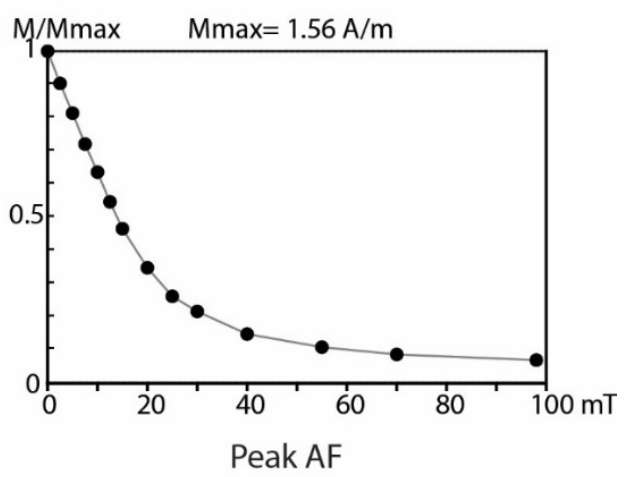

Figure 2-6: Representative vector component diagrams (Zijderveld, 1967) and corresponding NRM intensity plots for two specimens following thermal (Figure $a, b$ ) and alternating field (Figure $\mathrm{c}$ and $\mathrm{d}$ ) demagnetisation. The Zijderveld diagrams displayed on the left show the intensity and direction of the specimen's NRM during progressive demagnetisation steps (open circles: $\mathrm{z}$ vs. y, closed circles: $\mathrm{x}$ vs. y component). The NRM intensity graphs on the right display the intensity remaining after each treatment step. Both samples show single stable components of magnetisation with average directions of Dec $=334.6^{\circ} \mathrm{Inc}=15.7^{\circ}$ and $\mathrm{Dec}=31.0^{\circ}$, Inc $=-48.7^{\circ}$, respectively in specimen coordinates. After application of the correction for the core-orientation in the field (in geographic coordinates) the direction averages are $\operatorname{Dec}=354.6^{\circ}, \mathrm{Inc}=-41.4^{\circ}$ and $\mathrm{Dec}=17.8^{\circ}, \mathrm{Inc}=-61.4^{\circ}$. 


\subsection{Absolute palaeointensity}

\subsubsection{Introduction}

Determining the absolute strength or intensity of the ancient geomagnetic field is one of the major challenges in palaeomagnetic research. A number of different approaches have been proposed in the past, and the most frequently used are based on the Thellier method (Thellier and Thellier, 1959). Throughout this thesis, palaeointensity estimates were made using a combination of thermal and microwave based methods. Thermal experiments were carried out at the University of Liverpool and Victoria University of Wellington, microwave experiments at the University of Liverpool. While the demagnetisation/re-magnetisation process during microwave applications is different, both methods rely on the same principles and experimental details are explained for the thermal method in section 2.8.2, further information on the microwave technique is given in section 2.8.3.

\subsubsection{Concept and palaeointensity protocols}

In all methods, the palaeointensity $\mathrm{B}_{\mathrm{anc}}$ is estimated by assuming a linear relation between the thermoremanent magnetisation (TRM) and the field in which it was acquired. By comparing the NRM with a TRM grown in a known field in discrete intervals of the blocking temperature spectrum, the palaeomagnetic fieldstrength can be found using:

$$
B_{a n c}=\frac{|\Delta N R M|}{|p T R M|} B_{l a b}
$$

Where $|\triangle N R M|$ is the magnitude of NRM lost between two demagnetisation steps and $|\mathrm{pTRM}|$ is the magnitude of the partial TRM (pTRM) gained in a laboratory field between the two temperatures. In practice the method consists of three steps: Rock samples are stepwise heated from room temperature to temperatures close to the Curie point of common minerals, each temperature interval includes one heating and cooling cycle in a zero-field and one in a known stable field. The remanences lost and the pTRMs obtained in each cycle are calculated and displayed in respect to each other in a so-called Arai diagram (Figure 2-7). $\mathrm{B}_{\text {anc }}$ can be calculated from the best fitting slope to the data. For relation (1) to be valid the behaviour of the respective 
sample needs to obey three fundamental principles, based on the theory of single domain grains (Néel, 1955) :

(1) Independence: The pTRMs acquired after each heating step are independent of each other.

(2) Additivity of pTRM: The total TRM gained is equal to the sum of all pTRMs gained during individual temperature steps.

(3) Reversibility: The unblocking temperature $T_{u b}$ equals the blocking temperature $\mathrm{T}_{\mathrm{b}}$ for any magnetic carrier in the sample.

To obey this, the NRM must be a TRM. Further the magnetic carriers within a sample need to be thermally stable, non-interacting and of single-domain size. These requirements are rarely satisfied in nature. Titanomagnetites and titanohematites, the most prominent magnetic mineral phases found in samples of this study (chapter 3-5), are highly reactive when subjected to heating and the onset of thermal alteration is often observed within the temperature range applied during most standard Thellier experiments. Furthermore it has been shown that the reversibility and independence criteria are not satisfied in the presence of MD grains (Fabian, 2001; Levi, 1977; Shcherbakov et al., 2001). To detect non-ideal behaviour, a number of checks and modifications to the basic method have been proposed (e.g. Coe, 1967; Riisager and Riisager, 2001; Yu et al., 2004). In this thesis I applied the two most frequently used modifications, the Coe and IZZI type protocols: The conventional Coe type protocol (Coe, 1967) involves double heating steps, each temperature interval starting with the zero-field step, followed by an infield step. After every second in-field step an additional zero-field or tail check (Riisager and Riisager, 2001) was implemented. This check shows whether remanences acquired during the preceding pTRM check are adequately removed in the following zero-field steps and hence monitors the reversibility between $T_{b}$ and $T_{u b}$. Each tail check was followed by a pTRM check during which an earlier in-field step is repeated. This check helps to identify changes to the ability of a sample to retain a pTRM caused by thermo-chemical alteration. The IZZI protocol (Tauxe and Staudigel, 2004) involves double heating steps, alternating 
in order of zero field (Z) and infield (I) steps. pTRM checks are included between the zero-field steps. The protocol does not require tail checks: pTRM tails carried by MD grains would result in a systematic difference between the zero-field remanences measured during zero-field first (ZI) and in-field first (IZ) heating intervals.

In order to ensure that only reliable palaeointensity results are used for the calculation of a flow mean, in this thesis the data were subjected to stringent selection following a set of criteria that assesses the quality of the slope fit within the Arai plot, pTRM and tail checks. Different sets of selection criteria have been proposed in the past and often these were somewhat adjusted to the overall quality of the data. It is important to note that while too 'soft' criteria sets can result in acceptance of erroneous palaeointensity results, overly stringent sets can result in removal of useful data, where scatter is due to instrumental noise (e.g. Paterson et al., 2014).

For a more thorough discussion of the palaeointensity methods employed and the selection criteria used please refer to chapter 4.

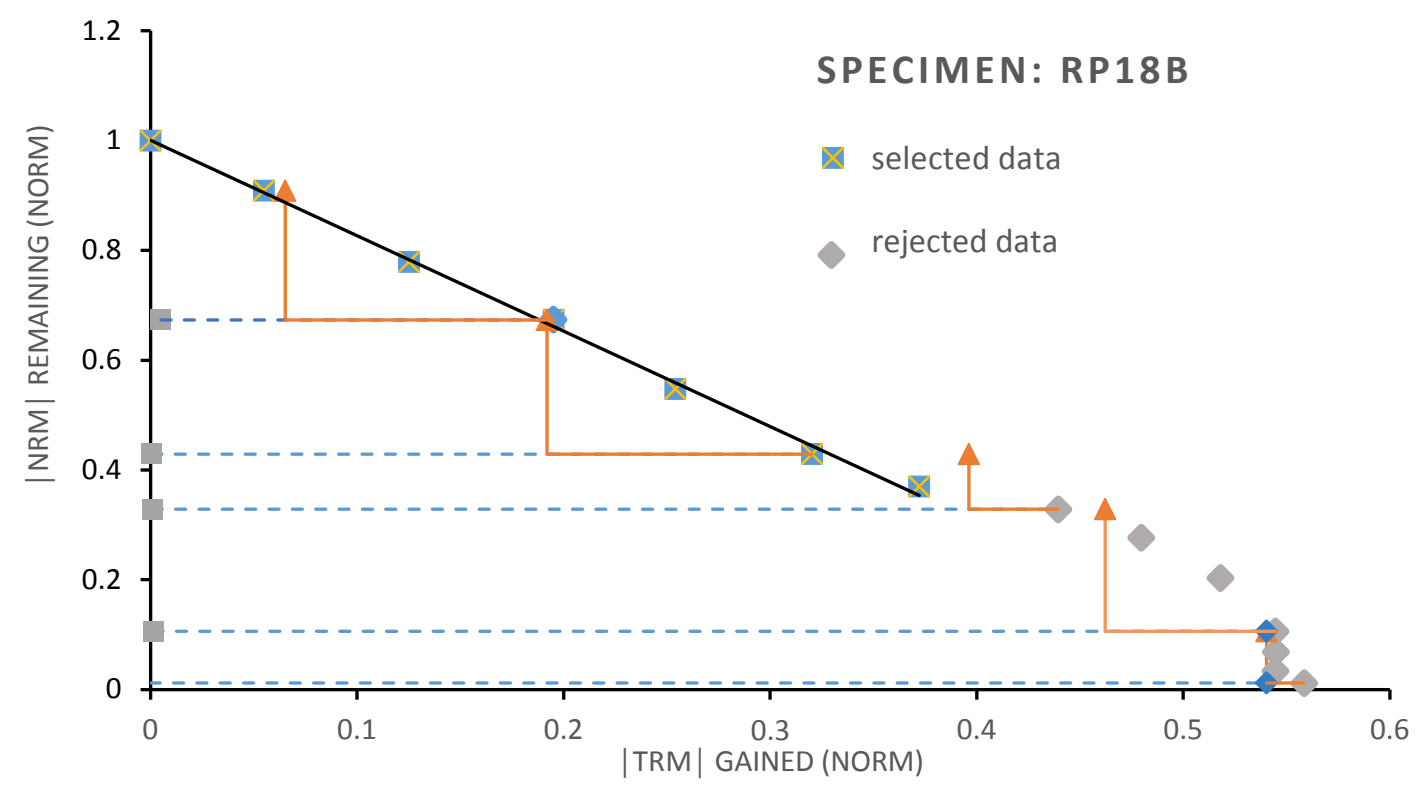

Figure 2-7: Representative Arai plot from a Thellier experiment (Coe type). The data shown includes passed and failed data points, pTRM and tailchecks. The |TRM| gained and $|\mathrm{NRM}|$ remaining are normalized against $\mathrm{NRM}_{0}$. Thermal alteration at temperature steps higher than $400^{\circ} \mathrm{C}$ results in a change in slope. These points, displayed in grey have been rejected from further analysis. The palaeointensity can be calculated from the best fitting slope. 


\subsubsection{Microwave palaeointensity}

The microwave technique (Hill and Shaw, 2000) was designed to minimize alteration by exciting the magnetic moments of the ferro-/ferrimagnetic grains using energetic microwaves instead of the heating-procedure, while otherwise using methods similar to those used for thermal palaeointensity determination. Heating of a sample results in lattice vibrations that excite spin waves and create magnetic moment. In contrast, high frequency microwaves can directly excite the electron spins without excessive heating of a sample, a technique known as ferromagnetic resonance (FMR) (Hill and Shaw, 1999; Walton et al., 1996). Microwave exposure times are usually between 3 and 15 seconds and the method is therefore significantly faster than thermal applications. This allows single specimes to be treated individually and enables better selection of adequate treatment steps than achieved during bulk heating experiments. To date, no theoretical relation has been established between microwave and thermal energy, but a number of comparative studies prove the method reliable (e.g. Hill et al., 2002).

Microwave palaeointensity experiments were conducted using the system at the University of Liverpool. The central part of the system is a microwave demagnetisation/re-magnetisation unit that is coupled to a Tristan Technologies, Inc. DRM300 cryogenic magnetometer (Suttie et al., 2010). The magnetometer has a maximum sensitivity of $10^{-11} \mathrm{Am}^{2}$ and needs to be fine-tuned prior to each experiment.

The microwave unit consists of a signal generator which produces a signal of frequency between 14 and $14.5 \mathrm{GhZ}$ and is connected to a resonance cavity along a horizontal brass tube, which acts as waveguide. The cavity is shielded from external magnetic fields and contains three field coils creating magnetic fields of pre-defined strength and direction during in-field steps. Specimens of $\sim 5 \mathrm{~mm}$ diameter and up to $3 \mathrm{~mm}$ length are mounted on a vertical quartz glass tube using a negative pressure system that allows automated movement of the sample between the microwave cavity, for demagnetisation or growth of a microwave induced remanence $\left(T_{M} R M\right)$, and the magnetometer for subsequent measurement. During microwave application the sample is placed in the centre of the cavity, at the node of minimum electric but maximum magnetic energy (Suttie et al., 2010). The resonance properties in the microwave 
cavity are dependent on the sample size and its position in the cavity. Prior to an experiment the exact frequency (range 14-14.5 GhZ) is fine-tuned by frequency sweeping in order to achieve maximum energy absorption rates.

The total energy applied to a sample is the integrated amplitude of the microwaves and exposure time, demagnetisation steps may be selected by increasing either the exposure time or the power of the microwave source. After each step the absorbed energy is plotted against the reflected energy. In an ideal case the total energy applied would be absorbed by the sample. Small changes to the positioning of the sample in the cavity or alteration to the magnetic minerals can result in changes. This can result in failure of Coe and IZZI type experiments, which require the total power absorbed between repeated treatment steps to remain consistent. Further it is noteworthy that although in theory no heating of the specimens is to be expected, di-electric heating has been found to result in heating of the bulk sample up to $250^{\circ} \mathrm{C}$ (Suttie et al., 2010). During the experiments carried out for this thesis I also identified small melt spots on a few samples. Similar observations were made for example by Stark (2011), suggesting that spot heating can be of much higher temperature. 


\section{Chapter 3}

\section{Secular variation and new palaeomagnetic age constraints on lava flows from the Tongariro Volcanic Centre, New Zealand}

A modified version of this chapter was published:

Greve, A.; Turner, G. M., Conway, C. E., Townsend, D., Gamble, J.A., Leonard, G. 2016. Palaeomagnetic refinement of the eruption ages of Holocene lava flows, and implications for the eruptive history of the Tongariro Volcanic Centre, New Zealand. Geophysical Journal International, 207, 702-718 doi: 10.1093/gji/ggw296

Co-author contributions

Gillian Turner and John Gamble provided the supervision for this thesis.

Chris Conway worked closely in the field, advised in finding suitable sampling sites, carried out some of the dating, provided editorial advice in particular for the description of the geological settings and description of lava flows and age controls. Dougal Townsend led the geological mapping programme on Mt Ruapehu and thus suggested suitable sampling sites. He reviewed early versions of the manuscript and provided editorial advice.

Graham Leonard was involved with the mapping programme, in particular with the ${ }^{40} \mathrm{Ar} /{ }^{39} \mathrm{Ar}$ dating of lavas around Mt Ruapehu.

\section{$\underline{\text { Relevant appendices (electronic) }}$}

a) Full demagnetisation data for all specimens analysed (file format: .*rs3) Path: Chapter 3/Data/rs3files (TgVC)

b) All rock magnetic data (file formats: *.irm, *. Coe, *.hys, *.rmp, *.cur) Path: Chapter 3/Data/VFTB; Kappa

c) Orientation data for all samples and included in this chapter (file format: *.xlxs). Path: Chapter 3/cores\&directions_TgVC.xlsx

d) All susceptibility checks carried out alongside demagnetisation and intensity experiments (file format: *.xlxs).

Path: Chapter 3/Thdemag_susc_TgVC.xlsx

e) Summary of all ChRM directions selected (file format: *.xlxs)

Path: Chapter3/Directions_TgVC.xlxs 


\subsection{Abstract}

The paucity of Holocene palaeomagnetic data from the southern hemisphere significantly limits the resolution of global models of palaeosecular variation. To date, studies on lava flows from the southern hemisphere, and New Zealand in particular, have been significantly hampered by a lack of adequate radiometric age control. We sampled 39 new sites on twelve Holocene basaltic andesite and andesitic lava flows from the Tongariro Volcanic Centre in the central North Island, New Zealand. Formation ages for these flows are constrained by new high-precision ${ }^{40} \mathrm{Ar} /{ }^{39} \mathrm{Ar}$ geochronological data and existing tephrostratigraphic controls. Lava flow morphology and characteristics vary considerably between the sites sampled, and we therefore explore different sampling strategies and statistical analysis of our data. The new results are compared with a recently published continuous lake sediment record from Lake Mavora, Fiordland. Demagnetisation experiments on all lava flows gave successful results and the spread of the flow mean directions is within the range of the secular variation indicated by the lake sediment record. Correlation between the Lake Mavora record and the new volcanic data allows us to refine the existing eruption age estimates of the Tongariro Volcanic Centre lava flows. Our refined ages carry uncertainties as low as 500 years in some cases, significantly improving the chronology of Holocene eruptions of volcanoes of the Tongariro Volcanic Centre. 


\subsection{Introduction}

Palaeomagnetic studies of volcanic rocks contribute both to our understanding of geomagnetic secular variation and to the eruptive history of the volcanic area studied. The palaeomagnetic information contained in the thermoremanent magnetisation (TRM) of lava acquired during cooling provides an instantaneous record of the palaeofield. Comparison of the palaeomagnetic direction and intensity recorded in a lava flow with a palaeosecular variation master record or model for the studied region can help to constrain its eruption age more precisely.

Understanding palaeosecular variation (PSV) on time-scales of hundreds to thousands of years is an important step in understanding the origin of Earth's magnetic field and the prediction of its future behaviour. However, current global field models (e.g.Korte et al., 2011; Nilsson et al., 2014) suffer from a paucity of data from the southern hemisphere. For instance, until recently only one continuous record, spanning the last 2500 years, was available from New Zealand (Turner and Lillis, 1994), the nearest other records being from Australia (Barton and Mc Elhinny, 1982; Constable and Mc Elhinny, 1985). Several attempts have been made to study PSV recorded in New Zealand volcanic rocks (Cox, 1969; Downey et al., 1994; Robertson, 1986; 2007; Tanaka et al., 1994; 1996; 1997; 2009) but these studies were constrained by the limited geological and/or age information available at the time. During a recent geologic mapping programme of the Tongariro Volcanic Centre (TgVC) (Conway et al., 2016; Townsend et al., in prep), new ${ }^{40} \mathrm{Ar} /{ }^{39} \mathrm{Ar}$ eruption ages, along with geochemical data, for lava flows from Ruapehu volcano have been acquired. These new data have been integrated with existing data to form a detailed eruptive history for Mt Ruapehu, which provides an ideal framework for palaeomagnetic studies of lava flows. Recent advances in the ${ }^{40} \mathrm{Ar} /{ }^{39} \mathrm{Ar}$ dating method have provided an opportunity to measure eruption ages for intermediate composition Holocene lava flows (Conway et al., 2016; Jicha et al., 2012). However, such results are still subject to uncertainty in the range of hundreds to thousands of years, which is significant for Holocene-aged lavas. 
Here we present the palaeomagnetic results on 12 Holocene lava flows from Ruapehu and Tongariro volcanoes. Eruption ages for the sampled flows are constrained by highprecision ${ }^{40} \mathrm{Ar} /{ }^{39} \mathrm{Ar}$ geochronology (Conway et al., 2016), tephrochronological or geomorphological information. The primary aim of this study is to develop a series of discrete secular variation records for this area for the past 15 kyrs. Comparison of our new data with a recently published lake sediment-based PSV record for New Zealand (Turner et al., 2015b) allows refinement of the existing age control of the lava flows. Our new data will significantly improve global and regional field models. In the long term we aim to establish a comprehensive dataset and field model for the southwest Pacific region, which will contribute to an understanding of the origins of the geomagnetic field and will also provide a powerful new dating tool for young volcanic deposits across the region.

\subsection{Geological Setting}

The Tongariro Volcanic Centre $(\mathrm{TgVC})$ is situated at the southern end of the Taupo Volcanic Zone, an area of geothermal and volcanic activity that extends as far north as White Island in the Bay of Plenty (Wilson et al., 1995) (Figure 3-1, inset). The TgVC comprises four main volcanic edifices: Kakaramea, Pihanga, Tongariro, and Ruapehu (Cole, 1978; Hobden, 1997). It is dominated by Mt Ruapehu at the southern end and a complex of smaller andesitic cones around Mt Tongariro (Hobden et al., 1996) on the northern end. The two main cones, Mts Ruapehu and Tongariro, are large and complex intermediate arc composite volcanoes with eruptive histories stretching back to at least 340 ka (Hobden et al., 1996; Tost and Cronin, 2015).

Pioneering work on the volcano stratigraphy of Mt Ruapehu was carried out by Hackett (1985), who defined four major formations (from oldest to youngest: Te Herenga, Wahianoa, Mangawhero and Whakapapa), which represent the deposits of episodes of effusive eruptive activity that $\mathrm{w}$ interrupted by periods of erosion and relative quiescence. Deglaciation of the edifice since ca. $15 \mathrm{ka}$ affected the distribution of lava flows due to the retreat of former large flank glaciers that had occupied valleys for at least the preceding ca. 35 kyr (Conway et al., 2015). Thus, 
post-glacial lava flows, which are assigned to the Whakapapa Formation $(<15 \mathrm{ka})$, can be identified primarily from their location within glaciated valleys and also the lack of evidence for large-scale lava-ice interaction or significant overlying moraines (Conway et al., 2015). Until now, absolute age control for flows belonging to the Whakapapa Formation has been sparse and prone to large uncertainty (Gamble et al., 2003). In addition to ${ }^{40} \mathrm{Ar} /{ }^{39} \mathrm{Ar}$ eruption ages presented by Conway et al. (2016) and used here, chronological constraints are provided by tephra and volcaniclastic marker beds from the well-dated suite of airfall deposits that have been catalogued in high-resolution studies of the ring plain stratigraphy (Donoghue et al., 1995; Donoghue and Neall, 2001; Moebis et al., 2011). Volcanic activity since $2 \mathrm{ka}$ at Mt Ruapehu has primarily been of a phreatomagmatic nature (Price et al., 2012). Detailed descriptions of the stratigraphy and morphology around Mt Tongariro shows a wide array of young lava flows (Hobden, 1997). Although no direct radiometric dates for these young flows are available, their minimum ages are constrained by overlying tephra marker beds with associated radiocarbon dates (Hobden, 1997). 


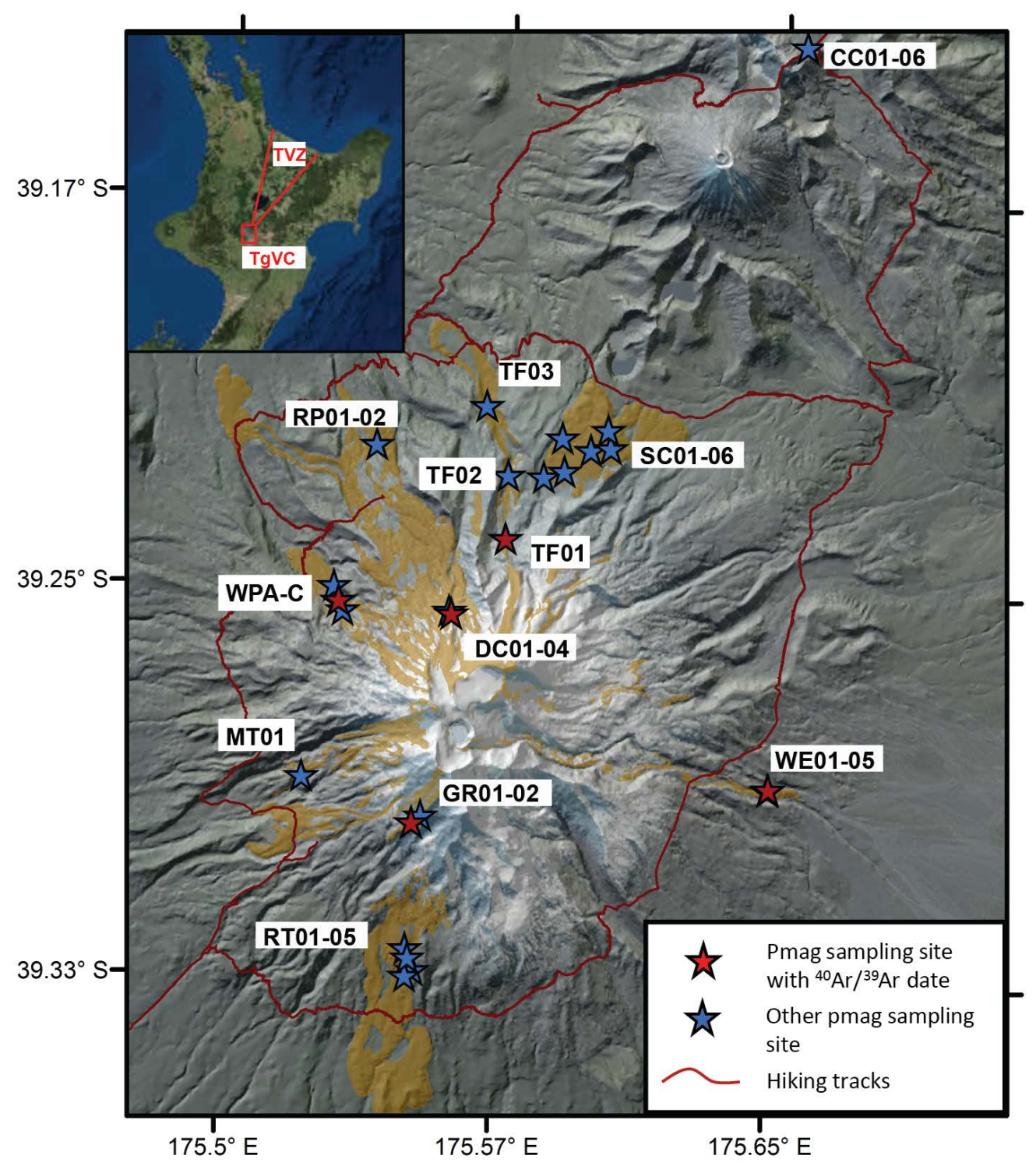

Figure 3-1: Digital topographic map of Mt Ruapehu within the Tongariro Volcanic Centre and palaeomagnetic sampling sites (stars). Sites, for which ${ }^{40} \mathrm{Ar} /{ }^{39} \mathrm{Ar}$ ages are available are indicated in red, others in blue. The postglacial lava flows on Mt Ruapehu, most of which belong to the Whakapapa Formation, are shown in brown. Inset: Location of the TgVC at the southern tip of the Taupo Volcanic Zone (TVZ) in the North Island, New Zealand. Base map information from Land Information New Zealand (LINZ). 


\subsection{Samples and ages}

Field sampling for palaeomagnetic analysis was carried out over two seasons from 2012 to 2014, alongside a geological mapping programme of the Tongariro National Park undertaken by GNS Science (Townsend et al., in prep). Holocene lava flows were selected on the basis of new ${ }^{40} \mathrm{Ar} /{ }^{39} \mathrm{Ar}$ eruption ages (Conway et al., 2016), and dating using available tephrochronology (Hobden, 1997; Topping, 1974) and morphological features (Conway et al., 2015).

Altogether we sampled 39 sites from 12 individual flows (Figure 3-1). The morphology and exposure of the individual flows vary considerably and are discussed below. Each flow was sampled at a minimum of three sites along the flow, accessibility permitting. The flow tops are usually strongly auto-brecciated into smaller blocks and they were therefore sampled at multiple sub-sites to verify that individual blocks were in situ. At every site or sub-site $4-10$ cores of $2.5 \mathrm{~cm}$ diameter and 6-12 cm length were drilled using a water-cooled, petrol driven hand drill. All cores were oriented using a magnetic compass, and sun-compass wherever possible. Magnetic compass bearings sometimes differed by several degrees from the sun-compass corrected orientations and so, when no sun was available, we took a bearing from a distance of ca. $10 \mathrm{~m}$ to verify correct orientation of the samples. At sites that proved unsuitable for drilling, hand samples were obtained following the marking and measuring of a suitable flat surface for later re-orientation. These were then drilled in the laboratory using a vertical drill press. All samples were cut into standard sized specimens. The sampling details for all twelve flow units are presented below. All Ruapehu flows studied belong to the Whakapapa Formation (Hackett, 1985; Townsend et al., in prep), and are listed together with the age information in Table 3-1. 
Table 3-1: Description and independent age information of the flows studied from the TgVC.

\begin{tabular}{|c|c|c|c|c|c|c|}
\hline Abb & Flow & Member & Age (ka) & Dating & Reference & $\begin{array}{l}\text { No } \\
\text { (sites) }\end{array}$ \\
\hline $\mathrm{CC}$ & Central Crater & & $<1.72 \pm 0.01$ & Tephra & Lowe et al. (2013) & 6 \\
\hline WE & Whangaehu & Crater Lake & $0.2 \pm 2.2 *$ & ${ }^{40} \mathrm{Ar} /{ }^{39} \mathrm{Ar}$ & Conway et al. (2016) & 5 \\
\hline DC & Delta Corner & Iwikau & $6 \pm 2.4^{*}$ & ${ }^{40} \mathrm{Ar} /{ }^{39} \mathrm{Ar}$ & Conway et al. (2016) & 4 \\
\hline RP & Bruce Road & Iwikau & $5-10$ & Tephra & Topping (1974) & 2 \\
\hline $\mathrm{TF}$ & Taranaki Falls & Iwikau & $8.8 \pm 2.8^{*}$ & ${ }^{40} \mathrm{Ar} /{ }^{39} \mathrm{Ar}$ & Conway et al. (2016) & 3 \\
\hline $\mathrm{SC}$ & Saddle Cone & Saddle Cone & $5-10$ & Tephra & Topping (1974) & 6 \\
\hline MT & Mangaturuturu & Turoa & $11.9 \pm 2.2 *$ & ${ }^{40} \mathrm{Ar} /{ }^{39} \mathrm{Ar}$ & Conway et al. (2016) & 1 \\
\hline WPA & Whakapapaiti "A" & Paretaitonga & $14.8 \pm 3 *$ & ${ }^{40} \mathrm{Ar} /{ }^{39} \mathrm{Ar}$ & Conway et al. (2016) & 3 \\
\hline WPB & Whakapapaiti "B" & Paretaitonga & $>$ WPA & Stratigraphy & Conway et al. (2016) & 1 \\
\hline WPC & Whakapapaiti "C" & Paretaitonga & $>$ WPB & Stratigraphy & Conway et al. (2016) & 1 \\
\hline GR & Skyline Ridge & Turoa & $15.1 \pm 2.4^{*}$ & ${ }^{40} \mathrm{Ar} /{ }^{39} \mathrm{Ar}$ & Conway et al. (2016) & 2 \\
\hline RT & Rangataua & Rangataua & $<9.7$ & Tephra & Price et al. (2012) & 5 \\
\hline
\end{tabular}

Note: Abb is the abbreviation for the flow/ unit name. The member corresponds to the classification revised in Townsend et al. (in prep). Central Crater flow (CC) is associated to Mt Tongariro. Age is the age control available for the respective flows from different sources with $2 \sigma$ standard error, if the age was obtained by radiometric dating. Site coordinates are listed in Table 2.*Sample ID's for the ${ }^{40} \mathrm{Ar}{ }^{39} \mathrm{Ar}$ dated sites in Conway et al. (2016): WE: GL1983, TF: CC279, DC: GL1030, MT: CC236, GR: CC130, WPA: CC335. CC: Tephra age in kyrs BP.

\subsubsection{Central Crater flow (CC)}

This basaltic andesite a'a flow is located in a broad shallow basin on Mt Tongariro known as Central Crater, just a few hundred metres from its vent, Red Crater. The lava forms a relatively thin flow with a maximum thickness of $2 \mathrm{~m}$, and there is no exposure of the flow interior (Figure 3-2a). Because auto-brecciation of the upper surface of the flow may have occurred as the lava was cooling during emplacement, we sampled six individual blocks (sites $\mathrm{CC} 01$ to $\mathrm{CC} 06$ ), distributed about the flow top surface, to assess the variability of palaeomagnetic directions. The samples range from moderately vesicular on the flow margins to non-vesicular further towards the centre of the flow. The lava flow is thought to be younger than $232 \pm 10$ AD (Lowe et al., 2013) because it is not overlain by Taupo Ignimbrite, a well-known marker bed in the area (Hobden, 1997), and it is therefore one of the youngest flows investigated in this study. The flow characteristics and exposure are significantly different from those of any of the Ruapehu andesitic flows discussed below, and block sampling has been carried out on only one other flow (SC). 


\subsubsection{Whangaehu flow (WE)}

This flow is located within a formerly glaciated valley and, with an ${ }^{40} \mathrm{Ar} /{ }^{39} \mathrm{Ar}$ eruption age of $0.2 \pm 2.2 \mathrm{ka}$, it is the youngest dated flow belonging to the Whakapapa Formation on Mt Ruapehu. Sample sites are at the distal end of this andesitic lava flow, where a deep gorge exposes an approximately $15 \mathrm{~m}$ thick section on the true right bank of the Whangaehu River.

We identified four different zones through the flow, based on texture and the pattern of cooling joints. This is representative of all other massive andesite flows sampled in this study (Figure 3-2b). The lowermost approximately $1.5 \mathrm{~m}$ of the flow is glassy and massive (zone A), while the flow centre (zone B) is pervasively fractured into subhorizontal curvilinear plates up to $30 \mathrm{~cm}$ long and about $5 \mathrm{~cm}$ thick. Above this is a massive, blocky-jointed zone (zone C) and an auto-brecciated upper flow surface (zone D). The different forms of fracturing in the flow are related to cooling rate (Conway et al., 2015; Lescinsky and Fink, 2000) and this may also affect the rock magnetic properties of the lava (Biggin et al., 2007; De Groot et al., 2014).

Whangaehu flow was sampled at five sites through its vertical thickness. Sites WE01 (zone A) and WE02 (zone B) are located on a small river terrace that accesses the flow base. Drilled samples were taken from zone A (WE01), while an un-oriented hand sample was taken from a large platey boulder that is assumed to originate from zone B (WE02); the collection of drill cores from zone B was not successful due to the fine-scale platey jointing. Sites WE04 and WE05 are located within zone C. Two oriented hand samples were taken from individual blocks along the flow top (WE03) (zone D). This flow provides a case study for assessing how different cooling rates may affect the rock magnetic characteristics and the palaeomagnetic data. 

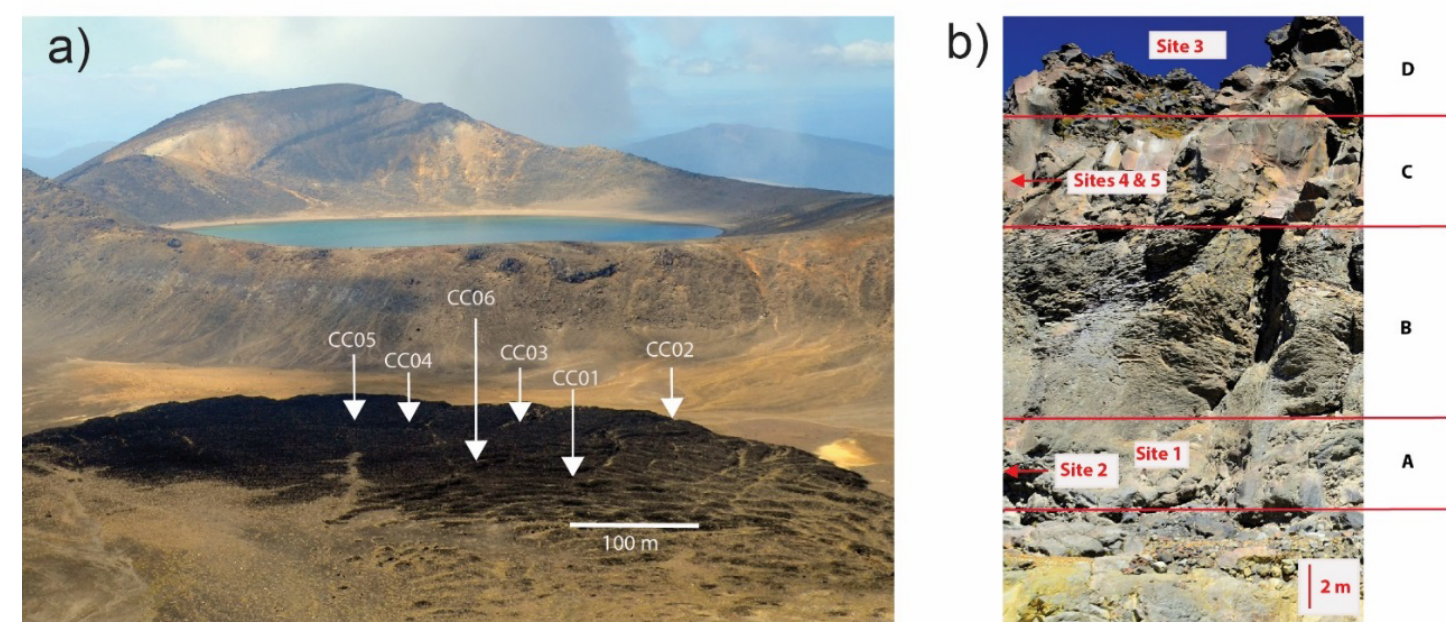

Figure 3-2: Sampling scheme on two lava flows. a) Site sampling along the flow top surface of Central Crater flow (CC), erupted from Red Crater. View looking north from Red Crater, towards Blue Lake. b) River-cut section of Whangaehu flow (WE), as representation of thick andesitic flows sampled and site locations. Zonation of the flow based on fracture characteristics is indicated on the right.

\subsubsection{Delta Corner flow (DC)}

Delta Corner (DC) and Bruce Road (RP) flows are part of a voluminous sequence of flows (the Iwikau member). They fill the inferred pathway of a widespread debris avalanche deposits (the Murimotu Formation) on the lower northern flank of $\mathrm{Mt}$ Ruapehu. The 10.5 ka depositional age of the Murimotu Formation (Eaves et al., 2015) provides a maximum age for the overlying lava flows. Delta Corner is a large flow feature, located within the Whakapapa ski-field, which forms a prominent ridge. A new ${ }^{40} \mathrm{Ar} /{ }^{39} \mathrm{Ar}$ eruption age of $6.0 \pm 2.4 \mathrm{ka}$, is consistent with the upper age limit constrained by the underlying Murimotu Formation. The flow shows clear structuring into the four zones described above for the Whangaehu flow. We collected drilled samples from three sites across a lateral distance of about $200 \mathrm{~m}$, representing zones A (DC01), B (DC04), C (DC03) and D (DC02). 


\subsubsection{Bruce Road flow (RP)}

The Bruce Road flows are part of an extensive series of a'a lava flows on the lower north-western exposure of the Iwikau member at the Whakapapa ski-field. Topping (1974) suggested an eruption age for one flow between 5 and $10 \mathrm{ka}$ based on the underlying Murimotu Formation and overlying tephra. The flows were sampled at two sites. RP01 is located inside a sharp bend in Bruce Road and RP02 is about $300 \mathrm{~m}$ west of RP01, in a steep gorge above Waipuna Stream. At both sites a section through the flow interior is accessible. This is more prominent at RP02 where the Waipuna Stream gorge exposes a vertical section through the flow and the zonation described for Whangaehu lava flow is again apparent. At site RP01 a loose, un-oriented hand sample was taken from the upper surface of the flow, and oriented samples were drilled at two additional sub-sites from the flow interior. RP02 was sampled at two sub-sites within zone $\mathrm{C}$.

\subsubsection{Taranaki Falls flow (TF)}

Taranaki Falls flow is also part of the Iwikau member and forms a lava flow that is exposed along Wairere stream over a distance of about $3 \mathrm{~km}$. Timing of flow emplacement is constrained by an ${ }^{40} \mathrm{Ar} /{ }^{39} \mathrm{Ar}$ eruption age of $8.8 \pm 2.8 \mathrm{ka}$. We sampled the flow TF at three sites from the rootless, exposed upper end (TF01) to the lower end (TF03) near the "Round the Mountain" walking track, at the top of Taranaki Falls. Palaeomagnetic sampling of this flow provides a good example of sites spread over a long lateral distance and therefore helps to assess whether sampling location and changes in the flow morphology can affect the recorded directions.

\subsubsection{Saddle Cone flows (SC)}

Saddle Cone lava flows originate from a small parasitic cone (Topping, 1974) and cover an area of approximately $4 \mathrm{~km}^{2}$ north of Mt Ruapehu. Topping (1974) proposed a minimum eruption age of $5 \mathrm{ka}$ based on a capping tephra. The flows were later associated with short-lived series of pyroclastic eruptions at around $10 \mathrm{ka}$ based on 
geochemical and petrographic correlations (Nakagawa et al., 1998). Outcrops include individual blocks along the auto-brecciated flow tops and at the flow fronts. The brecciated nature of the flow surface makes it difficult to distinguish between individual flows. Oriented samples were taken from six sites; at each site we usually sampled several blocks. Altogether 13 individual blocks (sub-sites) were sampled from six sites, dispersed across the area to assess whether significant differences in the palaeomagnetic direction might indicate significant age difference or post-cooling block movement.

\subsubsection{Mangaturuturu flow (MT)}

The Mangaturuturu flow (MT) sampled in this study is the middle of a sequence of three flows and exposed on a steep bluff within Mangaturuturu Valley. Samples were collected from a single site, from which an eruption age of $11.9 \pm 2.2 \mathrm{ka}$ was obtained. The outcrop comprises mainly fractured, platey lava. We therefore drilled coresamples where possible and otherwise collected hand samples from a wide area across the outcrop.

\subsubsection{Whakapapaiti A-C flows (WPA, WPB, WPC)}

The Whakapapaiti sequence comprises at least three post-glacial lava flows in the upper Whakapapaiti valley on the north-western flank of Mt Ruapehu. Timing of emplacement of the stratigraphically youngest flow (Whakapapaiti A (WPA)) is constrained by an ${ }^{40} \mathrm{Ar} /{ }^{39} \mathrm{Ar}$ eruption age of $14.8 \pm 3.0 \mathrm{ka}$. The flow can be traced about $1 \mathrm{~km}$ upslope from the locality of the sample taken for ${ }^{40} \mathrm{Ar} /{ }^{39} \mathrm{Ar}$ analysis; we sampled three sites along the length of the flow. WPA01 and WPA02 are located near the uppermost of a series of waterfalls, while WPA03 is $500 \mathrm{~m}$ further east, on the true left of the Whakapapaiti Stream. WPA01 corresponds to the dated locality and we collected both oriented hand- and drilled samples. Oriented hand samples were also taken from the underlying flows Whakapapaiti B (WPB) and Whakapapaiti C (WPC). This suite of flows is the only stratigraphic succession from field observations sampled in this study. 


\subsubsection{Skyline Ridge flow (GR)}

Two sites were sampled from the eastern side of this narrow, ridge-top flow on the south-western flank of Mt Ruapehu. Due to its location at high elevation and the frequent snow cover it is particularly prone to weathering. Timing of flow emplacement is constrained by an ${ }^{40} \mathrm{Ar} /{ }^{39} \mathrm{Ar}$ eruption age of $15.1 \pm 2.4 \mathrm{ka}$. The flow at the dated location is fractured by platey joints; the remaining exposed parts of the flow are blocky. Site GR01 was sampled at two sub-sites: oriented hand samples were taken from the platey section (zone B, GR01.1) and drilled samples from close by (zone C, GR01.2). Further oriented cores were taken from higher up the flow (zone C, site GR02).

\subsubsection{Rangataua flows (RT)}

Rangataua andesites are an extensive suite of lava flows on south Mt Ruapehu. Several stream cuts expose parts of the flow interior; however, the ubiquitous glassy nature of the groundmass precluded ${ }^{40} \mathrm{Ar} /{ }^{39} \mathrm{Ar}$ dating and age controls on these flows are based on field observations only - Price et al. (2012) suggested ages $<9.7$ ka for vent-proximal and medial deposits, and $>11.9 \mathrm{ka}$ for distal flows, while Conway et al. (2016) suggests the flows may have been emplaced during the late stages of the last glaciation and could be between 10 and $15 \mathrm{ka}$ old. Altogether we sampled five sites along a distance of $2 \mathrm{~km}$. All sites are located in proximal (RT04-RT05) or medial flows (RT01-RT03), located above the bush-line. Site RT01 is located on a small stream cut immediately beneath the flow top surface at the eastern margin, sites RT02 and RT03 are located within river cuts further downslope. At all three sites drilled samples were collected. Oriented hand samples were taken from the flow top surface at sites RT04 and RT05, but palaeomagnetic direction estimates were only made from the drilled samples. 


\subsection{Rock Magnetic Properties}

\subsubsection{Methods}

Detailed rock magnetic experiments were carried on samples from each flow. Here we summarize the most important rock magnetic findings needed to explain magnetic remanence. Isothermal remanent magnetisation (IRM) acquisition, backfield IRM curves, hysteresis and thermomagnetic curves were measured using a Magnetic Measurements Variable Field Translation Balance (VFTB) and further susceptibility-temperature experimentats were conducted under an inert (Ar) atmosphere in an AGICO Kappa Bridge at the University of Liverpool. All experiments were carried out on powdered rock chips or core offcuts. Thermomagnetic experiments included in-field heating of samples to a peak temperature of $700^{\circ} \mathrm{C}$ with a heating rate of $30^{\circ} \mathrm{C} / \mathrm{min}$ and subsequent cooling. All VFTB experiments were carried out with a peak field of $800 \mathrm{mT}$. Full analysis of the VFTB data was made using RockMag Analyser 1.0 (Leonhardt, 2006) and of susceptibility data using Cureval 8.0.2 (Chadima and Hrouda, 2012). Curie points were estimated from saturation magnetisation vs. temperature $\left(\mathrm{M}_{\mathrm{S}} \mathrm{vs.T}\right)$ graphs using the second derivative approach (Tauxe, 1998) and picked from susceptibility vs. temperature $(\chi$ vs. T) curves at the onset temperature of linearity in $1 / \chi$, which corresponds to the change from ferrimagnetic to paramagnetic behaviour (Petrovsky and Kapicka, 2006).

\subsubsection{Results: Hysteresis and IRM}

The hysteresis loops of all samples in this study are dominated by ferromagnetic behaviour with a variable paramagnetic component. Prior to the calculation of saturation remanence $\left(\mathrm{M}_{\mathrm{rs}}\right)$, saturation magnetisation $\left(\mathrm{M}_{\mathrm{s}}\right)$ and coercivity $\left(\mathrm{B}_{\mathrm{c}}\right)$, the paramagnetic component was removed by subtracting a linear function fit to the closed parts of each hysteresis loop. The coercivities of most andesite samples from Mt Ruapehu are between 6 and $15 \mathrm{mT}$, resulting in narrow loops (Figure 3-3b). This indicates that the remanence is carried by a magnetically "soft" mineral. IRM acquisition curves for these samples usually saturate at applied fields below 200 $\mathrm{mT}$. Atypical behaviour is observed on samples from Skyline Ridge flow (GR): 
While samples taken from zone B (site GR01.1), follow the general pattern described above, hysteresis loops of drilled samples taken from zone C (GR01.2 and GR02) have a pot-bellied shape (Figure 3-3b (iii)), and their magnetic coercivities range from 12 to $18 \mathrm{mT}$ - at the upper end of the range observed for all other andesitic samples. A pot-bellied hysteresis loop may result from a mixture of high and low coercivity phases (Tauxe et al., 1996). We note that IRM acquisition curves do not saturate at applied fields lower than 300 to $400 \mathrm{mT}$, which also indicates the presence of a second, high coercivity phase in these samples. Central Crater (CC) basaltic andesite samples (Figure 3-3c) showed considerable variability during thermomagnetic experiments, had higher coercivities (up to $60 \mathrm{mT}$ ), and IRM saturation at fields of up to 500 mT. The comparatively high coercivities may be explained by the presence of small single domain (SD) titanomagnetite grains, formed prior to rapid cooling of the lava at the flow top surface close to its source (Red Crater).

The ratios $\mathrm{M}_{\mathrm{rs}} / \mathrm{M}_{\mathrm{s}}$ and $\mathrm{B}_{\mathrm{cr}} / \mathrm{B}_{\mathrm{c}}$ of all samples fall into the pseudo-single domain (PSD) field of the Day plot (Day et al., 1977), however their overall distribution resembles hyperbolic trends calculated by Dunlop (2002) for mixtures of single (SD) and multi domain (MD) (titano)magnetite grains (Figure 3-3a). The CC samples plot closer to the top left, single-domain region of the Day plot.

\subsubsection{Results: Thermomagnetic experiments}

Thermomagnetic experiments on samples from different sites and flows yield a wide range of curve shapes with variable degrees of reversibility. We cannot assign a unique behaviour to individual flows, but we observe a strong dependence on the location within the lava flows sampled. The Curie temperatures range from 150 to $600^{\circ} \mathrm{C}$, leading in combination with hysteresis parameters, to the conclusion that titanomagnetites are the primary carrier of magnetic remanence and we relate the differences in the thermomagnetic properties to differing cooling rates and associated oxidation and exsolution states of the Fe-Ti oxides.

We classify the thermomagnetic curves into five general types (Figure 3-3c). Type 1 curves were found on samples from Central Crater flow (CC) only, types 2 to 5 
curves are characteristic of samples from different zones in the thick andesitic flows from Mt Ruapehu.

Type 1 behaviour differs between $\mathrm{M}_{\mathrm{s}}$ vs. $\mathrm{T}$ and $\chi$ vs. $\mathrm{T}$ experiments. Both curves show only one compositional phase, however, while the $\chi$ vs.T curves are nearly reversible, in the $M_{s}$ vs. $T$ curves, both $T_{c}$ and $M_{s}$ increase after heating. Type 2 curves reveal multiple compositional phases, with the lowest Curie temperature generally between 150 and $250^{\circ} \mathrm{C}$. The curves are fully reversible, and were most commonly obtained from samples from the brecciated tops (zone D) of thick andesitic flows. Type 3 curves also show two (or more) phases, with $\mathrm{T}_{\mathrm{c}}$ 's between 250 and $320^{\circ} \mathrm{C}$ and between 500 and $590^{\circ} \mathrm{C}$. However the Curie temperatures change after heating, with the shifts being dependent on the peak temperature reached during an experiment. These curves were obtained from samples from zones A and C. Type 4 curves show only one $\mathrm{T}_{\mathrm{c}}\left(\mathrm{ca} .540^{\circ} \mathrm{C}\right)$ on heating, but two (ca. 350 and $570^{\circ} \mathrm{C}$ ) on cooling. Type 5 is characterised by near-reversible behaviour, indicating a single compositional phase of high $\mathrm{T}_{\mathrm{c}}\left(\mathrm{ca} .500-590^{\circ} \mathrm{C}\right)$. Types 4 and 5 are typical of samples from zone B, the flow interior. 
(Page intentionally left blank) 

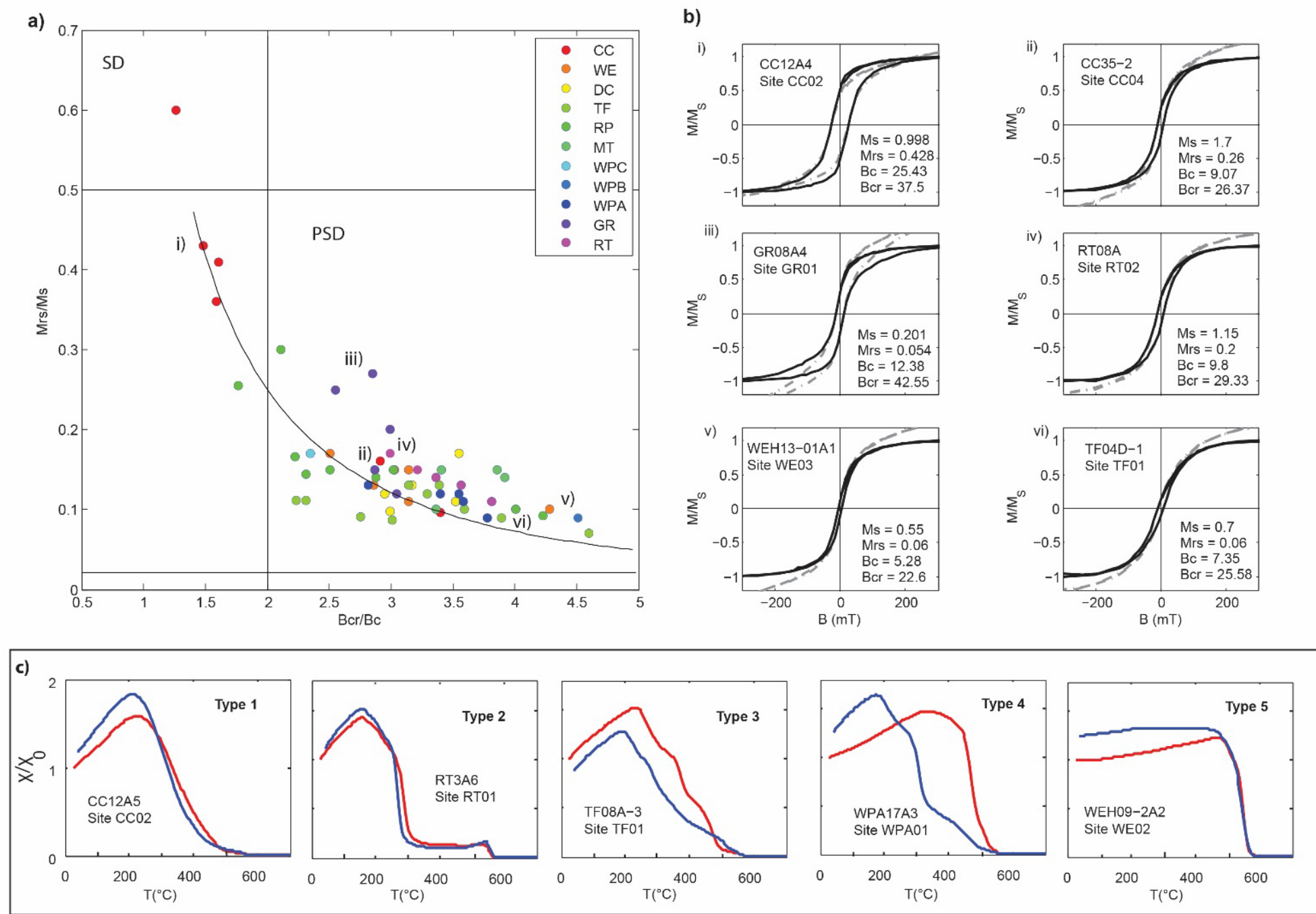
Figure 3-3: Day plot, representative hysteresis and thermomagnetic curves (TgVC). a) Day plot with the boundaries between SD and PSD behaviour and a theoretical SD-MD mixing curve after Dunlop (2002); b) representative hysteresis diagrams. The specimen ID, site ID and hysteresis parameters are displayed in each graph and the corresponding data points in the Day plot labelled from i - vi. Units for $\mathrm{M}_{\mathrm{s}}$, $\mathrm{M}_{\mathrm{rs}}$ are $* 10^{3} \mathrm{Am}^{2} / \mathrm{kg}, \mathrm{B}_{\mathrm{c}}, \mathrm{B}_{\mathrm{cr}}$ in $\mathrm{mT}$. The hysteresis parameters were calculated using RockMag Analyser 1.0 (Leonhardt, 2006); c) The five general types of thermomagnetic curves identified in this study. See text for details. 


\subsection{Palaeomagnetic methods}

Stepwise thermal and alternating field demagnetisation was carried out on up to ten specimens per site and subsequent remanence measurements were made using an $A G I C O$ JR6A magnetometer at Victoria University of Wellington or an AGICO JR6 magnetometer at the University of Liverpool. Preliminary thermal demagnetisation (THD) experimentation was carried out on two specimens per site, at temperature intervals of $50^{\circ} \mathrm{C}$ from room temperature to $600^{\circ} \mathrm{C}$ or until less than $10 \%$ of the initial natural remanent magnetisation (NRM) remained. All samples were subsequently divided into groups of similar behaviour for more detailed demagnetisation experiments. Each subsequent experiment contained ten or more steps of increasing temperature. Two specimens per site were also subjected to progressive alternating field demagnetisation (AFD) at intervals of between 5 and $15 \mathrm{mT}$ up to a peak alternating field of $90 \mathrm{mT}$. All data were displayed in vector component diagrams (Zijderveld, 1967) and the characteristic remanent magnetisation ChRM directions calculated by principal component analysis (PCA) (Kirschvink, 1980) using Remasoft 3.0 (Chadima and Hrouda, 2006). All heating experiments were accompanied by room temperature magnetic susceptibility checks to identify the onset of thermo-chemical alteration. Site and flow mean directions were calculated using Fisher statistics (Fisher, 1953) following the steps and criteria outlined below:

1) Specimen ChRM directions must include a minimum of five data points with a maximum angular deviation (MAD) of $5^{\circ}$. For specimens in which the ChRM data trend away from the origin in the high temperature/AF demagnetisation steps (possibly due to thermal alteration during the demagnetisation experiment), the ChRM was calculated anchored to the origin.

2) When more than one specimen was demagnetised from a core, their ChRM directions were averaged to give a sample mean. Hand sample averaging was conducted in a hierarchical way: a mean was calculated for each core extracted from a hand sample and all core means were subsequently averaged into a sample mean.

3) Site mean directions were calculated by averaging over the samples from each site. Data from individual samples were excluded from the calculation of a site mean if 
their ChRM directions are clearly outliers from the cluster described by other samples from the site and/or there is reason to doubt the result.

4) Finally, flow mean directions were calculated. In most cases, data were included only from sites for which the site mean direction has an $\alpha 95$ of less than $10^{\circ}$. Exceptions are site means calculated from three or fewer samples. If the site mean directions agree at the $95 \%$ level of confidence, or if their $\alpha 95$ cones overlap and site selection indicates that the samples should record the same direction, it was assumed that the dispersion between the sample data is due to random uncertainty and flow means were calculated by averaging all sample mean directions. At CC however, while the site-mean $95 \%$ confidence cones overlap, there is evidence of random syn-cooling block rotation on the flow surface, and a flow mean direction has therefore been calculated by averaging the site means (section 3.7.1).

\subsection{Demagnetisation behaviour and statistics}

In most samples, the demagnetisation behaviour mirrors the rock magnetic properties described above and is related to the thickness and the zone within the lava flow that was sampled. However some sites show anomalous behaviour that requires further discussion. Furthermore the method of averaging varied with the type of sampling carried out; detailed flow by flow descriptions are given below. Site mean and accepted directions for all flows are listed in Table 3-2, vector component plots for different styles of behaviour are shown in Figure 3-4 and Figure 3-5, and the corresponding site mean directions for each lava flow are displayed in Figure 3-6.

\subsubsection{Central Crater flow (CC)}

Central Crater specimens have NRM intensities ranging from 18 to $57 \mathrm{~A} / \mathrm{m}$ and are more strongly magnetized than any of the Ruapehu andesites discussed below. Specimens from most sites yield univectorial decay to the origin (Figure 3-4a,b) and their ChRM directions form tight clusters. While the $95 \%$ confidence cones overlap to some extent for specimens from sites $\mathrm{CC} 02, \mathrm{CC} 03, \mathrm{CC} 04$ and $\mathrm{CC} 05$, we discard all 
data from $\mathrm{CC} 01$ and $\mathrm{CC} 06$ due to anomalous directions and/or curved demagnetisation paths, which may have been caused by block movement during and/or after cooling. Despite the overlap between the $95 \%$ confidence cones it cannot be said with certainty that $\mathrm{CC} 02-\mathrm{CC} 05$ are indistinguishable: each block may have rotated, albeit very slightly during the final stages of cooling of the flow interior. On the assumption that any such movement is minor and random between sites, we calculate a flow mean from these four site mean directions, giving a best estimate of Dec $=20.8^{\circ}$, Inc $=-67.4^{\circ}$, $\alpha 95=7.4^{\circ}, \mathrm{N}=4$ sites (mean if calculated from individual samples: Dec $=20.3^{\circ}$, Inc $=-66.1^{\circ}, \alpha 95=3.8^{\circ}, \mathrm{N}=13$ ).

\subsubsection{Whangaehu flow (WE)}

Thermal and AF demagnetisation were carried out on drilled samples from sites WE01 (zone A), WE04 and WE05 (both zone C). Successful results from site WE01 show two distinct blocking temperature $\left(\mathrm{T}_{\mathrm{b}}\right)$ ranges $\left(100-300^{\circ} \mathrm{C}\right.$ and $\left.500-600^{\circ} \mathrm{C}\right)$ during thermal demagnetisation (Figure 3-4c). During AFD the remanence of a specimen from this site decays rapidly with a median destructive field of $10 \mathrm{mT}$. The low $\mathrm{T}_{\mathrm{b}}$ and low coercivity components carry between 40 and $80 \%$ of the total remanence. However, this component also carries anomalous directions and the ChRM has therefore been calculated from the high $T_{b}$, high coercivity components. In contrast, specimens from sites WE04 and WE05 retain $70 \%$ of their total NRM until they are heated to a temperature higher than $500^{\circ} \mathrm{C}$, and yield straight line decay during demagnetisation (Figure 3-4d). Sites WE01, WE04 and WE05 ChRM directions are mutually consistent, and an average direction of $\mathrm{Dec}=359.5^{\circ}$, Inc $=$ $-60.6^{\circ}, \alpha 95=3.3^{\circ}, \mathrm{N}=7$ was calculated for the flow.

\subsubsection{Delta Corner flow (DC)}

Thermal demagnetisation of samples from Delta Corner flow (DC) yields an unusual sequence of normal-reversed-normal polarity components. Similar behaviour was also observed in some specimens from the Whakapapaiti B (WPB) and Skyline Ridge (GR) flows. We attribute it to a partial self-reversal process in a narrow 
interval of blocking temperatures, as has been reported in other studies of andesiticdacitic materials (Paterson et al., 2010).

The NRM direction of all specimens is of normal polarity, however between 200 and $245^{\circ} \mathrm{C}$ an antiparallel component of reversed polarity is removed, causing an increase in the intensity by up to $38 \%$ (Figure $3-4 \mathrm{e}, \mathrm{f}$ ). Demagnetizing to higher temperatures results in rapid loss of intensity and a ChRM of normal polarity. The reversed component cannot be isolated during AF demagnetisation experiments, showing a lack of correspondence between blocking temperature and coercivity. A thermal event can be excluded as the cause for the antiparallel component, as if this were the case all grains with blocking temperatures below $250^{\circ} \mathrm{C}$ would carry a reversed remanence direction. The rock and thermomagnetic causes of partial self-reversal require further investigation and will be reported in a later study.

Palaeomagnetic directions were calculated from the high blocking temperature component $\left(\mathrm{T}_{\mathrm{b}}>250^{\circ} \mathrm{C}\right)$. Site $\mathrm{DC} 04$, sampled from the flow centre, records a significantly shallower inclination than sites DC01 and DC03, which were sampled from the base and the upper part of the flow. All three sites were collected from the same unit and are assumed to be in-situ based on our field observations. We therefore average all data into a flow mean direction of Dec $=8.5^{\circ}, \operatorname{Inc}=-68.3^{\circ}, \alpha 95=3.9^{\circ}$, $\mathrm{N}=10$.

\subsubsection{Bruce Road flow (RP)}

Successful ChRM directions and a site average were obtained only from site RP02. The ChRM directions from this site are well grouped and the NRM usually comprises two components which unblock between $200-300^{\circ} \mathrm{C}$ and $400-500^{\circ} \mathrm{C}$ (Figure 3-4h). Both blocking temperature components are parallel to each other. In contrast, the directions at RP01 display inconsistent declinations and anomalously low inclinations. The NRM intensities of RP01 specimens are up to two orders of magnitude higher than those of specimens taken at RP02. The demagnetisation behaviour is usually unidirectional, but a number of samples, collected ca. $20 \mathrm{~m}$ further along the outcrop on the same site show two components with an overlapping coercivity spectrum 
(Figure 3-4g). In the field we observed strong magnetic compass deflection at this site, and note that the site is situated beneath an isolated and exposed hill. We therefore suggest that the anomalously strong remanence and unusual remanence directions were induced during one or several lightning strikes that created short-lived, strong magnetic fields. The strength and directions of the magnetic field induced during a lightning strike is a function of the distance from the location of the strike. Several events in different, nearby locations may have therefore affected different coercivity populations, resulting in the presence of multiple components during demagnetisation. For this reason all data from site RP01 was discarded.

The flow mean direction includes demagnetisation data and the ChRM directions from three successful Thellier palaeointensity experiments from specimens collected at RP02 only. A full analysis of the intensity data will be reported in a later publication. The flow mean direction is: $\operatorname{Dec}=17.8^{\circ}, \mathrm{Inc}=-60.8^{\circ}, \alpha 95=4.0, \mathrm{~N}=7$. 


\subsubsection{Taranaki Falls flow (TF)}

Specimens from all three sites show only a single, consistent ChRM directions, carried in a broad $\mathrm{T}_{\mathrm{b}}$ range from $100-500^{\circ} \mathrm{C}$ (Figure 3-4i). During AF demagnetisation the remanence decreases rapidly; however most specimens retain between 5 and $25 \%$ of their NRM above peak alternating fields of $100 \mathrm{mT}$. Despite the separation of several kilometres between sites, all ChRM directions cluster about a mean direction of $\operatorname{Dec}=4.5^{\circ}$, Inc $=-49.5^{\circ}, \alpha 95=3.2^{\circ}, \mathrm{N}=16$, suggesting rapid emplacement and cooling of the flow.

\subsubsection{Saddle Cone flows (SC)}

With a few exceptions, the magnetic remanence of Saddle Cone samples unblocks in two temperature intervals $200-300^{\circ} \mathrm{C}$, and above $>400^{\circ} \mathrm{C}$ (Figure $3-4 \mathrm{j}$ ). However the magnetic remanence is consistent through the entire $\mathrm{T}_{b}$ range, with only a minor viscous remanence (VRM) in most samples. Exceptions are samples from sites SC03, SC05 and SC06. All specimens from site SC03 show a strong overprint, with similar characteristics to those observed at Bruce Road (site RP01), which we interpret as having been overprinted by lightning induced IRM. Samples from sites SC05 and SC06 carry strong low blocking temperature overprints and anomalous direction, suggesting movements of the sampled block during cooling and subsequently.

With the aim of identifying individual blocks that are not in-situ, we have examined the data from every sampled block separately and summarize all successful results into site means. Despite the wide sampling we identified only three blocks from sites SC01 and SC02 that give reliable results. Both sites were located on the south western end of the flow complex, however while SC01 was in an incised stream bed, SC02 comprises two independent blocks on the flow surface, ca. $50 \mathrm{~m}$ apart. While the mean direction from the two blocks sampled at site SC02 (SC02.1, SC02.2) agree, the palaeomagnetic direction obtained from sub-site SC01.1 has a more easterly declination, but similar inclination. We therefore calculate two means: SC01.1: $\operatorname{Dec}=12.2^{\circ}, \operatorname{Inc}=-58.3^{\circ}, \alpha 95=5.7^{\circ}, \mathrm{N}=4$ and SC02: $\operatorname{Dec}=358.7^{\circ}$, 
Inc $=-54.9^{\circ}, \alpha 95=3.0^{\circ}, \mathrm{N}=7$. We lay higher confidence on the mean from SC02, which includes the ChRM directions from two separate blocks.

\subsubsection{Mangaturuturu flow (MT)}

All samples show little or no viscous overprint (Figure 3-5a,b). However, specimens demagnetise predominantly either at temperatures below $200^{\circ} \mathrm{C}$ or at temperatures above $300^{\circ} \mathrm{C}$, in general agreement with differences interpreted from their rock magnetic properties. Site statistics were calculated separately for specimens taken from hand samples and cores. As expected, the hand sample data shows larger scatter than the drilled samples; however, distributions from both data sets overlie one another and all data have been included in an overall mean of Dec $=8.7^{\circ}$, Inc $=$ $-60.4^{\circ}, \alpha 95=4.0^{\circ}, \mathrm{N}=10$.

\subsubsection{Whakapapapaiti A - C flows (WPA, WPB, WPC)}

Figure 3-5(c, d, e) displays the vector component diagrams obtained for specimens from each of three sites on WPA, the oldest of the three Whakapapaiti flows sampled. Specimens from sites WPA01 and WPA02 have strong westerly overprints in the $\mathrm{T}_{\mathrm{b}}$ 's below $250^{\circ} \mathrm{C}$. Samples from WPA01 show an additional component, roughly parallel to this low temperature overprint that is isolated on heating to temperatures above $350^{\circ} \mathrm{C}$. In contrast, the remanence of all specimens from site WPA03 consists of single components with negligible overprint. The overprint at sites WPA01 and WPA02 is inconsistent between individual specimens (Figure 3-5f), and re-magnetisation can therefore not be attributed to a single secondary heating event. Samples from sites WPA01 and WPA02 show signs of weathering and we therefore suggest the presence of meta-stable, low temperature oxidation products that carry a chemical remanent magnetisation (CRM). ChRM directions were selected from the unaffected components, and a flow mean of Dec $=358.1^{\circ}, \mathrm{Inc}=-54.9^{\circ}, \alpha 95=2.7^{\circ}, \mathrm{N}=8$ was calculated. 
Specimens taken from two of three hand samples studied from the WPB flow yield a partially reversed component between 200 and $250^{\circ} \mathrm{C}$, similar to that described for the Delta Corner (DC) lava flow. Our best mean ChRM calculated from blocking temperatures above $250^{\circ} \mathrm{C}$ is Dec $=2.8^{\circ}, \mathrm{Inc}=-45.8^{\circ}, \alpha 95=4.1^{\circ}, \mathrm{N}=3$. Our best ChRM estimate for the youngest flow in the sequence WPC is Dec $=61.5^{\circ}$, Inc $=$ $-63.9^{\circ}, \alpha 95=3.6^{\circ}, \mathrm{N}=2$. This is anomalously easterly and we suggest the collection of drilled samples to verify the direction. Figure 3-5f displays the mean directions determined from all three Whakapapiti flows, including both the normal and reversed components from WPB.

\subsubsection{Skyline Ridge flow (GR)}

The behaviour of samples taken from the platey flow interior (zone B, site GR01.1) differs significantly from that of the upper massive part (zone C), sampled at sites GR01.2 and GR02. The NRM intensity of specimens from drilled samples collected from zone $\mathrm{C}$ is between 4 and $9 \mathrm{~A} / \mathrm{m}$, and therefore compatible with most other andesites sampled in this study. Thermomagnetic experiments indicate the presence of low and high $T_{c}$ phases in varying proportions (Type 3 ), and thermal demagnetisation occurs in two stages (stage 1: $250-300^{\circ} \mathrm{C}$, stage $2:>500^{\circ} \mathrm{C}$ ). The $\mathrm{ChRM}$ is always identified only at high blocking temperatures, suggesting that the low $\mathrm{T}_{\mathrm{b}}$ component/ low $\mathrm{T}_{\mathrm{c}}$ phase corresponds to a secondary mineral carrying a chemical remanent magnetisation (CRM) (Figure 3-5g).

In contrast, the hand samples taken from platey zone B (GR01.1) carry a much weaker remanence (approximately $0.5 \mathrm{~A} / \mathrm{m}$ ), they demagnetise at generally lower temperatures $\left(300-400^{\circ} \mathrm{C}\right)$ and carry low blocking temperature components that result in a slight rise in intensity between 200 and $250^{\circ} \mathrm{C}$ (Figure 3-5h). This is similar to the behaviour observed in samples from Delta Corner (DC) and Whakapapiti B (WPB) lava flows which show partial self-reversed magnetisation.

The hand sample data was excluded from the calculation of the flow mean due to its high degree of scatter. Our best mean for the flow $\left(\mathrm{Dec}=356.5^{\circ}, \mathrm{Inc}=-81.4^{\circ}, \alpha 95=\right.$ $3.8^{\circ}, \mathrm{N}=11$ ) yields an inclination steeper than expected for this period of time. 


\subsubsection{Rangataua flows (RT)}

Thermal and AF demagnetisation experiments were carried out on drilled samples from sites RT01, RT02 and RT03. All sites show similar THD behaviour, with small viscous overprints (Figure 3-5i). Despite being of single component, some of the thermal demagnetisation experiments show a deflection of the remanence from the origin in demagnetisation steps higher than $400^{\circ} \mathrm{C}$, which may be indicative of thermal alteration during demagnetisation. The mean direction for site RT01 has a significantly higher inclination than the mean directions from sites RT02 and RT03, suggesting that the flow sampled at RT01 is of different age. We therefore give two flow means: RT01: Dec $=358.1^{\circ}$, Inc $=-65.4^{\circ}, \alpha 95=3.8^{\circ}, \mathrm{N}=3$, and RT02 \& 03: $\operatorname{Dec}=10.7^{\circ}$, Inc $=-53.4^{\circ}, \alpha 95=2.7, \mathrm{~N}=11$. 

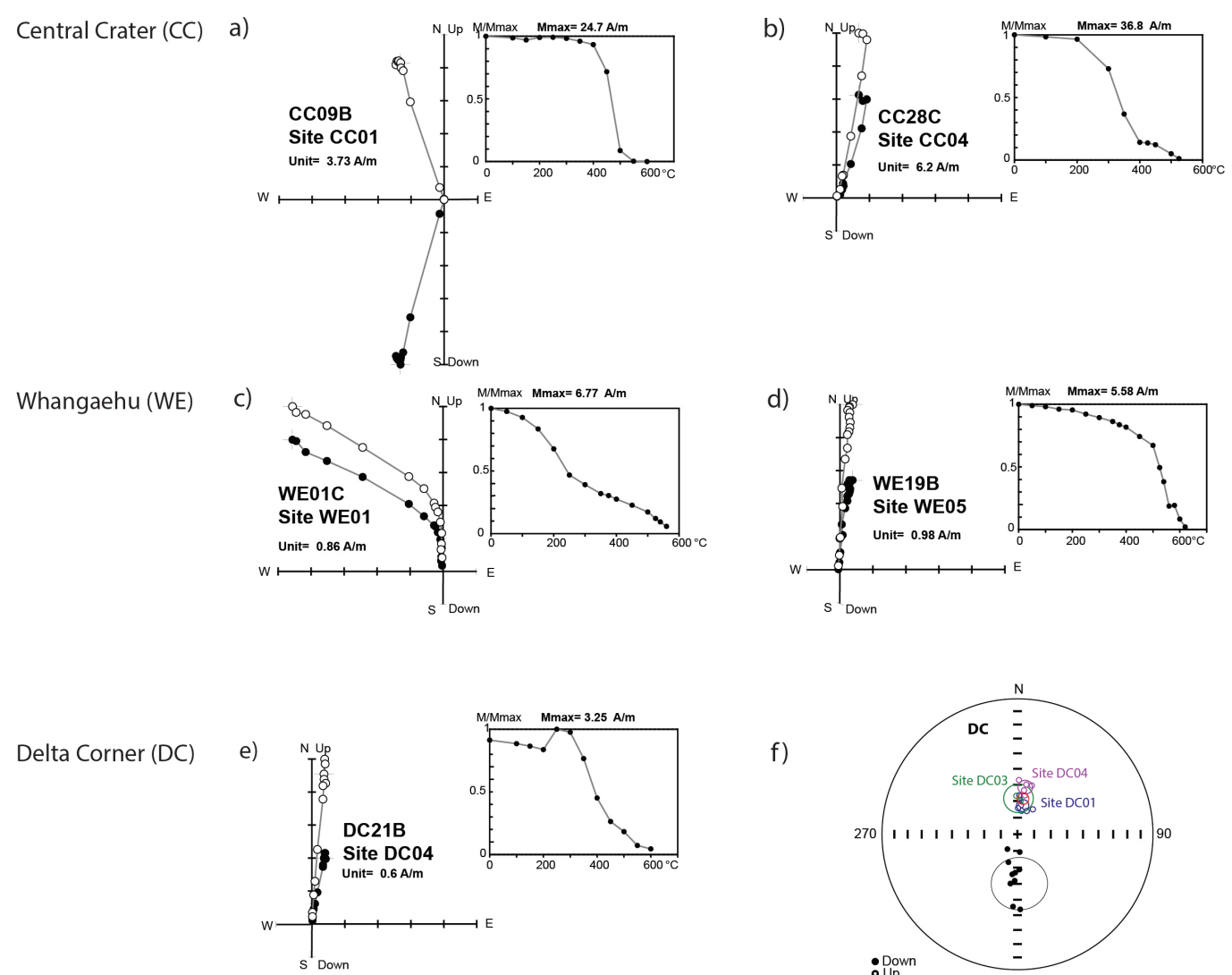

f)

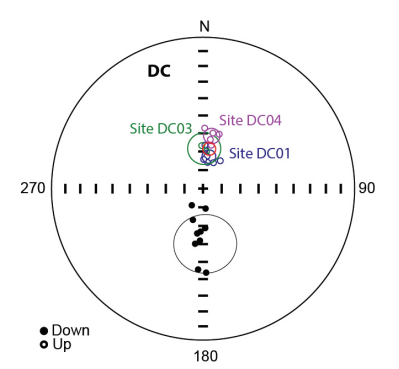

Bruce Road (RP)
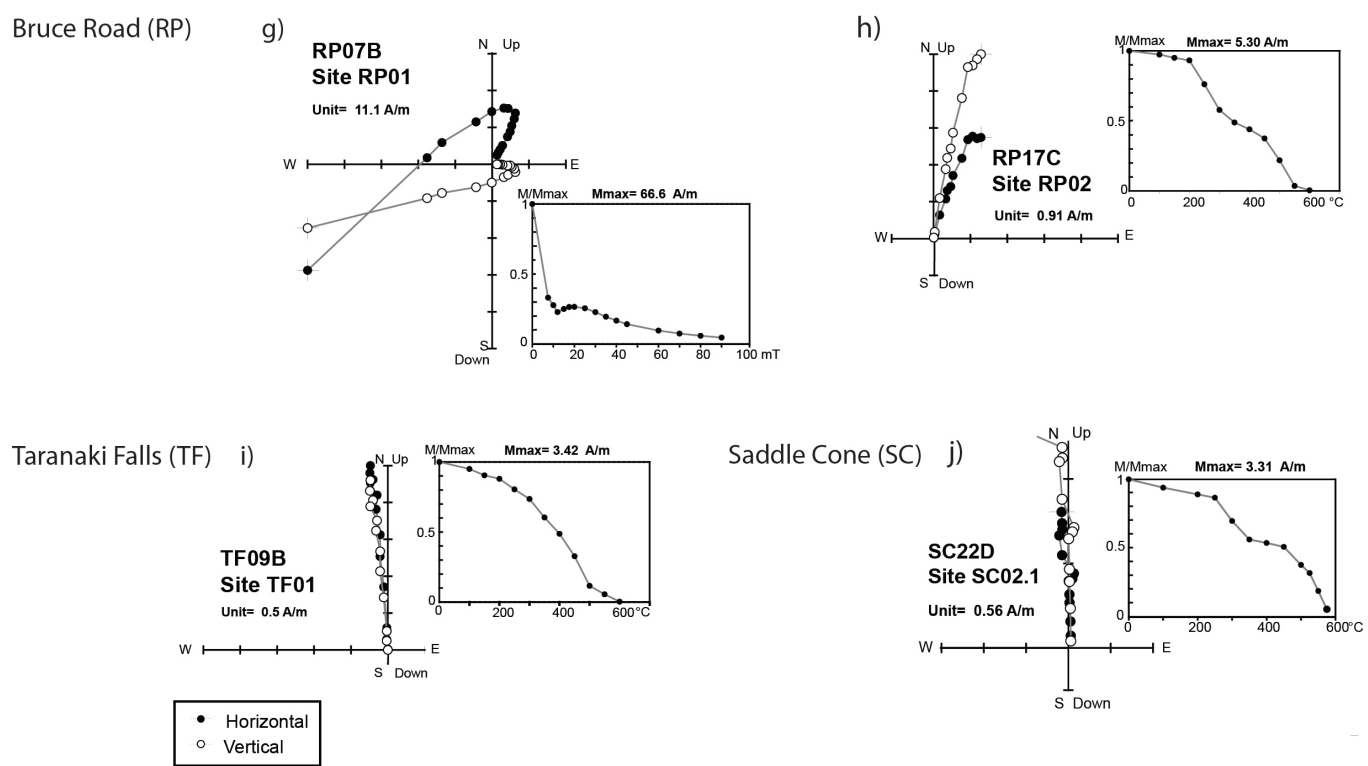

Figure 3-4: Representative vector component, $\mathrm{M} / \mathrm{M}_{0}$, and stereo-plots for specimens from lava flows $\mathrm{CC}, \mathrm{WE}, \mathrm{DC}, \mathrm{RP}$ and TF (TgVC). See text for details; the stereonet in (f) displays all normal (open circles) and antipodal (closed circles) directional components identified in specimens from Delta Corner flow (DC) (14 specimens from 3 sites). 
Mangaturuturu (MT)
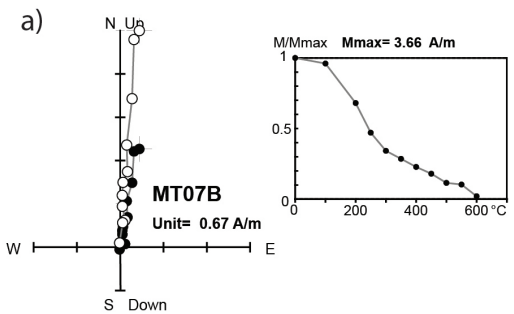

b)

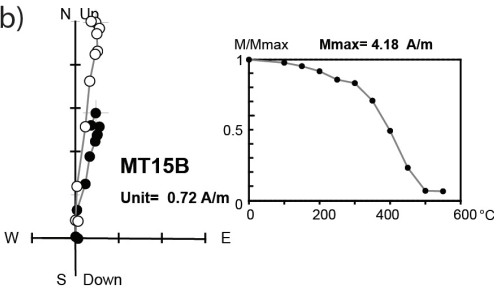

d)

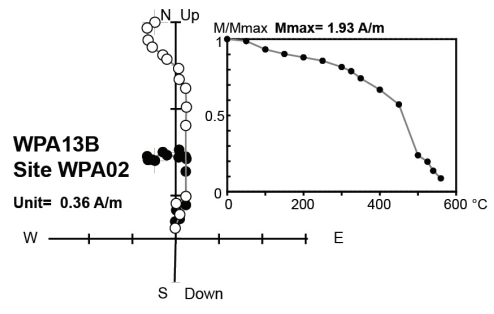

Whakapapaiti A (WPA)

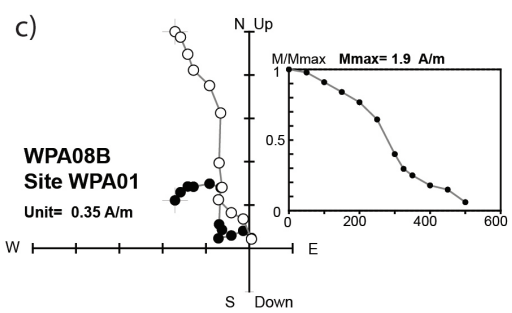

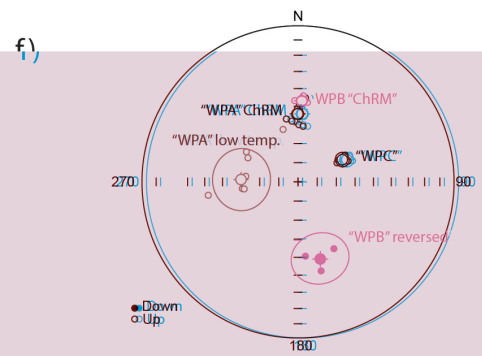

h)
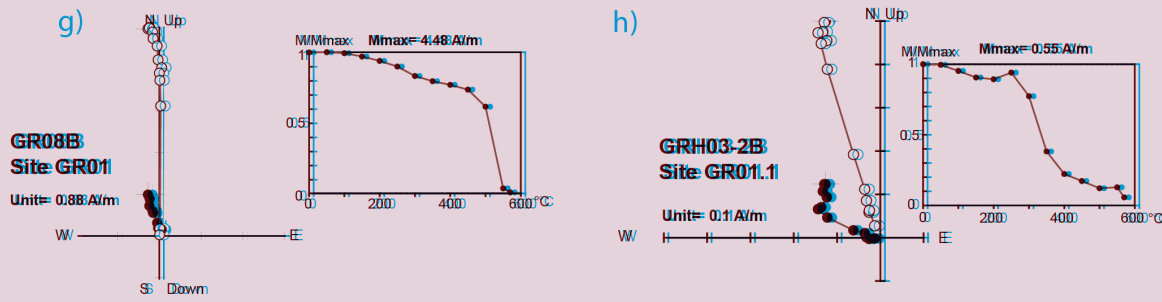

Rangataua (RT)

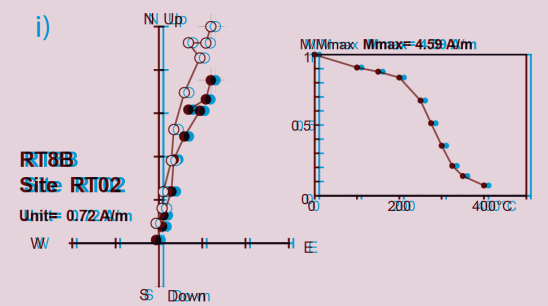

- Horizontall

Verticall

Figure 3-5: Representative vector component, $\mathrm{M} / \mathrm{M}_{0}$, and stereo-plots for specimens from lava flows MT, WPA, GR and RT (TgVC). See text for details. The stereonet in (d) shows all ChRM directions for flow WPA and also for the underlying flows WPB and WPC, with $\alpha 95$ for each cluster. In addition it displays the low blocking temperature components identified in WPA samples and the reversed polarity component from WPB. 
Table 3-2: Summary of the palaeomagnetic directional results from the TgVC by site and flow, showing independent age control, site and flow mean directions with 95\% confidence limits, and preferred age based on all available information, including correlation of the palaeomagnetic directions with the PSV Reference Curve of Turner et al. (2015). The inferred age ranges given by the programme are amalgamated if the time-span between two age ranges of high confidence is short ( $<100$ years). The mean direction from sites included in the calculation of flow mean directions are marked in bold.

\begin{tabular}{|c|c|c|c|c|c|c|c|c|c|}
\hline Flow & $\begin{array}{l}\text { Independent } \\
\text { Age (ka) }\end{array}$ & Site & Lat (S) & Long (E) & $\operatorname{Dec}\left({ }^{\circ}\right)$ & Inc $\left(^{\circ}\right)$ & $\alpha_{95}\left({ }^{\circ}\right)$ & $\mathbf{N} / \mathbf{n} / \mathbf{n}_{0}$ & $\begin{array}{l}\text { Pref. age } \\
\text { (yrs BP) }\end{array}$ \\
\hline \multirow{7}{*}{$\begin{array}{l}\text { Central Crater } \\
\text { (CC) }\end{array}$} & $<1.78 \pm 0.0$ & 1 & 39.1328 & 175.6548 & 334.6 & -61.9 & 12.1 & $2 / 3 / 3$ & $300 \pm 200$ \\
\hline & 1 & & & & & & & & \\
\hline & & 2 & 39.1311 & 175.6570 & 14.6 & -73.1 & 5.2 & $4 / 5 / 5$ & \\
\hline & & 3 & 39.1302 & 175.6565 & 27.9 & -67.7 & 6 & $4 / 4 / 4$ & \\
\hline & & 4 & 39.1299 & 175.6571 & 17.1 & -58.9 & 1.8 & $4 / 4 / 4$ & \\
\hline & & 5 & 39.1294 & 175.6559 & 23.7 & -69.7 & & $1 / 1 / 3$ & \\
\hline & & 6 & 39.1302 & 175.6554 & 19 & -64 & 16.4 & $2 / 2 / 2$ & \\
\hline \multicolumn{5}{|c|}{ Mean direction for flow CC } & 20.8 & -67.4 & 7.4 & 4 (sites) & \\
\hline
\end{tabular}

Data from Sites CC01, CC06 were excluded due to anomalous directions and/or failure to isolate a ChRM direction. The flow mean direction was calculated from the individual site means in order to accommodate inferred minor and random block rotations.

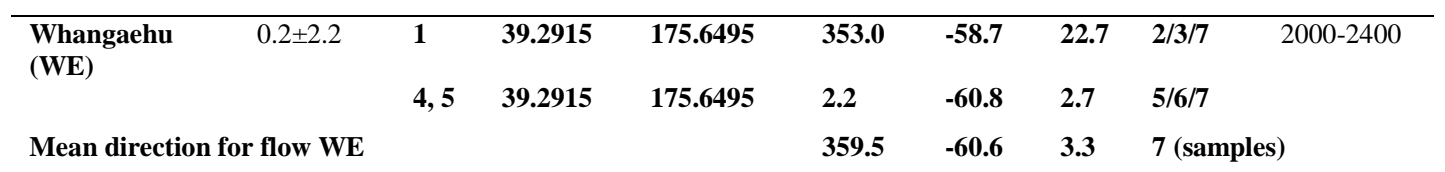

The flow mean was calculated from all sample ChRM directions obtained from sites WE01, WE04 and WE05. Samples from this flow were oriented using a magnetic compass, and the orientations confirmed from back-sightings.

\begin{tabular}{|c|c|c|c|c|c|c|c|c|c|}
\hline \multirow{3}{*}{$\begin{array}{l}\text { Delta Corner } \\
\text { (DC) }\end{array}$} & $6.0 \pm 2.4$ & 1 & 39.2548 & 175.5608 & 11.2 & -72.4 & 4.8 & $7 / 7 / 8$ & \multirow[t]{3}{*}{$\sim 8000$} \\
\hline & & 3 & 39.2548 & 175.5608 & 1.6 & -68.3 & 8.7 & $2 / 2 / 2$ & \\
\hline & & 4 & 39.2555 & 175.5615 & 9.2 & -61.4 & 5.1 & $3 / 5 / 5$ & \\
\hline \multicolumn{5}{|c|}{ Mean direction for flow DC } & 8.5 & -68.3 & 3.9 & 10 (sa & es) \\
\hline
\end{tabular}

The flow mean was calculated from the sample ChRM directions obtained from sites DC01, DC03 and DC04.

\begin{tabular}{|c|c|c|c|c|c|c|c|c|}
\hline $\begin{array}{l}\text { Bruce Road } \\
\text { (RP) }\end{array}$ & $5-10$ & 39.2720 & 175.5399 & 17.8 & -60.8 & 4.0 & $7 / 12 / 20$ & $\begin{array}{l}<9000 \\
(8400-8700)\end{array}$ \\
\hline
\end{tabular}

The flow mean was calculated from the sample ChRM directions at site RP02.

\begin{tabular}{llllllllll}
\hline Taranaki Falls & $8.8 \pm 2.8$ & $\mathbf{1}$ & $\mathbf{3 9 . 2 3 9 2}$ & $\mathbf{1 7 5 . 5 7 5 8}$ & $\mathbf{7 . 2}$ & $\mathbf{- 5 1 . 2}$ & $\mathbf{6 . 1}$ & $\mathbf{7 / 1 0 / 1 0}$ & $8900-9500$ \\
(TF) & 2 & $\mathbf{3 9 . 2 2 5 7}$ & $\mathbf{1 7 5 . 5 7 6 1}$ & $\mathbf{1 . 3}$ & $\mathbf{- 4 5 . 9}$ & $\mathbf{5 . 0}$ & $\mathbf{4} / \mathbf{6} / \mathbf{6}$ & $10,200-$ & 10,800 \\
& & 3 & $\mathbf{3 9 . 2 1 1}$ & $\mathbf{1 7 5 . 5 6 9 7}$ & $\mathbf{3 . 7}$ & $\mathbf{- 5 0 . 0}$ & $\mathbf{5 . 8}$ & $\mathbf{5 / 7 / 7}$ & \\
& & & & 4.5 & $\mathbf{- 4 9 . 5}$ & $\mathbf{3 . 2}$ & $\mathbf{1 6}$ (samples)
\end{tabular}

The flow mean was calculated from the sample ChRM directions from sites TF01, TF02 and TF03. 


\begin{tabular}{lccccccccc}
\hline Flow & $\begin{array}{l}\text { Independent } \\
\text { Age (ka) }\end{array}$ & Site & Lat (S) & Long (E) & Dec $\left(^{\circ}\right)$ & Inc $\left(^{\circ}\right)$ & $\mathbf{\alpha 9 5}\left(^{\circ}\right)$ & $\mathbf{N} / \mathbf{n} / \mathbf{n}_{\mathbf{0}}$ & $\begin{array}{c}\text { Pref. age } \\
(\mathbf{y r s} \mathbf{B P})\end{array}$ \\
\hline $\begin{array}{l}\text { Saddle Cone } \\
\text { (SC) }\end{array}$ & ca. 5-10 & 1.1 & 39.2258 & 175.5857 & 12.2 & -58.3 & 5.7 & $4 / 6 / 7$ & $8600-9600$ \\
& & 1.2 & 39.2258 & 175.5857 & 2.2 & -86.9 & 41.2 & $2 / 2 / 2$ & \\
& 1.4 & 39.2258 & 175.5857 & 50.9 & -70 & 6.8 & $3 / 3 / 3$ & \\
& & $\mathbf{2 . 1}$ & $\mathbf{3 9 . 2 2 4 5}$ & $\mathbf{1 7 5 . 5 9 1 4}$ & $\mathbf{3 5 9 . 4}$ & $\mathbf{- 5 3 . 7}$ & $\mathbf{5 . 4}$ & $\mathbf{5 / 6 / 6}$ & \\
& $\mathbf{2 . 2}$ & $\mathbf{3 9 . 2 2 4 5}$ & $\mathbf{1 7 5 . 5 9 1 4}$ & $\mathbf{3 5 5 . 3}$ & $\mathbf{- 5 7 . 5}$ & $\mathbf{3 . 2}$ & $\mathbf{2 / 3 / 3}$ & \\
& 5.1 & 39.2155 & 175.6031 & 337.3 & 15.3 & 21.9 & $2 / 2 / 2$ & \\
& 5.2 & 39.2155 & 175.6031 & 341.6 & 20.9 & 22.5 & $2 / 2 / 2$ & \\
& 6 & 39.2174 & 175.5907 & 326.4 & -82.6 & 14 & $2 / 5 / 5$ & \\
& & & & $\mathbf{3 5 8 . 7}$ & $\mathbf{- 5 4 . 9}$ & $\mathbf{3 . 0}$ & $\mathbf{7}(\mathbf{s a m p l e s )}$
\end{tabular}

A mean direction was calculated from all ChRM directions from the flow-top sub-sites SC02.1 and SC02.2, for which the site means agree at the $95 \%$ confidence level. The individual sub-site means from all other sites disagree and/or are of a direction that is anomalous in a normal polarity field and have therefore been excluded.

\begin{tabular}{|c|c|c|c|c|c|c|}
\hline \multirow{2}{*}{$\begin{array}{l}\text { Mangaturuturu } \\
\text { (MT) }\end{array}$} & $\begin{array}{ll}\text { drill } & 39.2908\end{array}$ & 175.5216 & 7.8 & -62.5 & 3.2 & $>10500$ \\
\hline & hand samples & & 10.3 & -55.5 & 14.8 & $3 / 5 / 5$ \\
\hline Mean direction for flow MT & & & 8.7 & -60.4 & 4.0 & 10 (samples) \\
\hline
\end{tabular}

Flow mean calculated from the individual sample ChRM directions. Note that hand samples were oriented using a magnetic compass only.

\begin{tabular}{|c|c|c|c|c|c|c|c|}
\hline \multirow{3}{*}{$\begin{array}{l}\text { Whakapapaiti A } 14.8 \pm 3.0 \\
\text { (WPA) }\end{array}$} & 1 & 39.2533 & 175.5303 & 359.8 & -54.4 & 4.4 & $4 / 4 / 4$ \\
\hline & 2 & 39.253 & 175.5303 & 354.7 & -55.9 & 7.1 & $3 / 4 / 4$ \\
\hline & 3 & 39.2552 & 175.5317 & 0.4 & -53.5 & & $1 / 2 / 2$ \\
\hline Mean direction for flow WP & & & & 358.1 & -54.9 & 2.7 & 8 (samples) \\
\hline
\end{tabular}

The flow mean was calculated from individual sample directions from sites WPA01, WPA02, WPA03.

\begin{tabular}{|c|c|c|c|c|c|c|c|}
\hline Whakapapaiti B (WPB) & & 39.2501 & 175.5291 & 2.8 & -45.8 & 4.1 & $3 / 4 / 5$ \\
\hline $\begin{array}{l}\text { Flow mean calculated from th } \\
\text { magnetic compass. }\end{array}$ & & & & han & les. & & \\
\hline Skyline Ridge & 1.1 & 39.3002 & 175.5521 & 336.7 & -73.4 & 17.9 & $3 / 7 / 7$ \\
\hline & 1 & 39.3002 & 175.5521 & 352.8 & -83.0 & 5.0 & 8/10/10 \\
\hline & 2 & 39.2987 & 175.5545 & 1.9 & -77.2 & 3.3 & $3 / 3 / 4$ \\
\hline Mean direction for flow GR & & & & 356.5 & -81.4 & 3.8 & 11 (samples) \\
\hline
\end{tabular}

The flow mean was calculated from the mean ChRM directions of drilled samples from sites GR01 and GR02. At sub-site GR01.1 only hand samples were collected from the strongly dissected zone B and their results were excluded due to the high data dispersion $\left(\alpha 95>15^{\circ}\right)$.

\begin{tabular}{lrllllll}
\hline $\begin{array}{l}\text { Rangataua } \\
\text { (RT) }\end{array}$ & 1 & 39.3316 & 175.5534 & 358.1 & -65.4 & 3.8 & $3 / 5 / 5$ \\
& 2 & 39.3329 & 175.5514 & 8.8 & -55.4 & 2.5 & $7 / 12 / 12$ \\
& 3 & 39.3341 & 175.5507 & 13.7 & -49.9 & 4.7 & $4 / 8 / 8$ \\
\multicolumn{2}{l}{ Mean direction from sites RT02 and RT03 } & & 10.7 & -53.4 & 2.7 & 11 (samples)
\end{tabular}

A flow mean was calculated from sample ChRM directions from sites RT02 and RT03, which yield overlapping 95\% confidence cones. The mean direction from RT01 is distinct from RT02 at the $95 \%$ confidence level from the site mean calculated for site RT01, suggesting that the lava sampled at RT01 is of different age.

Note: Flow is the name for each sampled unit as discussed in section 2. Independent age is given in ka, with $2 \sigma$ uncertainty if applicable: the sources are listed in Table 1. Lat and Long are the site geographic coordinates (WGS84). Dec, Inc refer to palaeomagnetic directions. $\mathrm{N} / \mathrm{n} / \mathrm{n}_{0}=$ total number of samples included in the average/total number of specimens included/ total number of specimens demagnetised. Sample orientations were calculated from sun-compass measurements, unless otherwise indicated. Preferred age is obtained from all available age control including correlation of the palaeodirection with the Lake Mavora PSV reference record (Turner et al., 2015). It is given as a range, and in years BP since the age probability distribution is in general not Gaussian, and the age model of the Mavora record is radiocarbon-based. See text and/or electronic appendices for other details. 


\subsection{Discussion}

\subsubsection{Accuracy and precision of the palaeomagnetic data}

In Figure 3-6 we plot the site mean directions and associated 95\% confidence limits $(\alpha 95)$ calculated from all data that passed our selection criteria, and our best estimates of each overall flow mean palaeomagnetic direction. The ChRM directions of all specimens are detailed in the electronic appendix. With flow mean $\alpha 95$ 's generally less than $5^{\circ}$, the data quality is comparable to or better than that obtained in other palaeosecular variation studies on lava flows (e.g.Speranza et al., 2008; Tanaka et al., 1997). Furthermore, for each flow, all site mean directions agree at the $95 \%$ level of confidence, unless otherwise discussed.

Random sources of error associated with field orientation of samples, measurement uncertainties and the estimation of ChRM directions, may be expected to lead to a scatter of $5-10^{\circ}$ at a site. With $4-10$ specimens per site, this means that an $\alpha 95$ of up to $5^{\circ}$ can be attributed to such random uncertainties. With current field and laboratory methods, it would be difficult to further reduce these uncertainties. Possible sources of significant differences between site mean directions for a given flow include syn- or postmagnetisation movement, and small scale magnetic field anomalies resulting in differences in the ambient field between sites at the time of magnetisation. We argue that syn- or post-magnetisation movement is likely and can account for the between-site/ block differences in direction in the cases of the Red Crater flow in Central Crater (CC) and the Saddle Cone flow (SC). In both of these flows we were limited to sampling blocks near the flow exterior which might be prone to such movement.

In the case of Delta Corner flow (DC), the inclination measured at site DC04 is shallower than that recorded at sites DC01 and DC03. The sites are from different zones within the flow and are spread over a lateral distance of $200 \mathrm{~m}$. Calculations (M. Ingham pers. comm.) indicate that an underlying lava flow with a normal magnetisation of $10 \mathrm{~A} / \mathrm{m}$ could produce anomalies of up to $9^{\circ}$ in declination and $3^{\circ}$ in inclination 1-2 m immediately above the flow edge, but these figures decrease to as little as $1^{\circ}$ within a distance of $20 \mathrm{~m}$. Magnetic field influences of this magnitude are not great enough to explain the differences. 
A local or regional anomaly due to a more extensive strongly magnetized underlying body might be expected to manifest in systematic differences between sample orientations derived from sun compass and magnetic compass bearings. Although we observed differences of up to $15^{\circ}$, they were not systematic, and were interpreted as being due to the magnetisation of immediately adjacent rock, i.e. that being sampled.

a)

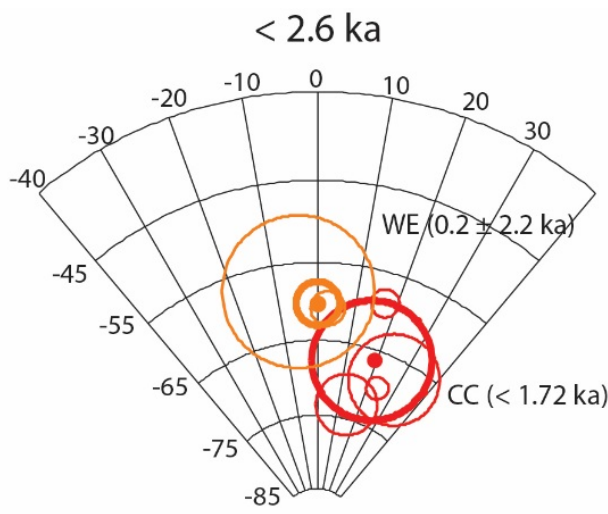

c)

$$
10-15 \mathrm{ka}
$$

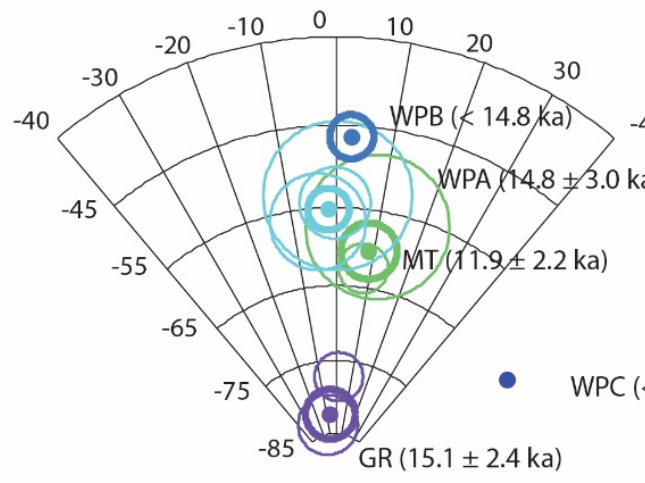

b) $\quad 5-10 \mathrm{ka}$

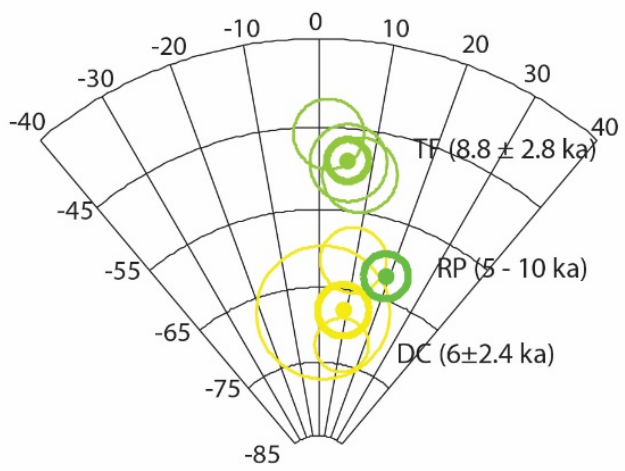

d)

unknown

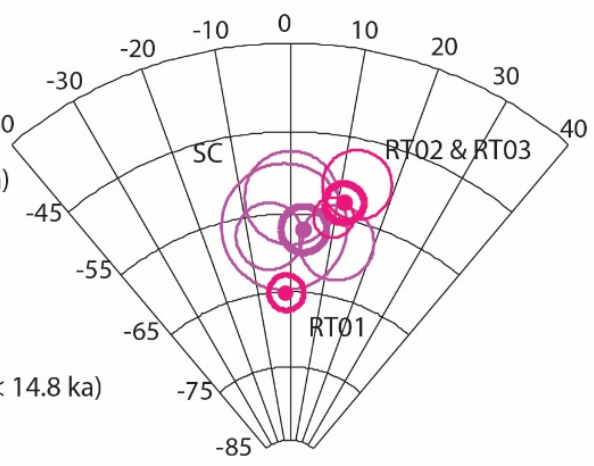

Figure 3-6: Equal angle (Wulff) projections of the direction and $\alpha 95$ from TgVC lavas (bold) and the $\alpha 95$ for individual sites (a) $<2.6$ ka flows, (b) 5-10 ka flows, (c) 10$15 \mathrm{ka}$ flows, (d) flows with no prior age control. 


\subsubsection{Comparison with previous New Zealand PSV studies}

In Figure 3-7 we display our flow mean palaeomagnetic directions with 95\% confidence limits and existing age control, superimposed on the recently published lake sediment PSV record from Lake Mavora, South Island, New Zealand, that covers the past 11,000 years (Turner et al., 2015b). The Lake Mavora record has been migrated to the location of Whakapapa Village $\left(175.54^{\circ} \mathrm{E}, 39.2^{\circ} \mathrm{S}\right)$ using a virtual geomagnetic dipole (VGP) transformation (Noel and Batt, 1990). This compensates, to a first order, for the latitudinal effect of the dipole component of the field. Our numerical experiments, on historical observational data, show that VGP relocation is accurate to approximately $0.15^{\circ}$ per $100 \mathrm{~km}$ over distances up to $1000 \mathrm{~km}$ in regions where the gradient of the field is low to moderate. This is well within the uncertainties in the data discussed above.

The mean direction of the Lake Mavora record $\left(\mathrm{Dec}=356.0^{\circ}\right.$, Inc $=-58.0^{\circ}$ when migrated to Whakapapa, $\left.\theta 63=4.9^{\circ}, \alpha 95=0.6^{\circ}\right)$ is slightly west of the geocentric axial dipole average $(\mathrm{GAD})\left(\mathrm{Dec}=0^{\circ}, \mathrm{Inc}=-58.5^{\circ}\right)$, while the mean of the Ruapehu flows (all flows: $\operatorname{Dec}=5.3^{\circ}, \mathrm{Inc}=-61.6^{\circ}, \theta-63=10.3^{\circ}, \alpha 95=5.1^{\circ}$; flows younger than 11 kyrs BP: Dec $=7.4^{\circ}, \operatorname{Inc}=-61.2^{\circ}, \theta-63=7.8^{\circ}, \alpha 95=5.1^{\circ}$ ) is more easterly than the GAD direction. The difference is partly due to clumping of the ages of the flows (there are few flows dated between 6000 and 2000 yrs BP), meaning that they do not average over secular variation. The Ruapehu flow directions are however generally more easterly than the most easterly peaks in the lake sediment record, suggesting that the sediment record may not have recorded the full amplitude of swings in the field direction. A measure of amplitude in records with randomly distributed data is the VGP angular dispersion. At a latitude of $40^{\circ}$, the standard deviation of VGPs $\left(\theta-63_{\mathrm{VGP}}\right)$ is expected to be between 14 and $16^{\circ}$, suggesting that the amplitude of the lake sediment record $\left(\theta-63_{\mathrm{VGP}}=6.8\right)$ is too low (McElhinny and McFadden, 1997). Amplitude reduction is a recognized feature of sedimentary records. It results from the detrital (depositional and/or post-depositional) remanent magnetisation process, and the fact that measurements are conducted on samples, including sediments that were emplaced over an interval of time (in this case about 50 years). Correlation of 
individual flow directions with the Lake Mavora record are discussed below, where we use palaeomagnetic dating to improve the precision of the independent age control.

Not shown on Figure 3-7 is the only other continuous record from New Zealand, a lacustrine record from lake Pounui (Turner et al, 1994), as it has recently been argued that the age model of the record is too old by several hundreds of years (e.g. Turner et al,, 2015b). For similar reasons we do not display the results of the earlier palaeomagnetic studies on volcanic materials from New Zealand or pedictions of global field models. A reinterpretation of the supporting age controls for these datasets is presented in chapter 6 .

Of direct relevance to this study are the results of a palaeomagnetic study on seven lava flows sampled of the Iwikau member, published by Tanaka et al. (1997). The flows were sampled about $1 \mathrm{~km}$ north-west of our Delta Corner site and their mean direction $\left(\mathrm{Dec}=9.9^{\circ}, \mathrm{Inc}=-54.2^{\circ}, \alpha 95=4.6^{\circ}\right)$ has a similar declination but is more than $10^{\circ}$ shallower than our DC flow mean. 

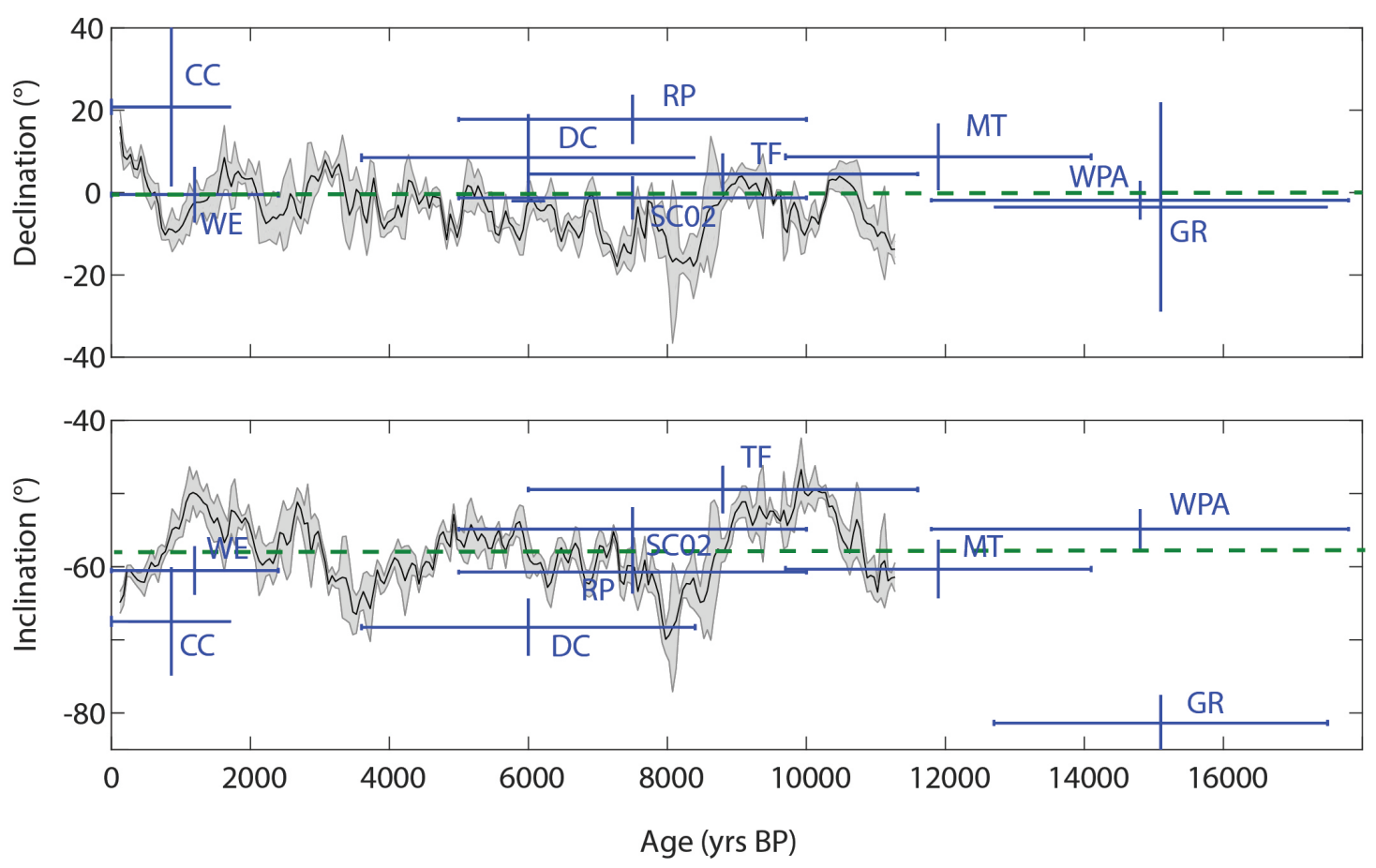

Figure 3-7: Comparison of the new palaeomagnetic data $(\mathrm{TgVC})$ with a continuous record from Lake Mavora (black line, with shaded 95\% confidence envelope) (Turner et al., 2015b). Our new data is displayed in red. The Lake Mavora record has been relocated to $39.2^{\circ} \mathrm{S}, 175.54^{\circ} \mathrm{E}$ using a VGP transformation. The uncertainties shown for both the Lake Mavora data and for the discrete datasets have been calculated following the Fisherian formulae for $95 \%$ confidence in the mean direction: $\Delta \mathrm{Inc}=\alpha 95, \Delta \mathrm{Dec}=\alpha 95 / \cos (\mathrm{Inc})$. Not displayed are the palaeomagnetic results from WPC, RT01 and RT02-03 for reasons discussed in the text. We also display the geocentric axial dipole field direction for latitude $39^{\circ} \mathrm{S}\left(\mathrm{Dec}=0^{\circ}\right.$, Inc $=$ $\left.-58^{\circ}\right)$, green dashed line.

\subsubsection{Palaeomagnetic refinement of the age-control on flows younger than 11 kyrs}

The current, independent age control of the lava flows studied is subject to uncertainties in the range of thousands of years. This is due to the relatively low potassium content of the Ruapehu andesites that were ${ }^{40} \mathrm{Ar} /{ }^{39} \mathrm{Ar}$ dated, and their low radiogenic ${ }^{40} \mathrm{Ar}$ yields, and to the long time intervals between the tephra marker beds used to bracket the ages of other flows. The availability of the Lake Mavora PSV record covering the past 11, 500 years, together with the high quality of flow mean palaeomagnetic directions, allows us to refine the existing geochronological age 
control. To obtain an objective correlation, we have employed the Matlab-based archaeomagnetic dating tool of Pavón-Carrasco et al. (2011).

The software package uses a Bayesian statistical approach (Lanos, 2004) to assign age ranges within which an undated discrete palaeomagnetic record with normally distributed uncertainty correlates with a dated master record, to a predefined level of confidence. Probability density functions (PDFs) are calculated separately for declination, inclination and, if the data is available, for intensity. The individual PDFs are then combined into a single PDF. The software package includes a number of global datasets, regional field models and PSV master curves for the northern hemisphere, and also allows the user to import new PSV curves. Here we import the Lake Mavora PSV record (Turner et al., 2015b). We constrain the calculated ages to lie within the ranges given in Table 1 and obtain results to a $95 \%$ level of confidence.

Central Crater flow (CC) has a palaeomagnetic direction $\left(\mathrm{Dec}=20.8^{\circ}, \mathrm{Inc}=-67.4^{\circ}\right.$, $\left.\alpha 95=7.4^{\circ}\right)$ close to the present day field $\left(\mathrm{Dec}=21.1^{\circ}, \mathrm{Inc}=-64.5^{\circ}\right)$. It is considered young, from its unweathered appearance and the absence on its surface of pumice from the $232 \pm 10$ AD Taupo eruption. Palaeomagnetic matching yields an age within the past 500 years. Given that no lava-producing eruptions have been observed from Red Crater in the past century, we assign an age of $300 \pm 200 \mathrm{yrs}$ BP to the CC flow.

The very young ${ }^{40} \mathrm{Ar} /{ }^{39} \mathrm{Ar}$ age of the Whangaehu (WE) lava flow $(0.2 \pm 2.2 \mathrm{ka})$ should be treated with caution as it is very close to the limit of the technique. The WE palaeomagnetic direction $\left(\mathrm{Dec}=359.5^{\circ}, \mathrm{Inc}=-60.6^{\circ}, \alpha 95=3.3^{\circ}\right)$ is northerly and shallower than $\mathrm{CC}$, suggesting an older age. Using 2400 yrs BP as a limit, the combined declination and inclination PDFs define two intervals: $2400-2000 \mathrm{yrs}$ BP and 700-300 yrs BP (Figure 3-8). Given the extent of weathering and the eroded appearance of the flow (Figure 3-2b), we consider the older interval more likely.

The radiometric ages of the three Iwikau member flows, Taranaki Falls $(8.8 \pm 2.8 \mathrm{ka})$, Delta Corner $(6.0 \pm 2.4 \mathrm{ka})$ and Bruce Road (ca. 5-10 ka), are statistically indistinguishable. However their mean palaeomagnetic directions differ significantly (Figure 3-6b), indicating that substantial time probably elapsed between their eruptions. Although the spatial distribution suggests that all flows were emplaced 
during a relatively short but productive period of effusive activity, small geochemical differences, particularly a higher $\mathrm{SiO}_{2}$ and lower $\mathrm{MgO}$ of Taranaki Falls flow (TF) (Conway et al., 2016) support this interpretation. As discussed previously, all three flows and a number of other Iwikau flows sampled by Tanaka et al. (1997) have easterly declinations, and inclinations ranging from $-49^{\circ}$ to $-68^{\circ}$. Between 9000 and 8000 y r s BP, the Lake Mavora record describes a rapid steepening of inclination accompanied by a declination swing from east to west. This is followed by a long period with only low amplitude secular variation from 8000 to 5000 yrs BP. The easterly declinations of our data from the Iwikau member, and the large differences in their inclinations, suggest that they may have been emplaced around the time of these rapid field changes.

Taranaki Falls $(\mathrm{TF})$ flow $\left(\mathrm{Dec}=4.5^{\circ}\right.$, Inc $\left.=-49.5^{\circ}, \alpha 95=3.2^{\circ}\right)$ has the shallowest inclination of the three Iwikau flows sampled. Palaeomagnetic dating suggests an age between 10700 and $10200 \mathrm{yrs}$ BP or between 9500 and $9000 \mathrm{yrs} \mathrm{BP}$, at the older end of the $8.8 \pm 2.8 \mathrm{ka}$ interval defined by ${ }^{40} \mathrm{Ar} /{ }^{39} \mathrm{Ar}$ (Figure 3-8).

The declination of the Bruce Road (RP) flow $\left(\operatorname{Dec}=17.8^{\circ}, \operatorname{Inc}=-60.8^{\circ}, \alpha 95=4.0^{\circ}\right)$ is more easterly than any directions in the Lake Mavora record in the assumed age range of 5 to $10 \mathrm{ka}$. The easterly direction is however consistent with the generally easterly directions obtained from Iwikau flows by Tanaka et al. (1997). While an accurate correlation cannot be made from the declination record, the steep inclination of the RP record suggests that the flow was emplaced after the swing to steeper inclination, and therefore is younger than 9000 yrs BP (probably 8400-8700 yrs BP).

Delta Corner (DC) flow (overall flow mean: Dec $=8.5^{\circ}$, Inc $=-68.3^{\circ}, \alpha 95=3.9^{\circ}$ ) also has a steep inclination, suggesting that it too was emplaced after $9000 \mathrm{yrs}$ BP. The differences in the site mean directions discussed in section 3.7.3 make it difficult to obtain a precise palaeomagnetic date. However the overall steep inclination suggests ages either at the lower or upper end of the ${ }^{40} \mathrm{Ar} /{ }^{39} \mathrm{Ar}$ range $(6.0 \pm 2.4 \mathrm{ka})$. Unless the Iwikau member flows were erupted over a period of more than 5000 years, then the older of these, ca. 8000 yrs BP, would seem the more probable age of the DC flow. 
The Saddle Cone (SC) flows were erupted from a small parasitic cone on the northern flank of Mt Ruapehu. While no direct dating of these flows has been done, Nakagawa et al. (1998) report that the Saddle Cone flows are bracketed by the ca 10 ka Pahoka-Mangamate (PM) pyroclastics and the ca 5 ka Papakai tephra, and are possibly late-stage products of the PM eruption sequence with which they share geochemical similarities. The palaeomagnetic direction for site $\mathrm{SC} 02\left(\mathrm{Dec}=358.7^{\circ}\right.$, Inc $\left.=-54.9^{\circ}, \alpha 95=3.0^{\circ}\right)$ is close to the GAD direction; it falls between the directions obtained from Taranaki Falls (TF) and Delta Corner (DC) lava flows, and is compatible with the Lake Mavora record between 9800 and 8600 yrs BP or between 6100 and 5000 yrs BP. The age estimate obtained from the more easterly direction from site SC01.1 falls into the range of the age brackets provided by SC02. If, as suggested above, the SC lavas do correlate with the end stage of the PM pyroclastic sequence, the older of these intervals would be more likely.

Mangaturuturu flow (MT) has an ${ }^{40} \mathrm{Ar} /{ }^{39} \mathrm{Ar}$ age of $11.9 \pm 2.2 \mathrm{ka}$, overlapping the oldest part of the Lake Mavora record. Palaeomagnetic matching yields a possible age of 10,800 - 10,500 yrs BP. An older age must also be considered possible.

Neither the Lake Mavora PSV record, nor any of the current global field models extends beyond 11,500 yrs BP, precluding the palaeomagnetic dating of the older flows studied, including the Whakapapaiti (WPA-C) and Skyline Ridge (GR) flows.

We also refrain from suggesting palaeomagnetic ages for the Rangataua flows. As discussed in section 3.7.10, current age estimates for this voluminous sequence of flows are based only on field relations and are contradictory; the latest field observations suggest that these flows pre-date the Lake Mavora record (Conway et al., 2016). The palaeomagnetic direction of flow RT01 $\left(\mathrm{Dec}=358.1^{\circ}, \mathrm{Inc}=-65.4^{\circ}, \alpha 95\right.$ $\left.=3.8^{\circ}\right)$ and the mean direction of RT02 and RT03 $\left(\mathrm{Dec}=10.7^{\circ}, \mathrm{Inc}=-53.4^{\circ}, \alpha 95=\right.$ $2.7^{\circ}$ ) differ by a significant amount and thus indicating significant secular variation between emplacement of the flows. 
Whangaehu (WE)

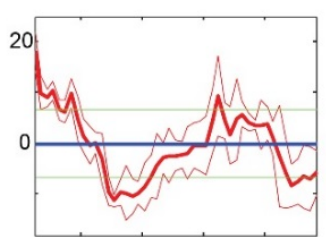

b)

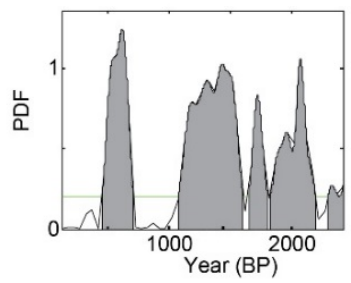

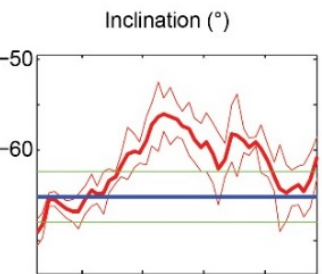
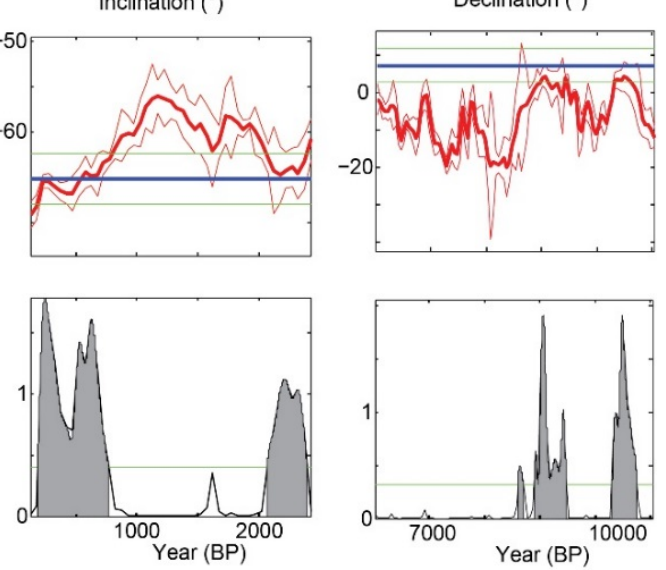

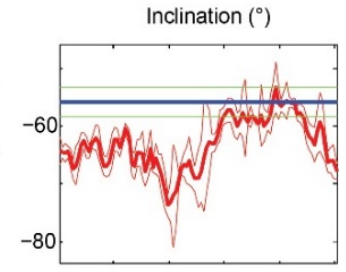

Taranaki Falls (TF)

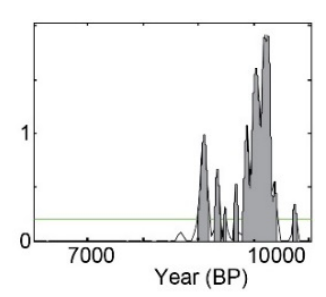

c)
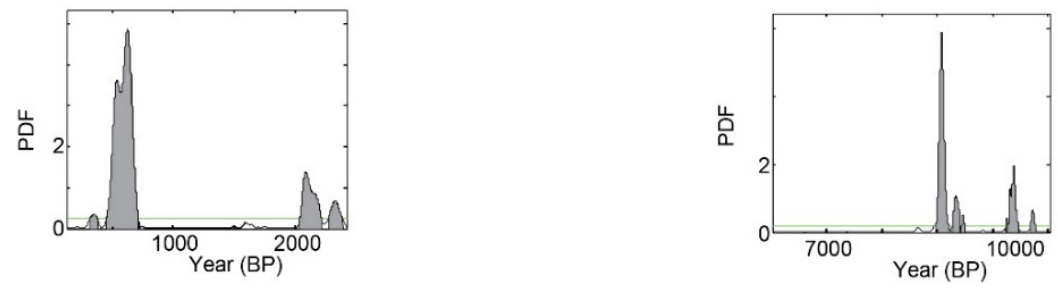

Figure 3-8: Examples of palaeomagnetic dating results on lavas from the $\mathrm{TgVC}$, for Whangaehu flow (WE) and Taranaki Falls flow (TF). a) PSV record for declination and inclination from Lake Mavora and 95\% confidence envelope, for the age range provided by the ${ }^{40} \mathrm{Ar} /{ }^{39} \mathrm{Ar}$ eruption ages, with the palaeomagnetic directions obtained in this study (blue line) with corresponding 95\% confidence limits (green). Note that for the purpose of palaeomagnetic dating the volcanic records are migrated to the sampling location of the Mavora record $\left(168.2^{\circ} \mathrm{E}, 45.3^{\circ} \mathrm{S}\right)$. b) Corresponding probability density functions (PDF, normalized), the green line displays the $95 \%$ confidence limit. c) combined probability density functions. 


\subsection{Conclusions}

A comprehensive palaeosecular variation study has provided new direction estimates on twelve lava flows from Mt Ruapehu and one lava flow from Red Crater on Mt Tongariro, in the central North Island, New Zealand. The new data compare well with a recently published palaeosecular variation (PSV) Master Curve from New Zealand (Turner et al., 2015b). However, some of our new data suggests that the field declination was previously more easterly at times than suggested by these continuous PSV records. Smoothing of the sedimentary PSV records decreases the resolution and amplitude of recorded palaeomagnetic field variations and, consequently, field models calculated from them; some of the observed differences between our new discrete data and the PSV curve may reflect this smoothing. The results from this study are a significant step towards improving the PSV records for the southern hemisphere, and in particular the SW Pacific region.

Existing eruption age constraints on the sampled Holocene flows have accompanying uncertainties of 2-3 kyrs due to the limitations of tephrochronology and the ${ }^{40} \mathrm{Ar} /{ }^{39} \mathrm{Ar}$ dating method. We use a Bayesian-based statistical Matlab tool (Pavón-Carrasco et al., 2011) to refine eruption ages of studied lava flows by matching our new data with the published PSV record (Turner et al., 2015b). Palaeomagnetic dating of five flows that belong to the Iwikau and Saddle Cone members on Mt Ruapehu and one Red Crater sourced flow, allows this uncertainty to be reduced to as little as 500 years in some cases, and so provides additional geochronological information for the eruptive stratigraphies of Tongariro and Ruapehu volcanoes. 


\section{Chapter 4}

\section{Rock magnetic characterization and palaeointensities of Holocene lava flows from the Tongariro Volcanic Centre, New Zealand.}

\section{$\underline{\text { Acknowledgements }}$}

Gillian Turner provided the primary supervision for this thesis.

Emma Hodgson introduced me to different palaeointensity methods, in particular the microwave method.

Andreas Nilsson helped during the initial fieldwork in 2013 and carried out some of the early microwave and rock magnetic experiments.

Mimi Hill leads the palaeomagnetism research group at the University of Liverpool. She helped with the interpretation of microwave and rock magnetic data and provided reviews on early versions of the manuscript.

$\underline{\text { Relevant appendices (electronic) }}$

See appendices chapter 3 (rock magnetic data, susceptibility measurements)

a) Summary of the lava flow petrography. Path: Chapter4/petrography.docx

a) Summary of the Variable Field Translation Balance (VFTB) data (file format:*xlxs). Path: Chapter4/VFTB.xlxs

b) Quantitative results of the wavelength dispersive X-ray spectroscopy (WDX) analysis (file format:*xlxs). Path: Chapter4/quantitative.docx

c) All palaeointensity measurements (file format: *tdt) Path: Chapter 4/Data/microwave PI; thermal PI

d) Summary of all the palaeointensity results (file format: *.xlxs) Path: Chapter 4/Intensity_TgVC.xlxs

e) All susceptibility measurements carried out alongside demagnetisation and intensity experiments (file format: *.xlxs).

Path: Chapter 5/Intensity_susc_TgVC.xlsx 


\subsection{Abstract}

This chapter is a presentation of the results of a palaeointensity study on the andesitic lavas from the Tongariro Volcanic Centre described in chapter 3. Palaeointensity experiments were conducted using the microwave technique and traditional Thelliertype double-heating method, using the IZZI and Coe type protocols. Successful palaeointensity estimates were obtained from six flows. These suggest an overall increase in palaeointensity from values around $37.0 \pm 5.7$ and $40.8 \pm 4.0 \mu \mathrm{T}$ measured on lavas older than $9 \mathrm{ka}$ to a maximum intensity of $70.6 \pm 4.1 \mu \mathrm{T}$, obtained for the youngest $(<1.72 \pm 0.01 \mathrm{kyrs}$ yrs BP) flow. The new absolute palaeointensity data correlate well with the relative palaeointensity record from Lake Mavora sediments. The study is accompanied by detailed magneto-mineralogical characterisation. The rock magnetic properties vary through the thickness of andesitic lava flows in association with differing cooling rates, directly affecting the palaeointensity results, Potential sources for experimental failure, data scatter and systematic differences between the palaeointensity results are discussed. 


\subsection{Introduction}

The thermoremanent magnetisation (TRM) acquired by lava flows during cooling provides a unique opportunity of obtaining instantaneous and absolute records of geomagnetic palaeointensity beyond times of direct observation. Intensity records give estimates of variations in Earth's dipole moment throughout time and thus yield important information about the dynamics within Earth's core (e.g. Olson, 2002). In order to obtain a reliable record of the global dipole moment, well distributed and unbiased datasets are required. Global databases are disproportionately populated by absolute palaeointensity data from the northern hemisphere (e.g. Donadini et al., 2006; Knudsen et al., 2008). For instance, to date only three studies (Tanaka et al., 1994; 1997; 2009) have provided absolute palaeointensity estimates for the Holocene time period in New Zealand, yielding a total of seven estimates, some of which are based on four or less successful results. Absolute palaeointensity studies in this region have been hampered by a lack of accurate and precise age control on the volcanic rocks and the stringent requirements for ideal sample material.

The Thellier method is the original palaeointensity method (Thellier and Thellier, 1959) and its modifications are to-date the most reliable technique of estimating absolute palaeointensities from natural TRM bearing samples (Selkin and Tauxe, 2000). It is based on the assumption of a linear relationship between a natural TRM and a laboratory induced TRM. In practice the NRM is replaced stepwise by a laboratory induced partial thermoremanent magnetisation (pTRM) while exposing the samples to a higher temperature with each step. For the linear relation to be valid, the primary remanence carrier should be of single domain (SD) size (e.g. Levi, 1977; Riisager and Riisager, 2001) and of a thermally stable composition, so that the ability to obtain a TRM during an experiment does not change (chapter 2). Neither of these requirements is easy to satisfy. Firstly, the grain sizes found throughout subaerial lava flows are usually within the pseudo-single domain (PSD) or multidomain (MD) grain range (Dunlop and Özdemir, 1997). Secondly the main remanence carriers in intermediate composition lava flows often belong to the Fe-Tioxide ternary system, which includes titanomagnetites and their oxidation products. Within this system equilibrium temperatures and oxygen fugacities control the 
composition of co-existing solid-solutions of the spinel (magnetite (mt) ulvospinel (ulv)) and orthorhombic (hematite (hem)-Ilmenite (Ilm)) phases (e.g. Sauerzapf et al., 2008). Rapid cooling or quenching of lava often results in the formation of solid solutions that are metastable at low temperature, and that evolve towards equilibrium composition when reheated during palaeointensity or thermomagnetic experiments. Such alteration affects the samples ability to carry TRM and can therefore result in significant errors in the palaeointensity results.

In this chapter we present the first comprehensive study of palaeointensity in New Zealand on lava flows from the Tongariro Volcanic Centre (TgVC), central North Island. Lava flows were sampled through their vertical thickness and over long lateral distances, targeting samples with a variety of rock magnetic properties. Ferrimagnetic grains in the sampled flows are titanomagnetites in close association with titanium rich titanohematites (chapter 3). Therefore, we are also able to address the effect different oxidation states of these remanence carriers on the palaeointensity results and success rates. In addition to the traditional thermal (Thellier) paleointensity experiments we also used the microwave method, which has the potential to reduce unwanted thermal alteration during the paleointensity experiments (e.g. Hill and Shaw, 2000). Furthermore in both thermal and microwave intensity experiments we applied the IZZI (Yu et al., 2004) and Coe type (Coe, 1967) protocols. This study is a continuation of the directional PSV study of chapter 3.

\subsection{Samples}

The PSV study described in chapter 3 involved a detailed sampling campaign of 12 andesitic lavas from the Tongariro Volcanic Centre (TgVC). The sampling campaign was carried out in conjunction with a geological mapping programme on Ruapehu Volcano (Townsend et al., in prep), located on the southern end of the TgVC (Figure 4-1). Palaeointensity experiments were conducted on 10 flows, for which reliable palaeomagnetic records were previously obtained. The geology, sampling details, age controls and the palaeomagnetic directions for the selected flows are described in detail in chapter 3 and summarized in Table 4-1. 
Where possible lava flows were sampled in several sites and through the flow interior and over large lateral distances. This enabled us to obtain samples with a wide variety of rock magnetic properties and to monitor any terrain-induced errors. Collection of drilled samples was often hampered by the hardness of the andesites. Thus additional hand samples were collected. These were usually removed from the outcrop after marking the strike and dip on an exposed surface, and later drilled with a vertical drillpress in the laboratory. Flat surfaces were not easy to find on the brecciated surface of a'a flow-tops and some hand samples were either poorly oriented or un-oriented. While these samples were not used for the demagnetisation experiments of chapter 3 , they still proved suitable for palaeointensity analysis, where sample orientation is not crucial, as long as a stable remanence direction is known from other, oriented samples (chapter 3). 


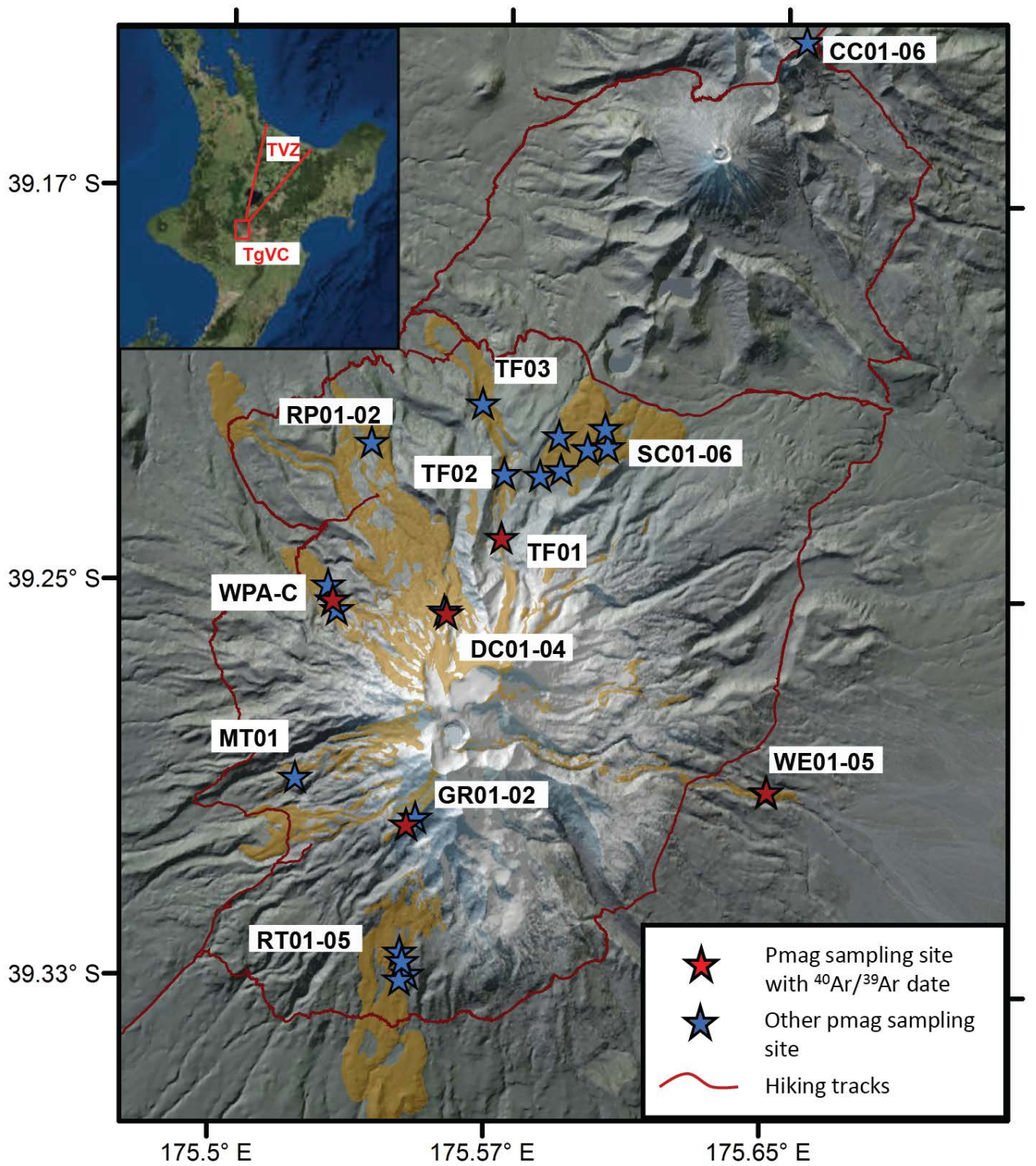

Figure 4-1: Digital topographic map of Ruapehu Volcano within the Tongariro Volcanic Centre, showing all palaeomagnetic sampling sites (stars). Sites, for which ${ }^{40} \mathrm{Ar} /{ }^{39} \mathrm{Ar}$ ages are available are indicated in red. The postglacial lava flows on $\mathrm{Mt}$ Ruapehu (Whakapapa Formation) are indicated in brown. Inset: Location of the TgVC at the southern tip of the Taupo Volcanic Zone (TVZ) in the North Island, New Zealand. No palaeointensity experiments were carried out for Saddle Cone (SC), Whakapapaiti B and C (WPB, WPC) flows. 
Table 4-1: Summary of the Holocene lava flows from the TgVC included in this palaeointensity study.

\begin{tabular}{|c|c|c|c|c|c|c|}
\hline Flow & Age (ka) & $\begin{array}{l}\text { Pmag Age } \\
(\text { yrs BP) }\end{array}$ & $\begin{array}{l}\text { Lat }\left({ }^{\circ} \mathbf{S}\right) \\
\text { Long }\left({ }^{\circ} \mathbf{E}\right)\end{array}$ & $\mathbf{N}$ & Pmag direction & Description \\
\hline $\begin{array}{l}\text { Central Crater } \\
(\mathrm{CC})\end{array}$ & $<1.72 \pm 0.01^{\mathrm{a}}$ & $300 \pm 200$ & $\begin{array}{l}39.133 \\
175.655\end{array}$ & 6 & $\begin{array}{l}\text { Dec }=20.8^{\circ}, \text { Inc } \\
=-67.4^{\circ}, \alpha 95= \\
7.4^{\circ}, \mathrm{N}=4 \text { (sites) }\end{array}$ & $\begin{array}{l}\text { Basaltic a'a flow, sourced from Red } \\
\text { Crater on the northern end of the } \\
\text { TgVC. Individual blocks were } \\
\text { sampled along the flow top surface. }\end{array}$ \\
\hline $\begin{array}{l}\text { Whangaehu } \\
\text { (WE) }\end{array}$ & $<2.4^{\mathrm{a}}$ & $\begin{array}{l}2000- \\
2400\end{array}$ & $\begin{array}{l}39.292 \\
175.650\end{array}$ & 5 & $\begin{array}{l}\text { Dec }=359.5^{\circ}, \text { Inc } \\
=-60.6^{\circ}, \alpha 95= \\
3.3^{\circ}, \mathrm{N}=7\end{array}$ & $\begin{array}{l}\text { Massive flow end of an andesitic lava } \\
\text { flow with a blocky flow top. Samples } \\
\text { were taken throughout the thickness } \\
\text { of the flow (zones A-D). }\end{array}$ \\
\hline $\begin{array}{l}\text { Delta } \\
\text { (DC) }\end{array}$ & $6 \pm 2.4^{\mathrm{a}}$ & $\sim 8000$ & $\begin{array}{l}39.255 \\
175.561\end{array}$ & 4 & $\begin{array}{l}\text { Dec }=8.5^{\circ}, \quad \text { Inc } \\
=-68.3^{\circ}, \alpha 95= \\
3.9^{\circ}, \mathrm{N}=10\end{array}$ & $\begin{array}{l}\text { Ridge forming andesitic flow within } \\
\text { Whakapapa ski field. Four sites were } \\
\text { sampled throughout the flows } \\
\text { thickness and across a lateral distance } \\
\text { of } \sim 200 \mathrm{~m} \text { (zones A-C). }\end{array}$ \\
\hline $\begin{array}{l}\text { Bruce } \\
\text { (RP) }\end{array}$ & $5-10^{b}$ & $\begin{array}{l}<9000 \\
(8400- \\
8700)\end{array}$ & $\begin{array}{l}39.220 \\
175.540\end{array}$ & 2 & $\begin{array}{l}\text { Dec }=17.8^{\circ}, \text { Inc } \\
=-60.8^{\circ}, \alpha 95= \\
4.0^{\circ}, \quad \mathrm{N}=7\end{array}$ & $\begin{array}{l}\text { A steep river gorge exposes a massive } \\
\text { section through the andesitic flow. } \\
\text { Here we present only the results from } \\
\text { one site sampled from zone C (site } \\
\text { RP02). }\end{array}$ \\
\hline $\begin{array}{l}\text { Taranaki Falls } \\
(\mathrm{TF})\end{array}$ & $8.8 \pm 2.8^{\mathrm{a}}$ & $\begin{array}{l}8900- \\
9500 \\
10200- \\
10500\end{array}$ & $\begin{array}{l}39.226 \\
175.576\end{array}$ & 3 & $\begin{array}{l}\text { Dec }=4.5^{\circ}, \quad \text { Inc } \\
=-49.5^{\circ}, \alpha 95= \\
3.2^{\circ}, \quad \mathrm{N}=16\end{array}$ & $\begin{array}{l}\text { Valley bottom flow, exposed along } \\
\text { Wairere streambed. Three sites were } \\
\text { sampled over a distance of ca. } 2 \mathrm{~km} \\
\text { from the out-washed flow interior } \\
\text { (probably zone } \mathrm{C} \text { ). }\end{array}$ \\
\hline $\begin{array}{l}\text { Mangaturuturu } \\
\text { (MT) }\end{array}$ & $11.9 \pm 2.2^{\mathrm{a}}$ & $>10500$ & $\begin{array}{l}39.291 \\
175.522\end{array}$ & 1 & $\begin{array}{l}\text { Dec }=8.7^{\circ}, \quad \text { Inc } \\
=-60.4^{\circ}, \alpha 95= \\
4.0^{\circ}, \quad \mathrm{N}=10\end{array}$ & $\begin{array}{l}\text { Andesitic flow, within a sequence of } \\
\text { flows, exposed within a steep bluff. } \\
\text { Hand samples and core samples were } \\
\text { taken from the platey flow interior } \\
\text { and directly surrounding rock (zone } \\
\text { B). }\end{array}$ \\
\hline $\begin{array}{l}\text { Whakapapaiti } \\
\text { "A" }\end{array}$ & $14.8 \pm 3.0^{\mathrm{a}}$ & & $\begin{array}{l}39.253 \\
175.530\end{array}$ & 3 & $\begin{array}{l}\text { Dec }=358.1^{\circ}, \text { Inc } \\
=-54.9^{\circ}, \alpha 95= \\
2.7^{\circ}, \quad \mathrm{N}=8\end{array}$ & $\begin{array}{l}\text { Ridge forming flow above a sequence } \\
\text { of waterfalls. Cored samples were } \\
\text { taken from three sites over a distance } \\
\text { of ca. } 500 \mathrm{~m} \text {, and } \\
\text { additional hand samples from the } \\
\text { platey interior (site WPA01) (zones } \\
\mathrm{B}, \mathrm{C} \text { ). }\end{array}$ \\
\hline $\begin{array}{l}\text { Skyline Ridge } \\
\text { (GR) }\end{array}$ & $15.1 \pm 2.4^{\mathrm{a}}$ & & $\begin{array}{l}39.002 \\
175.552\end{array}$ & 3 & $\begin{array}{l}\text { Dec }=356.5^{\circ}, \text { Inc } \\
=-81.4^{\circ}, \alpha 95= \\
3.8^{\circ}, \quad \mathrm{N}=11\end{array}$ & $\begin{array}{l}\text { Very exposed ridge top flow. } \\
\text { We sampled three sites over a } \\
\text { distance of } \sim 1.5 \mathrm{~km} \text {. Hand samples } \\
\text { were taken from the platey flow } \\
\text { centre (zones } \mathrm{B}, \mathrm{C} \text { ). }\end{array}$ \\
\hline Rangataua (RT) & $<15^{\mathrm{c})}$ & & $\begin{array}{l}39.333 \\
175.536\end{array}$ & 5 & $\begin{array}{l}\text { RT01: Dec }= \\
358.1^{\circ}, \text { Inc }=- \\
65.4^{\circ}, \alpha 95=3.8^{\circ}, \\
\mathrm{N}=3 \text { (samples). } \\
\text { RT02 \& RT03: } \\
\text { Dec }=10.7^{\circ}, \text { Inc } \\
=\quad-53.4^{\circ}, \\
\alpha 95=4.7, \mathrm{~N}=11\end{array}$ & $\begin{array}{l}\text { Suite of andesitic lava flows } \\
\text { covering an area of ca. } 40 \mathrm{~km}^{2} \\
\text { The flow interior is exposed in a } \\
\text { small number stream cuts only, } \\
\text { which were sampled at sites RT01- } \\
\text { RT03. Hand samples were taken } \\
\text { from the blocky flow top surface } \\
\text { (Sites RT04 and RT05) (zone D). }\end{array}$ \\
\hline
\end{tabular}


Table 4-1 continues..

Note: No intensity experiments were carried out on WPB, WPC and SC lava flows (chapter 3). Age (ka) based on a) ${ }^{40} \mathrm{Ar} /{ }^{39} \mathrm{Ar}$ dates (Conway et al., 2016), b) tephrochronology (Hobden, 1997; Lowe et al., 2013; Topping, 1974), c) morphology. Pmag age: Refined palaeomagnetic emplacement ages and directions, discussed in chapter 3. Lat, Long are the latitude and longitude of the sampling location, respectively, $\mathrm{N}$ the number of sites. Pmag direction: Palaeomagnetic direction. Refer to chapter 3 for a discussion of the statistical procedures applied. Note that for Rangatau flows we separate between two units and directions from site RT01 and sites RT02 \& RT03. Refer to section 4.4 for an explanation of the different zones throughout individual lava flows.

\subsection{Magnetic mineralogy}

\subsubsection{Introduction}

Detailed rock magnetic experiments were carried out on samples from each site and supplemented by petrographic imaging. Complementary backscattered electron imaging (BSE) and quantitative analyses of the titanium-oxides were obtained on a selected number of samples (e.g. samples from WE, DC, RP, TF, WPA, WPB flows).

A summary of the rock magnetic findings on lava flows from the $\mathrm{TgVC}$ was provided in chapter 3 to the extent needed to interpret the thermal demagnetisation data and to identify the primary carriers of the magnetic remanence. As discussed earlier in this chapter, Thellier-type palaeointensity methods are strongly dependent on the rock magnetic characteristics of the sample material (e.g. Biggin et al., 2007). In this chapter, the rock magnetic behaviour is therefore treated in greater detail, and together with the mineral-optical analyses. Common observations made between individual flows are discussed in the following sections. More detailed descriptions of the rock magnetic properties of every flow are provided together with the palaeointensity results in section 4.6. Data summaries from petrographic imaging and a list of all rock magnetic experiments are available in the appendices.

In chapter 3 we discussed a dependence of the rock magnetic behaviour within individual zones throughout the thickness of the andesitic flows around Mt Ruapehu and we will refer to it in the following analysis. Zone A corresponds to the lowermost part of the flow and is usually not exposed. Zone B corresponds to the flow centre and the lava is usually strongly fractured into curvilinear plates. Zone $\mathrm{C}$ is a massive blocky zone that is located between zone B and the auto-brecciated flow top (zone D) (Figure 4-9b). For details please refer to chapter 3, section 3.4.2 (Whangaehu flow). 


\subsubsection{Methods}

A $100 \mathrm{mg}$ crushed or powdered sample from each site was subjected to the measurement of induced remanent magnetisation (IRM), backfield coercivity of remanence, hysteresis and saturation magnetisation with temperature $\left(\mathrm{M}_{\mathrm{s}} \mathrm{vs}\right.$. T) curves using a Variable Field Translation Balance (VFTB). Additional low-field (200 A/m) magnetic susceptibility ( $\chi$ vs. T) were measured in a reducing argon environment (in order to prevent oxidation) upon cycling the samples from room temperature to the desired peak temperature using an AGICO MFK1-FA Kappa Bridge. All rock magnetic experiments were carried out at the palaeomagnetism laboratory of University of Liverpool. Strong-field experiments were conducted with a peak field of $800 \mathrm{mT}$, heating experiments to a maximum temperature of $700^{\circ} \mathrm{C}$ with a heating rate of $30^{\circ} \mathrm{C} /$ minute. A small number of samples that showed irreversible heating and cooling curves were also subjected to the measurement of incremental heating and cooling curves ( $\chi$ vs. T) to identify the onset of thermal alteration.

Polished thin sections were prepared by Stewart Bush at the School of Geography, Environment and Earth Sciences, Victoria University of Wellington. Thin sections were coated with a thin carbon film prior to electron microprobe analysis. For petrographic imaging we used an Olympus BX51 research microscope with a maximum magnification of 400x. Backscatter electron (BSE) imaging and quantitative analysis were carried out using a JEOL JXA-8230 scanning electron microprobe, equipped with a wavelength dispersive x-ray (WDX) detector system. The smallest diameter of the focused beam is $1 \mu \mathrm{m}$ and we used a $12 \mathrm{nA}$ beam current and an accelerating voltage of $15 \mathrm{keV}$. In addition to $\mathrm{Fe}$ and $\mathrm{Ti}$, we also probed for traces of $\mathrm{Al}, \mathrm{Mg}, \mathrm{Si}, \mathrm{Mn}$ and $\mathrm{Cr}$. Synthetic and natural mineral standards were used in calibration and monitoring analytical runs. Ti and Fe were standardized using a synthetic $\mathrm{FeTiO}_{3}$ (Ilmenite) and $\mathrm{Fe}_{3} \mathrm{O}_{4}$ (magnetite), respectively.

The $\mathrm{Fe}^{2+/} \mathrm{Fe}^{3+}$ cation distribution was calculated from the $\mathrm{Fe}$ analysis for identified spinel and rhombohedral phases based on ideal stoichiometry. The coefficients $\mathrm{X}_{\text {usp }}$ (ulvospinel) and $\mathrm{X}_{\mathrm{ilm}}$ (ilmenite) were calculated following Stormer (1983). In this calculation $\mathrm{X}_{\text {usp }}$ quantifies the number of $\mathrm{Fe}^{3+}$ cations replaced by $\mathrm{Fe}^{2+}$ and $\mathrm{Ti}^{4+}$ and 
other cations within the spinel solid solution $\mathrm{Fe}_{3-\mathrm{x}} \mathrm{Ti}_{\mathrm{x}} \mathrm{O}_{4}$, and $\mathrm{X}_{\mathrm{ilm}}$ is the corresponding mixing coefficient in the rhombohedral hematite-ilmenite solid solution $\mathrm{Fe}_{2-\mathrm{x}} \mathrm{Ti}_{\mathrm{x}} \mathrm{O}_{3}$.

\subsubsection{Petrographic description (microscopy and BSE imaging)}

The lava flows from Mt Ruapehu targeted in this study share similarities in composition and rock magnetic behaviour. Central Crater (CC) is the only flow sampled from a different cone and is of more mafic composition and entirely different morphology (chapter 3) and is thus not treated in as much detail. Central Crater (CC) samples are basaltic andesites (Phenocrysts: plagioclase (plag), orthpyroxene (opx), clinopyroxene (cpx), olivine (ol)), contain a quenched glassy matrix with isolated brown glass and ca. $30 \%$ vesicle space (flow-top samples) and isolated oxides in the sub-micron scale.

The samples from the Ruapehu flows are porphyritic andesites with a phenocryst (mainly plag, some opx and cpx) abundance of 30-50\% in a microcrystalline matrix consisting of mostly elongated plagioclase grains. The relative abundance of plagioclase vs. pyroxene varies between flows (see electronic appendix). Phenocryst grain sizes also vary between sites and flows. Xenoliths, crustal fragments incorporated to the magma during transport through basement rock, are a common constituent of the Ruapehu andesites: in several thin-sections they are seen as agglomerates of plagioclase and pyroxenes (Figure 4-2). A preferred orientation (textural anisotropy) was not identified in any of the samples. 

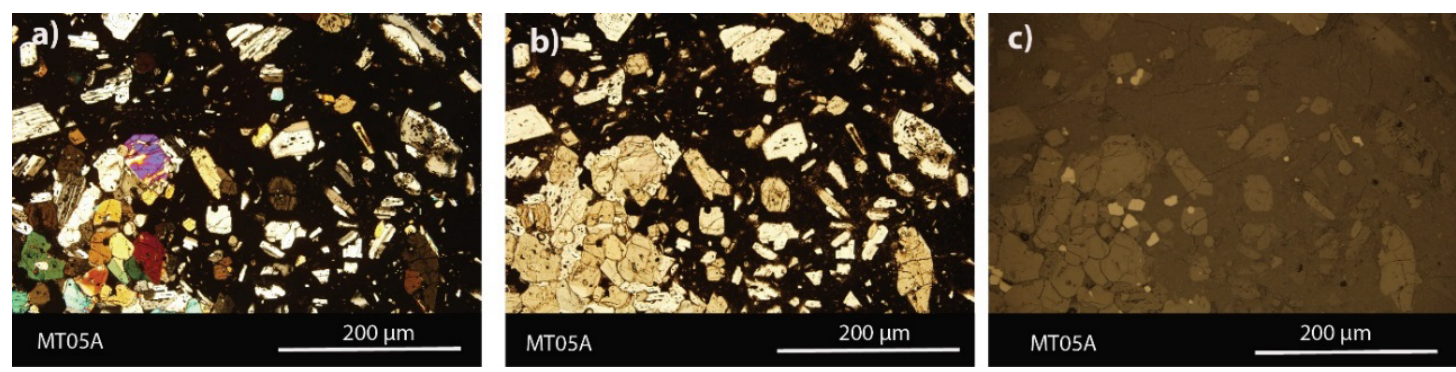

Figure 4-2: Photomicrographs of a porphyritic pyroxene andesite (Mangaturuturu flow). View under a) cross polarized transmitted light, b) plane polarized transmitted light, c) under reflected light. Note the aggregate of ortho- + clinopyroxene + plagioclase in the lower left corner. Aggregates like this are common constituents of Ruapehu andesite and they represent micro-xenoliths derived from deeper in the crust. In c) the iron-oxides appear lighter coloured under reflected light.

The Fe-Ti oxides are usually anhedral and are present in accessory proportions (1\% or less) of the total rock mass. They appear either as micro phenocrysts with grain sizes ranging up to $200 \mu \mathrm{m}$, inclusions in pyroxenes or as microcrystals in the groundmass.

BSE imaging shows that the Fe-Ti oxides exists either as homogeneous grains or with lamellar intergrowth of a highly reflective and less reflective component which we interpret as titanomagnetite and ilmenite, respectively. Within the visible range the lamellae have a maximum width of $4 \mu \mathrm{m}$ and are either cross-hatched or parallel (Figure 4-3b, c, d) and we suggest that they formed by progressive oxidationexsolution after formation in the magma chamber. This was probably caused by a shift in the equilibrium composition, for example during cooling and will be treated in more detail below.

Watkins and Haggerty (1968) classified the Fe-Ti oxides into groups with three different oxidation indices. Oxidation index 1 describes homogeneous titanomagnetite grains (Figure 4-3a), index 2 titanomagnetites with few exsolution lamellae along the grain boundaries and index 3 grains with abundant and well developed lamellae of ilmenite (Figure 4-3c). Progressive oxidation to a higher state would involve the formation of titanohematite-rutile intergrowth structures. In this study however, the highest oxidation state observed corresponds to index 3 . 
Later in this chapter (e.g. section 4.4.5) we describe differences in the rock magnetic properties in relation to their vertical position within the flows. At this state it is noteworthy that although the relative abundance and size of micro-lamellae in larger grains and the distribution of submicron sized grains within the groundmass vary strongly from flow to flow, we did not identify significant differences between different sites sampled on individual flows within the visible range $(\geq 1 \mu \mathrm{m})$.
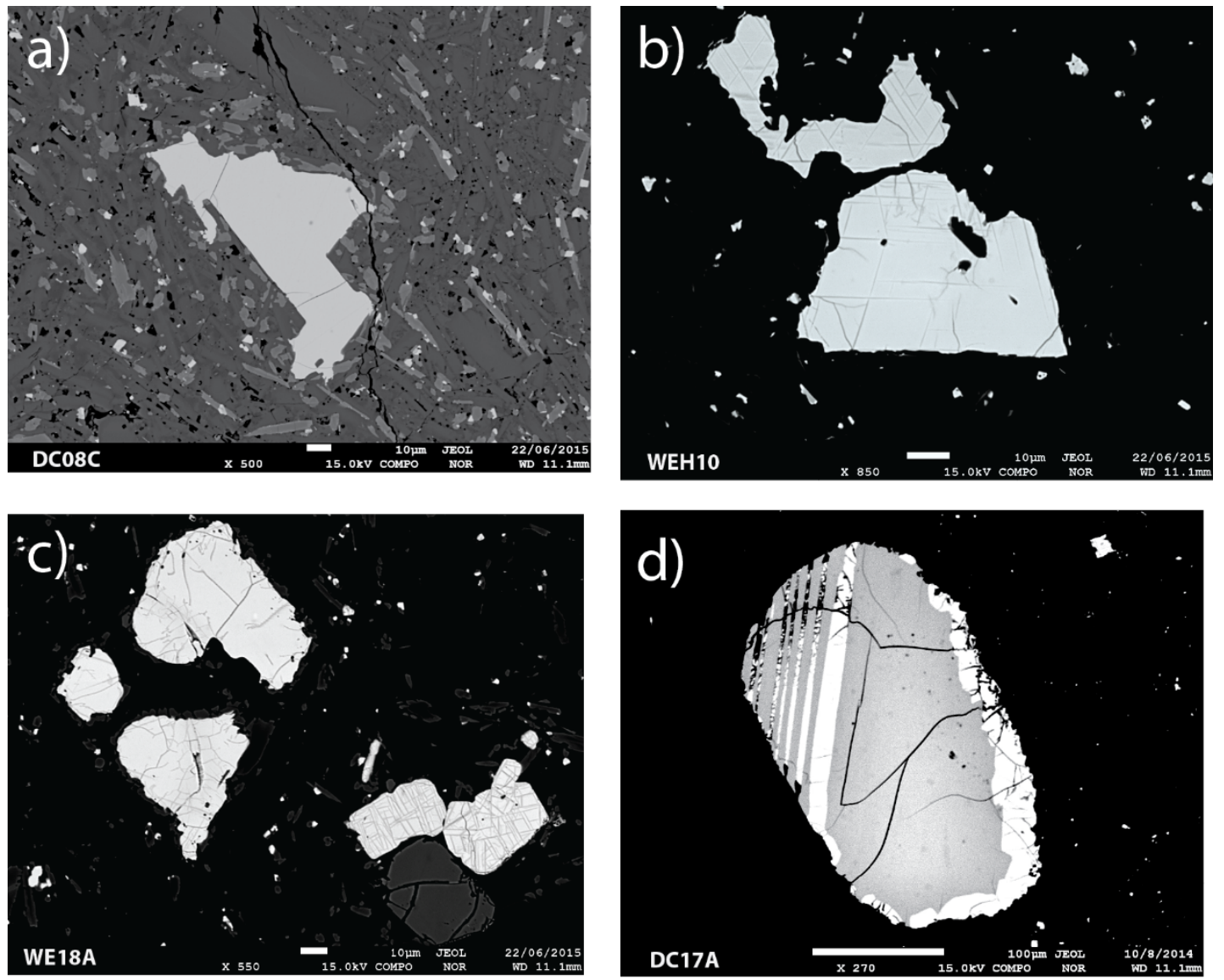

Figure 4-3: Representative back scattered electron (BSE) photomicrographs of opaque minerals in andesitic samples from TgVC flows a) homogeneous titanomagnetite, oxidation index 1 as defined by Watkins and Haggerty (1968) seen in a specimen from Delta Corner flow b) titanomagnetites with a small number of exsolution lamellae along the grain boundaries, oxidation index 2, found in a Whangaehu flow sample c) a number of titanomagnetite phenocrysts in microcrystalline groundmass. While the two grains in the right bottom corner contain a large number of exsolution lamellae throughout, corresponding to oxidation index 3, we associate the grains in the upper left corner with index $2 \mathrm{~d}$ ) lamellar titanomagnetite-ilmenite intergrowth. 
Low-temperature mineral alteration was identified only in thin sections from Whakapapaiti A (WPA) and Skyline Ridge (GR) flow. In thin sections, patches of alteration can be identified by a discoloration along the grain boundaries of both the silicate and oxide phases seen under transmitted and/or reflected light. Some grains also show faint lamellae without well-defined boundaries (Figure 4-4b).
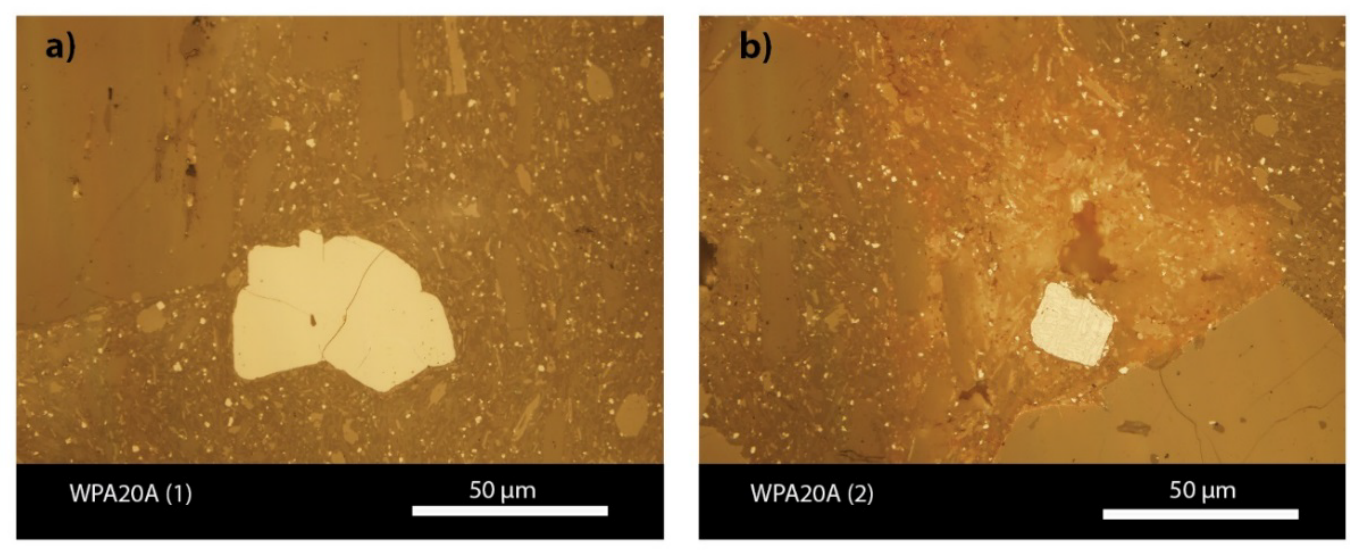

Figure 4-4: Reflected light microscopic images of two opaque grains in the same thin section from Whakapapaiti A flow (WPA). a) Homogeneous phenocryst in microcrystalline matrix. b) Strongly altered and exsolved oxide grain within a patchy altered matrix.

\subsubsection{Quantitative analysis (WDX)}

The quantitative wavelength dispersive $\mathrm{x}$-ray (WDX) analysis has a maximum resolution of $5 \mu \mathrm{m}$ and was therefore carried out on phenocrysts only. While coexisting titanomagnetite and ilmenite phases could be probed, ilmenite exsolution lamellae were usually too fine for individual analysis. The results show little compositional variability between samples from different sites and flows (Figure 4-5) and the ulvospinel mixing factor $\mathrm{X}_{\mathrm{usp}}$ ranges from $0.18-0.53$, consistent with the values described by Price et al. (2012) for the Whakapapa formation. Lower values of $\mathrm{X}_{\mathrm{usp}}(0.18-0.25)$ are usually found in grains that co-exist with ilmenite, while higher values $(0.48-0.53)$ are observed from homogeneous grains, or grains where lamellae where too fine to probe individually and the results therefore represent an average composition. The ilmenite mixing factor is relatively consistent and shows values around $\mathrm{X}_{\mathrm{ilm}}=0.9$. 

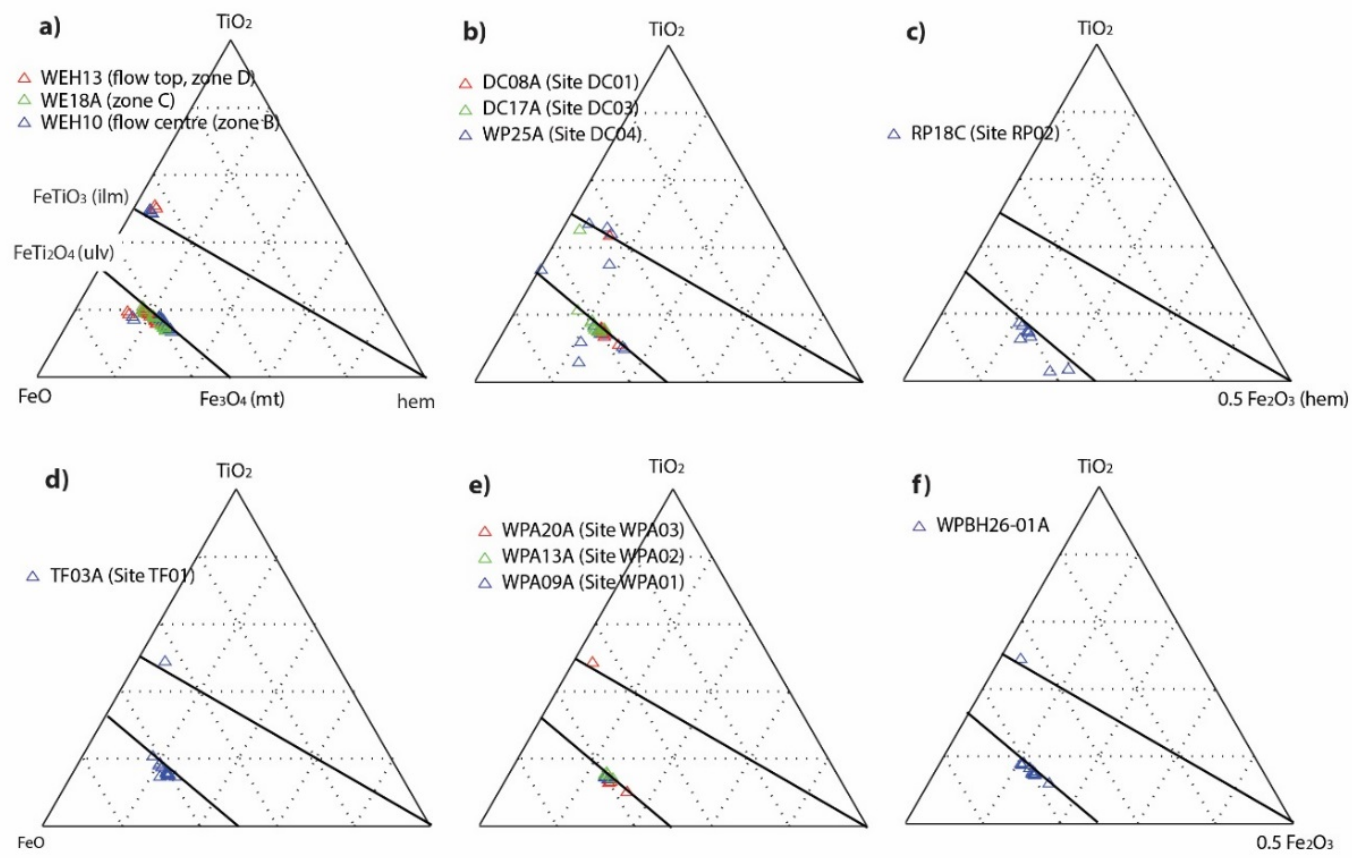

Figure 4-5: Iron oxide ternary diagrams showing ulvospinel and ilmenite $\left(\mathrm{X}_{\text {usp }}\right.$ and $\mathrm{X}_{\mathrm{ilm}}$ ) compositions on andesitic lavas from the TgVC, calculated following Stormer (1983). Overall the iron oxide phases display limited compositional variability. The solid lines are solid solution mixing curves of titanomagnetite (ulvospinel (ulv) magnetite (mt) end members) and hemoilmenite (ilmenite (ilm) - hematite (hem) a) Whangaehu flow, (WE) b) Delta Corner flow (DC), c) Bruce Road flow (RP), d) Taranaki Falls flow (TF), e) Whakapapaiti A flow (WPA) f) Whakapapaiti B flow (WPB).

\subsubsection{Rock and thermomagnetic behaviour}

The petrographic and quantitative analysis described above suggest that the magnetic minerals in samples from all sites and flows consist primarily of titanomagnetites or titanohematites with low to moderate oxidation states (indices 1 to 3 after Watkins and Haggerty, 1968).

The rock and thermomagnetic properties agree well with this observation. Isothermal remanent magnetisation (IRM) and backfield coercivity of remanence curves from all samples strongly resemble each other. The IRM curves saturate at applied fields lower than $250 \mathrm{mT}$ and require backfields (coercivities) between 15 and $30 \mathrm{mT}\left(\mathrm{B}_{\mathrm{cr}}\right)$ to demagnetise samples thereafter, as would be expected from these relatively soft remanence carriers (Figure 4-6). 
The magnetic coercivities for most samples range from 5-15 mT. Only samples from Central Crater (CC) and Bruce Road (RP) flow yield higher coercivities up to $30 \mathrm{mT}$ (Figure 4-7). The ratios between saturation remanent magnetisation $\left(\mathrm{M}_{\mathrm{rs}}\right)$ and saturation magnetisation $\left(\mathrm{M}_{\mathrm{s}}\right)$, coercivity of remanence $\left(\mathrm{B}_{\mathrm{cr}}\right)$ and coercivity $\left(\mathrm{B}_{\mathrm{c}}\right)$ fall into the range of values expected for pseudo-single domain (PSD) grains defined by Day et al. (1977) and Dunlop (2002) (chapter 3, Figure 3-3a). However based on the wide variation of grain sizes observed during mineral-optical analyses we suggest that these ratios may be representative for an average between different coercivity populations. Figure 4-7 displays $B_{c}$ vs. $M_{r s} / M_{s}$. Samples from each flow follow individual trends and the coercivities measured on samples from Whangaehu flow (WE) differ significantly: flow centre (zone B) samples yield coercivities approximately twice as high as a sample from the flow top (zone D). Differences in the magnetic mineralogy are unlikely to account for this and it is thus suggest that the samples from zone B have a smaller magnetic grain size.

As discussed in chapter 3 , the thermomagnetic curves also vary strongly from site to site. The Curie temperatures range from 150 to $600^{\circ} \mathrm{C}$, the lower end of the range agrees roughly with the $\mathrm{T}_{\mathrm{c}}$ expected for the composition measured during WDX analysis, while the higher Curie temperature $\left(\mathrm{T}_{\mathrm{c}}>550^{\circ} \mathrm{C}\right)$ is higher than the $\mathrm{T}_{\mathrm{c}}$ expected from any of the compositions measured (Table 4-3) (Lattard et al., 2006), suggesting the presence of low titanium-titanomagnetite phases with effective magnetic grain sizes that are smaller than the minimum resolution of the electron microprobe $(<5 \mu \mathrm{m})$. In chapter 3 we summarized the different thermomagnetic curves into five types, based on the Curie temperature distribution and the reversibility of heating and cooling curves (Table 4-3). Type 1 behaviour is unique to samples from Central Crater (CC) flow and shows accelerated mineral alteration upon heating in an ambient atmosphere ( $\mathrm{M}_{\mathrm{s}}$ vs. $\mathrm{T}$ experiments), as compared to heating experiments conducted in an inert atmosphere ( $\chi$ vs. T experiments) (Figure 4-8). In contrast, curve types 1 to 5, found on andesitic samples from Mt Ruapehu primarily differ by their Curie temperature distribution and reversibility. Mineral alteration occurs both during heating in an ambient and inert atmosphere. We cannot assign unique thermomagnetic behaviour to individual flows but we observe a strong dependence 
on the location, or zone within the thickness of the flows sampled (Figure 4-9). Each curve type indicates the presence of least one of four compositional phases identified in this study: $\mathrm{P} 1\left(150^{\circ}<\mathrm{T}_{\mathrm{c}}<250^{\circ} \mathrm{C}\right)$ appears only in the near reversible type 2 curves which we found on flow top samples (zone D), such as the ones sampled at Rangataua (RT) and Whangaehu (WE) lava flows. In contrast, the intermediate $T_{c}$ phases (P2: 250 $<\mathrm{T}_{\mathrm{c}}<320^{\circ}$ and $\mathrm{P} 3: 320^{\circ}<\mathrm{T}_{\mathrm{c}}<450^{\circ} \mathrm{C}$ ), dominate in the irreversible type 3 and type 4 curves over a high $\mathrm{T}_{\mathrm{c}}$ phase $\left(\mathrm{P} 4: \mathrm{T}_{\mathrm{c}}>500^{\circ} \mathrm{C}\right)$. Type 3 and 4 curves are the most commonly observed in this study and have been primarily identified on samples from within the flow (zones $\mathrm{A}$ and $\mathrm{C}$ ). Both curve types alter upon heating to temperatures higher than $400^{\circ} \mathrm{C}$, the shift in $\mathrm{T}_{\mathrm{c}}$ is dependent on the peak temperature (Figure 4-9c). Phase P4 dominates in the near reversible type 5 curves, typically abundant in samples from zone B (Figure 4-9e).

We suggest that these differences are the result of differing cooling rates throughout the andesitic flows sampled. The cooling, degassing and crystallisation process during and after emplacement of the lava flows may have caused a shift of the equilibrium composition within the spinel-orthorhombic system described by the Fe-Ti oxides (e.g. Sauerzapf et al., 2008). While quenching of the lava on the flow top preserved titanomagnetites close to their primary state (e.g. oxidation index 1 or 2 , after Watkins and Haggerty, 1986), cooling within the flow centre may have lasted up to weeks (Sigurdsson, 2000), which would have allowed the titanomagnetites to undergo subsolidus exsolution and oxidation. As discussed in section 4.4.3, these within flow differences were not directly visible during petrographic imaging and we thus suggest that oxidation after or during emplacement of the lavas resulted in the formation of sub-micron scale lamellae or additional growth of sub-micron sized grains in the rock matrix, which are optically unresolvable. 


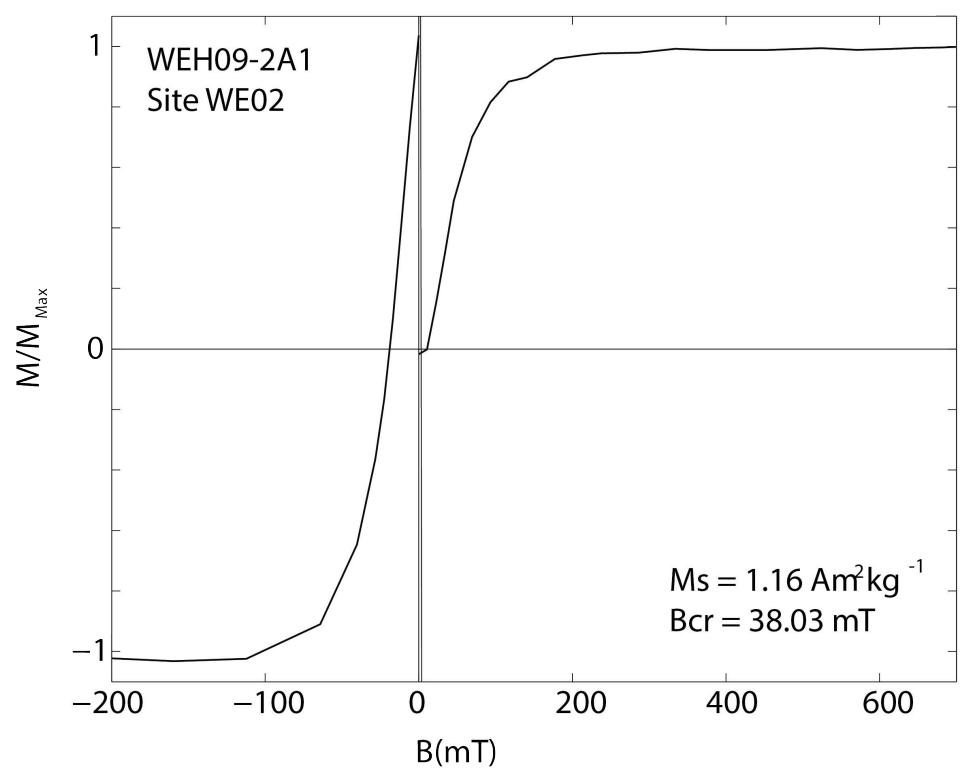

Figure 4-6: Representative IRM and backfield coercivity of remanence curve for sample WEH09-2A1 (Whangaehu flow, zone B). Curves from other sites and flows strongly resemble these.

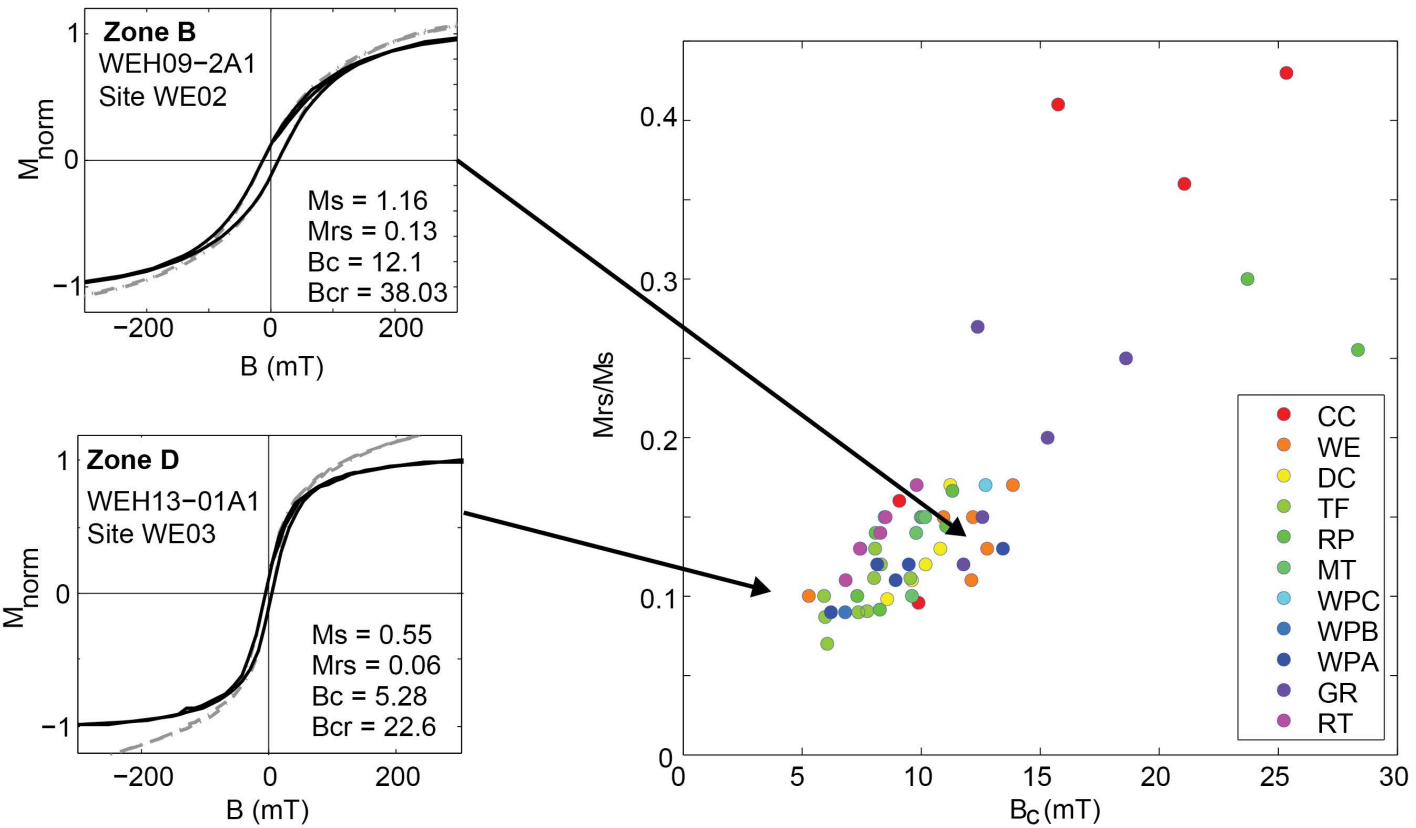

Figure 4-7: Hysteresis properties from TgVC samples, displayed in a $B_{c} v s M_{r s} / M_{s}$ diagram and representative hysteresis diagrams for samples taken from the top (zone D) and centre (zone B) of Whangaehu flow. The hysteresis properties are displayed with each diagram. Note that the coercivity of remanence $\left(\mathrm{B}_{\mathrm{cr}}\right)$ was extracted from backfield curves on the same samples. Units for $M_{s}, M_{r s}$ are $* 10^{3} A m^{2} / k g, B_{c}, B_{c r}$ in $\mathrm{mT}$ 
a)

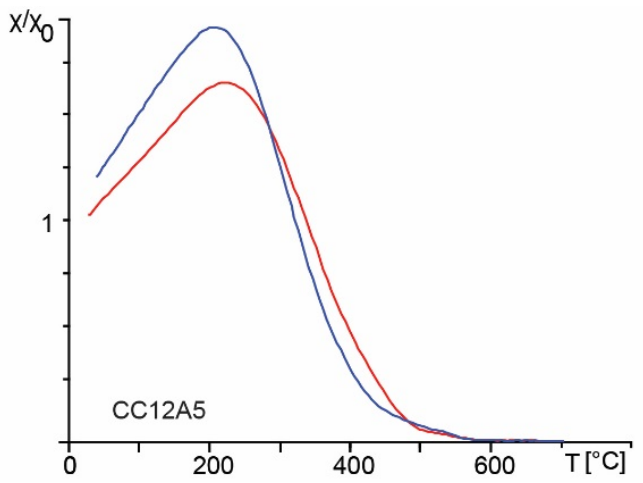

b)

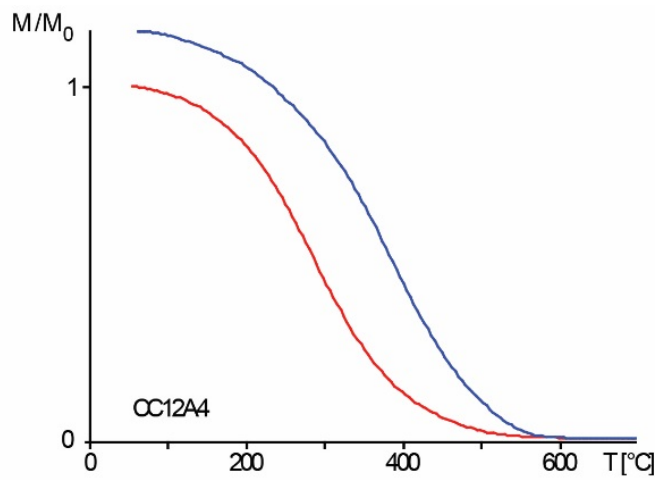

Figure 4-8: "Type 1" thermomagnetic curves measured on specimens from Central Crater flow a) $\chi$ vs. T curves measured during heating and subsequent cooling cycles in an Ar-atmosphere b) $M_{s}$ vs. T curves measured in ambient atmosphere. See text for details.

a)

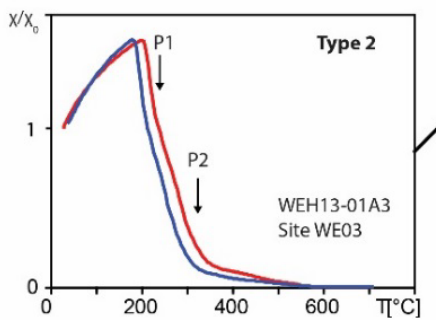

d)

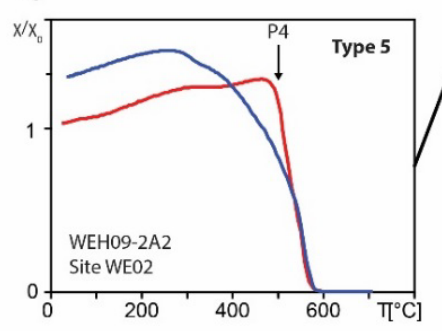

b)

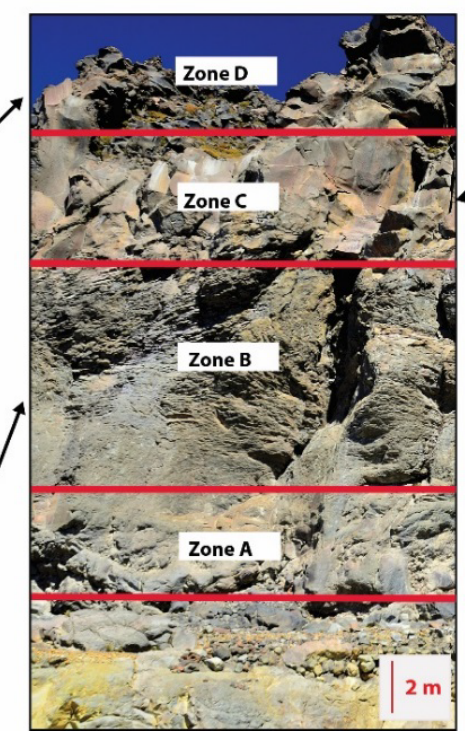

c)

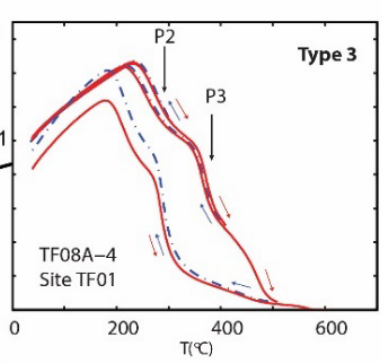

e)

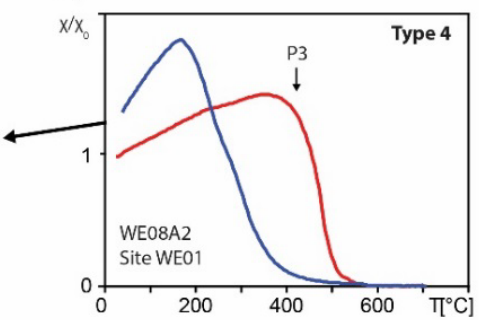

Figure 4-9: Representative $\chi$ vs.T curves measured in different zones throughout the thickness of Whangaehu lava flow. The curves correspond to types 2, 3, 4 and 5 as defined for the andesitic samples in Table 4-3. The location of the infliction points in the heating curves correspond roughly to the $\mathrm{T}_{\mathrm{c}}$ of the compositional phases $\mathrm{P} 1-\mathrm{P} 4$. Figure (c) displays an incremental heating curve, showing the decay of the compositional phases P2 and P3 into a composition with lower Curie temperature. The small arrows indicate the individual heating and cooling increments. Red: heating curves, blue: cooling curves. 
Table 4-2: Quantitative ulvospinel ( $\mathrm{X}_{\text {usp }}$ ) component and expected $\mathrm{T}_{\mathrm{c}}$ after Lattard et al. (2006) in comparison to the $T_{c}$ 's obtained from $M_{s}$ vs.T and $\chi$ vs.T curves on sister samples. The $\mathrm{X}_{\mathrm{usp}}$ component was calculated from the microprobe results following the steps outlined in Stormer (1983). $T_{c}$ 's were estimated using the second derivative approach from the $\mathrm{M}_{\mathrm{s}}$ vs.T curves and hand-picked from the onset of linearity in $1 / \chi$ from the $\chi$ vs.T curves (Petrovsky and Kapicka, 2006).

\begin{tabular}{|c|c|c|c|c|c|c|c|}
\hline \multicolumn{4}{|l|}{ Flow/ } & \multicolumn{2}{|l|}{ Sample } & \multicolumn{2}{|l|}{ Sample } \\
\hline Site & ID & $\mathbf{X}_{\text {usp }}$ & $\mathbf{T}_{\mathrm{c}}\left({ }^{\circ} \mathbf{C}\right)$ & VFTB & $\mathbf{T}_{\mathrm{c}}\left({ }^{\circ} \mathbf{C}\right)$ & Kappa & $\mathbf{T}_{\mathrm{c}}\left({ }^{\circ} \mathbf{C}\right)$ \\
\hline WE03 & WEH13-1A1 & $0.4-0.52$ & $230-330$ & WEH13-01A1 & 250,313 & WEH13-01A3 & $230,370,540$ \\
\hline WE02 & WEH10-2C1 & $0.31-0.5$ & $230-380$ & WEH10-2C1 & 578 & WEH10-2C1 & $350-550$ \\
\hline WE04 & WE18A & $0.33-0.53$ & $230-380$ & WE16A1 & 261,602 & WE15A5 & $210,460,540$ \\
\hline WPA01 & WPA09A & $0.34-0.39$ & $330-350$ & WPA7A3 & 536 & WPA7A2 & 520 \\
\hline WPA02 & WPA13A & $0.34-0.36$ & 380 & WPA11A3 & 565 & WPA11A2 & 508,540 \\
\hline WPA03 & WPA20A & $0.22-0.34$ & $380-450$ & WPA23A1 & 405,535 & & \\
\hline DC03 & DC17A & $0.38-0.58$ & $150-320$ & & & DC17A1 & 250,570 \\
\hline DC04 & DC25 & $0.19-0.43$ & $330-450$ & DC23A4 & 563 & $\mathrm{DC} 23 \mathrm{~A} 2$ & 570 \\
\hline TF01 & TF03A & $0.34-0.49$ & $230-370$ & TF04D-1 & 391,545 & TF08A & $302,377,486$ \\
\hline RP02 & RP18C & $0.33-0.43$ & $310-380$ & RP19A-2 & 261,391 & RP19A-1 & 214,305 \\
\hline
\end{tabular}

Table 4-3: Thermomagnetic curve characteristics as defined in chapter 3.

\begin{tabular}{lll}
\hline Type & $\begin{array}{l}\text { Zone of } \\
\text { flow }\end{array}$ & Characteristics \\
\hline 1 & N/A & $\begin{array}{l}\chi \text { vs.T curves show one phase and little alteration, while } \mathrm{M}_{\mathrm{s}} \text { vs.T curves show an } \\
\text { increase in } \mathrm{T}_{\mathrm{c}} \text { after heating, together with an increase in } \mathrm{M}_{\mathrm{s}} \text { after heating. }\end{array}$ \\
2 & $\mathrm{D}$ & $\begin{array}{l}\text { Characterised by multiple phases with different } \mathrm{T}_{\mathrm{c}} \text { 's }\left(\mathrm{P} 1: 150-250^{\circ} \mathrm{C}, \mathrm{P} 4:>\right. \\
\left.500^{\circ} \mathrm{C}\right) . \text { The curves are fully reversible. }\end{array}$ \\
3 & $\mathrm{~A}, \mathrm{C} \quad \begin{array}{l}\text { The heating curves show two or more phases with } \mathrm{T}_{\mathrm{c}} \text { 's between } 250 \text { and } 320^{\circ} \\
\mathrm{C}(\mathrm{P} 2) \text { and between } 320 \text { and } 450^{\circ} \mathrm{C}(\mathrm{P} 3) . \mathrm{T}^{\circ} \mathrm{T}_{\mathrm{c}} \text { 's change after heating, the } \mathrm{T}_{\mathrm{c}} \\
\text { shift is dependent on the peak temperature during an experiment. }\end{array}$ \\
4 & A, C $\quad \begin{array}{l}\left.\text { Some curves have only one } \mathrm{T}_{\mathrm{c}} \text { upon heating }\left(\mathrm{P} 4:>500^{\circ} \mathrm{C}\right), \text { but two } \mathrm{T}_{\mathrm{c}} \text { 's (P3, } \mathrm{P} 4\right) \\
\text { during cooling. }\end{array}$ \\
5 & $\mathrm{~B}$ & $\begin{array}{l}\text { Characterised by a single phase of high } \mathrm{T}_{\mathrm{c}}(\mathrm{P} 4), \text { the heating and cooling curves } \\
\text { are near reversible. }\end{array}$ \\
\hline
\end{tabular}




\subsection{Palaeointensity methods}

Palaeointensity experiments were carried out on a broad range of sites with a variety of rock magnetic properties, using both thermal and microwave palaeointensity procedures and applying Coe (Coe, 1967) and IZZI-type (Tauxe and Staudigel, 2004) protocols, as outlined in chapter 2. Adjusting the applied field near the actual palaeointensity can reduce the effect of experimental errors (Tanaka and Kono, 1984). We thus used a laboratory field of $30 \mu \mathrm{T}$ during the first suite of experiments, and a field of $50 \mu \mathrm{T}$ during later experiments, which spans the limits of intensity expected of the palaeomagnetic field at this latitude.

\subsubsection{Thermal palaeointensity method}

Up to 10 standard sized specimens per site were prepared for palaeointensity experimentation. Specimens were grouped according to their blocking temperature distribution and intensity experiments designed correspondingly. First palaeointensity experiments were carried out using the IZZI protocol and additional Coe-type experiments were conducted on specimens from sites that showed promising results during the first suite of experiments. All thermal experiments were accompanied by low field susceptibility checks using a Bartington MS2 in order to monitor mineral alteration. Thermal palaeointensity experiments were carried out using either a Magnetic Measurements Ltd. slow or fast cooling oven for thermal de- and remagnetization and measured using an AGICO JR6 Magnetometer at the University of Liverpool and an AGICO JR6A at Victoria University of Wellington. Prior to commencing the in-field steps, a profile of the total field strength along the oven was measured using a fluxgate magnetometer. The samples were placed within the most uniform (field variation max. 1\%) area within the centre of the oven and at each step held for 30 minutes at their respective temperature. The cooling times from temperatures between 300 and $600^{\circ} \mathrm{C}$ to near room temperature were approximately 30 minutes in the fast cooling, and up to two hours in the slow cooling oven. Sample orientation in the laboratory field can affect the outcome of pTRM tail checks and the palaeointensity result, if the samples suffer from strong remanence anisotropy. For 
instance, application of the field applied at a high angle to the NRM direction during infield steps enhances the effect of pTRM tails (Yu et al., 2004), while application of the laboratory field parallel to the NRM direction minimizes effects of magnetic anisotropy (e.g. Selkin et al., 2000). Because the laboratory set-up used for the thermal experiments only allowed specimens to be placed in the oven with the laboratory field applied along the core-axis, the specimens were placed in the oven so that, alternating between specimens, the field was applied either parallel or antiparallel to the z-axis. Alternating between specimens in this way we aimed to record either effect. Additionally, some palaeointensity experiments were aborted when the onset of thermal alteration became apparent from the susceptibility measurements.

\subsubsection{Microwave palaeointensity method}

Microwave palaeointensity experiments were carried out using the $14.5 \mathrm{GhZ}$ system at the University of Liverpool, described in detail in chapter 2. The technique uses ferromagnetic resonance (FMR) to excite the magnetic moments of the grains rather than heating the bulk sample but otherwise follows similar experimental procedures as the thermal experiments. For comparison, microwave experiments were carried out using similar protocols and, where possible, on specimens from the same samples of those used for thermal experiments. Sample size and positioning within the cavity varied slightly and the exact frequency (range 14-14.5 GhZ) was fine-tuned prior to each experiment in order to achieve maximum absorption rates. The parameter affecting the demagnetisation level is the total energy absorbed by a sample, which is

a function of the power and exposure time of microwaves. Slight variation of the energy absorption can be caused by movement of a sample within the cavity and/or mineral alteration. Repeatability of individual steps is a prerequisite for both Coe and IZZI type protocols and we rejected steps where the absorption varied by more than $10 \%$ from the first step at a given power level. The applied power was usually increased from a starting value of $10 \mathrm{~W}$ in steps of $2-5 \mathrm{~W}$, using an exposure time of $5 \mathrm{~s}$. If samples required further treatment after reaching $30 \mathrm{~W}$, we usually increased 
the exposure time. Previous microwave studies (e.g. Stark, 2011) have shown that this approach minimizes dielectric heating of the samples.

In contrast to the thermal experiments, microwave experiments were conducted on one specimen at a time, which enabled us to adjust the power steps according to the behaviour of the individual specimens. Prior to each intensity experiment we conducted a rapid demagnetisation experiment on each sample to design suitable power steps and eliminate samples that showed strong overprinting.

\subsubsection{Selection criteria and calculation of flow mean palaeointensities}

Palaeointensity selection criteria are applied to data in order to ensure that only high quality and reliable palaeointensity results are accepted. All palaeointensity data in this study were analysed using ThellierTool v4.22 (Leonhardt et al., 2004a) which outputs the most commonly used statistical parameters that quantify the quality of the slope fit within the Arai-plot as well as pTRM- and tail checks.

A range of different statistical parameters, combinations of these and values have been proposed in the past (e.g. Biggin et al., 2007; Kissel and Laj, 2004; Leonhardt et al., 2004a) and modified in later studies. In a recent effort to produce objective sets of criteria that effectively maximize the number of accurate results accepted and erroneous results rejected, Paterson et al. (2014) tested the most popular sets of selection criteria. Amongst the criteria sets examined in their study were ThellierTool software's internal default criteria TTA and TTB (Leonhardt et al., 2004a), where TTB is the less stringent. Paterson et al. (2014) found both criteria sets effective but suggested slight modifications, which have been adopted in this thesis and are referred to as $\mathrm{TTA}^{*}$ and $\mathrm{TTB}^{*}$ and are summarized below:

1) The zero-field remanence measurement should show straight line decay to the origin, the anchored fit $(\alpha)$ describe an angle no larger than $15^{\circ}$ with the free floating fit and yield a maximum angular deviation $\left(\mathrm{MAD}_{\mathrm{anc}}\right)$ smaller than $6^{\circ}$ or $15^{\circ}$ to pass $\mathrm{TTA}^{*}$ and $\mathrm{TTB}^{*}$, respectively. 
2) Palaeointensity estimates should be calculated from at least 5 data points and include at least $35 \%$ of the total NRM ( $\mathrm{f} \geq 0.35$ ).

3) The quality of the slope fit in the Arai-diagram $(\beta)$ is quantified using the standard error of the slope normalized by the absolute value of the slope. $\beta \leq$ 0.1 to pass TTA* and $\beta \leq 0.15$ to pass TTB*. Further we calculated the overall quality factor $q=f g \beta^{-1}$ where $\mathrm{g}$ is the gap between any two data points. $\mathrm{q} \geq 5$ to pass $\mathrm{TTA}^{*}$ and $\mathrm{q} \geq 0$ to pass $\mathrm{TTB}^{*}$

4) The maximum absolute difference produced by a pTRM check is calculated by vector subtraction and divided by the total $\mathrm{TRM}, \mathrm{dCK} \leq 7 \%$ and $\mathrm{dCK} \leq 9 \%$ to pass TTA* and TTB*, respectively. The cumulative pTRM check failure (dpal) is quantified from the difference between the slope of an uncorrected palaeointensity estimate and the slope, corrected by the added effect of the alteration (see Valet et al., 1996), normalized by the uncorrected slope: $\mathrm{dpal}=100 \frac{b-b *}{\mathrm{~b}}$ where $\mathrm{b}$ is the uncorrected and $\mathrm{b} *$ the corrected slope. dpal $\leq 10 \%\left(\right.$ TTA $\left.^{*}\right)$, dpal $\leq 18 \%\left(\mathrm{TTB}^{*}\right)$.

5) Tail checks are quantified using the maximum difference between a zero-field and a following tail check, normalized by the NRM, dTR $\leq 10 \%$ (TTA*), $20 \%$ (TTB*), and $\mathrm{dt}^{*}$, which accommodates the directional dependence of the pTRM tail (Leonhardt et al., 2004b), dt* $\leq 9 \%$ (TTA*), dt* $\leq 99 \%$ (TTB*).

Flow mean palaeointensities were averaged from all successful results, unless we identified systematic inter-site differences (e.g. see section 4.6.2, Whangaehu flow). Sample orientation is not crucial, so in contrast to the analysis on directional results in chapter 3 we did not calculate individual sample or site means. 


\subsection{Palaeointensity results}

Successful palaeointensity results were obtained on samples from six flows. The behaviour and success rates of individual specimens during the palaeointensity experiments varied from site to site in accordance with the differences observed between the rock magnetic properties. The palaeointensity and rock magnetic results are thus treated flow by flow. In section 4.4 we identified a dependence of the rock magnetic behaviour on the vertical location or zone within the thickness of the lava flows. All palaeointensity experiments are thus displayed in comparison to the thermomagnetic curves measured on samples from the same sites and displayed with their respective zones within the flows. For the hysteresis properties please refer to Figure 4-7. The accompanying susceptibility checks performed throughout the palaeointensity experiments usually showed a sudden increase or decrease in susceptibility at the onset point of thermal alteration $\left(\sim 400^{\circ} \mathrm{C}\right)$. This point usually coincided with the failure of the pTRM checks, and the susceptibility data are therefore not displayed. All susceptibility data can be found in the electronic appendices. Table 4-4 details all successful palaeointensity experiments, together with the statistics of tail and pTRM checks, where applicable.

\subsubsection{Central Crater flow (CC)}

Central Crater flow differs in its morphology and exposure from the thick andesitic flows of Mt Ruapehu described below and was sampled from the flow top only (chapter 3). Specimens from this flow are with NRM intensities around $10 \mathrm{~A} / \mathrm{m}$ more strongly magnetized than all other flows and display type 1 thermomagnetic curves, which is unique to this flow. On the other hand other rock magnetic parameters show similarities with other Ruapehu flows, suggesting a similar remanence carrier: The IRM acquisition curves saturate at applied fields below $300 \mathrm{mT}$ and the hysteresis parameters point to, on average PSD sized grains with coercivities ranging from 10 to $25 \mathrm{mT}$.

Palaeointensity experiments were carried out with a laboratory field of $50 \mu \mathrm{T}$, on samples from sites $\mathrm{CC} 02, \mathrm{CC} 03, \mathrm{CC} 04$ and $\mathrm{CC} 05$, which showed single component 
remanences during THD (chapter 3) and reliable ChRM directions. Microwave palaeointensity experiments were carried out on samples from all four sites, and thermal Thellier-type palaeointensity experiments on sites CC02 and CC03. The zerofield remanence measured on all specimens exhibit straight line decay to the origin and most samples also exhibit a linear relationship between the NRMs and pTRMs measured with excellent pTRM and tail checks (Figure 4-10, Table 4-4). Microwave experiments yield overall lower quality results than the thermal experiments, however inconsistency can often be directly linked to differences in the energy absorbed by the samples in the microwave cavity during zero-field and infield steps. For instance the results of sample CC38-1 only pass $\mathrm{TTB}^{*}$ prior to removal of all data from nonrepeatable power steps, subsequently these results pass the more stringent TTA* (Figure 4-10e).

One intriguing microwave result was obtained from site $\mathrm{CC} 02$ (CC12A2, Coe protocol). Despite obeying ideal linearity and passing both tail and pTRM checks, the Arai plot for this sample yields approximately $20 \%$ higher palaeointensity than the results obtained from sister samples using both the thermal (e.g. CC13B, CC13C) and microwave (e.g. CC12A1) palaeointensity method (Figure 4-10b, c). The results show that even the highest quality results can yield significant different palaeointensities. Our best mean palaeointensity results, calculated by averaging all results that pass at least the selection criteria $\mathrm{TTB}^{*}$, is $70.6 \pm 4.1 \mu \mathrm{T}(\mathrm{N}=6)$. 

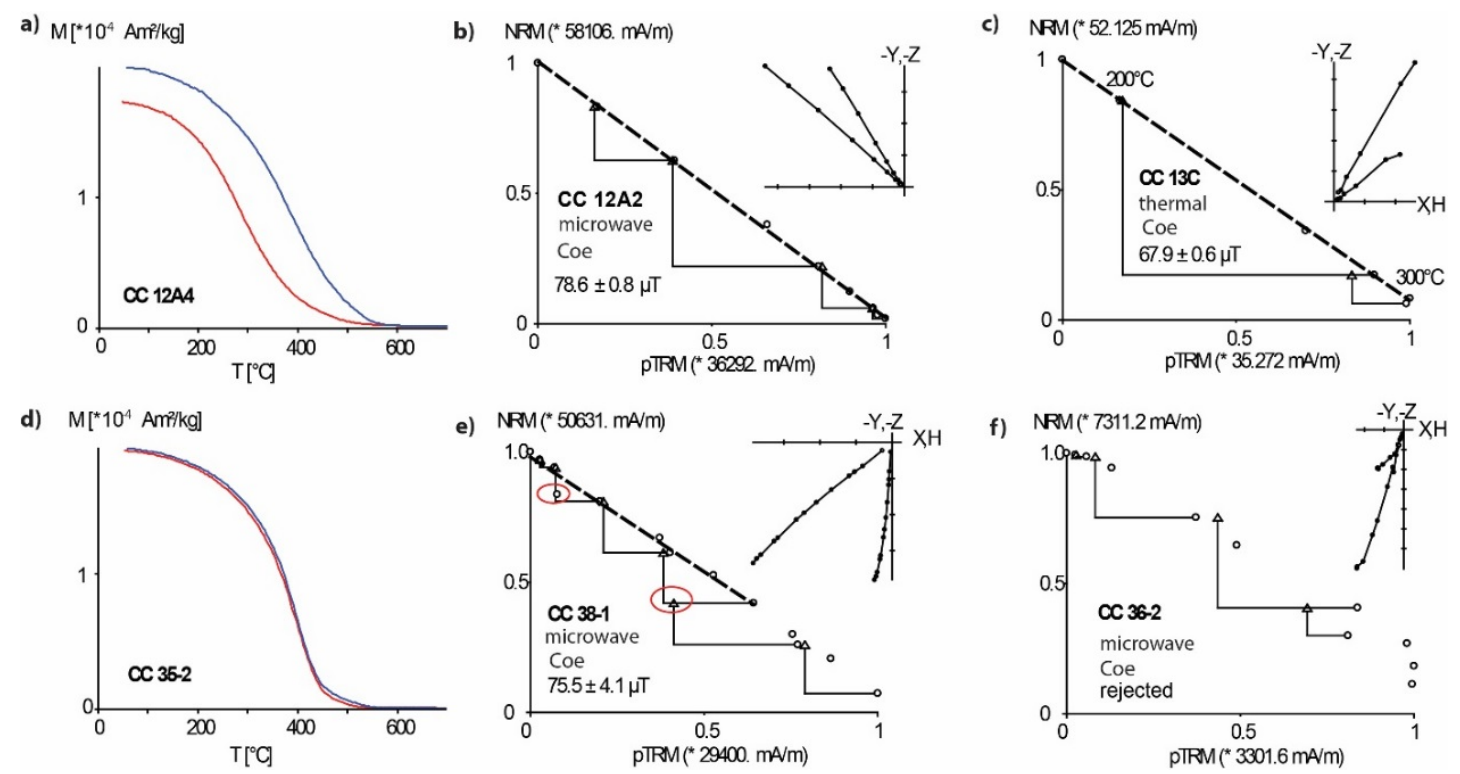

Figure 4-10: Representative rock magnetic and palaeointensity results, CC flow. a,d) Thermomagnetic curves measured on specimens from site $\mathrm{CC} 02$ and $\mathrm{CC} 05, \mathrm{~b}, \mathrm{c}, \mathrm{e}, \mathrm{f}$ ) Coe-type microwave and thermal palaeointensity results from the respective sites as indicated. Displayed are the Arai diagrams, including all pTRM checks and corresponding vector component plots (inset). In (e) we mark pTRM checks where failure was most probably associated to inconsistencies in the absorption of microwave energy during repeated treatment steps.

\subsubsection{Whangaehu flow (WE)}

The rockmagnetic behaviour observed on Whangaehu lava flow depends strongly on the location throughout the flow sampled (section 4.4.5). Flow interior (zone A, B, C) samples have higher coercivities $\left(10<\mathrm{B}_{\mathrm{c}}<15 \mathrm{mT}\right)$ and Curie temperatures (e.g. type $3,4,5$ thermomagnetic curves) than samples from the flow tops (zone $\mathrm{D} ; \mathrm{B}_{\mathrm{c}} \sim 5 \mathrm{mT}$, type 2).

Microwave palaeointensity experiments were conducted on a broad range of sample material from throughout the flow, while thermal experiments were focussed on hand samples taken from the flow top (zone D) and flow centre (zone B). All palaeointensity experiments were carried out with a laboratory field of $50 \mu \mathrm{T}$.

The rock magnetic differences reflect on the palaeointensity results from various sites. We expected higher success rates from the flow centre (zone B) samples, for which 
the higher coercivities suggested higher resilience against viscous remanences and the thermomagnetic curves indicated thermal stability. However, the contrary was the case. Most thermal and microwave palaeointensity results on zone B samples were unsuccessful, evident from strong zigzagging in the Arai plot about a median line during IZZI-type experiments, and associated with a concave shape and pTRM check failure (Figure 4-11i). Zones $\mathrm{A}$ and $\mathrm{C}$ and $\mathrm{D}$ gave higher success rates, where six out of eight experiments pass either TTA* or TTB* (Figure 4-11e, f). However, the palaeointensity estimate calculated from a flow top sample differs significantly from the palaeointensity results from all flow interior samples (zones A, B, C). The palaeointensity estimates from successful thermal and microwave experiments from zone D range from 51 to $55 \mu \mathrm{T}$ (mean: $54.4 \pm 1.9 \mu \mathrm{T}(\mathrm{N}=3)$, Figure $4-11 \mathrm{~b}, \mathrm{c})$ and are approximately $20 \%$ lower than the estimates made on samples from the flow interior (mean: $63.6 \pm 3.0 \mu \mathrm{T}(\mathrm{N}=5)$ ). There is experimental evidence that the correct palaeointensity result lies somewhere between the highest and the lowest palaeointensity result obtained (e.g. Biggin et al., 2007). We thus present our best estimate as the mean of the two averages (flow interior zones A-C, and the zone D average), and provide an uncertainty that encompasses the mean and standard deviation of the two extremes, giving: $59.6 \pm 7.0 \mu \mathrm{T}(\mathrm{N}=8)$. 

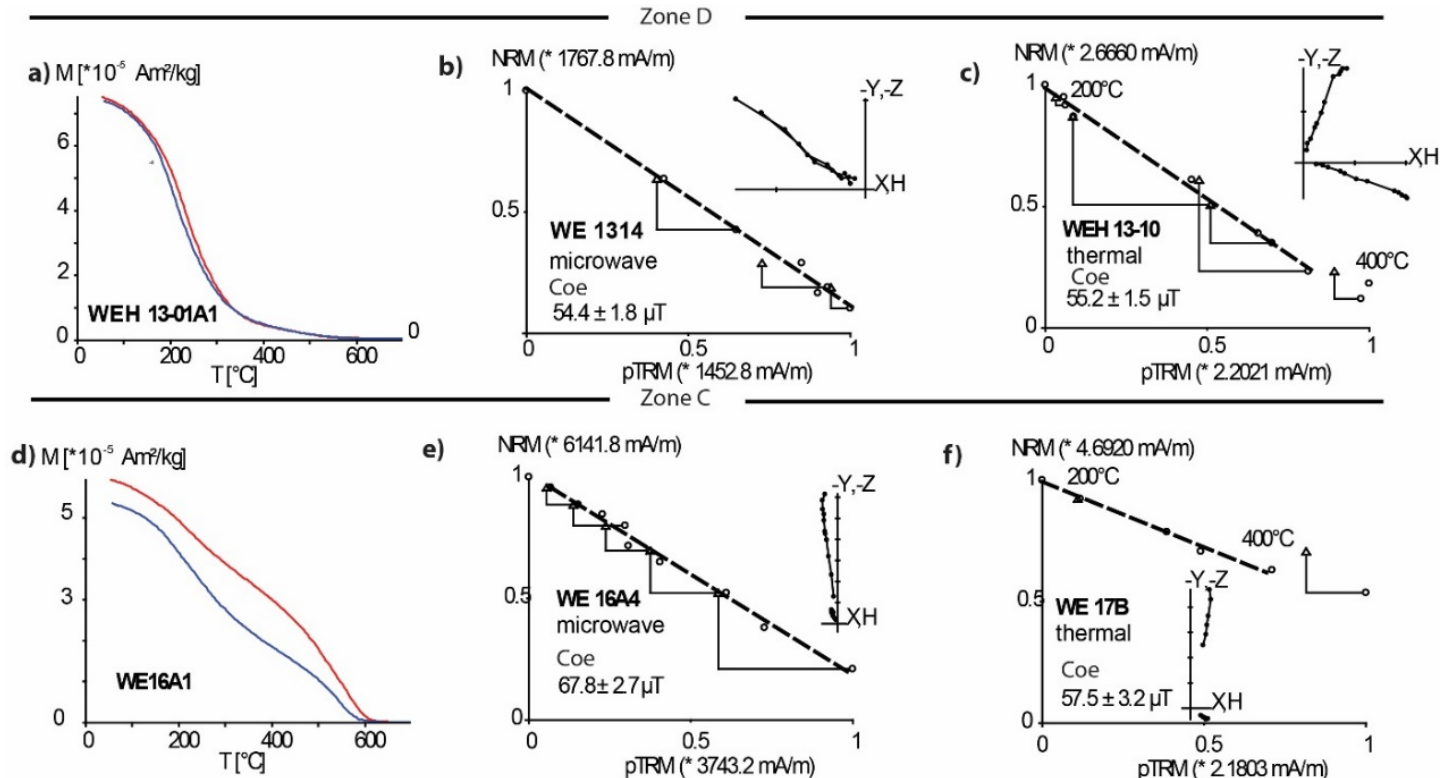

e)

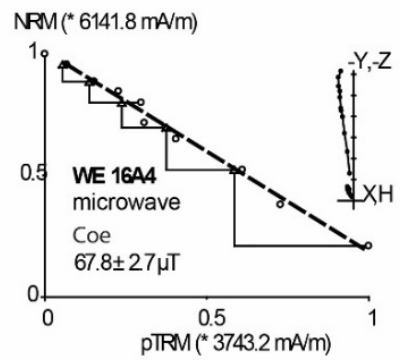

f) $\quad \mathrm{NPM}(* 4.6920 \mathrm{~mA} / \mathrm{m})$
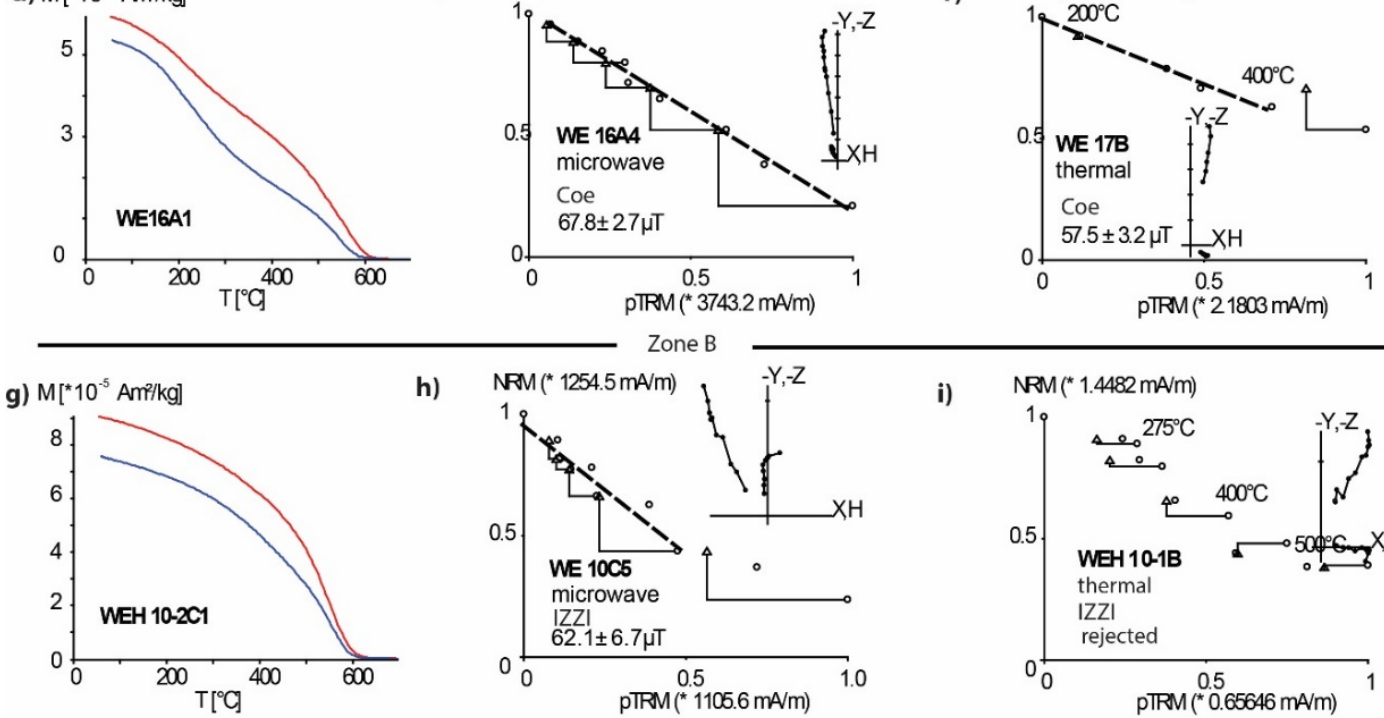

h)

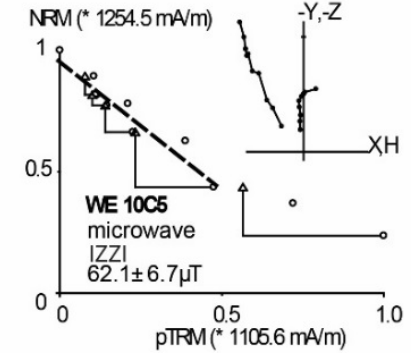

i)

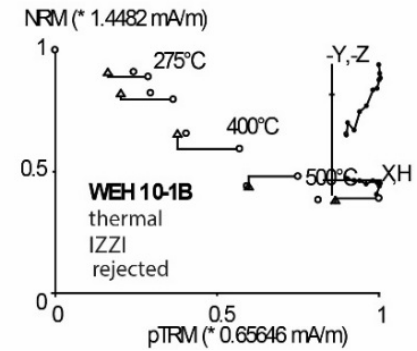

Figure 4-11: Representative thermomagnetic and palaeointensity results, WE flow, from various zones. Included are the results from thermal and microwave palaeointensity experiments and the IZZI and Coe type protocols, as indicated. See text for details.

\subsubsection{Delta Corner flow (DC)}

The rock magnetic behaviour of samples throughout the thickness of Delta Corner flow resembles those described for Whangaehu flow. All samples were taken from zones A-C, hysteresis loops exhibit dimensions typical for PSD grain sizes $\left(\mathrm{B}_{\mathrm{c}} \sim 10\right.$ $\mathrm{mT}$ ) and the thermomagnetic curves exhibit type 3 or 5 behaviour. Six thermal and four microwave experiments were carried out using either the IZZI or Coe type protocol. During THD experiments (chapter 3) we noted an antipodal directional component in the $\mathrm{T}_{\mathrm{b}}$ range $200-250^{\circ} \mathrm{C}$. This component manifests itself also during thermal palaeointensity experiments, and a relationship between the NRM lost and the pTRM obtained cannot be established (Figure 4-12b). Although the antipodal component was not detected during microwave experiments, a clear relationship 
between NRM and pTRM could not be defined during the latter experiments either (Figure 4-12c). Given the narrow $\mathrm{T}_{\mathrm{b}}$ range affected, this outcome may reflect differences in the microwave and thermal unblocking spectra.
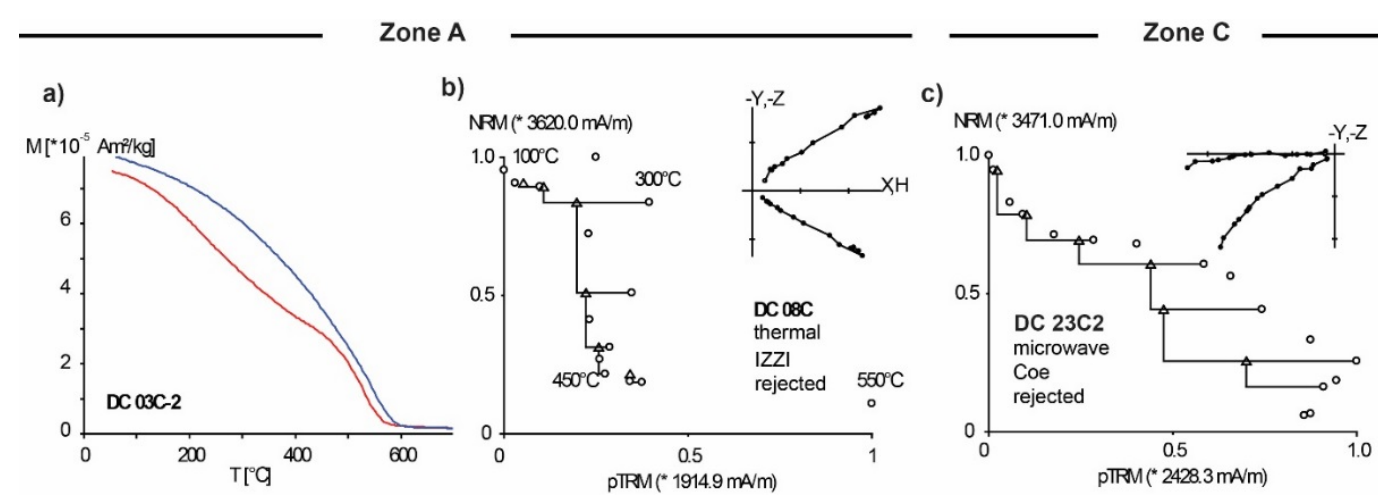

Figure 4-12: Representative rock magnetic and palaeointensity results, DC flow. See text for details.

\subsubsection{Bruce Road flow (RP)}

Intensity experiments on Bruce Road (RP) lava flow were conducted on samples from site RP02 only, which showed single component remanences during prior THD experiments (chapter 3). All samples at this site were taken from the flow interior (zone C) and exhibit typical type 3 thermomagnetic curves with two distinctive compositional phases (P2, P4) (Figure 4-13a) that show no alteration until heating cycles exceed $350^{\circ} \mathrm{C}$. Hysteresis loops yield coercivities around $10 \mathrm{mT}$.

Thermal and microwave palaeointensity experiments were carried out with a laboratory field of $30 \mu \mathrm{T}$. The behaviour of individual samples during thermal and microwave experiments is remarkably similar. Like the observations made during THD experiments (chapter 3), during zero-field steps the remanence decays in two distinct temperature ranges or microwave treatment intervals (Figure 4-13b,d). This is consistent with the thermomagnetic behaviour and we thus attribute the two demagnetisation stages to the two phases, $\mathrm{P} 2$ and $\mathrm{P} 4$.

Each phase carries approximately $50 \%$ of the total remanence. In both the thermal and microwave applications, the pTRM checks fail at the saddle point between the demagnetisation of P2 and P4 (Figure 4-13b, c). During heating experiments, this point also marks the onset temperature of thermo-chemical alteration $\left(\mathrm{T} \sim 350^{\circ} \mathrm{C}\right)$, evident 
also in the accompanying susceptibility checks. All palaeointensity results yield a stable relation between NRM and pTRM within the $\mathrm{T}_{\mathrm{b}}$ range $\mathrm{NRM}$ to $350^{\circ} \mathrm{C}$ and 6 out of 11 specimens pass the most stringent criteria set TTA* (Table 4-4). Our best mean intensity, including all accepted data averages to $51.2 \pm 3.5 \mu \mathrm{T}(\mathrm{N}=9)$.
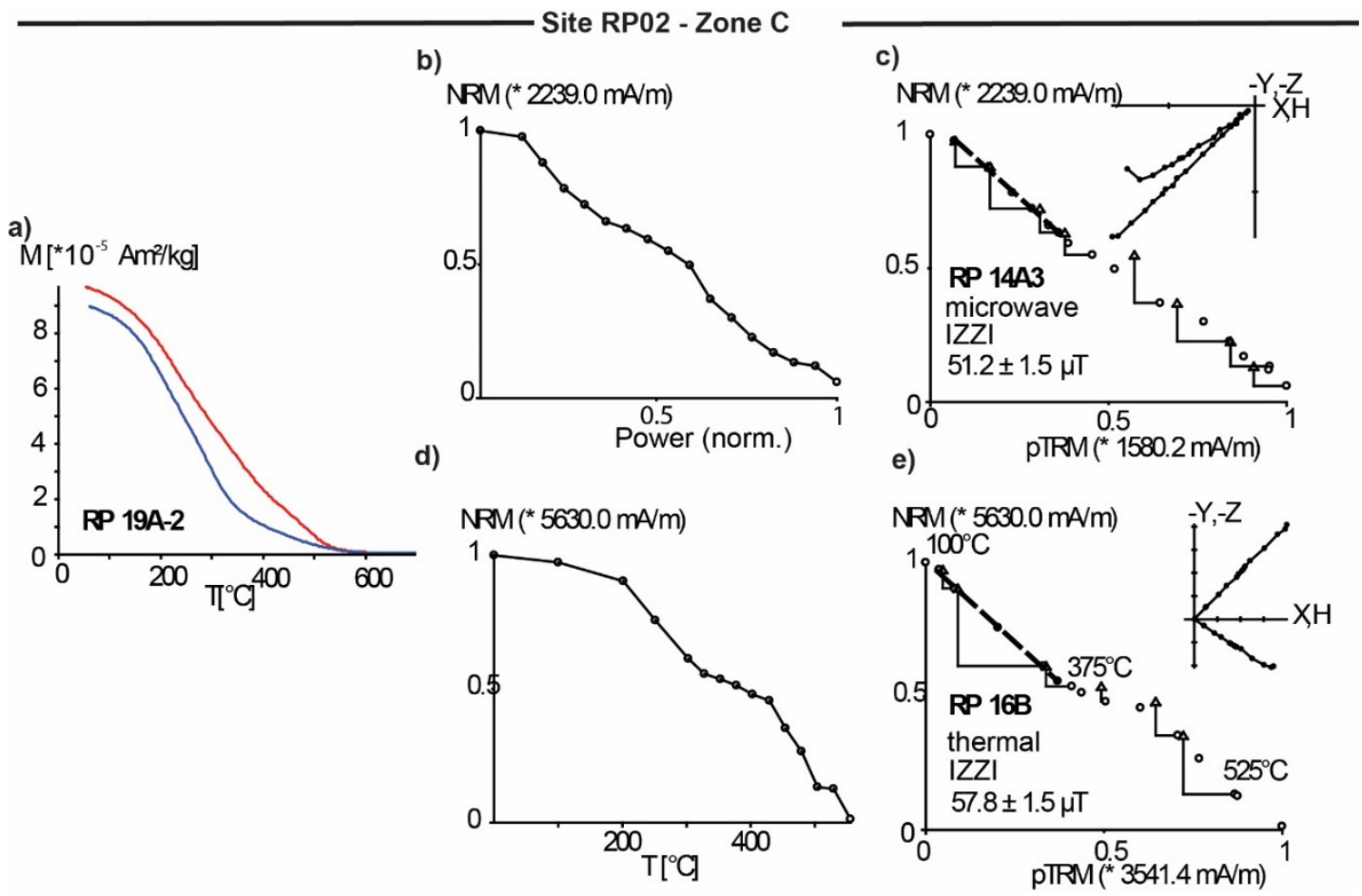

Figure 4-13: Representative rock magnetic and palaeointensity results, RP flow a) Thermomagnetic $\left(\mathrm{M}_{\mathrm{s}}\right.$ vs. $\left.\mathrm{T}\right)$ curve, zero-field remanence diagrams, Arai and Zijderveld plots from b,c) microwave palaeointensity and d,e) thermal palaeointensity experiment. 


\subsubsection{Taranaki Falls flow (TF)}

All samples from Taranaki Falls (TF) flow are from zones B or C and yield typical type 3 or 4 thermomagnetic curves such as observed at Whangaehu and Bruce Road flows (e.g Figure 4-14a). In contrast, the hysteresis curves are narrower $(\mathrm{Bc}<8 \mathrm{mT})$.

Thermal and a small number of microwave palaeointensity experiments were carried out, using a laboratory field of $30 \mu \mathrm{T}$. The overall success rate is with 8 out of 15 results that meet either $\mathrm{TTA}^{*}$ or TTB* criteria lower, but all successful palaeointensity results strongly resemble those of Bruce Road flow: zero-field remanence measurements show two distinctive $T_{b}$ ranges (not displayed in Figure 4-14). The lower $\mathrm{T}_{\mathrm{b}}$ range carries between 45 and $53 \%$ of the total remanence. Thermal alteration results in failure of the experiment at intermediate demagnetisation/ treatment levels (Figure 4-14 b,c). The rejected palaeointensity results are characterised by strong zigzagging of the remanence intensity during IZZI-type experiments and the zero-field direction deviates into the direction of the laboratory field used during infield steps (Figure 4-14d,e). Such a bias results when $T_{u b}>T_{b}$, and the sample retains a small remanence in the field direction. This can be caused either by a lack of symmetry in domain wall movement between zero- and infield steps, and therefore be indicative for the presence of MD grains (e.g. Levi, 1977) or it may result when a low $\mathrm{T}_{\mathrm{b}}$ phase alters into a phase of higher blocking temperature. The presence of MD grains is justified by the low coercivities measured on Taranaki Falls (TF) samples. Palaeointensity values from experiments that pass the most stringent selection criteria (TTA*) are within $3 \mu \mathrm{T}$ of each other and fall within our best mean and its uncertainty: $37.0 \pm 5.7 \mu \mathrm{T}(\mathrm{N}=8)$, which was calculated including the lower quality results, passing $\mathrm{TTB}^{*}$ criteria. 

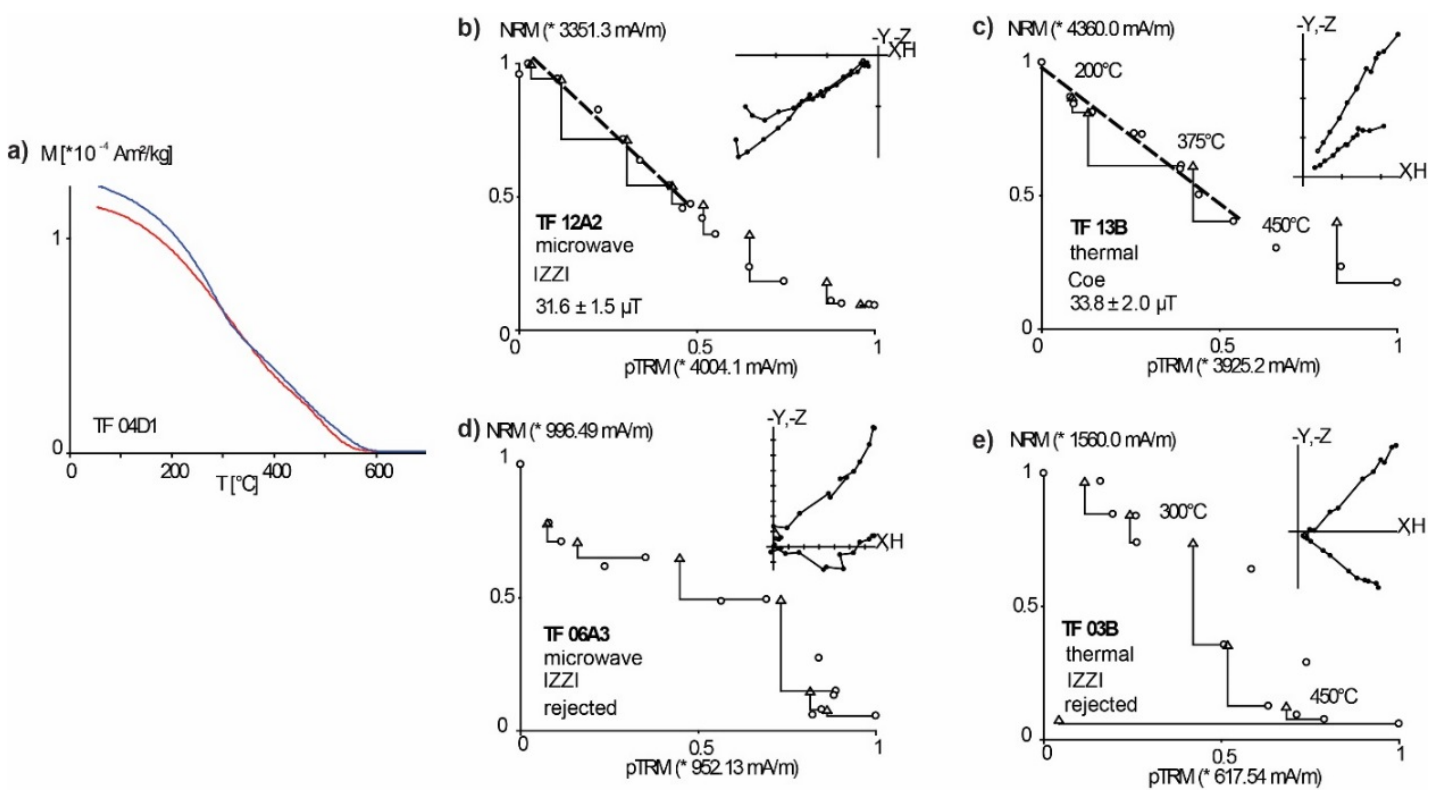

Figure 4-14: Representative rock magnetic and palaeointensity results from TF flow. a) Thermomagnetic curve $\left(\mathrm{M}_{\mathrm{s}}-\mathrm{T}\right)$ and $\mathrm{b}$-e) successful and rejected palaeointensity results using the thermal and microwave methods, respectively.

\subsubsection{Mangaturuturu flow (MT)}

Although Mangaturuturu flow was sampled at one site within the platey flow centre (zone B) only, the thermomagnetic behaviour varied considerably between individual samples. All $\mathrm{M}_{\mathrm{s}}$ vs. T curves are irreversible and can be roughly classified as type 3 or 4 (e.g. Figure 4-15a, Figure 4-16a, c). To accommodate the difference in the rock magnetic behaviour, microwave and thermal palaeointensity experiments were carried out on a broad range of sample material using a $50 \mu \mathrm{T}$ laboratory field. Most samples show viscous overprints that justify exclusion of low power or temperature steps. Experimental failure was either caused by non-linearity of the relation between NRM and pTRM displayed in the Arai plot (e.g. Figure 4-16c), or a deflection of the remanence direction from the origin (e.g. Figure 4-16b). Five out of nine microwave and four out of eight thermal palaeointensity experiments pass either set of selection criteria (Table 4-4), giving a mean of $40.8 \pm 4.0 \mu \mathrm{T}(\mathrm{N}=9)$. 
a) $\mathrm{M}\left[{ }^{*} 10^{-4} \mathrm{Am} / \mathrm{kg}\right]$

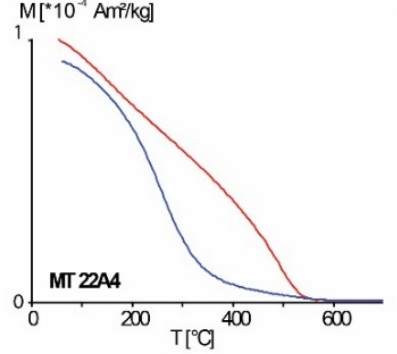

b)

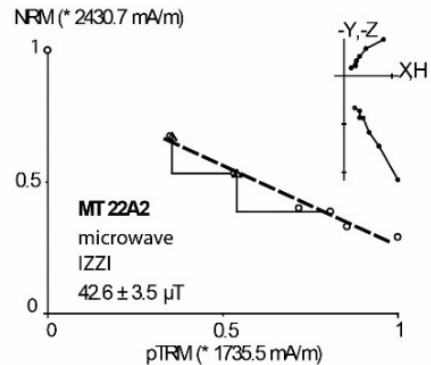

c) $\mathrm{NPM}\left({ }^{\star} 2.5640 \mathrm{~mA} / \mathrm{m}\right)$

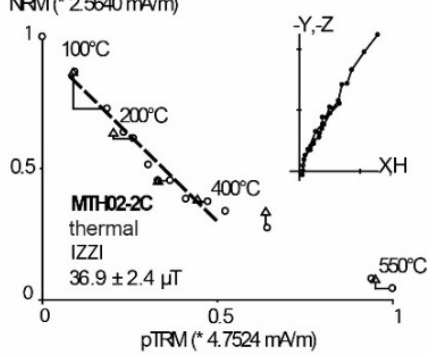

Figure 4-15: Representative rock magnetic and palaeointensity results, MT flow. a) Thermomagnetic curve, b) successful microwave and c) thermal palaeointensity results, measured on sister samples.
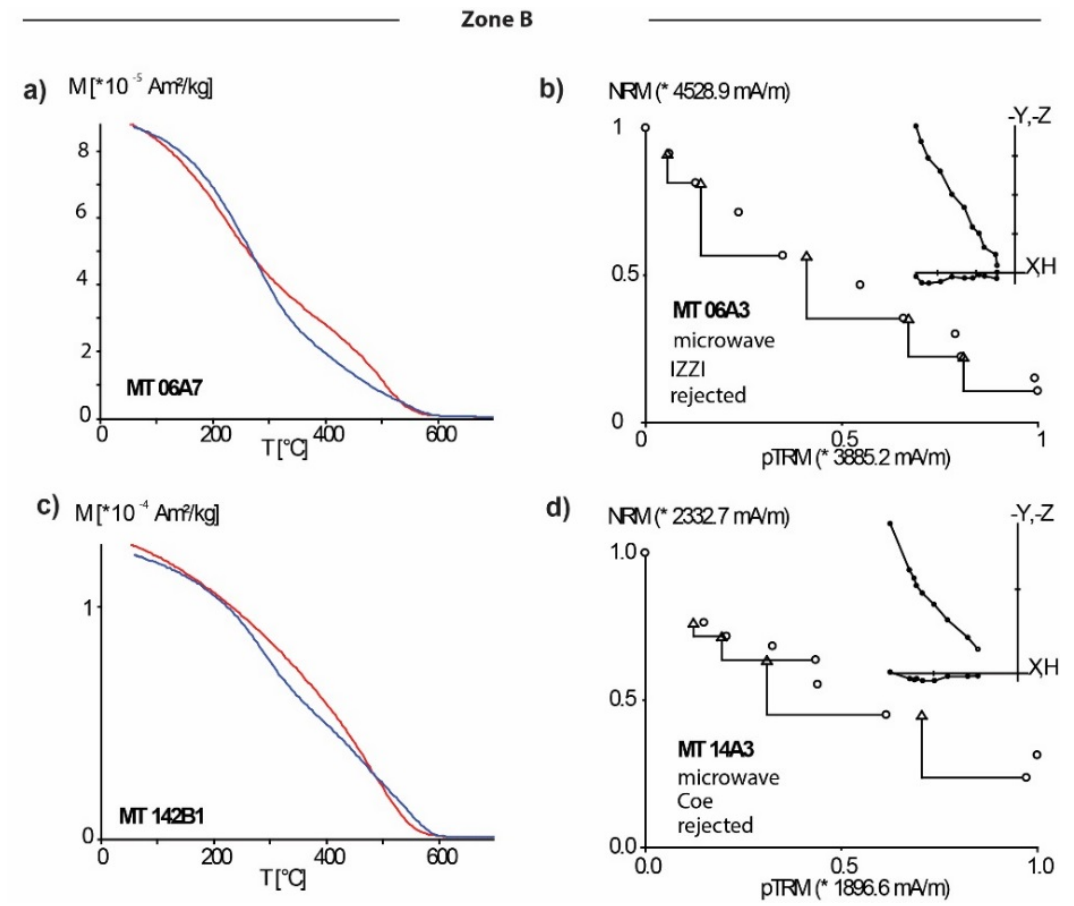

Figure 4-16: Representative thermomagnetic curves and rejected microwave palaeointensity results, MT flow. See text for details. 


\subsubsection{Whakapapaiti A flow (WPA) and Skyline Ridge flow (GR)}

As discussed in section 4.4.3, signs of mineral alteration were found in samples from both Whakapapaiti A and Skyline Ridge flows during petrographic imaging. This observation may explain distinctive CRM overprints identified during the THD experiments presented in chapter 3. Palaeointensity experiments require samples to carry un-altered primary remanences, and although a small number of microwave experiments were carried out on these flows, the results are not discussed any further (data: see appendices).

\subsubsection{Rangataua flows (RT)}

Samples were taken from at or near the flow top surface at six separate sites on this spatially extensive suite of flows. The rock and thermomagnetic properties for all sites are remarkably similar to those of flow top (zone D) samples at Whangaehu andesite (WE) lava flow: Hysteresis loops are narrow $\left(\mathrm{B}_{\mathrm{c}} \sim 8 \mathrm{mT}\right)$ and the thermomagnetic curves are classified as type 2 (Figure 4-17 a).

Microwave palaeointensity experiments were carried out on samples from sites RT01, RT05 and RT06, and thermal Thellier type experiments on hand samples from sites RT05 and RT06. Most samples carry a viscous overprint that is removed after the first treatment step. Because the magnetic remanence is primarily carried within the $\mathrm{T}_{\mathrm{b}}$ range $<320^{\circ}$, all palaeointensity experiments are completed prior to the usual onset of thermo-chemical alteration (Figure 4-17b ,c). However, some specimens were affected by strong viscous remanences, resulting in low quality results that did not meet the selection criteria. In chapter 3, we suggested that despite the rock magnetic similarities, site RT01 belonged to a lava flow that was emplaced separately from a flow containing sites RT02 and RT03. For the latter sites, we did not obtain successful palaeointensity data. The palaeointensity results from sites RT01, RT05, RT06 are statistically indistinguishable, allowing to calculate an average of $32.0 \pm 5.1 \mu \mathrm{T}(\mathrm{N}=8)$. 
a) $M\left[{ }^{*} 10^{-4} \mathrm{Am}^{2} / \mathrm{kg}\right]$

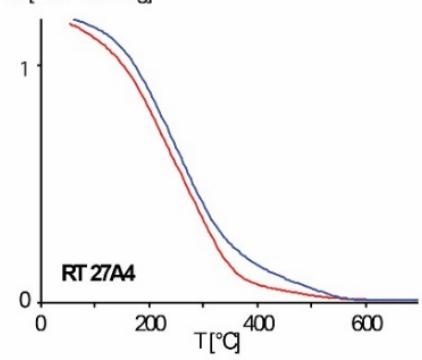

b) $\mathrm{NPM}(* 1771.5 \mathrm{~mA} / \mathrm{m})$

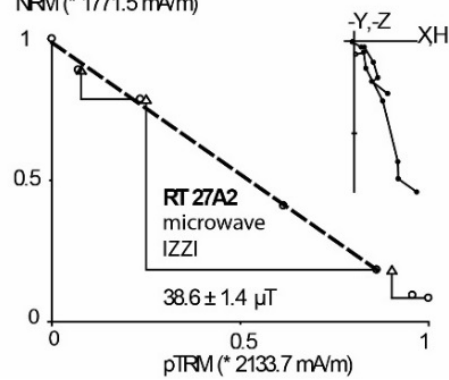

c) $\mathrm{NRM}\left({ }^{*} 3.3883 \mathrm{~mA} / \mathrm{m}\right)$

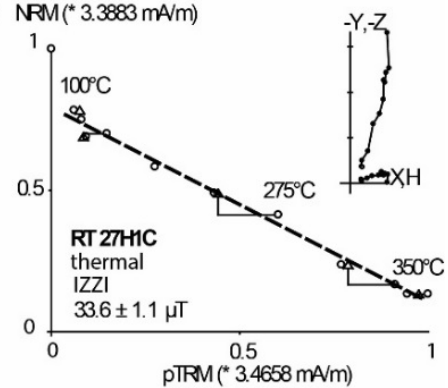

Figure 4-17: Representative rock magnetic and palaeointensity results, RT flow. 
Table 4-4: Accepted palaeointensity results from the TgVC. A summary of all palaeointensity experiments carried out is available in the appendices. The top two rows define the criteria sets used, which are based on Leonhardt's (2004a) criteria sets TTA and TTB, but include modifications suggested by Paterson et al. (2014). A small number of data are included that do not pass the stringent criteria sets, but for which failure can be attributed to known and acceptable sources (refer to notes below table).

\begin{tabular}{|c|c|c|c|c|c|c|c|c|c|c|c|c|c|c|c|c|c|c|}
\hline $\begin{array}{l}\text { Site } \\
\text { (Zone) }\end{array}$ & Spec. ID & Full ID & Type & Prot & Interv & $\mathbf{N}$ & f & $\beta$ & $\mathbf{q}$ & $\begin{array}{l}\text { MAD } \\
\left({ }^{\circ}\right)\end{array}$ & $\alpha\left(^{\circ}\right)$ & $\begin{array}{l}d C K \\
(\%)\end{array}$ & $\begin{array}{l}\text { dpal } \\
\text { (\%) }\end{array}$ & $\begin{array}{l}\text { dTR } \\
\text { (\%) }\end{array}$ & $\begin{array}{l}\mathrm{dt} \\
\text { (\%) }\end{array}$ & $\begin{array}{l}\text { Int } \\
(\mu T)\end{array}$ & $\sigma$ & $\begin{array}{l}\text { Sel/ } \\
(\mathbf{N} / \mathbf{n})\end{array}$ \\
\hline & & & & & & $\geq 5$ & $\geq 0.35$ & $\leq 0.1$ & $\geq 5$ & $\leq 6$ & $\leq 15$ & $\leq 7$ & $\leq 10$ & $\leq 10$ & $\leq 9$ & & & A \\
\hline & & & & & & $\geq 5$ & $\geq 0.35$ & $\leq 0.15$ & $\geq 0$ & $\leq 15$ & $\leq 15$ & $\leq 9$ & $\leq 18$ & $\leq 20$ & $\leq 99$ & & & B \\
\hline
\end{tabular}

Central Crater (CC) lava flow

\begin{tabular}{|c|c|c|c|c|c|c|c|c|c|c|c|c|c|c|c|c|c|c|}
\hline $\mathrm{CC} 02$ & $\mathrm{CC} 12 \mathrm{~A} 1$ & CC12A-1 & $\mathrm{M}$ & IZZI & $0-4$ & 5 & 0.49 & 0.03 & 13.3 & 1.3 & 1.70 & 1.5 & 8.53 & & & 71.4 & 1.8 & A \\
\hline $\mathrm{CC} 02$ & $\mathrm{CC} 12 \mathrm{~A} 2$ & $\mathrm{CC} 12 \mathrm{~A}-2$ & $\mathrm{M}$ & Coe & $0-8$ & 9 & 0.98 & 0.01 & 80.4 & 0.8 & 0.6 & 1.0 & 0.55 & 2.6 & 2.7 & 78.6 & 0.8 & A \\
\hline $\mathrm{CC} 02$ & CC13B & & $\mathrm{T}$ & Coe & $0-325$ & 6 & 0.88 & 0.02 & 44.7 & 1.5 & 10.7 & $16.0^{*}$ & $23.5^{*}$ & 2.3 & 3.5 & 69.6 & 1.0 & \\
\hline $\mathrm{CC} 02$ & $\mathrm{CC} 13 \mathrm{C}$ & & $\mathrm{T}$ & Coe & $0-300$ & 5 & 0.92 & 0.01 & 62.1 & 1.1 & 0.4 & 6.0 & 2.85 & 0.5 & 0.0 & 67.9 & 0.6 & B \\
\hline $\mathrm{CC} 02$ & CC14B & & $\mathrm{T}$ & Coe & $0-325$ & 6 & 0.80 & 0.02 & 40.5 & 1.6 & 8.4 & $11.6^{*}$ & $19.6^{*}$ & 0.5 & 5.2 & 69.9 & 1.0 & \\
\hline $\mathrm{CC} 05$ & CC38-1 & CC38-1 & $\mathrm{M}$ & Coe & $0-8$ & 9 & 0.57 & 0.05 & 8.8 & 1.1 & 3.0 & 1.9 & 0.89 & 1.9 & 35.9 & 75.5 & 4.1 & B \\
\hline
\end{tabular}

Whangaehu Andesite (WE) flow

\begin{tabular}{|c|c|c|c|c|c|c|c|c|c|c|c|c|c|c|c|c|c|c|}
\hline WE02 (B) & WE10C5 & WEH10-2C-5 & M & IZZI & $0-8$ & 9 & 0.55 & 0.11 & 4.2 & 3.3 & 3.8 & 3.3 & 7.17 & & & 62.1 & 6.7 & B \\
\hline WE04 (C) & WE16A3 & WE16A-3 & M & IZZI & $0-8$ & 7 & 0.74 & 0.02 & 23.3 & 1.2 & 4.9 & 5.7 & 2.90 & & & 61.2 & 1.3 & B \\
\hline WE04 (C) & WE16A4 & WE16A-4 & M & Coe & $1-10$ & 10 & 0.75 & 0.04 & 15.9 & 0.4 & 4.0 & 5.0 & $11.3^{*}$ & 4.1 & 2.6 & 67.8 & 2.7 & \\
\hline WE04 (C) & WE17B & WE17B & $\mathrm{T}$ & Coe & $0-400$ & 5 & 0.38 & 0.06 & 4.9 & 1.0 & 1.4 & $17.6^{*}$ & $35.16^{*}$ & 0.8 & 0 & 57.5 & 3.2 & \\
\hline WE05 (C) & WE20A4 & WE20A-4 & M & IZZI & $0-11$ & 12 & 0.81 & 0.02 & 32.9 & 1.6 & 5.3 & 7.1 & $24.6^{*}$ & & & 65.2 & 1.4 & \\
\hline
\end{tabular}




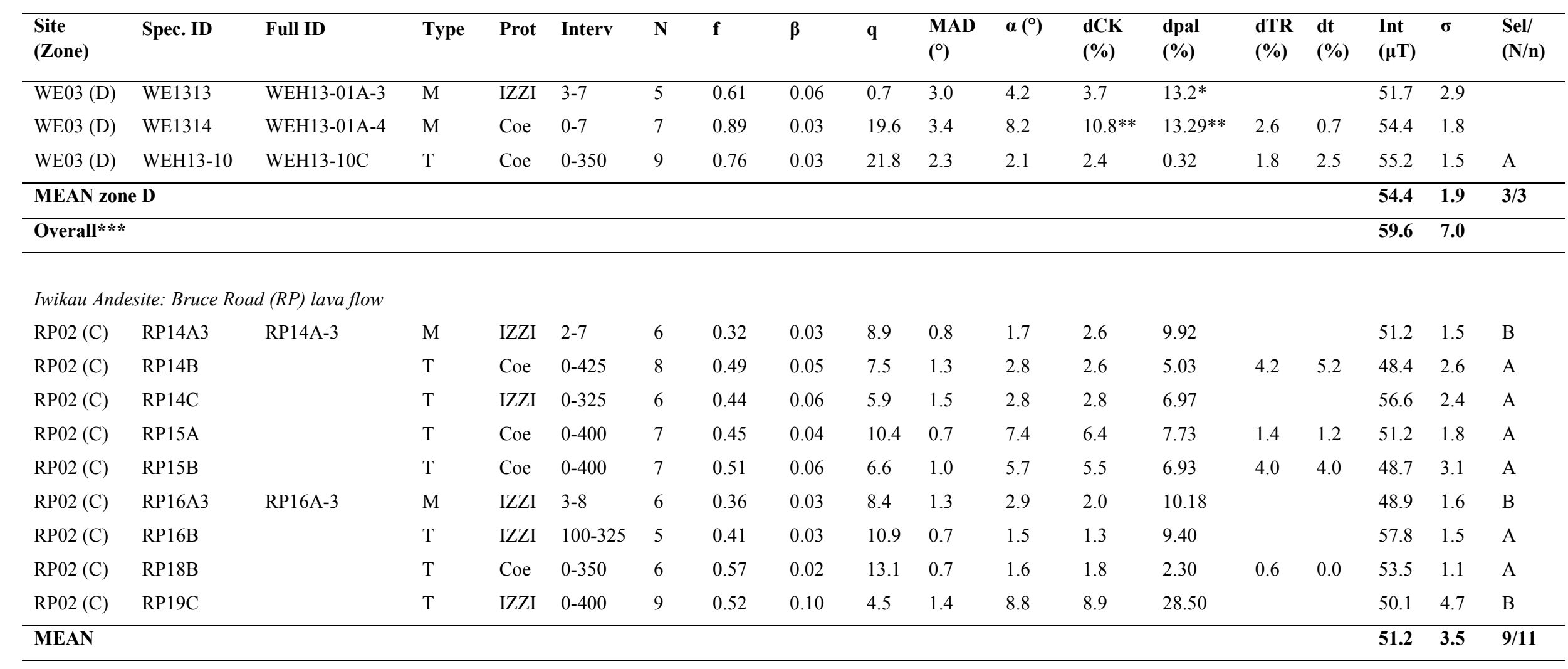




\begin{tabular}{|c|c|c|c|c|c|c|c|c|c|c|c|c|c|c|c|c|c|c|}
\hline $\begin{array}{l}\text { Site } \\
\text { (Zone) }\end{array}$ & Spec. ID & Full ID & Type & Prot & Interv & $\mathbf{N}$ & f & $\beta$ & $\mathbf{q}$ & $\begin{array}{l}\text { MAD } \\
\left({ }^{\circ}\right)\end{array}$ & $\alpha\left({ }^{\circ}\right)$ & $\begin{array}{l}d C K \\
(\%)\end{array}$ & $\begin{array}{l}\text { dpal } \\
(\%)\end{array}$ & $\begin{array}{l}\text { dTR } \\
(\%)\end{array}$ & $\begin{array}{l}\text { dt } \\
(\%)\end{array}$ & $\begin{array}{l}\text { Int } \\
(\mu T)\end{array}$ & $\sigma$ & $\begin{array}{l}\text { Sel/ } \\
(\mathbf{N} / \mathbf{n})\end{array}$ \\
\hline \multicolumn{19}{|c|}{ Taranaki Falls andesite (TF) } \\
\hline TF02 (C) & TF11B & & $\mathrm{T}$ & IZZI & $0-300$ & 5 & 0.49 & 0.11 & 3.2 & 1.3 & 2.0 & 1.7 & 1.50 & & & 41.3 & 4.6 & $\mathrm{~B}$ \\
\hline TF02 (C) & TF11C & & $\mathrm{T}$ & Coe & $0-425$ & 10 & 0.61 & 0.09 & 5.7 & 1.2 & 1.2 & 1.6 & 6.70 & 4.7 & 5.36 & 34.7 & 3.0 & $\mathrm{~A}$ \\
\hline TF02 (C) & $\mathrm{TF} 12 \mathrm{~A} 2$ & TF12A-2 & M & IZZI & $1-8$ & 8 & 0.52 & 0.05 & 9.1 & 3.0 & 1.8 & 1.4 & 9.15 & & & 31.6 & 1.5 & A \\
\hline TF02 (C) & TF13B & & $\mathrm{T}$ & Coe & $0-425$ & 10 & 0.58 & 0.07 & 5.4 & 1.8 & 3.7 & 3.2 & 3.26 & 1.2 & 2.08 & 33.8 & 2.0 & $\mathrm{~A}$ \\
\hline TF02 (C) & TF16B & & $\mathrm{T}$ & IZZI & $0-300$ & 5 & 0.54 & 0.03 & 15.3 & 1.6 & 3.7 & 3.4 & 10.36 & & & 41.0 & 1.0 & B \\
\hline TF03 (C) & TF19B & & $\mathrm{T}$ & IZZI & $0-300$ & 5 & 0.43 & 0.11 & 2.8 & 1.1 & 0.9 & 0.7 & 0.29 & & & 49.6 & 5.5 & $\mathrm{~B}$ \\
\hline TF03 (C) & TF21B & & $\mathrm{T}$ & $\mathrm{Coe}$ & $0-425$ & 10 & 0.54 & 0.07 & 6.2 & 1.7 & 4.7 & 3.9 & 8.36 & 2.5 & 3.23 & 37.1 & 2.4 & A \\
\hline TF03 (C) & $\mathrm{TF} 22 \mathrm{C}$ & & $\mathrm{T}$ & Coe & $0-425$ & 10 & 0.75 & 0.06 & 10.9 & 1.4 & 4.1 & 4.6 & 4.04 & 0.6 & 1.04 & 36.9 & 2.1 & A \\
\hline MEAN & & & & & & & & & & & & & & & & 37.0 & 5.7 & $8 / 15$ \\
\hline \multicolumn{19}{|c|}{ Turoa Cone andesite (MT) } \\
\hline MT01 & MT13A3 & MT13A-3 & M & IZZI & $1-6$ & 6 & 0.32 & 0.03 & 7.8 & 0.8 & 1.0 & 0.4 & 0.06 & & & 42.9 & 1.3 & $\mathrm{~B}$ \\
\hline \multirow[t]{2}{*}{ MT01 } & MT14A2 & MTH14-1A-2 & M & IZZI & $2-9$ & 8 & 0.87 & 0.04 & 15.9 & 2.8 & 3.7 & 3.8 & 7.40 & & & 32.4 & 1.6 & $\mathrm{~B}$ \\
\hline & & & & & & & & & & & & & & & 12.7 & & & \\
\hline MT01 & MT31A1 & MTH03-1A-1 & M & $\mathrm{Coe}$ & $2-6$ & 5 & 0.65 & 0.09 & 4.8 & 2.0 & 4.4 & 3.5 & 6.69 & 3.3 & 7 & 34.8 & 3.0 & $\mathrm{~B}$ \\
\hline MT01 (B) & MT31A2 & MTH03-1A-2 & M & IZZI & $1-5$ & 5 & 0.58 & 0.03 & 13.5 & 5.1 & 7.6 & 75.7 & 0.18 & & & 40.8 & 1.3 & $\mathrm{~B}$ \\
\hline MT01 (B) & MT22A2 & MTH02-2A-2 & M & IZZI & $1-6$ & 6 & 0.45 & 0.08 & 4.1 & 2.8 & 0.8 & 0.5 & 2.20 & & & 42.6 & 3.5 & B \\
\hline MT01 (B) & MTH02-2C & & $\mathrm{T}$ & IZZI & $0-400$ & 11 & 0.70 & 0.07 & 9.3 & 1.8 & 5.6 & 4.9 & 4.32 & & & 36.9 & 2.4 & A \\
\hline MT01 (B) & MTH02-4C & & $\mathrm{T}$ & IZZI & $0-400$ & 11 & 0.65 & 0.06 & 9.0 & 1.2 & 4.8 & 3.9 & 1.04 & & & 37.7 & 2.4 & A \\
\hline MT01 (B) & MTH02-3C & & $\mathrm{T}$ & $\mathrm{Coe}$ & $0-350$ & 7 & 0.64 & 0.04 & 12.5 & 1.6 & 3.5 & 2.9 & 4.33 & 2.4 & 2.01 & 41.1 & 1.7 & A \\
\hline MT01 (B) & MTH02-4B & & $\mathrm{T}$ & $\mathrm{Coe}$ & $0-350$ & 6 & 0.64 & 0.05 & 9.5 & 1.9 & 2.3 & 2.0 & 3.27 & 4.6 & 3.52 & 44.1 & 2.3 & B \\
\hline MEAN & & & & & & & & & & & & & & & & 40.8 & 4.0 & $9 / 17$ \\
\hline
\end{tabular}




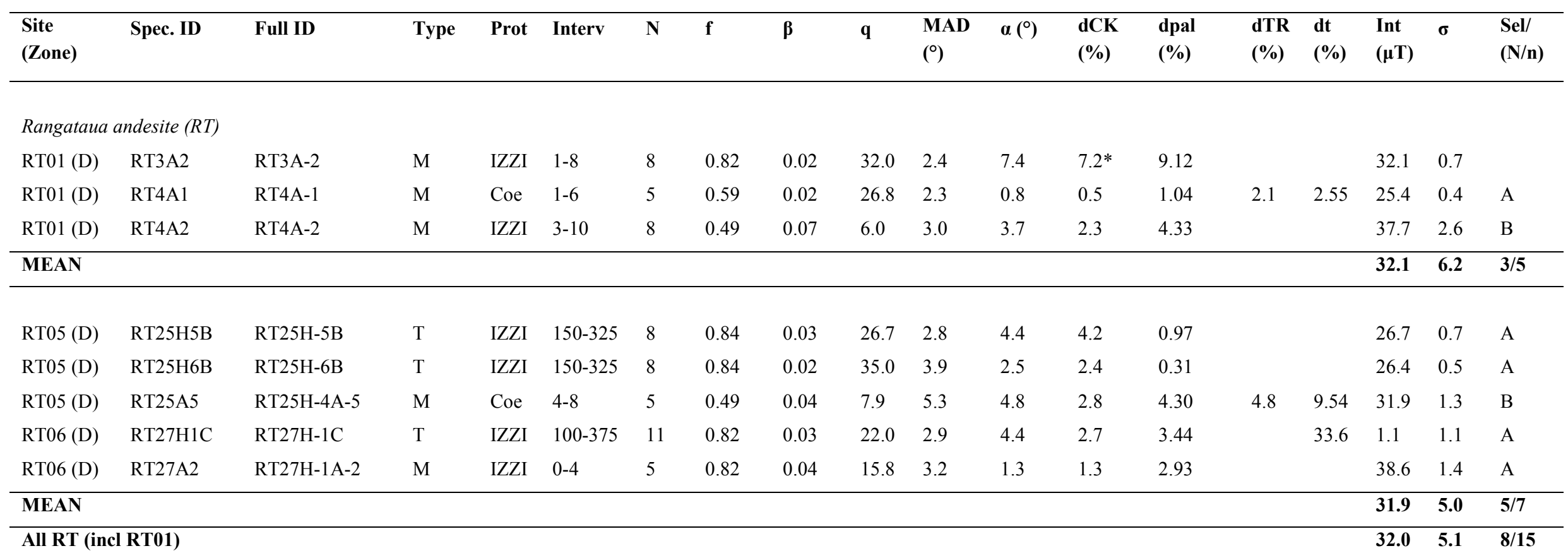

Note: Spec. ID corresponds to the specimen ID (shortened), Full ID to the specimen ID, Type: $\mathrm{M}=$ microwave palaeointensity, $\mathrm{T}=$ thermal palaeointensity, Prot. is the experimental protocol used, Interv, is the temperature interval/microwave steps selected, $\mathrm{n}, \mathrm{f}, \beta, \mathrm{q}, \mathrm{MAD} \mathrm{dCK}$, dpal, dTR, $\mathrm{dt}$ * are statistical parameters that were calculated following the standardized palaeointensity definitions (Paterson et al., 2014), whereas MAD corresponds to the maximum angular deviation when anchored to the origin. Int is the palaeointensity, and the standard error $\sigma$. Sel. are the selection criteria passed. $A=T_{T A}^{*}, B=T_{T B}^{*}$ as discussed in the text. Averaging: N/n = number of successful specimens included in average/ total number of experiments carried out. * pTRM checks did not meet the selection criteria due to the inclusion of high temperature/power steps. The additional data were only included when the slope of the high temperature/power steps is consistent with the one of lower temperature/power steps.

** pTRM check failure associated with inconsistencies in the energy absorbed during microwave treatment.

*** Our best mean palaeointensity for Whangaehu flow was calculated from the means of flow interior (zones A, B, C) and flow top (zone B) samples and encompasses their respective confidence limits 


\subsection{Discussion}

\subsubsection{Palaeointensity success rates and data quality}

The results of all palaeointensity experiments and selection criteria sets passed are summarized in Table 4-4. New palaeointensity estimates were obtained from six of the nine lava flows studied and altogether 48 out of 109 palaeointensity experiments carried out passed at least one set of selection criteria. A success rate of $45 \%$ compares well to other palaeointensity studies on Holocene lavas (e.g. Tanaka et al., 2009), however it is noteworthy that this rate was achieved by careful pre-selection of sample material. The behaviour and Arai plot statistics obtained from microwave and thermal experiments that were carried out on sister samples are remarkably similar and pTRM check failure often occurred at similar demagnetisation levels during both experiments (e.g. RP, TF). However due to the smaller amount of sample material required, microwave experiments were carried out on samples from a broader range of sites, including a wider variation in rock magnetic behaviour. During thermal experiments failure usually occurred at a temperature $>350^{\circ} \mathrm{C}$, which corresponds to the onset temperature of thermo-chemical alteration known from the repeated measurement of $\chi$ vs. T curves, with an increase in the temperature following each heating and cooling cycle (section 4.4.2), and also from accompanying susceptibility checks. However, the temperature in the microwave cavity is not expected to exceed $250^{\circ} \mathrm{C}$ (Hill and Shaw, 2000; Suttie et al., 2010) and it is therefore questionable what process leads to the pTRM check failure in these experiments.

The palaeointensity estimates made using thermal and microwave experiments by applying IZZI and Coe-type protocols compare well and no systematic offset was identified between the results from microwave or thermal experiments (Figure 4-18a). Palaeointensity estimates were made from specimens sampled over wide lateral distances (e.g. TF) and including a wide variety of rock and thermomagnetic properties (e.g. CC, MT). The standard deviation about the flow mean intensities, calculated from all successful results including both microwave and thermal palaeointensity results is usually $10 \%$ or less of the mean (TF, MT flows are exceptions) and the individual specimen intensities do not deviate by more than $20 \%$ of their mean (Figure $4-18$ ). The 
range of accepted values can be further reduced by the application of more stringent selection criteria (e.g. TTA*). However, it has frequently been discussed that too stringent data selection can result in removal of useful data (Biggin et al., 2007; Paterson et al., 2014) and, as shown in section 4.6.1 on specimens from Central Crater flow (CC), even the highest quality results may be erroneous. Removal of lower quality data may therefore place unduly high confidence on individual results and bias the resulting average.

On most flows the data scatter appears random. On Whangaehu flow (WE) however, we recorded a difference of $\sim 10 \%$ between the palaeointensity results obtained from the brecciated flow top (zone D) and flow interior (zones A, B and C). This difference correlates well with the varying nature of the thermomagnetic curves and hysteresis properties between zones. It is noteworthy that Whangaehu lava flow was the only flow where zone D was sampled together with zones A, B and $\mathrm{C}$ and such direct comparison could be made.

The overall success rates differed somewhat with location through the vertical thickness of the lava flows, and with associated differences in the rock and thermomagnetic properties. Highest failure rates were noted on samples taken from the centre of the thick andesitic flows (zone B, e.g. WE02, MT01, WPA, GR01.1) and highest overall success rates from zone $\mathrm{C}$, followed by zone $\mathrm{D}$. The lower success rate at zone D is caused by CRM overprints on the Rangataua (RT) samples studied (section 4.6.8). 
a)

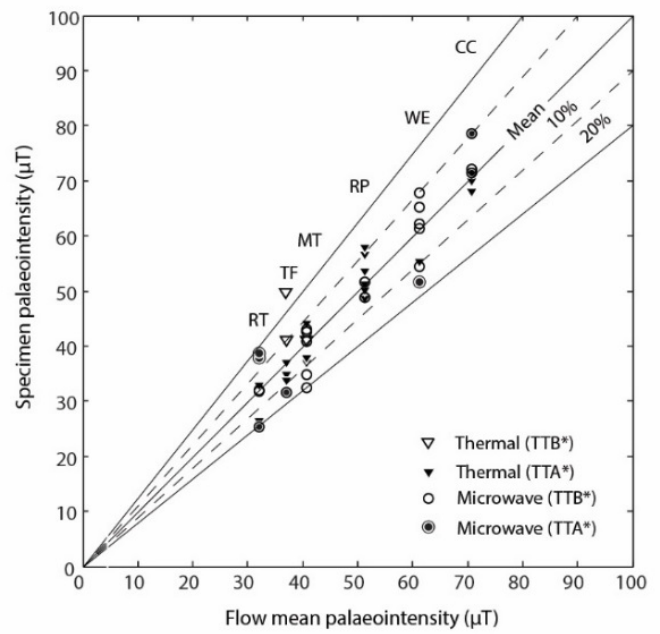

b)

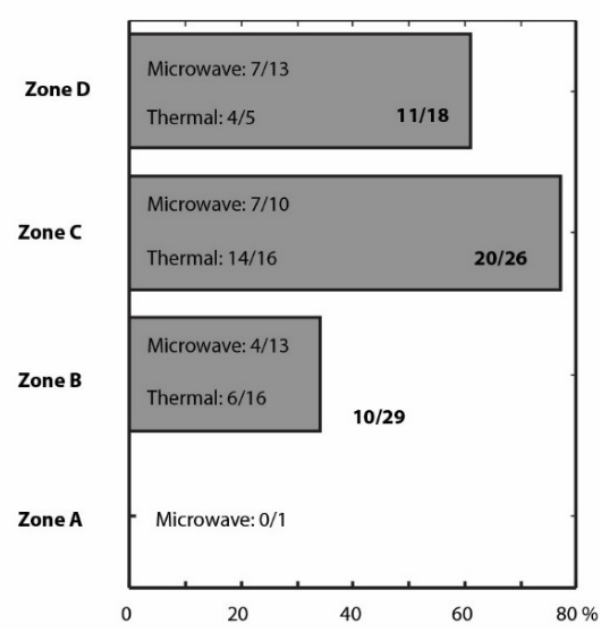

Figure 4-18: Distribution of the successful palaeointensity results and success rates. a) Distribution of all successful palaeointensity data about the mean direction averaged for each flow. b) Percentage of successful vs. total number of experiments carried out on samples from the individual zones in this study. For each zone we also display the number of successful/total experiments carried out using the microwave and thermal method. The statistic excludes any experiments carried out on Skyline Ridge (GR), Whakapapaiti A (WPA) and Delta Corner (DC) flows. 


\subsubsection{Origins of data scatter and experimental failure}

Systematic differences between the palaeointensity results obtained from units of the same age, potential sources for data scatter and failure in the palaeointensity experiments have been described widely (e.g. Biggin et al., 2007; De Groot et al., 2014; Yamamoto et al., 2003). Chapter 3 established that local magnetic anomalies or experimental errors have not significantly affected the palaeomagnetic information recorded by lavas from the $\mathrm{TgVC}$. Here we discuss potential sources for a dispersion of the palaeointensity results in light of the rock magnetic and petrographic findings presented earlier in this chapter.

In section 4.4 we suggested that the magnetic remanence of all flows is primarily carried by titanomagnetites or titanohematites. The rock magnetic behaviour differed with the vertical location within the flows sampled and we suggested that samples were subjected to progressive oxidation and exsolution after emplacement of the lavas. Highest Curie temperatures and hence inferred oxidation state were observed on flow centre (zone B) samples. On the basis of the results of thermomagnetic experiments and quantitative analysis, we defined four different compositional phases P1-P4 (section 4.4.5) and refer to these in the following analysis.

Samples from all sites altered during the palaeointensity experiments regardless their oxidation state upon heating to temperatures higher than 350 or $400^{\circ} \mathrm{C}$. The onset point of thermal alteration was usually clearly identified from pTRM check failure and changes in the magnetic susceptibility. Consequently all the affected data were removed. This resulted in higher success rates on flow top samples or those from zones $\mathrm{A}$ and $\mathrm{C}$, where much of the remanence was carried by the compositional phases $\mathrm{P} 1$ and $\mathrm{P} 2$, which have $\mathrm{T}_{\mathrm{c}}$ 's below $320^{\circ} \mathrm{C}$. We assume that magnetic mineral alteration was caused by a shift in the equilibrium composition of the titanomagnetites during re-heating.

If formed below the Curie temperature, for example during progressive exsolution, ferro-/ferrimagnetic grains carry a thermo-chemical remanence (TCRM) rather than a TRM (Draeger et al., 2006), resulting in non-linearity in the Arai plots (e.g. McClelland, 1996). If present we would expect a TCRM to be carried by 
titanomagnetites of compositions $\mathrm{P} 3$ and $\mathrm{P} 4$, which most probably formed from the low- $\mathrm{T}_{\mathrm{c}}$ primary phases $\mathrm{P} 1$ and $\mathrm{P} 2$.

Weathering of a lava under frequent exposure to snow and water can result in the lowtemperature transformation of (titano)magnetites to metastable (titano)maghemites (Tauxe, 2015). Petrographic investigations showed patchy alteration throughout the rock matrix, affecting the grain boundaries of titanomagnetites on Skyline Ridge (GR) and Whakapapaiti A (WPA) lava flows and palaeointensity experiments were therefore not undertaken on samples of these flows. Signs of maghemitization were not found on any other flows from rock magnetic or mineral-optic investigations (section 4.4.3), and therefore we believe it is unlikely to have significantly affected the palaeointensity results presented in this study.

Magnetic coercivity can be a measure of grain size, and can therefore vary with the cooling time of a lava (e.g. De Groot et al., 2014). The higher coercivities found within flow centre samples may be a result of longer cooling times during which large MD grains exsolved into sub-micron scaled titanomagnetite-ilmenite lamellae (section 4.4.3). It is also possible that sub-micron sized grains formed within the rock matrix. Despite the overall higher coercivities observed, samples from the flow centres (zones $B, C$ ) often showed pTRM tails, characteristic of $T_{u b}>T_{b}$, caused by MD behaviour (e.g. section 4.6.5). We suggest that in mixtures of SD and MD titanomagnetites with high $\mathrm{T}_{\mathrm{c}}$ 's $\left(\mathrm{T}_{\mathrm{c}}>450^{\circ} \mathrm{C}\right)$, low $\mathrm{T}_{\mathrm{b}}$ unblocking is dominated by low coercivity unblocking of the MD grains. In contrast, in samples that are dominated by magnetic mineral phases $\mathrm{P} 1$ and $\mathrm{P} 2$ with $\mathrm{T}_{\mathrm{c}}$ 's $<320^{\circ} \mathrm{C}$, unblocking of the entire coercivity range occurs at low temperature, and the overall MD effect is thus significantly smaller. MD behaviour is also known to result in concave upwards shape of the relation NRM/TRM displayed in the Arai plots (Levi, 1977), which may explain the higher palaeointensities measured from the $\mathrm{T}_{\mathrm{b}}$ range $<350^{\circ} \mathrm{C}$ on flow centre samples, such as found on Whangaehu lava flow.

TRM acquisition is not only a function of temperature but also cooling time (e.g. Biggin et al., 2013; Bowles et al., 2005; Leonhardt et al., 2006) and in theory variation in the cooling rate throughout the thickness of the lava flows may also directly affect 
the palaeointensity results (e.g. Biggin et al., 2007). In the laboratory we applied two different sets of cooling rates: During thermal experiments, cooling from temperatures between 100 and $600^{\circ} \mathrm{C}$ lasted between 30 minutes to two hours (see chapter 2), while the maximum treatment interval during microwave experiments was $15 \mathrm{~s}$. Nevertheless, the results from both experiments are similar, which suggest that on these samples cooling rates had only a minor primary effect on the palaeointensity results measured. However we acknowledge that the theoretical foundation for the $\mathrm{T}_{\mathrm{M}} \mathrm{RM}$ acquisition in the microwave is not adequately established. The cooling rate effects may be quantified experimentally (e.g. Biggin et al., 2013) but further experimentation was beyond the scope of this thesis.

\subsubsection{Errors associated with averaging}

The best estimate palaeointensity for all but one flow was calculated from all successful specimens by averaging. This approach is based on the assumption that the data is distributed normally around the mean and is subject to random uncertainty or noise. In this approach, highest confidence is usually placed on estimates with the lowest standard deviation.

However there is evidence that the noise present in our data is not random. For example, Whangaehu lava flow samples exhibit a bias, which varies with the location in the vertical position of the sampled lava flow. As discussed in section 4.7.2 such a bias is not uncommon (e.g. Biggin et al., 2007) and is probably linked to factors such as MD-type behaviour, cooling rate or other rock magnetic contributions. The implication is that if a palaeointensity estimate is calculated from the results obtained from one location in the thickness of a flow only, the estimate may have a low standard deviation but be inaccurate. In the present study, this applies to Bruce Road flow (RP): with a standard deviation of $6 \%$ about the mean and overall high quality (TTA*) results the data appears reliable. However the results were obtained from within one zone of the flow only with little variation in the rock magnetic behaviour and the results may thus be biased to either too high or low palaeointensity results. 
Highest confidence should therefore be placed on the palaeointensity results from flows where consistent results were obtained from spatially separate sites and where consistent results were obtained from samples showing differences in the rock magnetic behaviour (e.g. Taranaki Falls flow). Such ideal results are rarely observed. While sources for data scatter or intensity biases have been discussed widely (e.g. Biggin et al., 2007; De Groot et al., 2014; Yamamoto et al., 2003), it is difficult to quantify the effect of different contributions. In the case of Whangaehu flow, where a systematic offset between the results from the flow interior and flow top was apparent, we thus provided an error estimate that encompasses the two extremes. This approach, first suggested by Biggin et al. (2007) fails on all other flows, where differences in the palaeointensity results are more difficult to link to a location within a flow sampled (e.g. Mangaturuturu flow).

Simple averaging as done in this thesis may thus exhibit significantly larger uncertainty than suggested from the standard deviation provided. To improve such results a better understanding how rock magnetic mineralogy and other factors relate to the palaeointensity recorded is needed.

\subsubsection{Comparison with previous datasets from New Zealand}

Figure 4-19 shows the palaeomagnetic directions (chapter 3), together with the new palaeointensity data on the TgVC lavas superimposed on a continuous record from Lake Mavora (Turner et al., 2015b). A priori, the sedimentary record provides relative palaeointensity only. To make it comparable to the discrete data we apply the scaling factor suggested by Turner et al. (2015b), which is based on the earliest absolute intensity recordings from New Zealand prior to relocating the data to Whakapapa Village $\left(39.2^{\circ} \mathrm{S}, 175.54^{\circ} \mathrm{E}\right)$ using a VGP-transformation (refer to chapter 3 for details).

We also display the field predictions from the latest spherical harmonic global field model pfm9k (Nilsson et al., 2014).

The PSV swings recorded by the Lake Mavora record are of significantly shorter periodicity and higher amplitude than the ones suggested by the lower resolution 
global field predictions extracted from model pfm9k. However, the model and the PSV record show an overall trend from lower to higher palaeointensities throughout the Holocene with some non-periodic swings superimposed. The lowest intensity values, recorded prior to $9 \mathrm{ka}$ are $<40 \mu \mathrm{T}$ and the intensity record described by the pfm $9 \mathrm{k}$ curves peaks with $\sim 70 \mu \mathrm{T}, 200$ years BP. This overall trend is reflected in our new discrete data: The pre 9 ka lavas, such as Mangaturuturu (MT) and Taranaki Falls (TF) flow yield relatively low intensities of $40.8 \pm 4.0$ and $37.0 \pm 5.7 \mu \mathrm{T}$, the intensities of the younger flows $(\mathrm{RP}, \mathrm{WE}, \mathrm{CC})$ range from $51.2 \pm 3.5 \mu \mathrm{T}(\mathrm{RP})$ to $59.6 \pm 7.0 \mu \mathrm{T}$ (WE) and peak at $70.6 \pm 4.1 \mu \mathrm{T}$ for the youngest flow sampled (CC, tephra age: $<1.72 \pm 0.01$ kyrs BP. Taranaki flow does not only record a low palaeointensity but also a shallow inclination. Both the palaeointensity and palaeomagnetic direction of Bruce Road (RP) lava flow overlap at the 95\% confidence level with the palaeomagnetic data published by Tanaka et al. (1997) on one of seven Iwikau flows they sampled from Ruapehu Volcano (Lava NR05: Dec $=24.3$, Inc $=-59.6, \alpha 95=$ 2.0, Int $=54.5 \pm 3.6 \mu \mathrm{T})$. The spatial separation of ca. $3 \mathrm{~km}$ between the site NR05 (Tanaka et al., 1997) and site RP02 (this study) does not allow a field correlation, however based on the PSV data this suggests that the sites either belong to the same lava flow or to flows that were emplaced during a short time-period.

Our new data also correlates exceptionally well with the scaled Lake Mavora Curve within uncertainties of the palaeomagnetic ages of chapter 3 . We opted not to include intensity as a third component in the palaeomagnetic dating, due firstly to the additional uncertainties from the data scatter described above and secondly the scaling of the relative intensity record. However to a first order, the correlation shown in Figure 4-19 strongly supports the palae omagnetic dating results presented. 

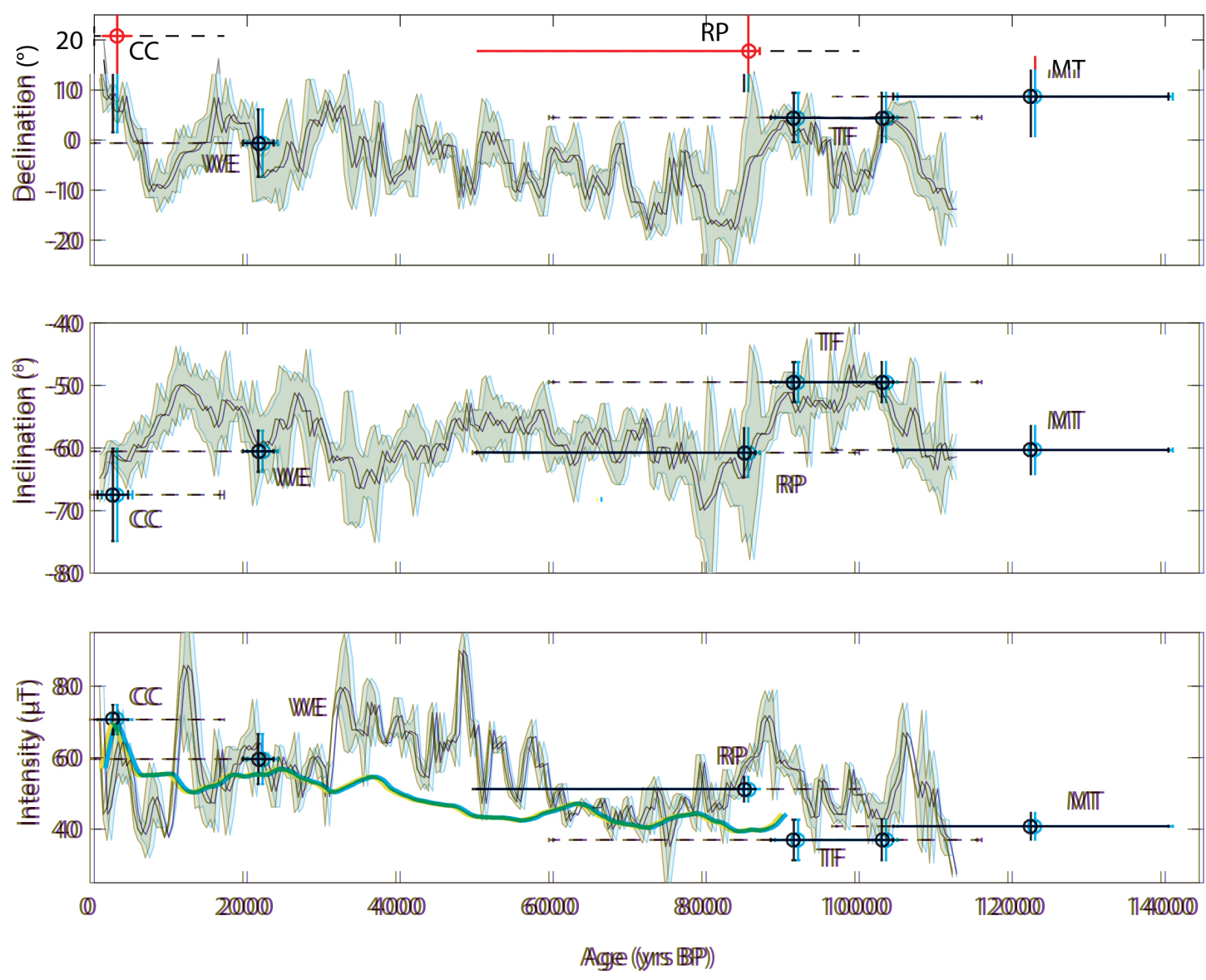

Figure 4-19: Records of palaeomagnetic declination, inclination and intensity from the TgVC. Displayed are the discrete directional records discussed in chapter 3 and the new palaeointensity data for the Holocene time-period presented in this chapter superimposed on the continuous lake sediment record from Mavora (Turner et al., $2015 \mathrm{~b}$ ) and the global field model pfm9k (Nilsson et al., 2014) (green line). Prior the relocation, the relative palaeointensity curve from Lake Mavora was scaled using a constant factor of $64 \mu \mathrm{T}$. The discrete data is displayed with our preferred palaeomagnetic ages presented in chapter 3 (red) and the age brackets of the independent constraints (dashed lines). 


\subsection{Conclusions}

This chapter presents detailed rock magnetic and palaeointensity studies on the andesitic lava flows of Mt Ruapehu and Tongariro described in chapter 3. New palaeointensity estimates were made on six andesitic lava flows from the Tongariro Volcanic Centre (TgVC) in New Zealand using a combination of microwave and thermal Thellier-type palaeointensity procedures. The rock magnetic properties vary considerably through the thickness of individual flows, and differing success rates and data dispersion were linked to these. The new discrete, absolute palaeointensity data range from $37.0 \pm 5.7 \mu \mathrm{T}$ to $70.6 \pm 4.1 \mu \mathrm{T}$. These values fall well into the range of palaeosecular variation swings suggested by the scaled relative palaeointensity curve from Lake Mavora (Turner et al., 2015b) and describe a similar overall trend from low to higher palaeointensities throughout the Holocene, as is also suggested by the global field predictions from model pfm9k (Nilsson et al., 2014). 


\section{Chapter 5}

\section{Palaeosecular variation studies of rhyolitic lavas from the Taupo Volcanic Zone, New Zealand: revision and new data}

\section{$\underline{\text { Acknowledgements }}$}

Palaeomagnetic fieldwork on the Okataina Volcanic Centre, sample preparation and some preliminary demagnetisation experiments were carried out with the help of Robyn Vasco, who visited from July - September, 2014 during a DAAD-funded summer internship.

The VFTB measurements were carried out by Elliot Hurst at the University of Liverpool.

$\underline{\text { Relevant appendices (electronic) }}$

a) Full demagnetisation data for all specimens analysed (file format: .*rs3) Path: Chapter 5/Data/rs3files (TVZ)

b) Full palaeointensity determination data (file format: .*tdt) Path: Chapter 5/Data/tdtfiles (TVZ)

c) All rock magnetic data (file formats: *.irm, *. Coe, *.hys, *.rmp) Path: Chapter 5/Data/VFTB

d) Orientation data for all samples from the TVZ (file format: *.xlxs). Path: Chapter 5/cores\&directions_TVZ.xlsx

e) All susceptibility checks carried out alongside demagnetisation and intensity experiments (file format: *.xlxs).

Path: Chapter 5/Intensity_susc_TVZ.xlsx; Thdemag_susc_TVZ.xlsx

f) Summary of all ChRM directions selected (file format: *.xlxs) Path: Chapter5/directions_TVZ.xlxs

g) Summary of the results of all intensity experiments carried out (file format: *.xlxs). Path: Chapter 5/Intensity_TVZ.xlxs 


\subsection{Abstract}

In this chapter we present new palaeomagnetic directions and palaeointensities from seven Holocene rhyolitic lava domes and flows from the Taupo Volcanic Zone in New Zealand, with a focus on the Okataina Volcanic Centre. Palaeomagnetic directions and intensities on several of the units were previously published. The original data dispersed more than expected in a normal polarity field and, if available, the palaeointensity estimates were calculated from few successful data only.

Thermal and alternating field demagnetisation of new samples revealed ChRM directions that range from $326.5^{\circ} \mathrm{W}$ to $14.6^{\circ} \mathrm{E}$ of $\mathrm{N}$ and $-69.7^{\circ}$ to $-54.2^{\circ}$ inclination. Palaeointensity experiments were carried out on four lavas using the Coe-type double heating method. Succesfull palaeointensity estimates, made on three units range from $51.7 \pm 3.2 \mu \mathrm{T}$ to $63.3 \pm 1.2 \mu \mathrm{T}$. The new palaeomagnetic data generally compares well or is an improvement to the palaeomagnetic results published on the same lavas during previous studies. 


\subsection{Introduction}

Accurate, well-resolved records of palaeomagnetic direction and absolute palaeointensity through time are required to understand the dynamics of the outer core of the Earth - the geodynamo. Over the last decade much effort has been invested in creating global data compilations (Donadini et al., 2009; Korte et al., 2005, and following publications), and in setting up global databases such as GEOMAGIA50 (Brown et al., 2015; Donadini et al., 2006; Korhonen et al., 2008), MagIC (Constable et al., 2006) and Pint (Biggin et al., 2009; Biggin et al., 2010). The geomagnetic field observed on Earth's surface is traditionally modelled by least squares fitting of the available data to spherical harmonic functions. Such analysis is carried out both from direct observations on centennial (Jackson et al., 2000) and palaeomagnetic data on millennial (Korte et al., 2011; Nilsson et al., 2014) time-scales. However, all models and global databases are strongly affected by the quality and spatial distribution of the data. For instance, the statistical data treatment and the methodologies in palaeomagnetic analysis and in particular for the determination of palaeointensities improve continuously and the quality of the data previously published and that have entered databases is therefore highly variable (e.g. Donadini et al., 2006). Furthermore, all data compilations are strongly hampered by a shortage of data from the southern hemisphere and the south west Pacific region in particular. Reasons for the latter are the isolation and lack of landmass in the region but also a shortage of well dated sedimentary or volcanic deposits. A collaborative effort to build a new high resolution palaeosecular variation (PSV) record for the Holocene time-period in New Zealand from accurately dated lake sediment, volcanic and archaeological materials (Turner at al., 2015a) is underway. While the new datasets presented in chapter 3 and 4 compare well with each other some of the previously published datasets disperse widely about the geocentric axial dipolar (GAD) average and need to be verified.

In this chapter we sampled, obtained new palaeomagnetic directions and carried out palaeointensity experiments on six rhyolitic lava flows and domes from Okataina and Taupo Centres in theTaupo Volcanic Zone (TVZ). Palaeomagnetic data for most units sampled had previously been published in two studies by Tanaka et al. (1994; 2009), however this data included extreme easterly and westerly declinations 
and very high intensities that are not typical of the PSV of a stable normal polarity field. We finally revise all discrete datasets on Holocene $(<15 \mathrm{ka})$ volcanic materials and compare the data to regional datasets and global field reconstructions.

\subsection{Geological Setting}

New Zealand's youngest and current volcanic activity is focussed within the Taupo Volcanic Zone (TVZ), an area of high geothermal flux, active extension and voluminous rhyolitic volcanism (Bibby et al., 1995; Wilson et al., 1995) (Figure 5-1, inset). Some activity is also seen in the monogenetic Auckland Volcanic Field and around Mt Taranaki (Figure 5-1, inset). The TVZ results from subduction of the Pacific plate beneath the Australian plate along the HikurangiKermadec Trench system; it strikes roughly north-east from the Tongariro Volcanic Centre (TgVC) to White Island in the Bay of Plenty, from where it extends into the oceanic Kermadec-Tonga arc-back-arc system. Over the last $\sim 60$ ka the silicic eruptive activity has focussed on four major volcanic centres: Okataina, Maroa, Kapenga and Taupo (Wilson et al., 1995).

The Pleistocene eruptive activity of Taupo Volcano was dominated by the $25.4 \pm 0.2$ ka Oruanui supereruption, which formed much of the present day Taupo caldera (Van Eaton and Wilson, 2012; Vandergoes et al., 2013). At least 28 distinct eruptive episodes have occurred since (Wilson, 1993) and while the early activity was dacidic in composition, at least 10 rhyolitic eruptions have occurred in three distinct periods through the Holocene (Barker et al., 2014). The eruptive stratigraphy is primarily defined from pyroclastic deposits and the vent sites are mostly inferred to be submerged beneath the eastern part of Lake Taupo. Only four associated lava flows or domes are exposed on Lake Taupo's eastern and northern shores (Wilson, 1993). The most prominent and latest eruption from Taupo Volcano occurred $1.72 \pm 0.01$ ka ago and produced widespread pyroclastic and airfall deposits, including the Taupo Ignimbrite, a frequently discussed marker bed within the central North Island (Houghton et al., 2010; Lowe et al., 2013). 
More recent activity has occurred in the Okataina Volcanic Centre (OVC) - the historic basaltic Tarawera eruption occurred only 130 years ago. Volcanic activity around the OVC is believed to extend back to at least $550 \mathrm{ka}$ (Cole et al., 2010) and its evolution is defined by at least four major phases of caldera collapse, which are associated with widespread pyroclastic and tephra deposits. The youngest $(<61$ ka) and presently dominant caldera is Haroharo, which covers an area of approximately $450 \mathrm{~km}^{2}$ (Nairn, 2002). It is infilled by the products of at least eleven distinctive eruptive episodes during the last $26 \mathrm{kyrs}$ that have formed the massive volcanic dome complexes of Haroharo at the northern end and Tarawera in the south (Figure 5-1b). Each episode included, in short succession, voluminous pyroclastic, plinian and effusive eruptions (Smith et al., 2006), sourced from multiple, simultaneously active vents that are aligned along two linear zones that include the Tarawera and Haroharo Volcanic Complex (Nairn, 2002; Smith et al., 2006). Plinian pyroclastic eruptions dispersed tephra over much of the central and eastern North Island, and these form characteristic marker beds in distal sedimentary sequences, which are often dated by radiocarbon methods. Based on these, a stratigraphic framework has been developed (Froggatt and Lowe, 1990 and revised by Lowe et al., 2013) and adopted for the naming of associated eruptive episodes that formed voluminous vent-proximal pyroclastics deposits, ignimbrites, lava flows and domes. All these deposits have been summarized in the 1:50,000 scale geological map of the Okataina Volcanic Centre (Nairn, 2002).

Nairn (2002) showed that the radiocarbon ages of a number of proximal deposits are within 100 to 300 years of Frogatt and Lowe's (1990) tephra ages and thus assigned each eruptive episode with an "accepted" age that was rounded from their stratigraphic and radiocarbon ages. Since the geological map was published, the geological framework has not changed significantly, however many of the tephra ages have been revised (Lowe et al., 2013). 


\subsection{Samples}

Palaeomagnetic field sampling was carried out in October 2012 and August 2014. Field sampling for the OVC was limited to its northern end, for which sampling permission was given by local by iwi and forestry companies. The sampled sites were selected based on the accessibility in the field and from outcrops that appeared in-situ. Altogether we sampled ten sites from six rhyolitic lava flows or domes from the OVZ that were emplaced during the Whakatane, Mamaku, Rotoma and Waiohau eruptive sequences. We also sampled four sites on a dome structure located at the northern end of Lake Taupo. At each site we sampled cores of $2.5 \mathrm{~cm}$ diameter and $10 \mathrm{~cm}$ length using a water cooled hand drill. All samples were oriented using a suncompass. The site locations often correspond or are near the location from previous studies, both are displayed in Figure 5-1. The sampling details, geological and age information, and palaeomagnetic directions for all lavas sampled in this study are summarized together with the previously published data Table 5-2. The sampling details are also discussed in detail, flow by flow below. The tephra ages cited for the individual eruptive sequences correspond to revised and calibrated radiocarbon ages proposed by Lowe et al. (2013). A more thorough discussion for these ages is provided in chapter 6. 

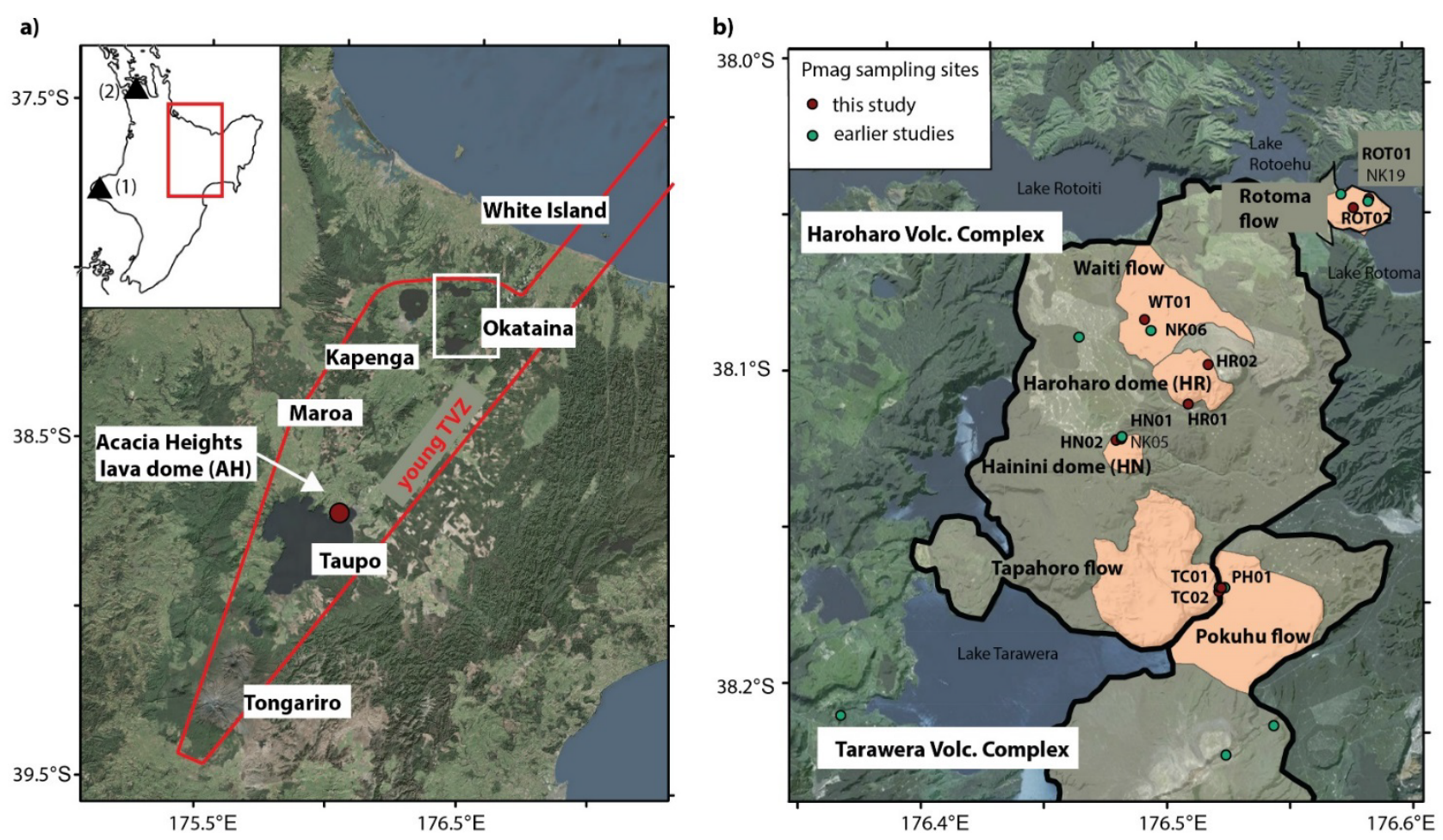

Figure 5-1: Map of the main young volcanic centres in New Zealand. a) Map showing the location of the young $(<65$ ka) Taupo Volcanic Zone (after Wilson et al., 1995) and the volcanic regions or cones/domes discussed in this study. The cones outside the TVZ and displayed in the inset correspond to (1) Taranaki volcano and (2) the Auckland Volcanic Field. b) Map showing the young ( $<65$ ka) Okataina Volcanic Centre including the two complexes of Haroharo and Tarawera. The units sampled in this study are highlighted and all sampling sites discussed marked. Base map information from Land Information New Zealand (LNZ), geological map simplified after Nairn (2002). 


\subsubsection{Tapahoro flow (TC)}

Tapahoro flow is part of a sequence of flows, sourced from the Haroharo Volcanic Complex. The flow margins form steep cliffs above the northern end of Lake Tarawera and its outlet area in the east (Figure 5-1b). Two sites, TC01 and TC02, were sampled, the sampling coordinates suggest that both sites are located within $200 \mathrm{~m}$ of the sampling coordinates of site NK02 of Tanaka et al. (2009). The flows are believed to have been emplaced during the $5526 \pm 145$ cal yrs BP Whakatane eruptive episode.

\subsubsection{Haroharo dome (HR)}

This lava dome covers an area of roughly $1 \times 2 \mathrm{~km}$ and rises to a high point $\sim 200$ $\mathrm{m}$ above the Haroharo Volcanic Complex. It is the only unit addressed in this study for which no previous palaeomagnetic data is available and it was sampled at two sites. Site HR01 is located in a streambed on the southern flanks of the dome complex, site HR02 is in a small quarry site near the top of the dome ca. $1 \mathrm{~km}$ from site HR01 and was sampled at two sub-sites. It is located on top of much of the Haroharo Volcanic Complex and thus believed to have been emplaced during the Whakatane sequence as well.

\subsubsection{Hainini dome (HN)}

Hainini dome is a ca. $1.5 \mathrm{~km}^{2}$ rhyolitic dome at the centre of the Haroharo Volanic Complex. It was emplaced alongside numerous other flows during the $7940 \pm 257 \mathrm{cal}$ yrs BP Mamaku sequence. The steep northern face of the dome was sampled at two sites, separated by a distance of $300 \mathrm{~m}$. Site HN01 was sampled from a road cut and corresponds to site NK05 of Tanaka et al. (2009). Site HN02 was sampled from a steep bluff ca. $50 \mathrm{~m}$ from the closest access point on the forest road. 


\subsubsection{Waiti flow (WT)}

Waiti flow is situated in a densely forested area which provides little exposure of the flow interior. In the 1:50,000 geological map (Nairn, 2002) it was first associated to the Mamaku eruptive episode. Based on recent geochemical findings by Schmith (2006) it is more likely that it was already emplaced during the earlier $9423 \pm 120 \mathrm{cal}$ yrs BP Rotoma eruptive sequence. The flow was sampled in a small road-cut, approximately $20 \mathrm{~m}$ in length, at two sub-sites, WT01.1 and WT01.2.

\subsubsection{Rotoma flow (ROT)}

Rotoma lava flow is exposed along the southwestern lake shore of Lake Rotoma (Figure 5-1b). At its highest point it is rises ca. $100 \mathrm{~m}$ above lake level and the terrain drops steeply into the lake on its northern end where most of the surface exposure is found. We sampled two sites: Site ROT01 is located on the north-eastern lake shore and was sampled at several sub-sites over a distance of $30 \mathrm{~m}$. Site ROT02 is located near the flow top: sub-sites (ROT02.1, ROT02.2) comprise weathered road-cuts, $50 \mathrm{~m}$ apart. The flow was also emplaced during the $9423 \pm 120$ cal yrs BP Rotoma eruptive sequence.

\subsubsection{Acacia Heights dome (AH)}

Acacia Heights is a ca. $1.5 \times 1 \mathrm{~km}^{2}$ rhyolitic dome, located near Acacia Bay on the northern shore of Lake Taupo. It is one of four lavas associated with Holocene silicic eruptions from Taupo Volcano (Wilson, 1993). Like every other rhyolitic lava in this study its emplacement age is defined by correlation with tephra deposits. It was first associated with the $11,170 \pm 115 \mathrm{cal}$ yrs BP Poronui tephra (Froggatt, 1981). However recently Wilson (1993) suggested that it is located on the inferred vent location of a deposit (unit D) that is approximately 20 years younger than the Poronui tephra. We thus infer a tephra age of $11,150 \pm 115 \mathrm{cal}$ yrs BP.

The dome was sampled at three sites on the upper surface of the dome. Site AH01 is a ca. 5 by $5 \mathrm{~m}$ sized outcrop that marks the topographically highest point. This outcrop 
was sampled at four sub-sites (AH01.1 - AH01.4) from various orientations. Site AH02 was sampled on a ca. $10 \mathrm{~m}$ long road outcrop, located approximately $100 \mathrm{~m}$ northeast of site AH01.

\subsubsection{Pokuhu lava flow (PH)}

Pokuhu flow is the only lava sampled in this study that was sourced from the Tarawera Volcanic Complex. It is associated to the $14,009 \pm 155$ cal yrs BP Waiohau eruptive episode and is most prominently exposed on the $\sim 30 \mathrm{~m}$ high Tarawera Falls (Figure 5-1b). Drilled samples were taken from only one site, spread over a distance of approximately $15 \mathrm{~m}$. The site sampled corresponds to NK01 in Tanaka et al. (2009).

\subsection{Magnetic mineralogy}

\subsubsection{Methods}

Rock magnetic experiments were carried out using a Variable Field Translation Balance (VFTB) at the University of Liverpool. Isothermal Remanent Magnetisation (IRM) acquisition, backfield coercivity of remanence, hysteresis and saturation magnetisation vs. temperature $\left(\mathrm{M}_{\mathrm{s}} \mathrm{vs}\right.$. T) measurements were made on a ca. $150 \mathrm{mg}$ sample of each unit. The maximum field applied during in-field measurements was $800 \mathrm{mT}$ and thermomagnetic curves were measured to a peak temperature of $700^{\circ} \mathrm{C}$. The VFTB data were analysed using RockMag Analyser 1.0 (Leonhardt, 2006). In addition to displaying the data, this software calculates the hysteresis parameters including the magnetic coercivity $\left(B_{c}\right)$, the saturation remanence $\left(M_{s}\right)$ and the remanent saturation magnetisation $\left(\mathrm{M}_{\mathrm{rs}}\right)$ from the hysteresis data after removal of a linear trend fitted to the closed parts of each loop, to correct for the paramagnetic component. The magnetic coercivity of remanence $\left(B_{c r}\right)$ is calculated from the backfield IRM curves. Curie temperatures were estimated to be the temperature at which the second derivative $\mathrm{d}^{2} \mathrm{M}_{\mathrm{s}} / \mathrm{dT}^{2}$ is a maximum (Tauxe, 1998).

The thermomagnetic curves allow assessment of the thermal stability of the magnetic remanence carriers. If identified, the onset temperature of alteration is of major 
importance for the analysis of thermal demagnetisation (THD) and palaeointensity data. The onset temperature can be best identified by measuring magnetic susceptibility in heating and cooling cycles to stepwise higher temperatues (e.g. see chapter 2). These experiments were not carried out on the rhyolitic samples addressed in this chapter. However the magnetic susceptibility $(\chi)$ was monitored alongside the THD experiments described in section 5.7. Variations in $\chi$ give important clues about potential mineral alteration and we thus discuss the results alongside the rockmagnetic data.

\subsubsection{Results}

The rhyolitic domes or flows sampled generally comprise pumiceous to crystalline lavas. At three sites (HN02, TC01, TC02) we sampled highly fractured volcanic obsidians. The texture can change from pumiceous to obsidian over a few meters, as is typical for rhyolitic lavas (Sigurdsson, 2000). For instance, site HN01 is on the outer rim of Hainini dome and comprises semi-crystalline pumice, while site HN02, located only a few hundred meters away comprised obsidian. These textural differences however do not affect the rock magnetic behaviour, suggesting that magnetic minerals formed prior to and remained in their present state after their emplacement.

The IRM acquisition curves of all samples studied saturate at fields lower than $250 \mathrm{mT}$, indicative of a relatively "soft" magnetic remanence carrier such as titanomagnetites or (titano)maghemites (Figure 5-2). The hysteresis loops indicate dominance of a ferro-/ferrimagnetic component and mostly yield hysteresis parameters traditionally associated with pseudo-single domain carriers (Dunlop, 2002). Exceptions are samples from Haroharo (HR) and Waiti (WT) lavas, which yield higher $B_{c r} / B_{c}$ ratios but similar $M_{r s} / M_{s}$ ratios to all other flows. The samples that fall into the PSD size range follow a theoretical trend for mixtures between SD and MD grains suggested by Dunlop (2002), which was also observed on the andesitic lavas described in chapter 3 (Figure 5-3a). The actual magnetic grainsize can not be determined 
without additional experimental data, such as First Order Reversal Curves (FORC) (Roberts, 2000) or petrographic images.

In relation to the magnetic domain state, the magnetic coercivities vary between individual flows: The hysteresis loops measured on samples from Haroharo (HR) and Waiti (WT) lavas are extremely narrow and have coercivities between 3 and $8 \mathrm{mT}$. Intermediate values $\left(8 \leq \mathrm{B}_{\mathrm{c}} \leq 17 \mathrm{mT}\right)$ were observed on Tapahoro (TC), Rotoma (ROT) and Acacia Height (AH) lavas, while me measured a higher value of $24 \mathrm{mT}$ on a Pokuhu (PH) flow sample (Figure 5-3b, Table 5-1). Only small variations were found between the $\mathrm{M}_{\mathrm{s}}$ vs. T curves measured on samples from different units and sites. All curves reveal the presence of one or two compositional phases with Curie temperatures between 500 and $580^{\circ} \mathrm{C}$, suggesting low titanium titanomagnetites. The degree of reversibility between heating and cooling curves differs slightly between individual units and we roughly distinguish between three curve types (Figure 5-4, Table 5-1): Type 1 is reversible and was found on specimens from Acacia Height (AH), Hainini (HN) and Waiti (WT) lavas. Type 2 is near reversible, however the cooling curves show a lower $M_{s}$ and similar or lower $T_{c}$ than the heating curves. This curve type was identified on specimens from Pokuhu (PH) and Tapahoro (TC) flows. Type 3 is characterised by heating and cooling curves with similar $\mathrm{M}_{\mathrm{s}}$, however the cooling curves have a lower Curie temperature than the heating curves. This behaviour was found on specimens from Haroharo dome (HR) and Rotoma flow (ROT) (Table 5-1). Susceptibility checks, measured alongside the THD experiments show that the onset of thermal alteration on specimens from most samples does not occur at temperatures lower than $450^{\circ} \mathrm{C}$ (Figure 5-5). Pokuhu flow is an exception in that specimens show a gradual increase in the susceptibility during heating steps to temperatures higher than $250^{\circ} \mathrm{C}$. 


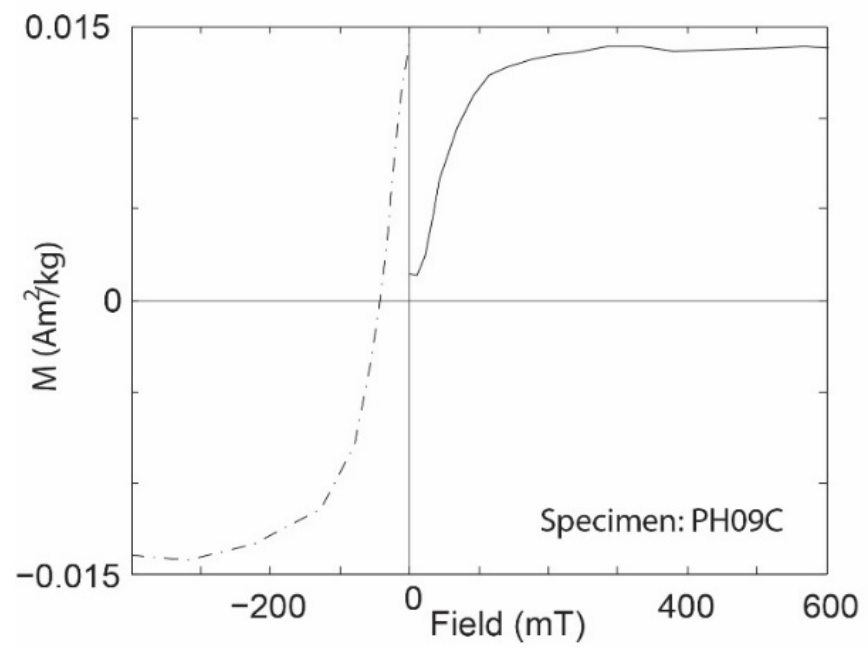

Figure 5-2: Typical IRM acquisition and backfield curves for samples from the Okataina Volcanic Centre. 
a)

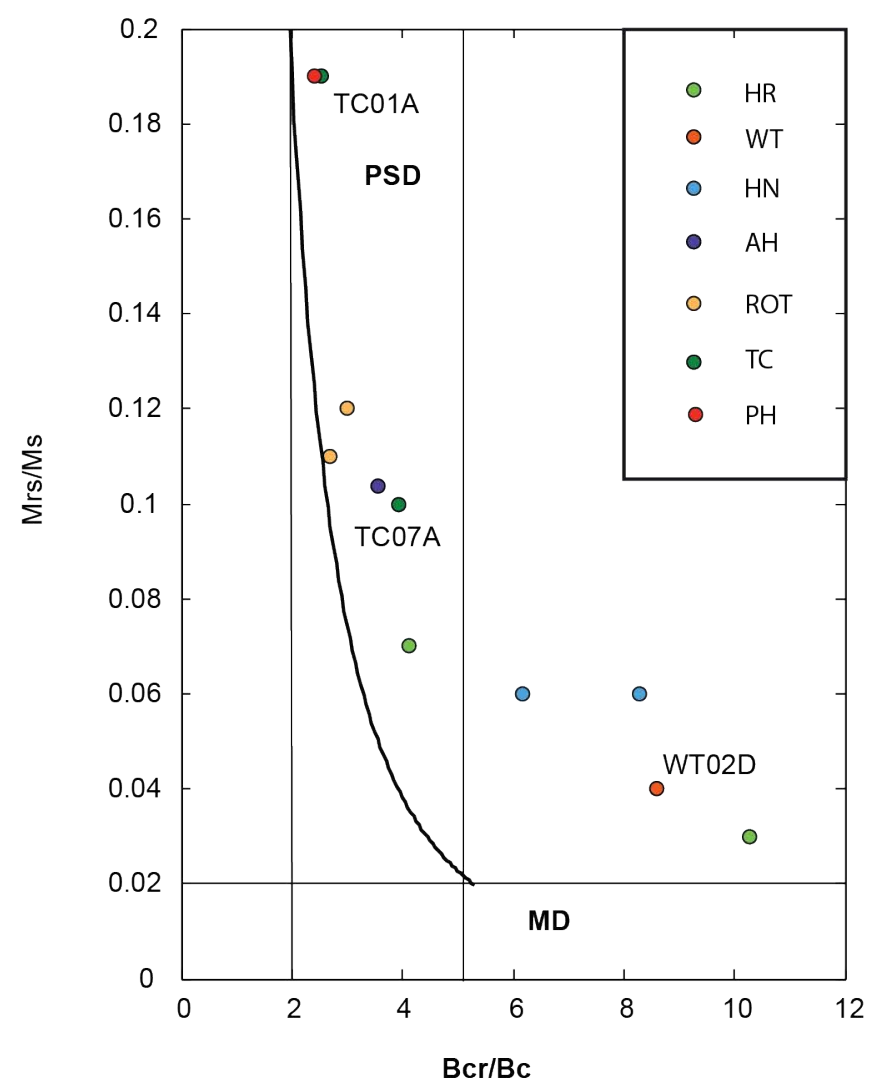

b)

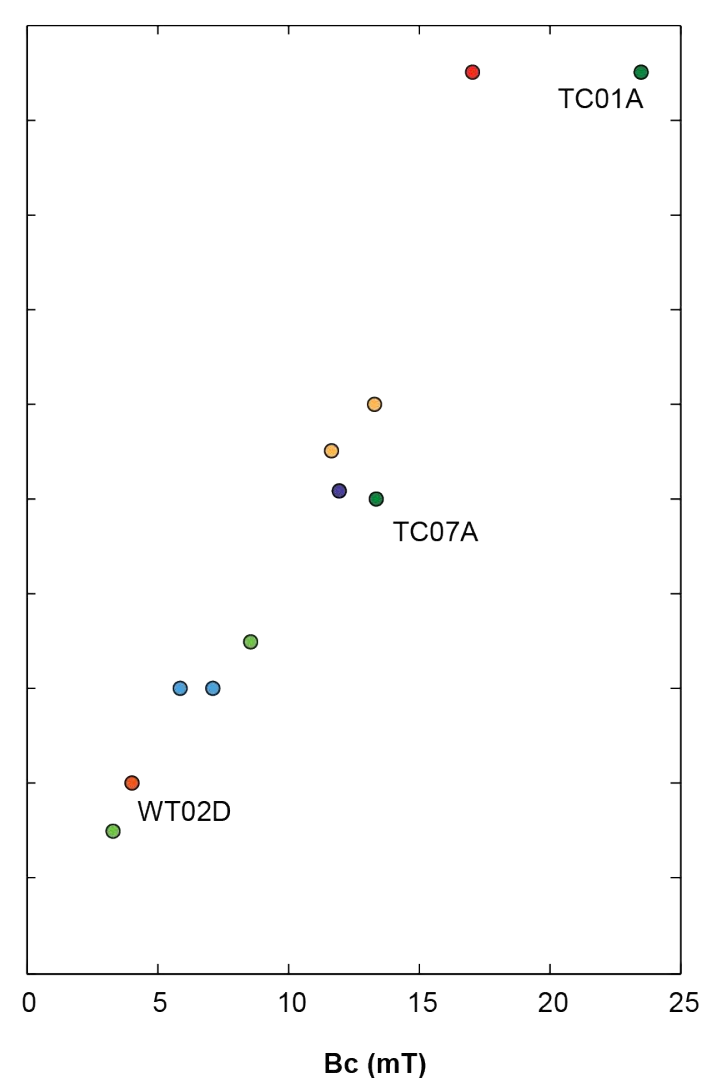

c)

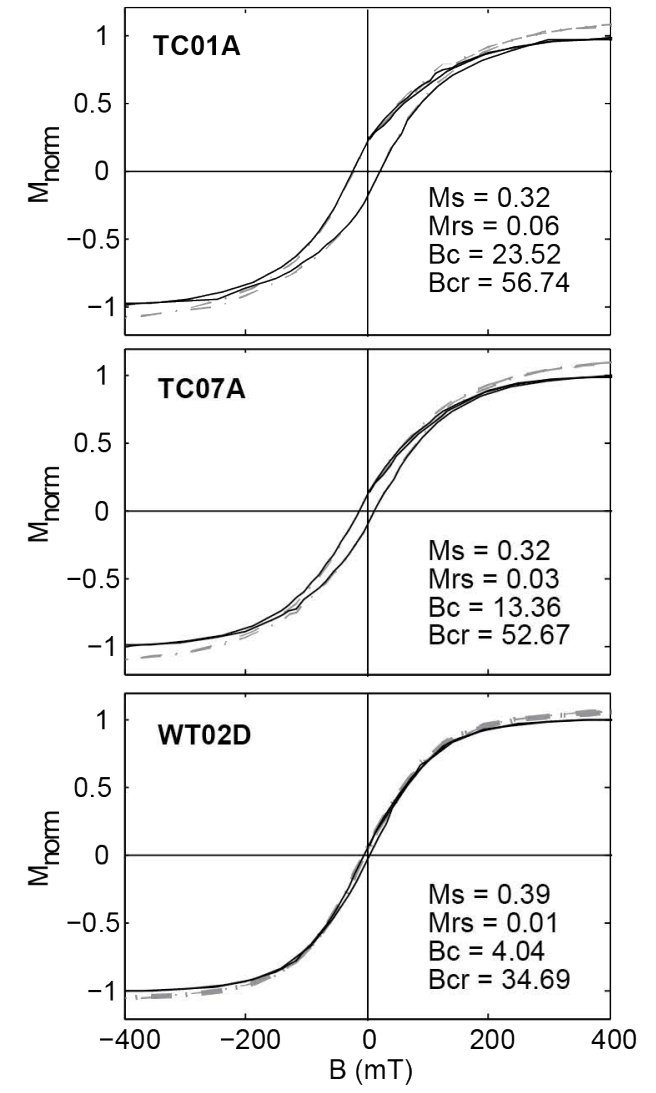

Figure 5-3: Hysteresis properties for the rhyolitic lavas. a) "Day-plot" including a theoretical mixing curve and boundaries between PSD and MD-type behaviour as defined by Dunlop (2002). b) $\mathrm{M}_{\mathrm{rs}} \mathrm{M}_{\mathrm{s}}$ vs. $\mathrm{B}_{\mathrm{c}}$ plot displaying the same data, but allowing identification of $\mathrm{B}_{\mathrm{c}}$. c) Typical hysteresis loops. Units for $\mathrm{M}_{\mathrm{s}}, \mathrm{M}_{\mathrm{rs}}$ are $* 10^{3} \mathrm{Am}^{2} / \mathrm{kg}, \mathrm{B}_{\mathrm{c}}, \mathrm{B}_{\mathrm{cr}}$ in $\mathrm{mT}$ 
Table 5-1: Rock magnetic properties extracted from IRM acquisition, backfield, hysteresis and thermomagnetic curves. The Curie temperatures were estimated from the point where the second derivative is at a maximum (Tauxe, 1998). Type is the thermomagnetic curve type, defined in Figure 5-4.

\begin{tabular}{|c|c|c|c|c|c|c|c|c|c|c|}
\hline Site & ID & $\mathbf{M}_{\mathrm{rs}}$ & $\mathbf{M}_{\mathrm{s}}$ & $\mathbf{B}_{\mathrm{c}}(\mathbf{m T})$ & $\mathbf{B}_{\mathrm{cr}}(\mathrm{mT})$ & $\mathbf{T}_{\mathrm{c} 1}(\mathrm{HC})$ & $\mathrm{T}_{\mathrm{c} 2}(\mathrm{HC})$ & $\mathbf{T}_{\mathrm{cl}}(\mathrm{CC})$ & $T_{\mathrm{c} 2}(\mathrm{CC})$ & Type \\
\hline HN01 & HNO2e & 0.14 & 2.31 & 5.88 & 36.21 & 482 & 542 & 557 & & 1 \\
\hline HN02 & HN16d & 0.14 & 2.23 & 7.13 & 59.17 & 494 & 564 & 549 & 473 & 1 \\
\hline HR01 & HR01d & 0.08 & 2.84 & 3.34 & 34.42 & 514 & & 479 & 565 & 3 \\
\hline HR02 & HR15d & 0.19 & 2.71 & 8.57 & 35.22 & 564 & & 553 & & 1 \\
\hline PH01 & PH09c & 0.98 & 5.25 & 17.08 & 43.08 & 545 & & 544 & & 2 \\
\hline ROT01 & ROT17c & 0.71 & 6.77 & 11.67 & 31.53 & 544 & & 459 & & 3 \\
\hline ROT02 & ROT30c & 0.4 & 3.37 & 13.33 & 39.86 & 554 & & 529 & & 3 \\
\hline $\mathrm{TC} 01$ & $\mathrm{TC} 01 \mathrm{a}$ & 0.6 & 3.17 & 23.52 & 56.74 & 574 & & 559 & & 2 \\
\hline TC02 & $\mathrm{TC} 07 \mathrm{a}$ & 0.34 & 3.23 & 13.36 & 52.67 & 574 & & 548 & & 2 \\
\hline WT01 & WT02d & 0.14 & 3.92 & 4.04 & 34.69 & 536 & & 523 & & 1 \\
\hline $\mathrm{AH} 02$ & $\mathrm{NZ02A}$ & 0.16 & 1.41 & 12.17 & 41.2 & 537 & & 546 & & 1 \\
\hline
\end{tabular}

Note: Site is the Site ID, ID the specimen ID, $\mathrm{T}_{\mathrm{c} 1}(\mathrm{HC}), \mathrm{T}_{\mathrm{C} 2}(\mathrm{HC})$ are the Curie temperatures extracted from the heating curves, $\mathrm{T}_{\mathrm{Cl}}(\mathrm{CC})$ and $\mathrm{T}_{\mathrm{C} 2}(\mathrm{CC})$ are the ones extracted from the cooling curves. Type is the thermomagnetic curve type, defined in Figure 5-4. $\mathrm{M}_{\mathrm{rs}}$ and $\mathrm{M}_{\mathrm{s}}$ are given in $* 10^{4} \mathrm{Am} \mathrm{kg}^{-1}$.
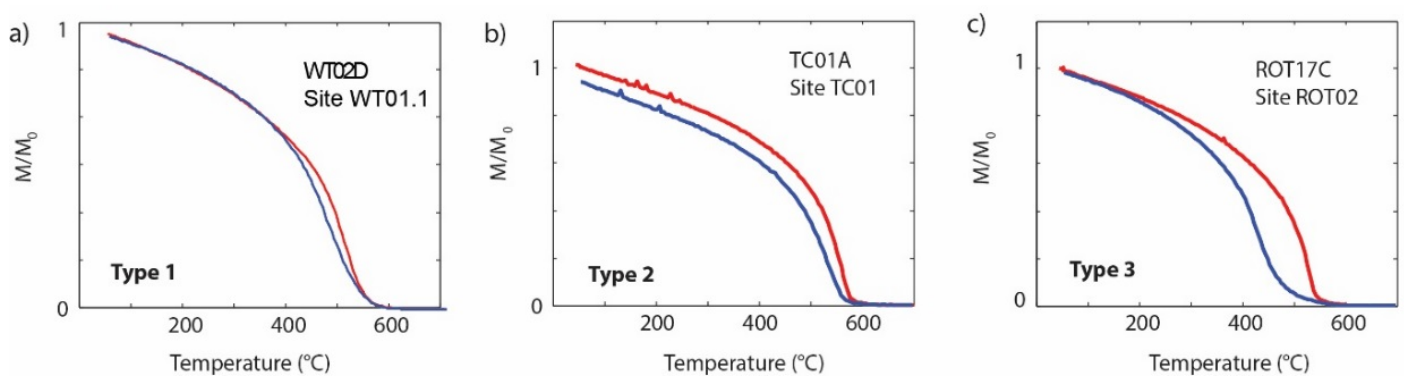

Figure 5-4: Representative thermomagnetic curves for the rhyolitic lavas sampled in this study. All three curves show one or two compositional phases with estimated Curie temperatures between 500 and $580^{\circ} \mathrm{C}$. See text for details. 


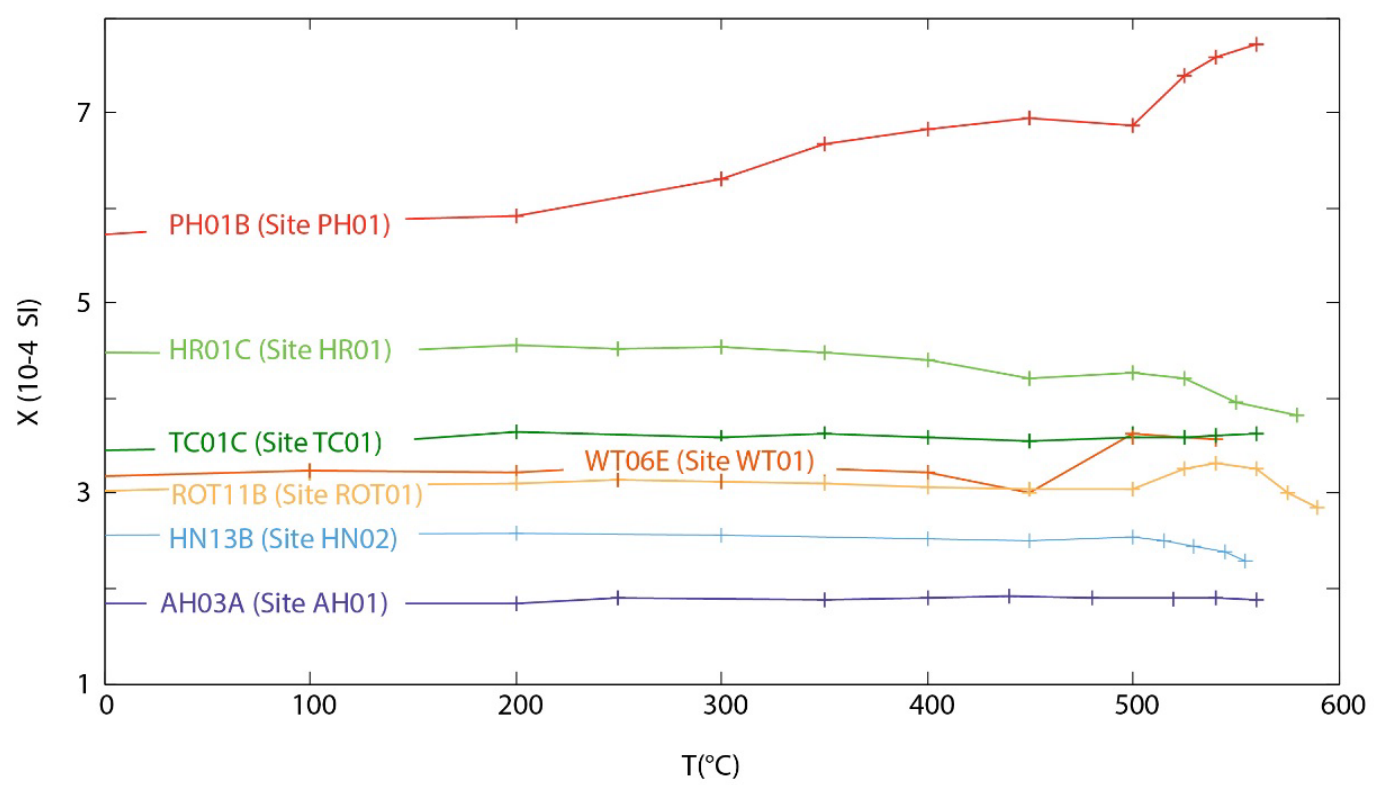

Figure 5-5: Typical sample behaviour during susceptibility checks, carried out on individual specimens following each heating step during THD experiments. Susceptibility checks are used in this chapter to identify the onset temperature of thermo-chemical alteration during heating experiments. 


\subsection{Demagnetisation methods and site averaging}

On the assumption that the characteristic remanent magnetisation (ChRM) is a thermoremanent magnetisation (TRM), demagnetisation experiments were focussed on thermal methods. At least five specimens, from different samples per site were subjected to stepwise demagnetisation using a Magnetic Measurements Ltd thermal demagnetiser. Temperature intervals were selected on the basis of the thermomagnetic properties and samples were held for 30 minutes at each temperature prior to cooling to ensure equilibration. Progressive demagnetisation was conducted until less than $10 \%$ of the natural remanent magnetisation (NRM) remained. The low-field magnetic susceptibility of individual specimens was monitored after each heating step using a Bartington MS2 meter with the aim of identifying any magnetomineralogical alteration. We also subjected two specimens per site to alternating field (AF) demagnetisation using a Molspin AF demagnetiser. Starting from a treatment step with a peak field of $5 \mathrm{mT}$, the peak field was increased in 5 $\mathrm{mT}$ increments from 0 up to $30 \mathrm{mT}$, subsequently the step size was increased to 10 mT. AF demagnetisation experiments were carried out to a maximum peak field of $95 \mathrm{mT}$, by which point a characteristic remanence (ChRM) could be clearly identified from all specimens. Following thermal or alternating field treatment steps, all specimens were measured using an AGICO JR6A spinner magnetometer. All data analysis was carried out using Remasoft 3.0 (Chadima and Hrouda, 2006). The remanence directions and intensities are displayed in vector component diagrams (Zijderveld, 1967). Statistical analysis was carried out following (Fisher, 1953). Flow mean and site means were calculated following the criteria and steps outlined below, and included the zero-field remanence measurements from palaeointensity experiments, where available:

- All core orientations were referenced to geographic coordinates using the orientations measured using a suncompass in the field. The sun-compass orientations usually differed by up to $3^{\circ}$ from the magnetic compass bearings and were accepted as more reliable. A table listing the individual sample orientations and differences between the magnetic and suncompass orientations can be accessed in the electronic appendices. 
- With the exception Waiti (WT) lava flow, ChRM directions were calculated from the most stable (high $\mathrm{T}_{\mathrm{b}}$ ) component using principal component analysis (PCA) (Kirschvink, 1980), using a minimum of five data points. On flows where block rotation was identified as source for thermal overprinting, the ChRM directions were selected from the most recent (low $\mathrm{T}_{\mathrm{b}}$ ) component. ChRM directions that did not lie within the cone of directions containing 95\% of all directions $(\theta 95)$ from a site were classified as outliers and rejected. For details on the interpretation of the demagnetisation results from Waiti (WT) flow specimens please refer to section 5.7.4.

- If more than one specimen was analysed from the same core, the ChRM directions extracted from each specimen were averaged into a sample mean.

- Site mean directions and associated cones of 95\% confidence $(\alpha 95)$ were calculated from all accepted sample means following Fisher (1953).

- If the site means of the same flow/unit agree at the $95 \%$ level of confidence or if the $95 \%$ confidence cones overlap it is assumed that all samples belong to the same population and an average for the respective unit is calculated from the individual sample directions. If a similar number of samples was available from each site, flow means were calculated from the sample means, otherwise flow means were calculated from the site mean directions. 


\subsection{Palaeomagnetic results}

As discussed in section 5.5 we noted little variation in the rock magnetic properties between individual units and sites sampled, and the subsequent behaviour during demagnetisation experiments is similar for many of the sites sampled. The sampling details and palaeomagnetic results are outlined for each unit and the results summarised in Table 5-2.

\subsubsection{Tapahoro flow (TC)}

Specimens have NRM intensities that range from 0.7 to $5 \mathrm{~A} / \mathrm{m}$ and demagnetise primarily in the temperature range $450-560^{\circ} \mathrm{C}$, and over a broad range of peak alternating fields between 5 and $90 \mathrm{mT}$. The vector component diagrams yield straight line decay with only small viscous overprints (Figure 5-6a). Site mean directions were calculated including the results from the palaeointensity experiments presented in section 5.9. The palaeomagnetic results from two specimens sampled from a small block at site TC01 yield an anomalously easterly declination and steep inclination and were excluded from the calculation of the site mean. The site mean from TC02 was calculated from three specimens only and therefore has a high $\alpha 95$. However the directions from the two sites are not distinct at the $95 \%$ confidence level, and give a mean direction of $\mathrm{Dec}=8.5^{\circ}, \mathrm{Inc}=-63.0^{\circ}, \alpha 95=4.2^{\circ}, \mathrm{N}=7$.

\subsubsection{Haroharo dome (HR)}

With values around $0.3 \mathrm{~A} / \mathrm{m}$ the specimen NRM intensities fall well into the range of intensities measured on most other rhyolitic samples discussed in the following sections. During THD specimens from both sites (HR01 and HR02) lose their remanence in two major blocking temperature intervals $\left(200-300^{\circ} \mathrm{C}\right.$ and $500-600^{\circ}$ C), the two components being slightly in different direction (Figure 5-6c). Separation of the two components is more difficult from the data of AF demagnetisation experiments, which are characterised by a rapid decrease in the remanence at peak fields lower than $20 \mathrm{mT}$, in agreement with the low $\mathrm{B}_{\mathrm{c}}$ measured during hysteresis experiments (Figure 5-6d). 
There are two possible interpretations for the presence of a low temperature component: It could be either caused by a chemical remanent magnetisation (CRM), carried for example by a maghemite that inverts to a more stable endmember (e.g. hematite) between 200 and $300^{\circ} \mathrm{C}$ and thus causing a sudden decrease in the NRM intensity. However such an inversion or similar alteration effects would manifest in a sudden change of the magnetic susceptibility monitored alongside the heating experiment, which we did not find (see electronic appendix). We did not identify any secondary compositional phases in the thermomagnetic curves (section 5.5) and thus suggest that the sampled outcrop moved during cooling. In this case, the low temperature component contains the most recent reliable record of the palaeomagnetic field. The mean calculated from the low temperature component from HR01 specimens $\left(\mathrm{Dec}=15.0^{\circ}, \mathrm{Inc}=-59.9^{\circ}, \alpha 95=4.5^{\circ}, \mathrm{N}=6\right)$ agrees with the flow mean obtained from Tapahoro flow (TC) (Table 5-2), which was emplaced during the same eruptive episode and also supports the later interpretation. The sub-site means calculated from the low temperature component at site HR02 disagree and are of more westerly direction (Figure 5-9b), suggesting that block movement at this site continued after cooling (Mean site HR02.1: Dec $=354.6^{\circ}, \mathrm{Inc}=-54.5^{\circ}, \alpha 95=4.2^{\circ}, \mathrm{N}=5$; HR02.2: $\operatorname{Dec}=350.9^{\circ}$, Inc $=-71.9^{\circ}, \alpha 95=7.3^{\circ}, \mathrm{N}=3$ ). 

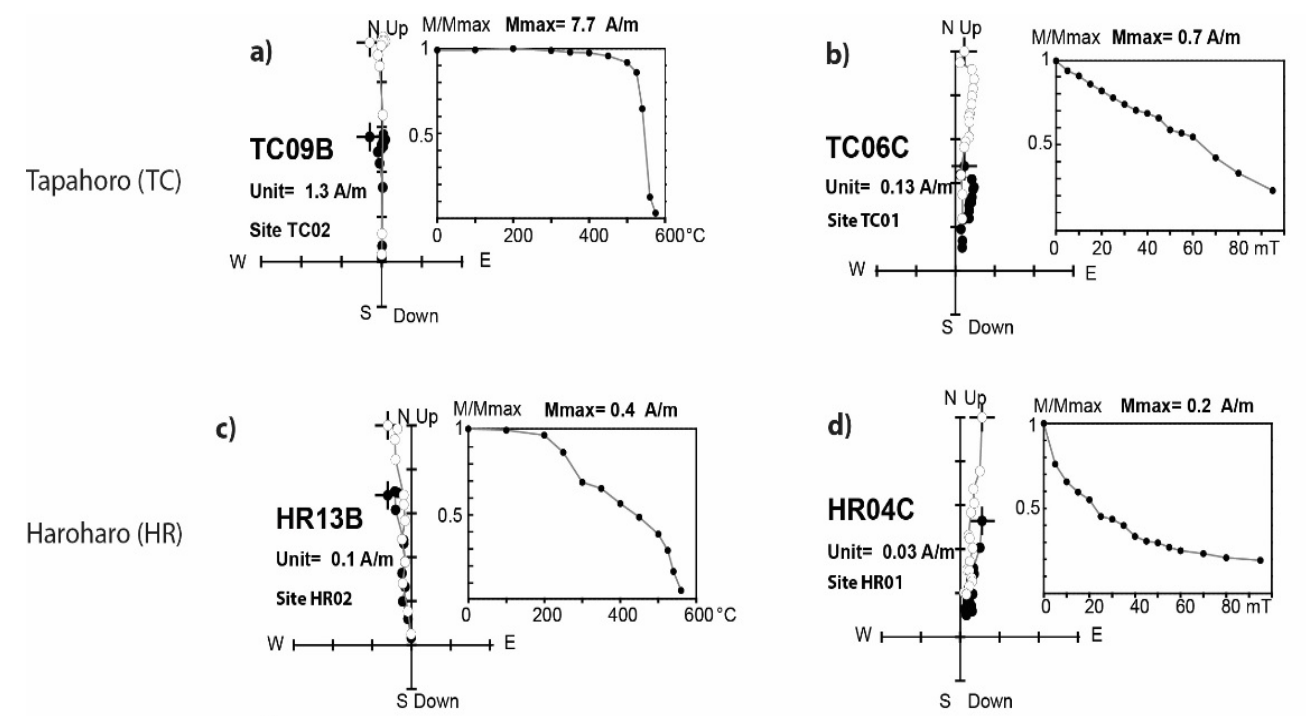

e)
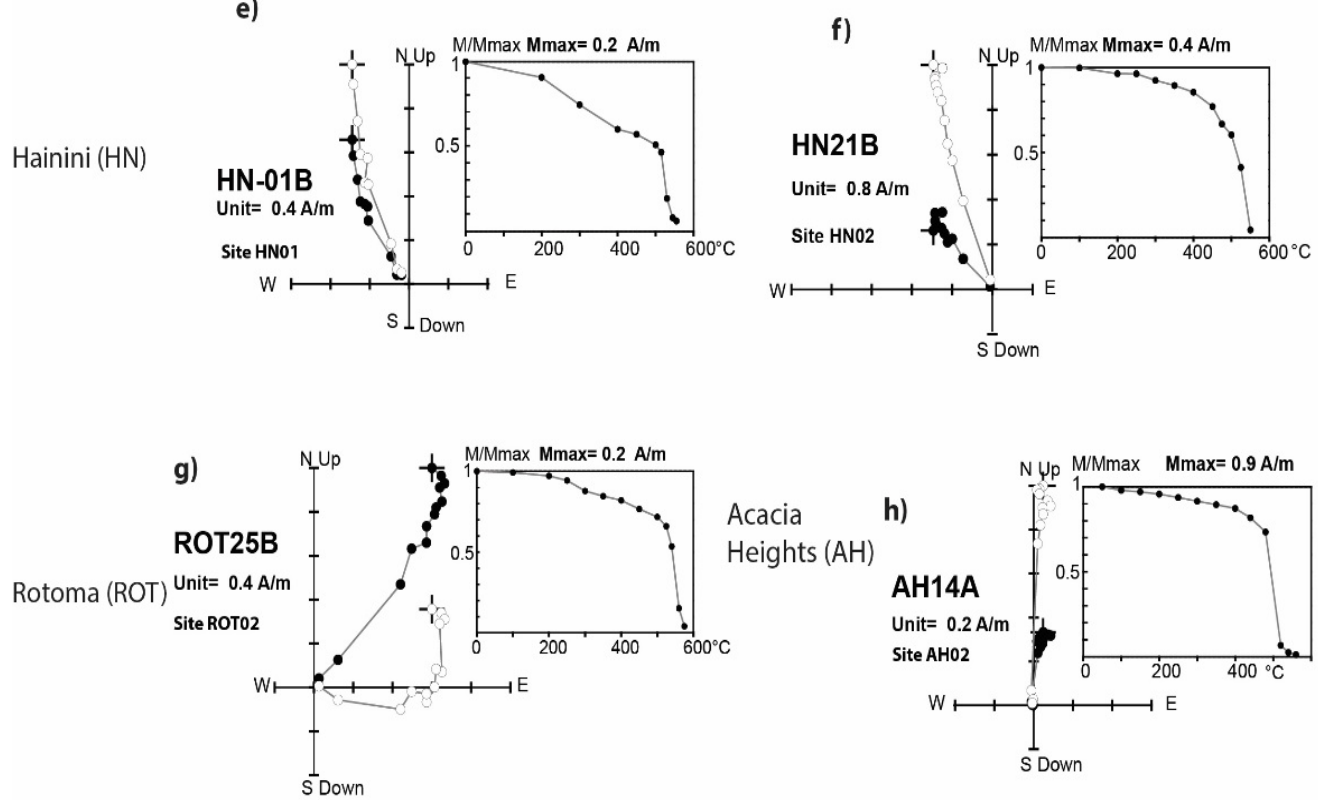

Figure 5-6: Representative vector component and corresponding $\mathrm{M} / \mathrm{M}_{0}$ plots on rhyolitic lavas for units TC, HR, HN, ROT and AH. See text for details. 


\subsubsection{Hainini dome (HN)}

Specimens from site HN01 demagnetise in two steps $\left(200-400^{\circ} \mathrm{C}\right.$ and $\left.500-600^{\circ} \mathrm{C}\right)$, with the low temperature component showing a more easterly direction than the high temperature component. In contrast, all specimens from site HN02 show linear decay to the origin in the range of $400^{\circ} \mathrm{C}$ to $600^{\circ} \mathrm{C}$ (Figure 5-6f). The mean calculated from the low blocking temperature component from site HN01 is consistent with the direction obtained from the entire blocking temperature interval from site HN02 specimens. We therefore suggest that site HN01 may have been subject to some form of block movement during cooling, for example during endogeneous dome growth and calculate a best mean from the most recently magnetised components discussed above: $\operatorname{Dec}=326.5^{\circ}$, Inc $=-61.3^{\circ}, \alpha 95=3.6, \mathrm{~N}=16$.

\subsubsection{Waiti flow (WT)}

All WT specimens demagnetise over a broad blocking temperature range between 200 and $580^{\circ} \mathrm{C}$ but demagnetise rapidly during $\mathrm{AF}$ treatment, with median destructive fields around $7 \mathrm{mT}$. Specimens from both sub-sites carry overprints of random direction and the ChRM usually only comprises $10-20 \%$ of the total NRM (Figure 5-7 a,b,c). The ChRM can be resolved more successfully from AF data than from the results of thermal experiments. In fact, while during thermal experiments a ChRM direction could only be defined within a very narrow blocking temperature interval at temperatures higher than $500^{\circ} \mathrm{C}$, the overprints are removed at an applied field of 20 mT during AF treatment (Figure 5-7c). Tanaka et al. (2009) identified a similar overprint on their samples and suggested that it may either be of viscous nature, carried by the very low coercivity or multi-domain grains consistent with the low coercivities measured during hysteresis experiments. Otherwise it could be an isothermal remanent magnetisation (IRM) produced, by lightning strike or during the construction of the road cut. ChRM endpoint directions were defined from three specimens from sub-site WT01.1 and the AF demagnetisation results on one specimen from sub-site WT01.2. Data from each other specimen was fitted with the best fitting great circle (normalized) (Figure 5-7d). A mean direction for the flow was calculated from the four ChRM 
directions and the best fitting direction on each remagnetisation great circle, determined using the iterative procedure outlined in by McFadden and McElhinny (1988). Best mean: Dec $=352^{\circ}$, Inc $=-50.8^{\circ}, \alpha 95=5.0^{\circ}, \mathrm{N}=8$.
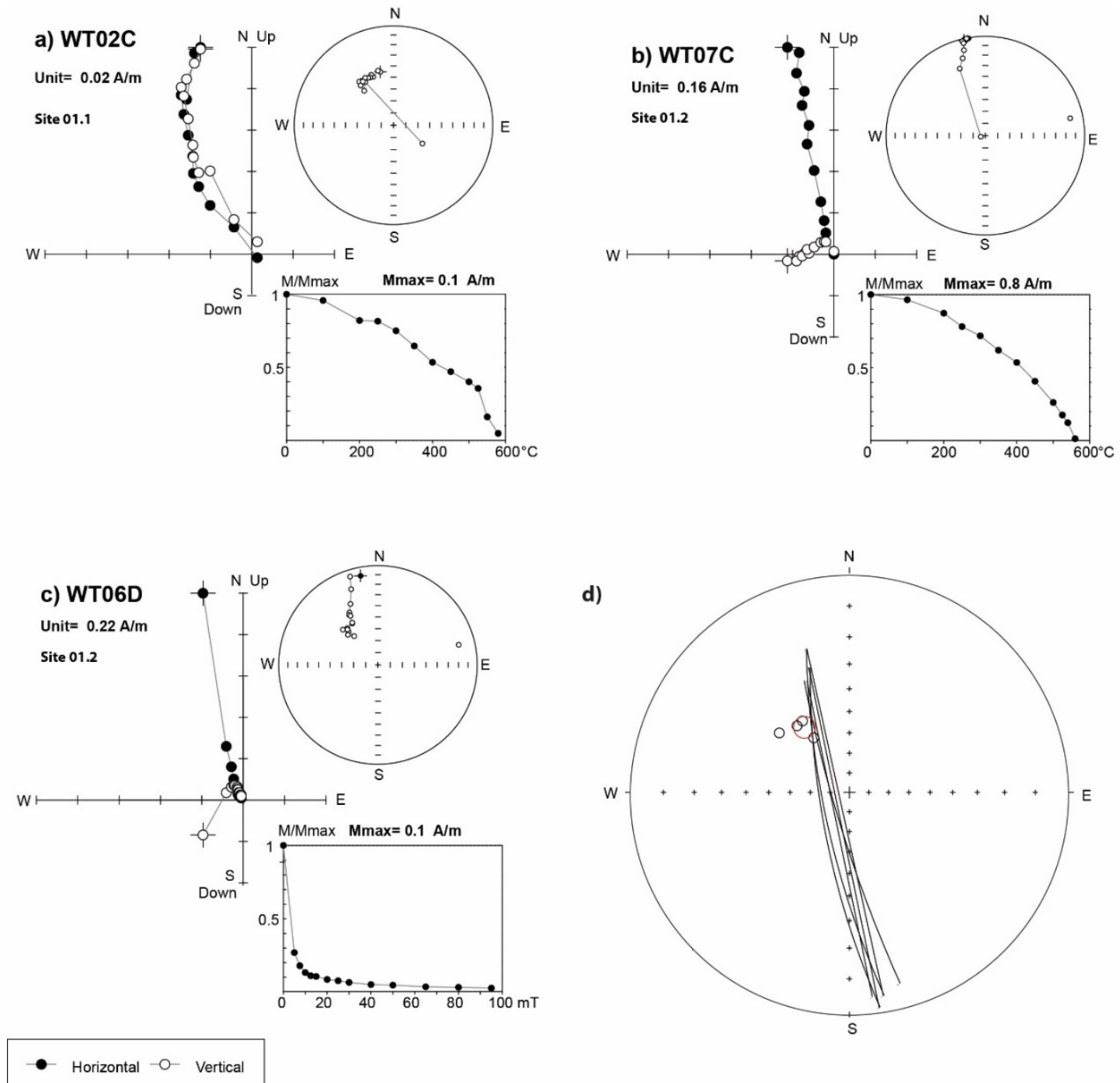

Figure 5-7: Representative Zijderveld, stereoplot and $\mathrm{M} / \mathrm{M}_{0}$ plots from rhyolitic lavas for Waiti lava flow (WT). a) THD data for a site WT01.1 specimen b) THD data for a site WT01.2 specimen, c) AF demagnetisation data for a site WT01.2. specimen and d) stereographic projection of the endpoint ChRM selected from suitable specimens and remagnetisation great circles for specimen directions with strong overprints. 


\subsubsection{Rotoma flow (ROT)}

The behaviour of samples from the individual sites and sub-sites differs. In general, all specimens lose their remanence primarily between 400 and $560^{\circ} \mathrm{C}$, hower single component remanences were only identified on specimens from sub-site 1.1 while all other specimens are strongly overprinted (Figure 5-6g). The ChRM directions extracted agree at a sub-site level, however the individual site means disagree with each other and are thus treated separately (Figure 5-9b). None of the mean directions agree with Tanaka et al.'s (2009) best estimate (NK19: Dec $=357.6^{\circ}$, Inc $=-61.5^{\circ}$, $\alpha 95=4.3^{\circ}, N=7$ ). We suggest that the outcrops sampled were subject to some form of block movement along the flow-top surface or margins during cooling. A reliable direction estimate could therefore not be made for this flow.

\subsubsection{Acacia Heights dome (AH)}

All specimens demagnetise in a narrow blocking temperature interval between 450 and $550^{\circ} \mathrm{C}$, and yield straight line decay to the origin with only minor viscous overprints (Figure 5-6h) which is consistent with the thermomagnetic curves measured (section 5.5). In order to detect any potential post-cooling block movement on the dome top we calculated mean directions for each individual sub-site. Overlap between the $95 \%$ confidence cones is seen for all sub-sites other than AH01.4. Specimens from AH01.4 show an anomalously low inclination (Figure 5-9d). While the source could not be identified based on field relations, we rejected all data from this sub-site, in consideration of the inconsistency between this result and those of other sub-sites close-by. The site means from AH02 and AH03 are steeper than the mean direction found at site $\mathrm{AH} 01$ and we suggest that some form of minor block movement occured after cooling. Assuming that the small-scale block movements noted were random, a site mean was calculated from the mean directions of individual sub-sites and our best estimate is $\operatorname{Dec}=6.1^{\circ}$, Inc $=-69.7^{\circ}, \alpha 95=8.2, \mathrm{~N}=6$ (mean direction if calculated from all sample directions: $\mathrm{Dec}=4.7^{\circ}, \mathrm{Inc}=-69.1^{\circ}, \alpha 95=2.8, \mathrm{~N}=31$ ). 


\subsubsection{Pokuhu flow (PH)}

With an average NRM intensity of ca. $5 \mathrm{~A} / \mathrm{m}$, samples from this flow are one order of magnitude more strongly magnetised than most other rhyolitic samples discussed in the sections above. In addition, all specimens from this flow showed unusual behaviour during thermal demagnetisation. While the NRM direction measured is of normal polarity, stepwise THD revealed a distinct reversed polarity component in the $\mathrm{T}_{\mathrm{b}}$ range between 300 and $500^{\circ} \mathrm{C}$, which causes a net increase in the magnetic remanence by approximately $20 \%$ (Figure 5-8a). Further demagnetisation results in a rapid loss in remanence in a narrow blocking temperature interval between 500 and $560^{\circ} \mathrm{C}$. During AF demagnetisation samples demagnetise over a broad coercivity range between 10 and $50 \mathrm{mT}$, and at a peak field of $90 \mathrm{mT} \sim 20 \%$ of the remanence remains (Figure 5-8b). This compares well with the relatively high coervities found during hysteresis experiments (section 5.5.2). However in contrast to the results of thermal demagnetisation experiments, during AF demagnetisation all samples yield linear decay to the origin with no reversed polarity component. In chapter 3 we described a similar antipodal component within a narrow blocking temperature interval in andesitic samples from Delta Corner (DC) lava from Mt Ruapehu. We associated it with some form of self reversal during the magnetisation process, however further study is required to fully understand the physical origin of these results. ChRM directions were selected from the high $\mathrm{T}_{\mathrm{b}}$ component in thermal demagnetisation experiments and the entire $T_{b}$ distribution in AF demagnetisation plots, such as suggested in chapter 3 , giving a mean of Dec $=14.6^{\circ}$, Inc $=-54.2^{\circ}$, $\alpha 95=5.5^{\circ}, \mathrm{N}=7$. 
a)

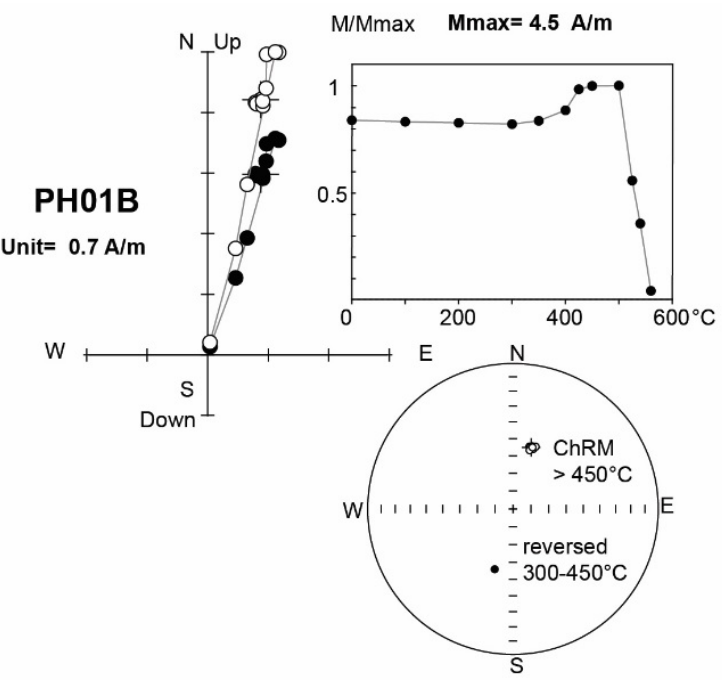

b)

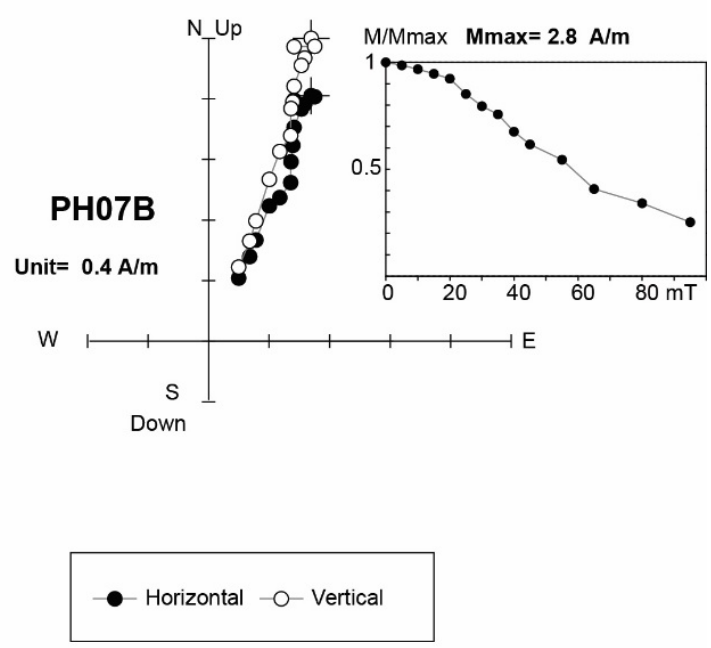

Figure 5-8: Representative Zijderveld and $\mathrm{M} / \mathrm{M}_{0}$ from Pokuhu lava flow (inset). a) THD diagrams, we also display a stereonet displaying the ChRM and antipodal components b) AF demagnetisation diagram. 
a)

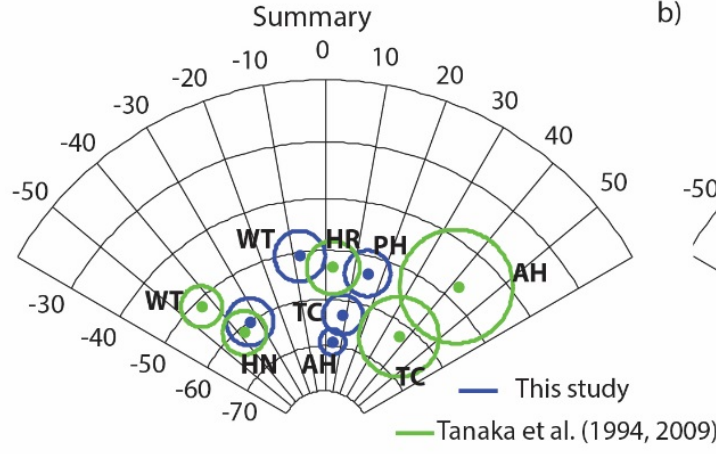

Whakatane $(5526 \pm 145 \mathrm{cal}$ yrs BP $)$

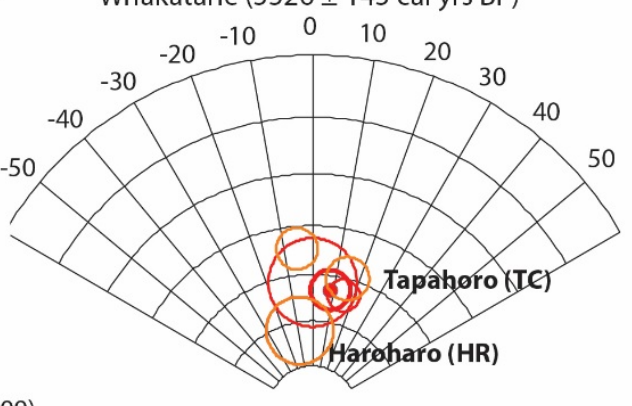

c) and Pokohu (Waiohau: $9423 \pm 120$ cal yrs BP)

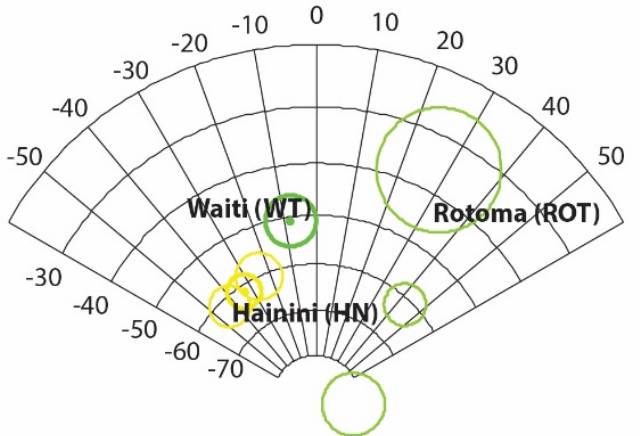

d) Acacia Heights $(11150 \pm 115$ cal yrs BP $)$ and Pokohu (Waiohau: $14009 \pm 155$ cal yrs BP)

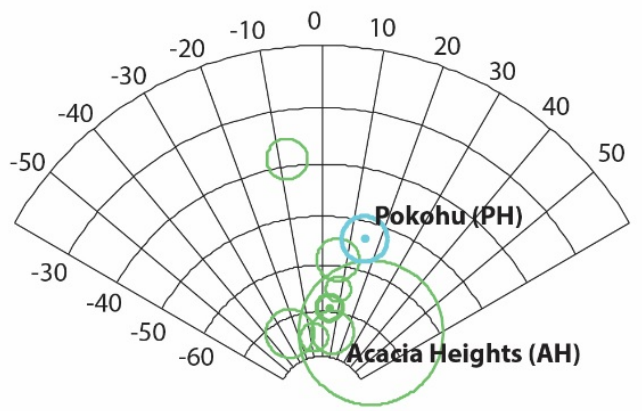

Figure 5-9: Equal angle (Wulff) projections of the site means of the rhyolitic lavas studied. a) Mean directions and associated 95\% confidence cones for all units that were successfully re-sampled in this study in comparison to the data previously published. b, c, d) $\alpha 95$ about site mean ChRM directions for the individual sites sampled and our best mean estimates (bold) on units where the site means overlap b) OVC units associated with the Whakatane c) Mamaku and Rotoma eruptive episodes d) for the Taupo- sourced Acacia Heights dome and OVC Pokuhu flow (Waiohau eruptive sequence). 
Table 5-2: Summary of all TVZ sites and units sampled in this study showing the associated eruptive episode and most recently published tephra ages for each unit. Both the site and flow mean palaeomagnetic directions are presented together with previously published palaeomagnetic results.

\begin{tabular}{|c|c|c|c|c|c|c|c|c|c|}
\hline Unit & $\begin{array}{l}\text { Eruptive } \\
\text { episode }\end{array}$ & $\begin{array}{l}\text { Tephra age } \\
\text { (cal yrs BP) }\end{array}$ & Site & Lat (S) & Long (E) & $\operatorname{Dec}\left({ }^{\circ}\right)$ & Inc $\left(^{\circ}\right)$ & $\alpha 95\left(^{\circ}\right)$ & $\mathbf{N} / \mathbf{n}^{\prime} \mathbf{n}_{0}$ \\
\hline \multirow[t]{2}{*}{$\begin{array}{l}\text { Tapahoro } \\
\text { flow }\end{array}$} & Whakatane & $5526 \pm 145$ & 1 & 38.1657 & 176.5176 & 15.2 & -63.6 & 3.4 & $4 / 8 / 11$ \\
\hline & & & 2 & 38.1657 & 176.5176 & 0.1 & -61.7 & 9.2 & $3 / 3 / 3$ \\
\hline \multicolumn{6}{|c|}{ Mean direction for Tapahoro lava flow } & 8.5 & -63.0 & 4.2 & 7 \\
\hline \multicolumn{6}{|c|}{ Mean direction published in Tanaka et al. (2009) (NK02) } & 37 & -62.7 & 8.4 & 7 \\
\hline
\end{tabular}

This study: Flow mean calculated from the sample ChRM directions from sites TC01 and TC02, including the data from both demagnetisation experiments and the ChRM directions extracted from the zero-field remanence measurements made during palaeointensity experiments.

\begin{tabular}{llrlllllll}
\hline $\begin{array}{l}\text { Haroharo } \\
\text { dome }\end{array}$ & Whakatane & $5526 \pm 145$ & 1 & 38.1073 & 176.5024 & 15.0 & -59.9 & 4.5 & $6 / 6 / 8$ \\
& & 2.1 & 38.0932 & 176.5098 & 354.6 & -54.5 & 4.2 & $5 / 5 / 5$ \\
& & & & & & & & &
\end{tabular}

Individual sub-site means are treated independently and are different at the $95 \%$ confidence level, suggesting post-cooling block movement. A flow mean was not calculated.

\begin{tabular}{lrrrrrrr}
\hline $\begin{array}{l}\text { Hainini } \\
\text { dome }\end{array}$ Mamaku $7940 \pm 257$ & 1 & 38.1180 & 176.4756 & 317.2 & -61.9 & 4.3 & $8 / 12 / 14$ \\
& 2 & 38.1185 & 176.4736 & 335.3 & -60.0 & 4.9 & $7 / 12 / 12$ \\
& & & & $\mathbf{3 2 6 . 5}$ & $\mathbf{- 6 1 . 3}$ & $\mathbf{3 . 6}$ & $\mathbf{1 6}$ \\
Mean direction for Hainini Dome & & & & 321.8 & -61.2 & 4.6 & 7
\end{tabular}

This study: Flow mean calculated from the sample ChRM directions from sites HN01 and HN02, including the data from both demagnetisation experiments and the ChRM directions extracted from the zero-field remanence measurements made during palaeointensity experiments.

\begin{tabular}{lrrrrrr}
\hline Waiti flow Rotoma & $9423 \pm 120$ & 38.0796 & 176.4834 & 352.0 & -50.8 & 5.0 \\
Mean direction published in Tanaka et al. (2009) (NKO6) & & & 316.2 & -51.3 & 4.1 & 7
\end{tabular}

This study: Analysis conducted following McFadden and McElhinny (1988), refer to section 5.7.4 for details.

\begin{tabular}{|c|c|c|c|c|c|c|c|c|c|}
\hline \multirow[t]{3}{*}{$\begin{array}{l}\text { Rotoma } \\
\text { flow }\end{array}$} & Rotoma & $9423 \pm 120$ & 1.1 & 38.0381 & 176.5724 & 96.7 & -81.5 & 7 & $6 / 6 / 6$ \\
\hline & & & 1.2 & & & 28.2 & -35.6 & 10.6 & $3 / 3 / 4$ \\
\hline & & & 2.2 & 38.0373 & 176.562 & 43.1 & -61.2 & 4.4 & $3 / 3 / 3$ \\
\hline Mean dir & publishe & ka et al. $(20$ & $K 19$ & & & 357.6 & -61.5 & 4 & 7 \\
\hline
\end{tabular}

This study: Individual sub-site means are treated independently and are different at the $95 \%$ confidence level, suggesting post-cooling block movement. A flow mean was not calculated.

\begin{tabular}{|c|c|c|c|c|c|c|c|c|}
\hline \multirow[t]{7}{*}{ Acacia Heights dome } & \multirow[t]{7}{*}{$11150 \pm 115$} & 1.1 & \multirow[t]{4}{*}{38.7032} & \multirow[t]{4}{*}{176.0244} & 3.3 & -56.2 & 6.0 & $4 / 4 / 4$ \\
\hline & & 1.2 & & & 10.2 & -63.9 & 2.8 & $6 / 8 / 8$ \\
\hline & & 1.3 & & & 334.8 & -73.3 & 5.3 & $3 / 3 / 3$ \\
\hline & & 1.4 & & & 352.7 & -38.4 & 6.2 & $3 / 5 / 5$ \\
\hline & & 2.1 & \multirow[t]{3}{*}{38.7058} & \multirow[t]{3}{*}{176.0228} & 354.8 & -75 & 4.1 & $5 / 7 / 11$ \\
\hline & & 2.2 & & & 13.9 & -73.7 & 4.7 & $5 / 7 / 7$ \\
\hline & & 3 & & & 35.7 & -71.2 & 15.2 & $1 / 2 / 2$ \\
\hline \multicolumn{5}{|c|}{ Mean direction for Acacia Heights dome } & 6.1 & -69.7 & 8.2 & 6 sites \\
\hline \multicolumn{5}{|c|}{ Mean direction published in Tanaka et al. (2009) (NZ09) } & 41.5 & -47.3 & 10.7 & 7 \\
\hline
\end{tabular}

This study: Individual sub-site means are treated independently. The origin of small-scale inter-site differences in the palaeomagnetic results are not known but assumed to be random and a flow mean was calculated from the site means. The individual site means were calculated including the data from both demagnetisation experiments and the ChRM directions extracted from the zero-field remanence measurements made during palaeointensity experiments. 


\begin{tabular}{|c|c|c|c|c|c|}
\hline 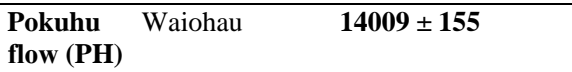 & $\begin{array}{ll}38.165 & 176.519\end{array}$ & 14.6 & -54.2 & 5.5 & $7 / 9 / 10$ \\
\hline $\begin{array}{l}\text { Mean direction published in Tanaka et al. (2009) } \\
\text { (NK01) }\end{array}$ & & 2.8 & -53.4 & 5.3 & 7 \\
\hline
\end{tabular}

Note: he tephra ages from Lowe et al (2013) are given in calendar years before present with $2 \sigma$ confidence limits. Lat and Long are the site latitude and longitude, respectively. Dec is the ChRM declination and Inc the ChRM inclination. $\mathrm{N} / \mathrm{n} / \mathrm{n}_{0}=$ total number of samples included in the average/total number of specimens included/ total number of specimens demagnetised.

\subsection{Palaeointensity methods}

\subsubsection{Experimental procedures}

Palaeointensity experiments were carried out on samples from sites that showed consistent ChRM directions during THD and AFD, including Tapahoro, Hainini, Pokuhu and Acacia Heights lavas.

All palaeointensity experiments were carried out using the thermal palaeointensity method (Thellier and Thellier, 1959), following the Coe-type protocol (Coe, 1967) and including additional tail-checks (Riisager and Riisager, 2001). Some experiments on samples from Acacia Heights dome were also conducted using the IZZI type protocol (Yu et al., 2004). Please refer to chapters 2 and 4 description of the individual procedures. In this study we used a laboratory field of $50 \mu \mathrm{T}$ during in-field steps, which is close to the average palaeointensity expected for the time-period. Each experiment was accompanied by susceptibility checks on individual specimens following each heating interval. The laboratory field was applied along the z-axis for each specimen, however the field was alternated between being applied parallel or antiparallel to the remanence direction, with the aim of enhancing potential pTRM tails (chapter 4). Temperature intervals were selected on the basis of behaviour observed during thermal demagnetisation experiments and, while we used large step sizes of 100 or $200^{\circ} \mathrm{C}$ up to a temperature of $500^{\circ} \mathrm{C}$, we subsequently decreased the temperature increments to $15^{\circ} \mathrm{C}$.

\subsubsection{Data analysis and selection criteria}

The data analysis was carried out using ThellierTool 4.11 (Leonhardt et al., 2004a) and the results were displayed in Arai plots, in which the NRM remaining after each 
zero-field demagnetisation step is plotted against the TRM gained during the corresponding in-field step. Palaeointensities were calculated from the best fitting slopes to selected data points. Based on the quality of the best fitting slope in the Arai plot, pTRM and tail checks we classify the individual specimen results into those that pass the more stringent TTA* selection criteria or the less stringent TTB* of Leonhardt et al. (2004a) and modified by Paterson et al. (2014). The individual statistical parameters were detailed in chapter 4 and calculated following the "Standard Palaeointensity Definitions v1.0" by Paterson et al. (2014) and the values are summarized in Table 5-3.

\subsection{Palaeointensity results}

Successful palaeointensity estimates were obtained on 12 out of 25 specimens, and include samples from Tapahoro (TC) lava flow, Hainini dome (HN) and Acacia Heights dome (AH). Representative Arai-plots and their corresponding vector component diagrams are shown in Figure 5-10, and the results discussed unit by unit below.

\subsubsection{Tapahoro flow (TC)}

All specimens yield a single component direction in the zero-field remanence steps and excellent repeatability in the ability to grow a TRM throughout the $T_{b}$ spectrum as seen from pTRM checks. However the relation between NRM and TRM displayed in the Arai plots yields a slightly concave upwards shape. A linear fit to the low temperature segment $\left(\mathrm{T}<500^{\circ} \mathrm{C}\right)$ of the plot yields a steeper slope than an approximation to data from the high temperature segment $\left(\mathrm{T}=500-580^{\circ} \mathrm{C}\right)$ (Figure 5-10a). The resultant palaeointensity estimates for all specimens average to $61.3 \pm$ $2.8 \mu \mathrm{T}$ for the low temperature, $31.1 \pm 1.8 \mu \mathrm{T}$ for the high temperature component and $45.5 \pm 1.5 \mu \mathrm{T}$ if data from throughout the entire $\mathrm{T}_{\mathrm{b}}$ spectrum is included (Figure 5-10b, Table 5-3). In all three cases the data pass the selection criteria set TTB*. The lowest palaeointensity estimate is consistent with the estimate of $31.0 \pm 3.5 \mu \mathrm{T}$ published in 
Tanaka et al. (2009), which like ours is based on the high temperature segment only. However, we did not see indication of a separate low $\mathrm{T}_{\mathrm{b}}$ directional component to justify the exclusion of any data. We also noted small differences between the remanence measured during zero-field and later tail checks and therefore suggest that this behaviour may be indicative of slight MD behaviour. Levi (1977) shows that for MD magnetites that do not alter during an experiment, an accurate palaeointensity estimate could be made from the two endpoint ratios within the Arai plots which correlates with the average calculated from the entire $T_{b}$ spectrum. We therefore suggest that the intensity result provided by Tanaka et al. (2009) may be an underestimate and prefer our intermediate value of $45.5 \pm 1.5 \mu \mathrm{T}$, which is close to the value calculated from the endpoint ratios only.

\subsubsection{Hainini dome (HN)}

The palaeointensity results on most specimens pass at least the selection criteria TTB*, however in consideration of the block rotation discussed in section 5.7.3, all data from site HN01 were discarded. All successful specimens show a drop in the magnetic susceptibility at heating steps to temperatures higher than $500^{\circ} \mathrm{C}$ which correlates with a change in the relation between NRM and pTRM displayed in the Arai diagrams. We therefore reject all high temperature data from the calculation of intensities. Our final palaeointensity estimate of $51.7 \pm 3.2 \mu \mathrm{T}(\mathrm{N}=3 / 10)$ is placed near Tanaka et al.'s (2009) estimate of $58.1 \pm 2.9 \mu \mathrm{T}$.

\subsubsection{Acacia Heights dome (AH)}

High quality palaeointensity data was obtained from 5 out of 6 specimens studied from Acacia Heights dome (AH). Experiments on this unit were carried out using the IZZI protocol. As discussed in section 5.7.6 the magnetic remanence is primarily carried within a narrow blocking temperature interval between 480 and $520^{\circ} \mathrm{C}$. Samples do not alter, resulting in excellent repeatability of the ability to grow a pTRM throughout the experiments. No or insignificant scatter about the best fitting slope in the Arai 
diagrams was noted during IZZI experiments and the remanence direction shows single component decay to the origin (Figure 5-10e). Our best mean intensity from five successful specimens is $63.3 \pm 1.2 \mu \mathrm{T}(\mathrm{N}=4 / 5)$.

\subsubsection{Pokuhu flow (PH)}

All palaeointensity experiments carried out on samples from Pokuhu flow fail. As discussed in section 5.7.7, all specimens from this flow carry a component with a remanence direction that is antipodal to the overall remanence direction in the blocking temperature interval $300-500^{\circ} \mathrm{C}$, resulting in an increase of the $\mathrm{NRM}$ intensity in zerofield remanence and Arai plots by up to 20\%. pTRM and tail checks fail at temperatures $\mathrm{T}>500^{\circ} \mathrm{C}$ (Figure 5-10e). 
(Page intentionally left blank) 
a) $\mathrm{NPM}\left({ }^{*} 0.79766 \mathrm{~mA} / \mathrm{m}\right)$

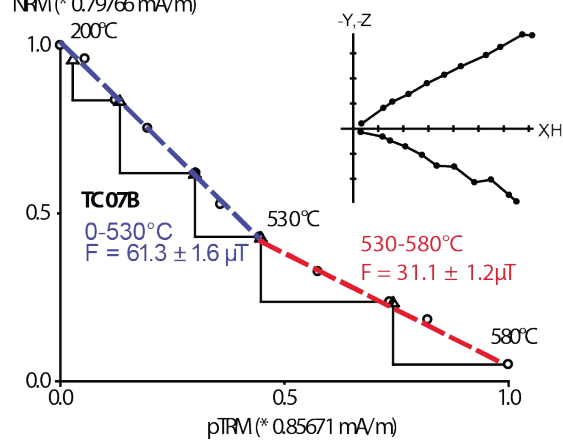

Tapahoro (TC)

Hainini (HN)

C)

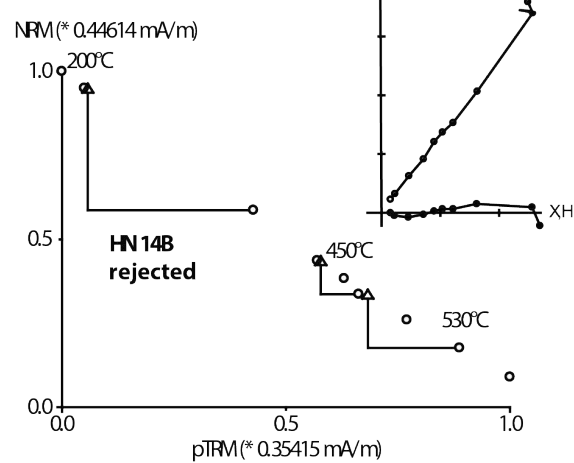

e)

Acacia Heights $(\mathrm{AH})$

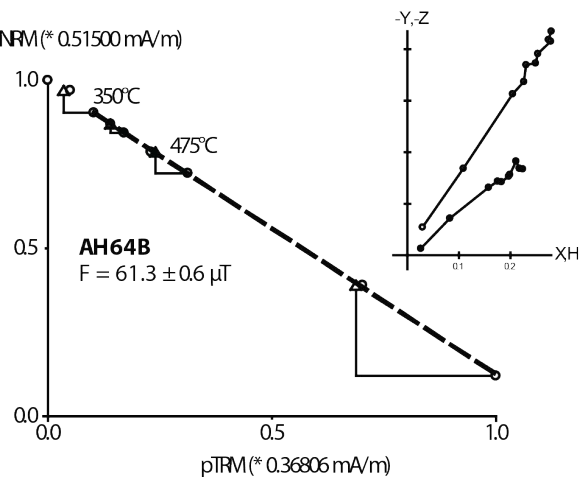

g)

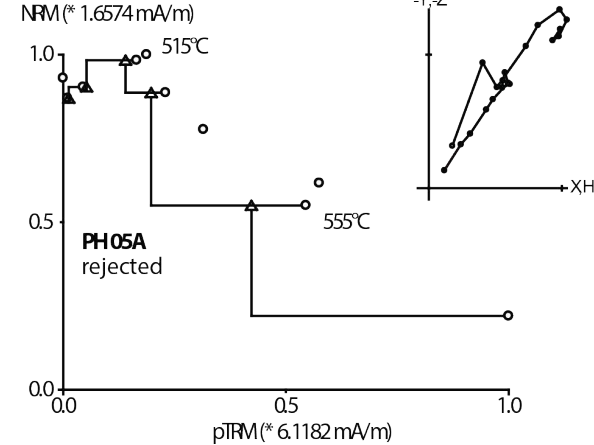

b)

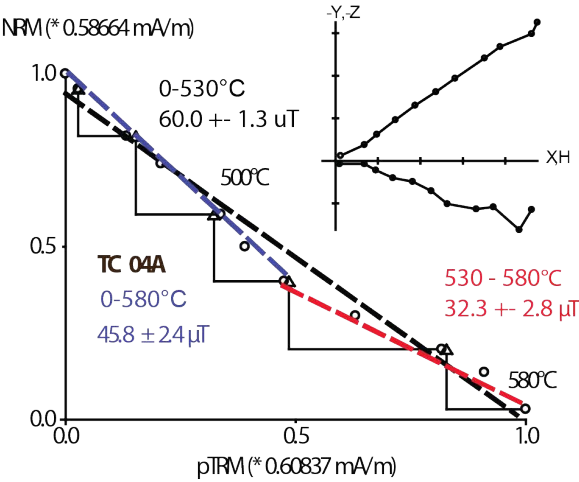

d)

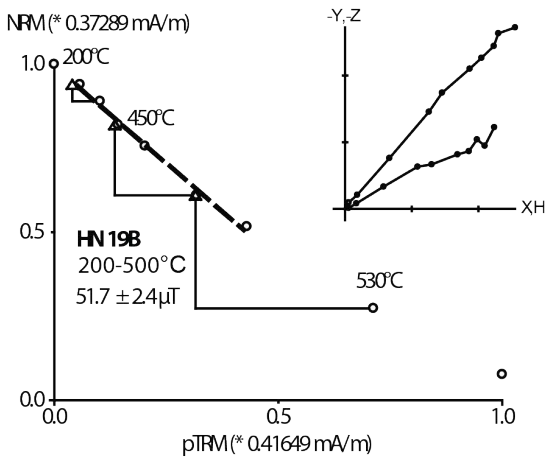

f) $\mathrm{NPM}\left({ }^{*} 0.64348 \mathrm{~mA} / \mathrm{m}\right)$

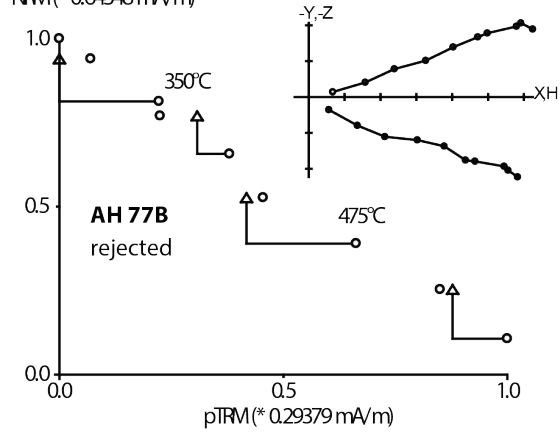

h)

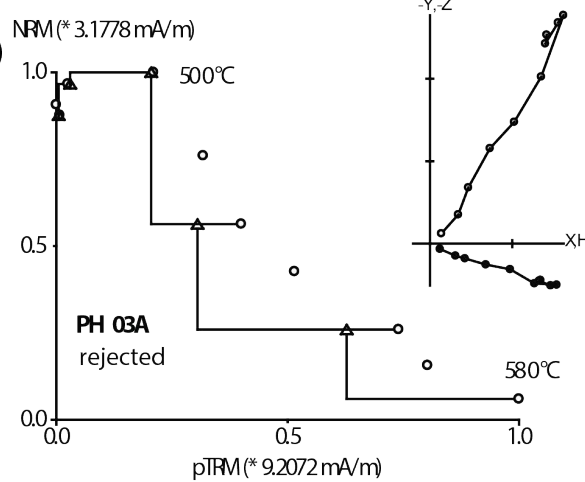


Figure 5-10: Representative Arai plots and corresponding vector component plots from the TVZ (insets) for specimens from the four volcanic units studied. a,b) Results from Tapahoro lava flow. Both Arai plots have a concave upwards shape and the intensity is therefore dependent on the fraction of the plot selected. c, d) results for Hainini lava dome. The Arai plots on both specimens yield a lower gradient slope for the high temperature component. However, based on a decrease in the magnetic susceptibility at temperature steps $\mathrm{T}>500^{\circ} \mathrm{C}$, this has been associated with thermal alteration. e) successful and f) rejected palaeointensity result for Acacia Height (AH) dome. The result was rejected due to the pTRM check failure at temperatures above $350^{\circ} \mathrm{C}$ g,h) Arai plots for Pokuhu flow show an increase in the $\mathrm{NRM}$ intensity in the blocking temperature range between 300 and $500^{\circ} \mathrm{C}$, which corresponds to an antipodal directional component of magnetisation. 
Table 5-3: Selected palaeointensity results from the TVZ. A summary of all data is available in the appendices. The top two rows define the criteria sets used which are modified versions of the criteria sets TTA and TTB (Leonhardt et al, 2004a, modifications suggested by Paterson et al, 2014). For Tapahoro lava flow we calculate the best estimates from the low temperature, high temperature and across the entire temperature range, respectively. See text for details. The palaeointensity experiments on Tapahoro flow and Hainini dome were carried out using the Coe-type protocol and the experiments on samples from Acacia Heights dome using the IZZI protocol.

\begin{tabular}{|c|c|c|c|c|c|c|c|c|c|c|c|c|c|c|c|}
\hline Site & Spec. ID & Interv & $\mathbf{N}$ & f & $\beta$ & $\mathbf{q}$ & MAD $_{\text {anc }}\left({ }^{\circ}\right)$ & $\alpha\left({ }^{\circ}\right)$ & $\operatorname{dCK}(\%)$ & dpal (\%) & dTR (\%) & $\mathrm{dt}^{*}(\%)$ & Intensity $(\mu \mathrm{T})$ & $\sigma$ & sel crit. (N/n) \\
\hline & & & $\geq 5$ & $\geq 0.3 \xi$ & $\leq 0.1$ & $\geq 5$ & $\leq 6$ & $\leq 15$ & $\leq 7$ & $\leq 10$ & $\leq 10$ & $\leq 9$ & & & TTA* \\
\hline & & & $\geq 5$ & $\geq 0.3 \xi$ & $\leq 0.15$ & $\geq 0$ & $\leq 15$ & $\leq 15$ & $\leq 9$ & $\leq 18$ & $\leq 20$ & $\leq 99$ & & & TTB* \\
\hline
\end{tabular}

Tapahoro flow $(T C)^{*}$

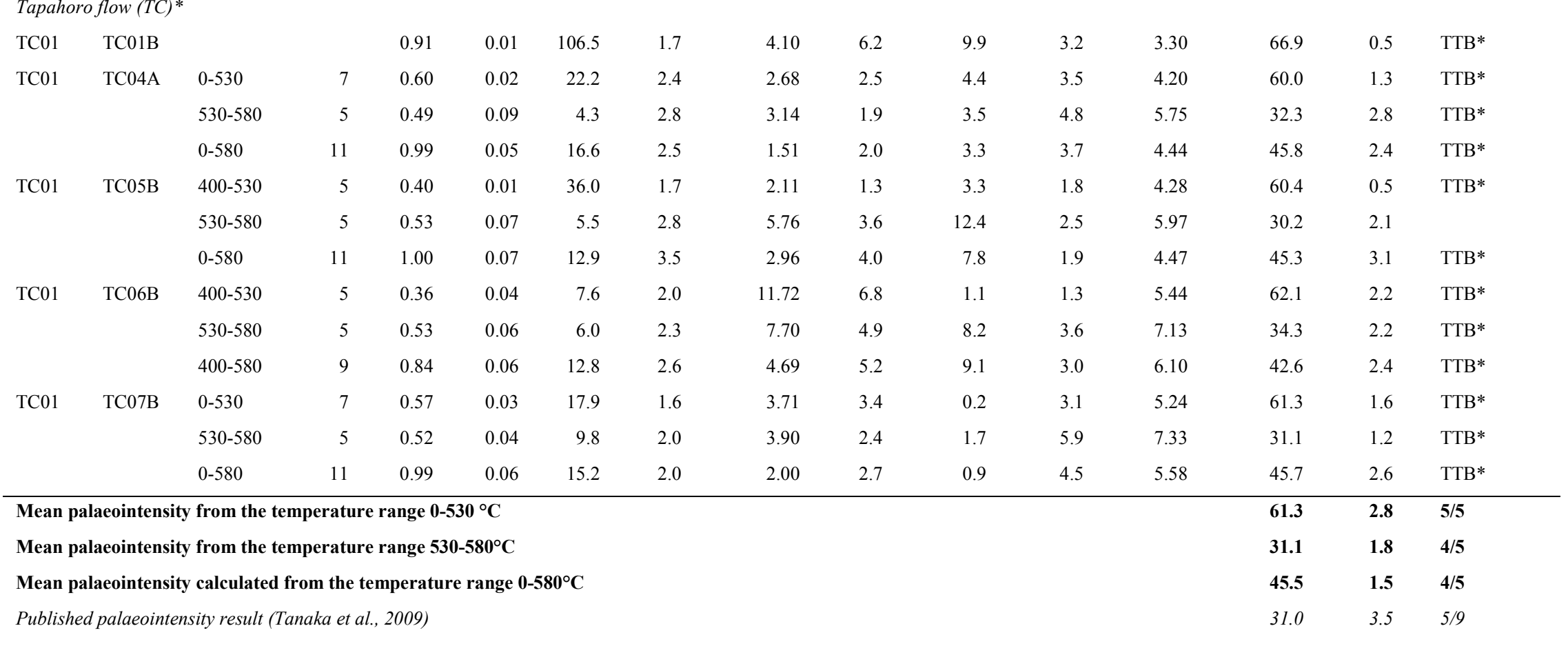




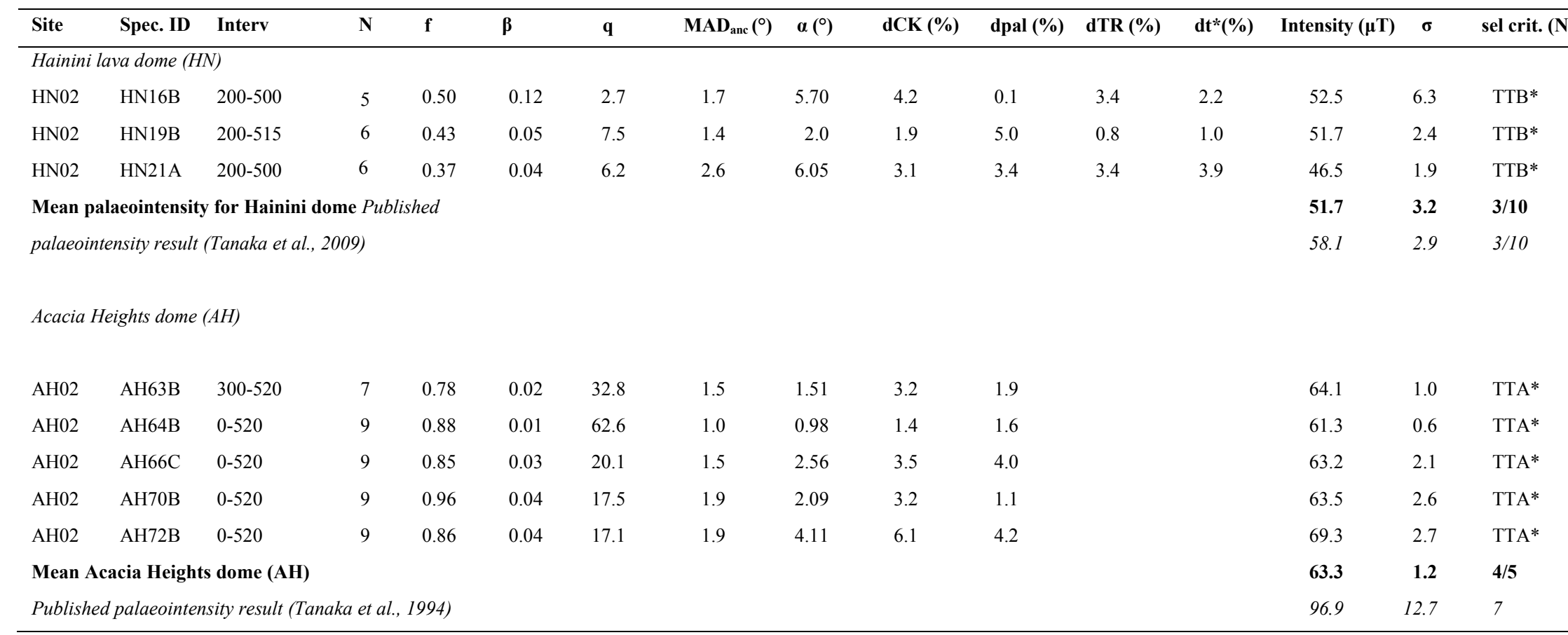

Note: Spec. ID corresponds to the specimen ID, Interv. is the temperature interval selected, $\mathrm{n}, \mathrm{f}, \beta, \mathrm{q}, \mathrm{MAD} \mathrm{dCK}$, dpal, dTR, dt* are statistical parameters that were calculated following the "Standardized Palaeointensity Definitions" (Paterson et al., 2014), whereas MAD corresponds to the maximum angular deviation when anchored to the origin. Sel. criteria the set of selection criteria passed, as discussed in the text. Calculation of the best estimates: N/n number of successful experiments/ total number of experiments carried out. 


\subsection{Discussion: Data quality and comparison with previous results}

The mean directions and 95\% confidence limits ( $\alpha 95)$ for all sites addressed in this study are displayed in a stereographic projection in Figure 5-9 together with our best estimate for each unit, and the previously published directions. Figure 5-11 displays the new data as a time series, in comparison to the previously published results, superimposed on the continuous record from Lake Mavora (Turner et al., 2015b), all relocated to $39.2^{\circ} \mathrm{S}, 175.54^{\circ} \mathrm{E}$. Within the limitations mentioned previously and further discussed in chapter 6, the Mavora curve provides a reference frame for the directional and intensity values to be expected.

The $\alpha 95$ 's of the new flow mean directions range from 3 to $8^{\circ}$ and the data dispersion is smaller than that of previously published data from the TVZ (Tanaka et al., 1994; 2009) and within the range of the PSV study described in chapter 3. Although all sampled outcrops appeared in-situ, the palaeomagnetic directions measured from multiple sites from Haroharo dome (HR) and Rotoma flow (ROT) differ significantly. Sites on both units were located on the outer rims or upper surface of the dome and/or flow complex and we suggest that some of the sampled outcrops may have tilted, for example during endogeneous dome growth. Data from these units have therefore been excluded from further analysis. In contrast, we place high confidence on the palaeomagnetic results from units where internally consistent results were found over a wide spread of sites, such as Tapahoro flow (TC) and Hainini dome $(\mathrm{HN})$. The new directional result of Hainini flow is extremely westerly (e.g. Figure 5-11) but agrees with the data previously published by Tanaka et al. (2009). In contrast, the directional estimates made on Tapahoro (TC), Waiti (WT) and Acacia Heights (AH) lavas fall significantly closer to the expected PSV values than was suggested by the original data (Tanaka et al., 1994; 2009) (Figure 5-11). The coordinates for site NK02 at Tapahoro flow listed by Tanaka et al. (2009) suggest a location that is approximately $200 \mathrm{~m}$ east of the margins of the flows and the sampled material may thus not have been in-situ (e.g. Table 5-2). We could not identify sampling location NK06 of Tanaka et al. (1994) at Acacia Heights dome but 
note that the original study was conducted with the primary aim of providing palaeointensity data and smaller emphasis may have been placed on the selection of in-situ sampling sites and interpretation of the directional data. Specimens from Waiti flow (WT) were affected by strong viscous overprints, described first by Tanaka et al. (2009) and also identified during this resampling campaign. These introduced some ambiguity in the data interpretation. We place confidence in our palaeomagnetic result which was calculated using the combined analysis of ChRM directions from four specimens and remagnetisation circles from four further specimens as described by McFadden and McElhinny (1988). For all three flows we suggest replacing the original data with our new directions.

Successful palaeointensity results were obtained from three lavas, which correspond to the units that Tanaka et al. $(1994 ; 2009)$ published results on. The overall success rate is $50 \%$, comparable to that described on andesitic lavas in chapter 4 and the data dispersion at each site is $9 \%$ or less of its mean. High quality and consistent $(\sigma=1.2$ $\mu \mathrm{T})$ palaeointensity results were obtained for Acacia Heights dome (AH). The result falls into the range of palaeointensity values expected on the basis of the Lake Mavora record and other absolute palaeointensities obtained in this study, and is considered more probable than the very high estimate published previously (Tanaka et al., 1994). In contrast, the palaeointensity estimate made for Hainini (HN) dome agrees with the originally published data (Tanaka et al., 2009). The behaviour identified in the palaeointensity results on samples from Tapahoro (TC) flow also compares well to the data displayed by Tanaka et al. (2009). Samples display a slightly concave shape in the Arai plots, as discussed in section 5.9.1, and we suggest selection of a different temperature range than proposed by Tanaka et al. (2009). The resulting palaeointensity estimate is significantly lower than the original value of Tanaka et al. (2009). While this estimate is adopted for the discussion below it should be regarded as tentative and used with caution during modelling or for comparative studies. 

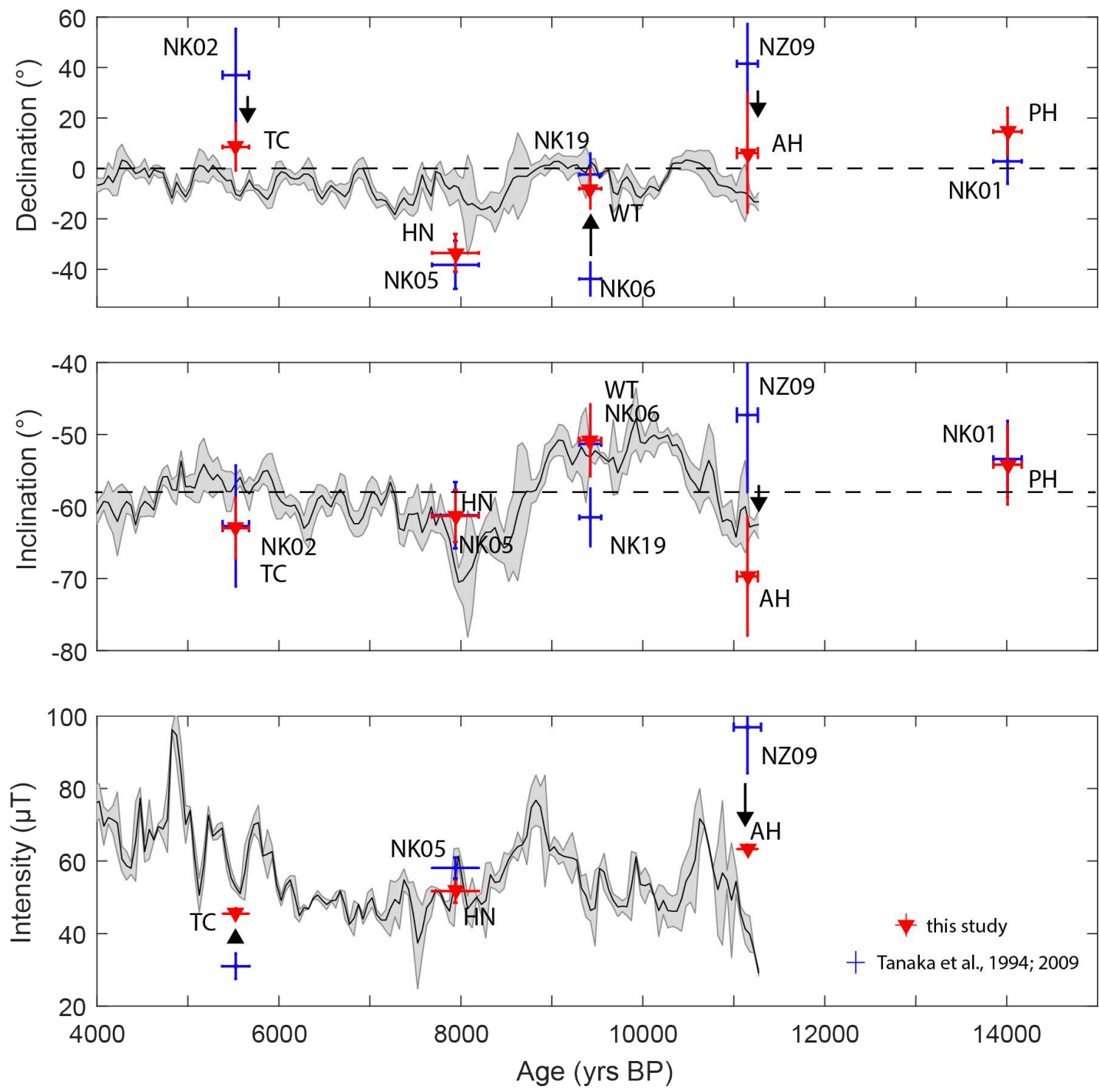

Figure 5-11: Palaeosecular variation described by the rhyolitic lavas between 5 and 15 kyrs BP. Our new refined data is displayed in red and compared to the previously published data (blue). Directional and intensity data that was previously of an anomalous direction is marked with an arrow pointing towards the refined values. The data is displayed in comparison to a continuous PSV record from Lake Mavora (black line with grey shaded error bar) (Turner et al., 2015b), which was relocated to the central North Island and provides a reference frame for the directions and intensities to be expected. Prior to its relocation the relative palaeointensity curve was scaled with a constant factor of $64 \mu \mathrm{T}$ as suggested by Turner et al. (2015b). 


\subsection{Conclusions}

This chapter presents the results of a palaeomagnetic study on seven Holocene rhyolitic lavas from the Okataina and Taupo Volcanic Centres. Data for most units were previously published in two studies by Tanaka et al. (1994; 2009). Recently available tephrochronology studies have enabled us to update the age control of each unit sampled, leading to revisions of up to 1000 years. The results suggest new palaeomagnetic directions on four flows, two of which gave unexpectedly easterly or westerly directions in the original publications. In contrast, an atypical westerly direction on a ca. 7.9 ka lava from the OVZ was confirmed as accurate. Successful palaeointensity estimates on three flows fall into the range of palaeointensities measured on flows from the Tongariro Volcanic Centre (TgVC). While one estimate agrees with the data previously published, we suggest adopting the new palaeointensity values for lavas dated at ca. 11 and $5.5 \mathrm{ka}$. 


\section{Chapter 6}

Discussion and Future Work 


\subsection{Introduction}

The main goal of this study was to build a sequence of discrete palaeomagnetic secular variation records and to review previously published data for the Holocene time-period in New Zealand from volcanic rocks of the Taupo Volcanic Zone.

Chapters 3, 4 and 5 presented the results of a comprehensive palaeomagnetic study on the volcanoes of the Taupo Volcanic Zone. Chapter 3 presented sampling strategies and directional results on andesitic lavas from the Tongariro Volcanic Centre (TgVC). Chapter 4 complemented this with a detailed rock magnetic and palaeointensity study on the same flows. Besides collecting new palaeomagnetic data, in chapter 3 the ages of six lava flows from the $\mathrm{TgVC}$ were refined by comparison of their palaeomagnetic directions with the most recently published continuous lake sediment record from New Zealand (Turner et al., 2015b). Chapter 5 focussed on a palaeomagnetic study of rhyolitic lavas, primarily from the Okataina Volcanic Centre (OVZ). Palaeomagnetic data on most of the sampled units from the OVZ had previously been published (Tanaka et al., 1994; Tanaka et al., 2009) and this study reevaluated and revised the early palaeomagnetic datasets from the area.

In this chapter, all new and existing palaeomagnetic datasets from Holocene $(<15$ kyrs BP) volcanic materials are compiled and the value of the dataset for regional and global PSV studies is then discussed. Future avenues for on-going and new research are presented. 


\subsection{Dataset}

Table 6-1 is a compilation of all discrete palaeomagnetic data from volcanic material younger than $15 \mathrm{ka}$ from New Zealand for which reasonable age control is available. Key datasets are the revised directions and intensities on rhyolitic lavas from the Taupo Volcanic Zone, presented in chapter 5, the data obtained from andesitic lavas from the $\mathrm{TgVC}$, presented in the chapters 3 and 4, and other published results described below.

The OVC sampling campaign included a number of units for which palaeomagnetic data had previously been published by Tanaka et al. (1994; 2009). The earlier of these studies reports a palaeomagnetic direction and intensity for Acacia Heights dome. Tanaka et al.'s (2009) publication on rhyolitic lava flows, domes and pyroclastic deposits from the $\mathrm{OVC}$, includes 14 units from 8 eruptive sequences younger than $15 \mathrm{ka}$. Many of the mean directions described from volcaniclastic deposits have extremely large uncertainties and directions with 95\% confidence circles larger than $10^{\circ}$ are excluded in this study. Further as discussed chapter 5 , some of Tanaka et al.'s (2009) directions on lavas were surprisingly far from the expected average direction (at latitude $39^{\circ}$, approximately Dec $=0^{\circ}$, Inc $=-58.5^{\circ}$ ) and were resampled in this study. Where successful results were obtained during our sampling campaign, we replace Tanaka et al.'s (2009) original palaeomagnetic directions and intensities with our revised data. We also replace Tanaka et al.'s (2009) direction on a lava associated with the $636 \pm 12$ cal yrs BP Kaharoa eruptive sequence, which is the youngest rhyolitic episode recorded from the TVZ, with the results of a detailed sampling campaign on the same unit by Robertson (2007). We also include the palaeointensity results from an obsidian from Mayor Island in the Bay of Plenty described by Ferk et al. (2011) and dated at $8800 \pm 200$ cal. yrs BP (Buck et al., 1981 recalibrated using SHCAL13, Hogg et al., 2013).

In addition we also include the palaeomagnetic results of two earlier studies which were conducted with a different focus: Robertson (1986) studied the basaltic lavas of Rangitoto Island, Auckland. At the time these lavas were thought to represent an extended period of activity, but more recent work (Needham et al., 2010) suggests 
just two phases of eruption at $504 \pm 5$ cal yrs BP and $553 \pm 7$ cal yrs BP. We assign an age range of $529 \pm 31 \mathrm{cal}$ yrs $\mathrm{BP}$, which encompasses both eruptive phases and the associated age uncertainty and use the average palaeodirection of Robertson (1986) ( $\mathrm{Dec}=0.2^{\circ}, \mathrm{Inc}=-61.7^{\circ}, \alpha 95=1.8^{\circ}, 92$ specimens from $\mathrm{N}=11$ sites $)$. McClelland et al. (2004) obtained a comprehensive palaeomagnetic dataset from 44 sites sampled from the Taupo Ignimbrite $(1720 \pm 10$ cal yrs BP after Lowe et al. (2013)). Although the primary aim of this study was to gain insight into the emplacement temperatures, the ChRM directions extracted also provide an excellent record of the palaeomagnetic field. The dataset provides a mean direction for each site sampled, using the ChRM directions extracted from the low $T_{b}$ range of a maximum of 13 specimens per site. The within site ChRM directions scatter widely and the site $\alpha 95$ 's average $13^{\circ}$, however the site mean directions are relatively well clustered. We average all site mean directions into an overall mean direction $\left(\mathrm{Dec}=3.9^{\circ}\right.$, Inc $=$ $-52.2^{\circ}, \alpha 95=2.4^{\circ}, \mathrm{N}=44$ site mean directions calculated from 323 specimens).

Not included in this compilation are the results of a number of earlier palaeomagnetic studies. In a statistical study of secular variation in New Zealand, Cox (1969) sampled several units of Holocene age, which returned predominantly easterly declinations and inclinations close to the GAD value. Cox (1969) however made little use of demagnetisation techniques, and so the similarity to the present day field may reflect overprinting. Downey et al. (1994) reported palaeomagnetic directions from several series of flows on Egmont volcano (Mt Taranaki). They obtained predominantly easterly declinations, and inclinations between $-50^{\circ}$ and $-70^{\circ}$, but, with little stratigraphic age control, it is presently difficult to incorporate these results into our compilation.

\subsection{Addressing ages and age uncertainties}

In order to be able to compare the discrete data with each other and with continuous records, precise and comparable age controls are required. The age information provided in Table 6-1 is based on three different radiometric and correlation methods: 
The andesitic lavas from the $\mathrm{TgVC}$ were dated either by ${ }^{40} \mathrm{Ar} /{ }^{39} \mathrm{Ar}$ dating or from under- or overlying, radiocarbon-dated tephra layers (Conway et al., 2016; Hobden et al., 1996; Lowe et al., 2013; Topping, 1974). Within the Holocene timeperiod the ${ }^{40} \mathrm{Ar} /{ }^{39} \mathrm{Ar}$ method has limited precision due to the slow decay of ${ }^{40} \mathrm{~K}$, and overall low potassium content in the lavas. Stratigraphic controls, on the other hand, are limited by the time intervals between the emplacements of over and/or underlying tephra beds. All independent age controls on these lavas thus carry uncertainties in the range of 2 - 3000 years. In chapter 3 we refined these age brackets by amalgamating field relations and a comparison of our new palaeomagnetic directions with the continuous PSV record from Lake Mavora (Turner et al., 2015b), for which age control is available from the Bayesian modelling of sedimentation rate between 28 independent radiocarbon age estimates on leaf fragments throughout the record. The independence of such continuous records and discrete records that have been dated by comparison with them in this way is questionable, for example if both datasets are included in the same modelling exercise. For future reference therefore, we include in Table 6-1 both the palaeomagnetically-refined, more precise ages and the independent but less precise sets of age control..

Confidence in the palaeomagnetically-refined ages is further increased both by supporting field observations and agreement of our discrete palaeointensity data with the scaled relative palaeointensity record from Lake Mavora. In the following discussion, we therefore adopt the palaeomagnetically refined ages for the $\mathrm{TgVC}$ units.

Age controls on the rhyolitic lavas or other deposits included in our compilation were usually provided by correlation with distal tephra deposits. Most of these tephras are dispersed widely over the North Island in New Zealand and form distinctive marker beds in sedimentary environments. Once continuous PSV records have become available from this region, a direct correlation with the discrete palaeomagnetic data along the tephra horizons may be possible. To this end we adopted the radiocarbon ages from the most recent revision of the tephra ages and stratigraphies in New Zealand by Lowe et al. (2013). Lowe et al. (2013) calculated each tephra age from multiple ${ }^{14} \mathrm{C}$ ages of organic matter that was over and/or underlying the respective tephra horizon. 
The standard deviation thus encompasses an unknown time period prior and after emplacement of the tephra. In contrast to ${ }^{40} \mathrm{Ar} /{ }^{39} \mathrm{Ar},{ }^{14} \mathrm{C}$ ages are affected by fluctuations in the atmospheric ${ }^{14} \mathrm{C}$ concentration, which affects the measured ratio between radioactive isotope ${ }^{14} \mathrm{C}$ and the stable isotope ${ }^{12} \mathrm{C}$. Lowe et al. (2013) referenced the ages cited in this study to calendar ages, measured prior to $1950 \mathrm{AD}$, by correlation with the calibration curve SHCAL04 (McCormack et al., 2004). For the Holocene time period there is little difference between SHCAL04 and the more recent SHCAL13 (Hogg et al., 2013) which was used in calibrating the age model of the Lake Mavora sediments (Turner et al., 2015b). Calibration is necessary in order to compare the ${ }^{14} \mathrm{C}$-based age estimates of the rhyolitic flows with absolute ${ }^{40} \mathrm{Ar} /{ }^{39} \mathrm{Ar}$ ages, palaeomagnetic ages and the Mavora timescale itself.

Calibration to calendar years BP can result in a shift of up to 900 years from the uncalibrated ${ }^{14} \mathrm{C}$ ages listed in the initial publications (Tanaka et al., 1994; 2009). Whereas the uncertainty quoted in an uncalibrated ${ }^{14} \mathrm{C}$ age arises primarily from experimental counting uncertainties, calibration introduces additional uncertainty associated with the calibration curve itself. Occasionally ambiguities arise, where a given ${ }^{14} \mathrm{C} /{ }^{12} \mathrm{C}$ ratio occurred more than once during the Holocene, and two (or more) ranges of calibrated ages are possible. In general however, the tephra ages carry much lower uncertainties than the ${ }^{40} \mathrm{Ar} /{ }^{39} \mathrm{Ar}$ ages, in the range of 50-250 years.

It should be noted that the assignation of ages assumes a direct correlation of the proximal deposits, including the lavas and volcaniclastic materials sampled for palaeomagnetic study with the distal tephra in the sequences studied by Lowe et al. (2013). An additional source of age uncertainty of individual proximal units arises from the duration of individual eruptive sequences. Nairn (2002) found that ${ }^{14} \mathrm{C}$ ages of charcoal from proximal deposits of the OVC usually fell within 100 to 300 years of the distal tephra ages, which provides an estimate to the additional uncertainty to be expected due to this. 
(Page intentionally left blank) 
Table 6-1: Compilation of Holocene $(<15 \mathrm{ka})$ records of palaeomagnetic directions and intensities from New Zealand volcanic rocks.

\begin{tabular}{|c|c|c|c|c|c|c|c|c|c|c|c|c|c|c|c|c|}
\hline ID & Unit & $\begin{array}{l}\text { Published age } \\
\text { (yrs BP) }\end{array}$ & $\begin{array}{l}\text { Pmag age (yrs } \\
\text { BP) }\end{array}$ & $\begin{array}{l}\text { Lat } \\
\left({ }^{\circ} \mathrm{S}\right)\end{array}$ & $\begin{array}{l}\text { Long } \\
\left({ }^{\circ} \mathbf{E}\right)\end{array}$ & $\begin{array}{l}\text { Dec } \\
\left({ }^{\circ}\right)\end{array}$ & $\begin{array}{l}\text { Inc } \\
()^{\circ}\end{array}$ & $\begin{array}{l}\alpha 95 \\
\left({ }^{\circ}\right)\end{array}$ & $\mathbf{N}_{\mathrm{si}} / \mathbf{N}_{\mathrm{sa}} / \mathbf{N}_{\mathrm{sp}}$ & $\begin{array}{l}\text { Int } \\
(\mu \mathrm{T})\end{array}$ & $\begin{array}{l}\sigma \\
(\mu \mathrm{T})\end{array}$ & $\mathbf{n}$ & $\begin{array}{l}\text { VDM } \\
\left(* 10^{22} \mathbf{A m}^{2}\right)\end{array}$ & $\begin{array}{l}\text { VADM } \\
\left(* 10^{22} \mathbf{A m}^{2}\right)\end{array}$ & $\begin{array}{l}\begin{array}{l}\text { Ref. } \\
\text { pmag }\end{array} \\
\end{array}$ & $\begin{array}{l}\text { Ref } \\
\text { age }\end{array}$ \\
\hline \multicolumn{17}{|c|}{ Andesitic lavas, Tongariro Volcanic Centre, chapters 3 and 4} \\
\hline $\mathrm{CC}$ & Central Crater & $<1720 \pm 0.01^{1}$ & $300 \pm 200$ & -39.13 & 175.66 & 20.8 & -67.4 & 7.4 & $4 / 13 / 14$ & 70.6 & 4.1 & 8 & \multirow{2}{*}{$\begin{array}{l}11.2 \pm 0.8 \\
10.1 \pm 1.2\end{array}$} & \multirow{2}{*}{$\begin{array}{l}12.3 \pm 0.9 \\
10.4 \pm 1.2\end{array}$} & 4 & 8,14 \\
\hline WE & Whangaehu & $200 \pm 2200^{1}$ & $2200 \pm 200$ & -39.29 & 175.65 & 359.5 & -60.6 & 2.8 & $1 / 7 / 9$ & 59.6 & 7.0 & 7 & & & 4 & 8 \\
\hline $\mathrm{DC}$ & Delta Corner & $6000 \pm 2400^{1}$ & $\sim 8000$ & -39.26 & 175.56 & 8.5 & -68.3 & 3.9 & $1 / 10 / 14$ & & & & \multirow[b]{2}{*}{$8.5 \pm 0.6$} & \multirow[b]{2}{*}{$8.9 \pm 0.6$} & 4 & 8 \\
\hline $\mathrm{RP}$ & Bruce Road & $7500 \pm 2500^{1}$ & $8550 \pm 150$ & -39.27 & 175.54 & 17.8 & -60.8 & 2.9 & $1 / 7 / 12$ & 51.2 & 3.5 & 9 & & & 4 & 13 \\
\hline $\mathrm{TF}$ & Taranaki Falls & $8800 \pm 2800^{1}$ & $\begin{array}{l}9200 \pm 300 \\
10,350 \pm 150\end{array}$ & -39.24 & 175.58 & 4.5 & -49.5 & 3.2 & $1 / 16 / 23$ & 37.0 & 5.7 & 8 & \multirow{5}{*}{$\begin{array}{l}7.3 \pm 1.1 \\
7.0 \pm 0.7\end{array}$} & \multirow{5}{*}{$\begin{array}{l}6.4 \pm 1.0 \\
7.1 \pm 0.7\end{array}$} & 4 & 8 \\
\hline MT & Mangaturuturu & $11,900 \pm 2200^{1}$ & $12,300 \pm 1800$ & -39.29 & 175.52 & 8.7 & -60.4 & 4.0 & $1 / 10 / 12$ & 40.8 & 4.0 & 9 & & & 4 & 8 \\
\hline $\mathrm{SC}$ & Saddle Cone & $7500 \pm 2500^{1}$ & $9100 \pm 500$ & -39.23 & 175.59 & 358.7 & -54.9 & 3.0 & $1 / 7 / 9$ & & & & & & 4 & 13 \\
\hline WPA & Whakapapaiti A & $14,800 \pm 3000^{1}$ & & -39.25 & 175.53 & 358.1 & -54.9 & 2.7 & $1 / 8 / 10$ & & & & & & 4 & 8 \\
\hline GR & Skyline Ridge & $15,100 \pm 2400^{1}$ & & -39.3 & 175.55 & 356.5 & -81.4 & 3.8 & $1 / 11 / 13$ & & & & & & 4 & 8 \\
\hline \multicolumn{17}{|c|}{ Rhyolitic lavas, chapter 5, revisions for data previously published by Tanaka et al. $(1994 ; 2009)$} \\
\hline $\mathrm{TC}(\mathrm{NK} 02)$ & Tapahoro & $5526 \pm 145^{2}$ & & -38.16 & 176.52 & 8.5 & -63 & 4.2 & $1 / 7 / 11$ & 45.5 & 1.5 & 5 & \multirow{4}{*}{$\begin{array}{l}7.5 \pm 0.2 \\
8.8 \pm 0.8\end{array}$} & \multirow{4}{*}{$\begin{array}{l}7.9 \pm 0.3 \\
9.2 \pm 0.8\end{array}$} & $1,(2)$ & 9,11 \\
\hline $\mathrm{HN}$ (NK05) & Hainini & $7940 \pm 257^{2}$ & & -38.12 & 176.48 & 326.5 & -61.3 & 3.6 & $1 / 16 / 24$ & 51.7 & 3.2 & 3 & & & $1,(2)$ & 9,11 \\
\hline WT (NK06) & Waiti & $9423 \pm 120^{2}$ & & -38.08 & 176.49 & 352 & -50.8 & 5 & $1 / 8 / 8$ & & & & & & $1,(2)$ & 9,15 \\
\hline PH (NK01) & Pokuhu & $14,009 \pm 155^{2}$ & & -38.17 & 176.52 & 14.6 & -54.2 & 5.5 & $1 / 7 / 9$ & & & & & & $1,(2)$ & 9,11 \\
\hline $\mathrm{AH}(\mathrm{NZ06})$ & Acacia Heights & $11,150 \pm 115^{2}$ & & -38.7 & 176.03 & 6.1 & -69.7 & 8.2 & $6 / 31 / 31$ & 63.3 & 1.2 & 4 & $9.6 \pm 0.2$ & $11.0 \pm 0.2$ & $1,(3)$ & 9,12 \\
\hline
\end{tabular}

Okataina Volcanic Centre, Tanaka et al. (2009) and Robertson (2007), primarily rhyolitic lavas, NK09: basaltic lava, NK16: avalanche breccia, NK14 pyroclastics

\begin{tabular}{|c|c|c|c|c|c|c|c|c|c|c|c|c|c|c|c|}
\hline NK09 & Tarawera & $1886 \mathrm{AD}^{3}$ & -38.22 & 176.52 & 26 & -53.3 & 4.5 & $1 / 8 / 8$ & 62.9 & 5.7 & 6 & $11.7 \pm 1.1$ & $11.1 \pm 1.0$ & 3 & 11 \\
\hline KH (NK10) & Kahaora & $636 \pm 12^{2}$ & -38.2 & 176.5 & 354.6 & -61.2 & 4.3 & $11 / 72 / 72$ & & & & & & $6,(2)$ & 9,11 \\
\hline NK16 & Edgecumbe & $2425 \pm 275^{2}$ & -38.1 & 176.73 & 350.1 & -64.9 & 2.9 & $1 / 5 / 6$ & & & & & & 3 & \\
\hline NK19 & Rotoma & $9423 \pm 120^{2}$ & -38.04 & 176.57 & 357.6 & -61.5 & 4 & $1 / 7 / 7$ & & & & & & 3 & 9,11 \\
\hline NK08 & Waikakareao & $14,009 \pm 155^{2}$ & -38.21 & 176.37 & 9.7 & -46.3 & 4.7 & $1 / 8 / 8$ & & & & & & 3 & 9,11 \\
\hline NK14 & Rotorua & $15,635 \pm 412^{2}$ & -38.21 & 176.37 & 13.7 & -61.4 & 5.2 & $1 / 6 / 6$ & & & & & & 3 & 9,11 \\
\hline NK11 & Rotomahana & $17,496 \pm 462^{2}$ & -38.25 & 176.47 & 342.7 & -58.2 & 4.4 & $1 / 8 / 8$ & & & & & & 3 & 9,11 \\
\hline
\end{tabular}




\begin{tabular}{|c|c|c|c|c|c|c|c|c|c|c|c|c|c|c|c|}
\hline ID & Unit & Published age (yrs BP) & $\begin{array}{l}\text { Lat } \\
\left({ }^{\circ} \mathbf{S}\right)\end{array}$ & $\begin{array}{l}\text { Long } \\
\left({ }^{(} \mathbf{E}\right)\end{array}$ & $\begin{array}{l}\text { Dec } \\
\left({ }^{\circ}\right)\end{array}$ & $\begin{array}{l}\text { Inc } \\
\left({ }^{\circ}\right)\end{array}$ & $\begin{array}{l}\alpha 95 \\
\left({ }^{\circ}\right)\end{array}$ & $\mathbf{N}_{\mathrm{si}} / \mathbf{N}_{\mathrm{sa}} / \mathbf{N}_{\mathrm{sp}}$ & $\begin{array}{l}\text { Int } \\
(\mu T)\end{array}$ & $\begin{array}{l}\sigma \\
(\mu \mathrm{T})\end{array}$ & $\mathrm{N}$ & $\begin{array}{l}\text { VDM } \\
\left(* 10^{22} \mathbf{A m}^{2}\right)\end{array}$ & $\begin{array}{l}\text { VADM } \\
\left({ }^{*} 10^{22} \mathbf{A m}^{2}\right)\end{array}$ & $\begin{array}{l}\text { Ref. } \\
\text { pmag }\end{array}$ & $\begin{array}{l}\text { Ref } \\
\text { age }\end{array}$ \\
\hline \multicolumn{16}{|c|}{ Other volcanic data } \\
\hline TI & Taupo Ignimbr. & $1720 \pm 10^{2}$ & -39 & 176 & 3.9 & -52.2 & 2.4 & $44 / 323 / 323$ & & & & & & 1,7 & 9 \\
\hline RG & Rangitoto & $529 \pm 31^{2}$ & -36.8 & 174.8 & 0.2 & -61.7 & 1.8 & $11 / 92 / 92$ & & & & & & 1,5 & 8 \\
\hline MI & Mayor Island & $8800 \pm 200^{2}$ & -37.28 & 176.26 & & & & & 57.0 & 1.0 & 24 & & $9.9 \pm 0.17$ & 16 & 17 \\
\hline
\end{tabular}

Note: ID is an abbreviation allocated to each unit and corresponds to the ones provided by the respective studies, age is the published age: $1{ }^{40} \mathrm{Ar} /{ }^{39} \mathrm{Ar}$ age, $2{ }^{14} \mathrm{C}$ age, calibrated to calendar yrs BP. 3 historic event. Pmag age: Age determined by palaeomagnetic dating and from field relations, as discussed in chapter 3. Lat and Long are the site latitude and longitude in geographic coordinates (WGS84). Dec is the magnetic declination and Inc the magnetic inclination. $\mathrm{N}_{\mathrm{s} i} / \mathrm{N}_{\mathrm{sa}} / \mathrm{N}_{\mathrm{sp}}$ are the number of sites averaged over/number of samples included/total number specimens. See text for details. Int is the palaeointensity and $\sigma$ the corresponding standard deviation. Ref pmag is the reference for the palaeomagnetic data, Ref age the reference for the age provided.

References: 1 This study, 2 Tanaka et al. (2009), 2 Tanaka et al. (1994), 3 chapters 3 and 4, 5 Robertson (1986), 6 Robertson (2007), 7 McClelland et al. (2004), 8 Needham et al. (2010), 9 Lowe et al. (2013), 10 Conway et al. (2016), 11 Nairn (2002), 12 Wilson (1993), 13 Topping (1974), 14 Hobden et al. (1996), 15 Smith et al. (2006), 16 Ferk et al. (2011), 17 Buck et al. (1981) 


\subsection{Integration with regional datasets and global field model 'pfm9k'}

\subsubsection{Comparison to the Lake Mavora PSV record (11,250 yrs BP - present)}

Figure 6-2 displays all discrete palaeomagnetic data from New Zealand listed in Table 6-1 superimposed on the recently published continuous lake sediment record from Lake Mavora, in the South Island of New Zealand, covering the last 11,500 years BP (Turner et al., 2015b).

In order to accommodate the differences in the palaeomagnetic record expected due to the geographic separation between the sampling sites, all data were migrated to a common location within the central North Island $\left(39.2^{\circ} \mathrm{S}, 175.54^{\circ} \mathrm{E}\right)$ using a VGP transformation (Noel and Batt, 1990). This transformation is strictly valid only in a dipolar field. However experiments on the relocation of field directions calculated from the gufm1 model (Jackson et al., 2000), which is based on historical data spanning the last 400 years, suggested that the migration error in this region and over a maximum distance of $1000 \mathrm{~km}$ is not expected to exceed $1.5^{\circ}$ (pers. comm. Turner) which falls into the existing uncertainty of our data.

The discrete records summarized in Table 6-1 range between extremes of $326.5^{\circ}$ west to $20.8^{\circ}$ east and inclination extremes of $-46.3^{\circ}$ and $-81.4^{\circ}$. They average to Dec $=$ $2.9^{\circ}$, Inc $=-62.4^{\circ}, \theta-63=9.9^{\circ}, \alpha-95=3.6^{\circ}, \mathrm{N}=23$ (Figure 6-1) (or including only data $<11.5$ kyrs BP: Dec $=2.4^{\circ}$, Inc $\left.=-62.1^{\circ}, \theta-63=9.2^{\circ}, \alpha-95=4.2^{\circ}, \mathrm{N}=14\right)$. This mean is slightly but insignificantly east and steeper than the direction of a geocentric axial dipolar $(\mathrm{GAD})$ field at the site $\left(\mathrm{Dec}=0^{\circ}, \mathrm{Inc}=-58.5^{\circ}\right)$. It is commonly believed that in a temporarily well-distributed, unbiassed dataset, averaged over a sufficient time-interval (probably 10,000 - 100,000 years), secular variation averages to a geocentric axial dipolar field and the GAD direction would be an appropriate assumption (Merill et al., 1998; Turner et al., 2015b). However in chapter 3 we 
suggested that many of the Holocene flows from the $\mathrm{TgVC}$ were probably emplaced during a relatively short time-period during which the declination was significantly east of north. For instance the mean direction calculated from the discrete data listed in Table 6-1, other than the TgVC lavas $\left(\mathrm{Dec}=1.1^{\circ}, \mathrm{Inc}=-61.5^{\circ}, \theta-63=9.9^{\circ}, \alpha-95=\right.$ $4.6^{\circ}, \mathrm{N}=14$, including only data $<11.5$ kyrs: $\mathrm{Dec}=357.1^{\circ}, \mathrm{Inc}=-63.1^{\circ}, \theta-63=$ $10.5^{\circ}, \alpha-95=6.8^{\circ}, \mathrm{N}=7$ ) to the average of the Mavora Curve relocated to $39.2^{\circ} \mathrm{S}$, $172.5^{\circ} \mathrm{E}\left(\mathrm{Dec}=356.3^{\circ}, \mathrm{Inc}=-58.2^{\circ}, \theta 63=5.4, \alpha-95=0.6^{\circ}\right)$. Volcanic activity in a single region often occurs in pulses of extensive activity interspersed with quiescent periods and as demonstrated here, a combination of datasets from different cones and areas may provide a better temporal distribution of the data. However, the current dataset presented in Table 6-1 still lacks discrete PSV data in the time-period 2-5 kyrs BP.

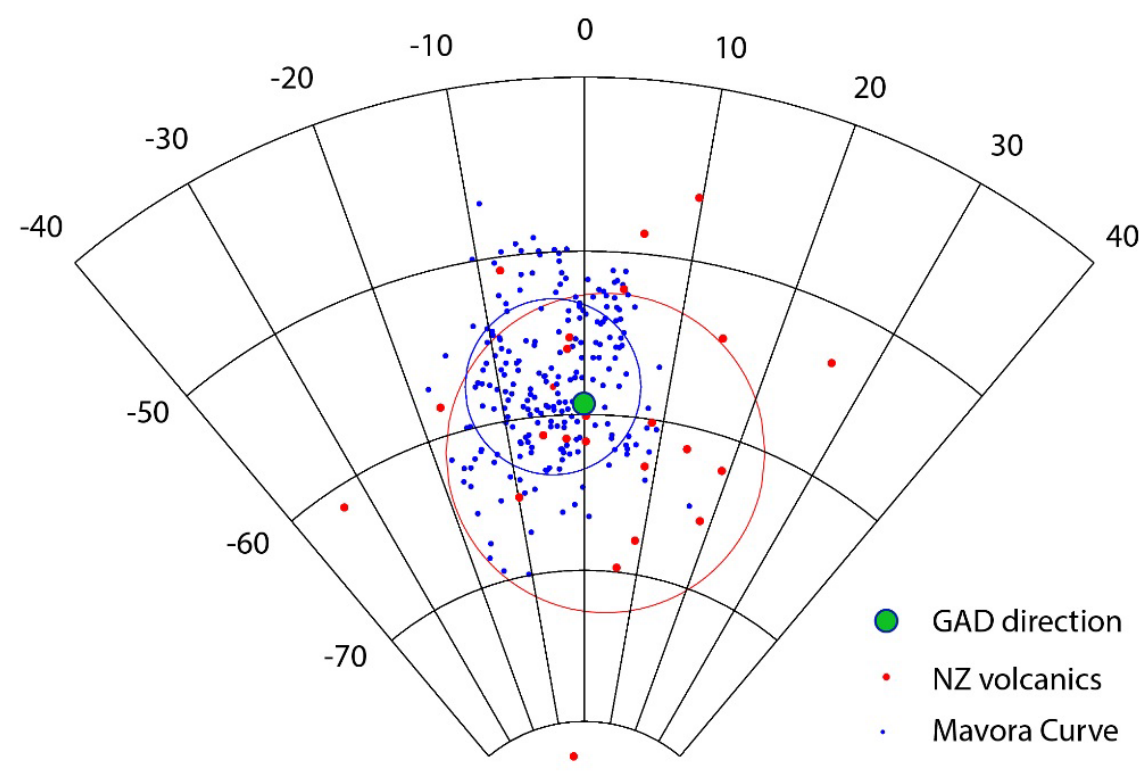

Figure 6-1: Distribution of the Mavora data (blue) and all discrete palaeomagnetic directions presented in Table 6-1 (red) and associated angular standard deviation $\theta 63$. All data were relocated to $175.5^{\circ} \mathrm{E}, 39.2^{\circ} \mathrm{S}$. Projection: Wulff (equal angle). 
Volcanic and sedimentary records complement each other in that, while the volcanic data provide absolute and instantaneous records of the palaeomagnetic field, the sequences of sedimentary records are quasi-continuous. The sedimentary records however are unavoidably smoothed to some extent and often display erroneously shallow inclinations, as result of the depositional process and later sampling procedure. Furthermore these records only provide relative palaeointensity and declination as they are not oriented azimuthally and thus require calibration with independent and absolute records. The Lake Mavora directional curve was oriented based on a correlation with the gufm1 global field model (Jackson et al., 2000; Turner et al., 2015b). Furthermore Turner et al. (2015b) corrected the original inclinations in the younger part $\left(<2900 \mathrm{yrs}\right.$ BP) of the record by $2.5^{\circ}$ towards steeper values based on the gufm 1 model and by $8.5^{\circ}$ in the earlier part of the record ( $>2900$ yrs BP), so that the mean inclination agrees with the GAD direction and the latest global field model pfm9k (Nilsson et al., 2014).

Turner et al. (2015b) also suggested calibration of the Mavora relative palaeointensity record by matching the uppermost relative palaeointensity at $75 \mathrm{BP}$ with the earliest observatory measurement in New Zealand, relocated to Mavora. The calibrated directional Mavora Curve describes prominent PSV swings in the early $(\sim 8000-11,000$ yrs BP) and later part (present -4000 yrs BP) of the record with a period of a relatively low amplitude secular variation in between (Figure 6-2). Turner et al. (2015b) noted some significant differences between the character of the PSV between the early and the late part of the record, which they relate to differences in the behaviour of the geomagnetic field. The early Holocene $(11,500-8000 \mathrm{BP})$ is characterised by a long wavelength swing to easterly declinations and shallow inclinations, which could for example be caused by tilting of the dipole field or a progressive development of high latitude flux lobes. The shorter wavelength fluctuations of declination and inclination records in the late Holocene (4000 - 0 BP) differ in phase and describe looping motion of the field vector which could be indicative for example of a westward drift of the non-dipolar field over the region. 
Overall, the discrete data presented in Table 6-1 agree with these features extremely well. A direct and independent comparison between the directional record of the TgVC lavas and the Lake Mavora Curve is difficult because the independent age controls on the $\mathrm{TgVC}$ lavas are subject to large uncertainty and the refined ages are based on a comparison with the Lake Mavora Curve itself. However, as discussed in chapter 3, many of the pre-5 ka lavas from the Tongariro Volcanic Centre (TgVC) describe a strongly easterly declination that compares well to the field recorded by the Mavora lake sediment prior to $8 \mathrm{ka}$. Field evidence and its ${ }^{40} \mathrm{Ar} /{ }^{39} \mathrm{Ar}$ age suggest that Taranaki Falls flow (TF) is the oldest of a sequence of flows with easterly directions (chapter 3) and the flow has a much shallower inclination than the younger flows of Delta Corner (DC) and Bruce Road (RP) (Figure 6-2) which agrees with the behaviour of the field at around 8-9000 yrs BP. All other volcanic records resampled in this study or revised in Table 6-1 have independent and more precise ages that allow a more rigorous comparison. In the late Holocene, a remarkably good match is seen between the palaeomagnetic directions from Rangitoto Island (RT), the Kaharoa $(\mathrm{KH})$ rhyolite and Taupo Ignimbrite (TI) and the Mavora Curve. In the early Holocene (prior to 5 kyrs BP) the discrete data correlate fairly well with the swings of the Mavora Curve. The palaeomagnetic direction of Waiti (WT) flow is slightly west of the GAD field direction (at $39.2^{\circ} \mathrm{S}$ : Dec $=0^{\circ}$, Inc $=-58.5^{\circ}$ ) and agrees with the Mavora Curve. The more extreme westerly direction obtained for Hainini (HN) and steeper inclination from Acacia Heights $(\mathrm{AH})$ dome plot near similar extremes in the Mavora Curve and/or their respective 95\% confidence limits overlap.

The palaeointensity datasets also correlate well. All discrete palaeointensity data fall well into the range of swings suggested by the Mavora Curve, after applying the calibration suggested by Turner et al. (2015b). As discussed in chapter 4, the discrete palaeointensity record from the Tongariro Volcanic Centre (TgVC) compares well with the relative palaeointensity curve, within the age brackets obtained by palaeomagnetic dating using the directional records in chapter 3. Further the data follow an overall trend from lower to higher palaeointensities throughout the Holocene, as is also described by the most recent global model pfm9k (Nilsson et al., 2014). The discrete data from the rhyolitic 
units sampled in this study or revised in Table 6-1 support the additional short periodicity swings described by the Lake Mavora Curve. The good data fit is remarkable considering the difficulties discussed in chapters 4 and 5 with the extraction of palaeointensity data from lavas and that the relative palaeointensities of the sediments and the absolute palaeointensity data were obtained during two significantly different physical methods.

Overall the agreement between the discrete directional and, where available, intensity records with the Mavora Curve suggest that both the discrete and the continuous records are reliable recorders of the palaeomagnetic field and support Turner et al.'s (2015b) observations on geomagnetic field behaviour. This outcome also supports the orientation and inclination corrections applied by Turner et al. (2015b) to the Mavora raw data and the proposed calibration of the relative palaeointensity curve. This outcome also enhances our confidence in the palaeomagnetic ages of the TgVC flows, which were refined using the Mavora directions (chapter 3). 

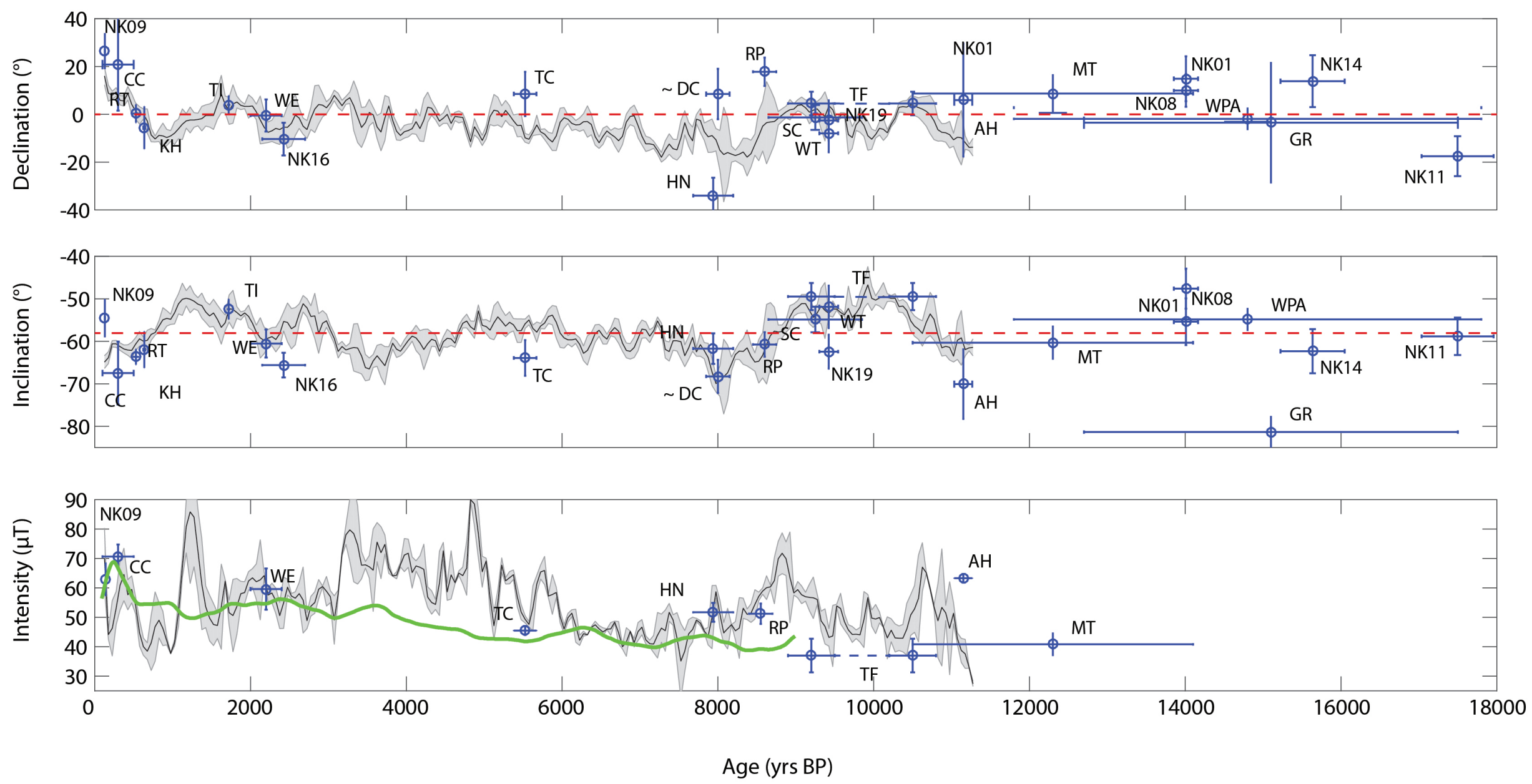
Figure 6-2: Palaeosecular variation in New Zealand over the last 15,000 years. The discrete data listed in Table 6-1 are displayed in comparison to a continuous PSV record from Lake Mavora (Turner et al, 2015b) and the GAD direction, the palaeointensity data are displayed also in comparison to the global field predictions of model pfm9k.1a (Nilsson et al, 2014). All data was relocated and the model prediction calculated at $39.2^{\circ} \mathrm{S}, 175.54^{\circ} \mathrm{E}$. The uncertainties for the Lake Mavora data (grey shaded envelope) are displayed, and the discrete datasets have been calculated following the Fisherian formulae for $95 \%$ confidence in the mean direction $(\Delta \operatorname{Inc}=\alpha 95, \Delta \mathrm{Dec}=\alpha 95 / \cos (\operatorname{Inc}))$, and correspond to the standard error in intensity. 


\subsubsection{Scaling of the amplitudes of the Lake Mavora PSV record}

As discussed above, sedimentary records are almost always affected by some form of amplitude reduction (e.g. Barton and McElhinny, 1881; Turner and Thompson, 1982). Amplitude reduction was also suggested for the Mavora record (chapter 3) based on a comparison with the discrete datasets from the $\mathrm{TgVC}$. Correction of the amplitude reduction is required to understand the full scale of variations in Earth's magnetic field in this region and will also improve the accuracy of further palaeomagnetic dating studies. The derivation of a suitable scaling factor however is difficult. Earlier palaeomagnetic studies (e.g. Turner and Thompson, 1982) used a peak-to peak comparison of several sedimentary curves with a different data distribution from the same region to estimate a scaling factor. This scaling factor can be used to correct the amplitude reduction present within a sedimentary record. This approach however relies on the assumption that at least one of the continuous datasets included in the comparison describes the full scale of PSV swings.

An alternative approach may be to compare the sedimentary PSV datasets to the absolute directional estimates from volcanic materials. A scaling factor could then be calculated by either

a) Direct matching between individual data points from volcanic materials with the Mavora Curve or by calculating a least squares fit between the continuous and discrete data. The uncertainty in the estimate of the scaling factor will be large when the independent ages of the volcanic data have excessively large uncertainties, such as the TgVC lavas in this study, and the directional data thus have a number of potential tie points within the Mavora Curve.

b) Matching the dispersion of the PSV described by the Mavora record to the statistical distribution of the volcanic dataset. This approach requires a detailed analysis of the statistical distributions of the sedimentary dataset to be scaled and the volcanic records. It also requires an investigation of experimental noise in both datasets. A preliminary statistical analysis is conducted below and difficulties of a scaling approach using the volcanic dataset of this study outlined. 
Many of the volcanic records listed in Table 6-1 are not different from the Mavora Curve at the $95 \%$ confidence level (e.g. the $95 \%$ confidence limits overlaps the confidence limit of the Mavora Curve), which to a first order suggests validity of the data comparison conducted above and the results of palaeomagnetic dating conducted in chapter 3 . However, the flow mean directions often suggest overall broader swings (Figure 6-2). In Figure 6-3 we display a) the distribution of the Mavora data about their mean, b) the distribution of all volcanic data records that sample the same time-period $(<11.5 \mathrm{kyrs}$ BP) as the Mavora Curve about their mean c) the distribution of all volcanic data listed in Table 6-1 about their mean direction. The relatively large data volume of the Mavora Curve $(\mathrm{N}=224)$ is roughly Fisher-distributed, and has a dispersion of $5.4^{\circ}$ after its relocation to $39.2^{\circ} \mathrm{S}, 175.2^{\circ} \mathrm{E}$ (Mavora $\theta 63=4.8^{\circ}$ prior to its relocation). In contrast the discrete datasets displayed in Figure 6-3b and Figure 6-3c have dispersions of $\theta 63=9.1^{\circ}$ and $\theta 63=9.9^{\circ}$, respectively. Inter-site directional scatter or other noise, resulting from local magnetic anomalies in the field, sampling and experimental procedures are likely to enhance the dispersion of the records from volcanic materials but cannot account for the large difference between the Mavora Curve and the discrete dataset.

In a preliminary approach a scaling factor for the amplitude of the Mavora record could therefore be derived by matching the statistical distribution of the Mavora record to the one described by the volcanic dataset, including data from materials < 11.5 kyrs, which implies a scaling factor of ca. 1.7. We note however that the relatively small number of volcanic data included in Figure 6-3b do not present a large enough sample of the PSV distribution to form a distribution and hence to make an accurate estimation of its statistical parameters, also seen from the difference of its mean from the mean of the Mavora record. Inclusion of additional data $>11.5$ kyrs (Figure 6-3c) would widen the dataset but would be conducted under the assumption that PSV prior to $11.5 \mathrm{ka}$ followed similar patterns as in the later Holocene. Furthermore, as discussed earlier in this chapter, the volcanic dataset primarily samples two periods of high amplitude secular variation and it may therefore not be representative for the entire record. Rigorous statistical analysis thus requires a much larger and temporarily well distributed dataset. 

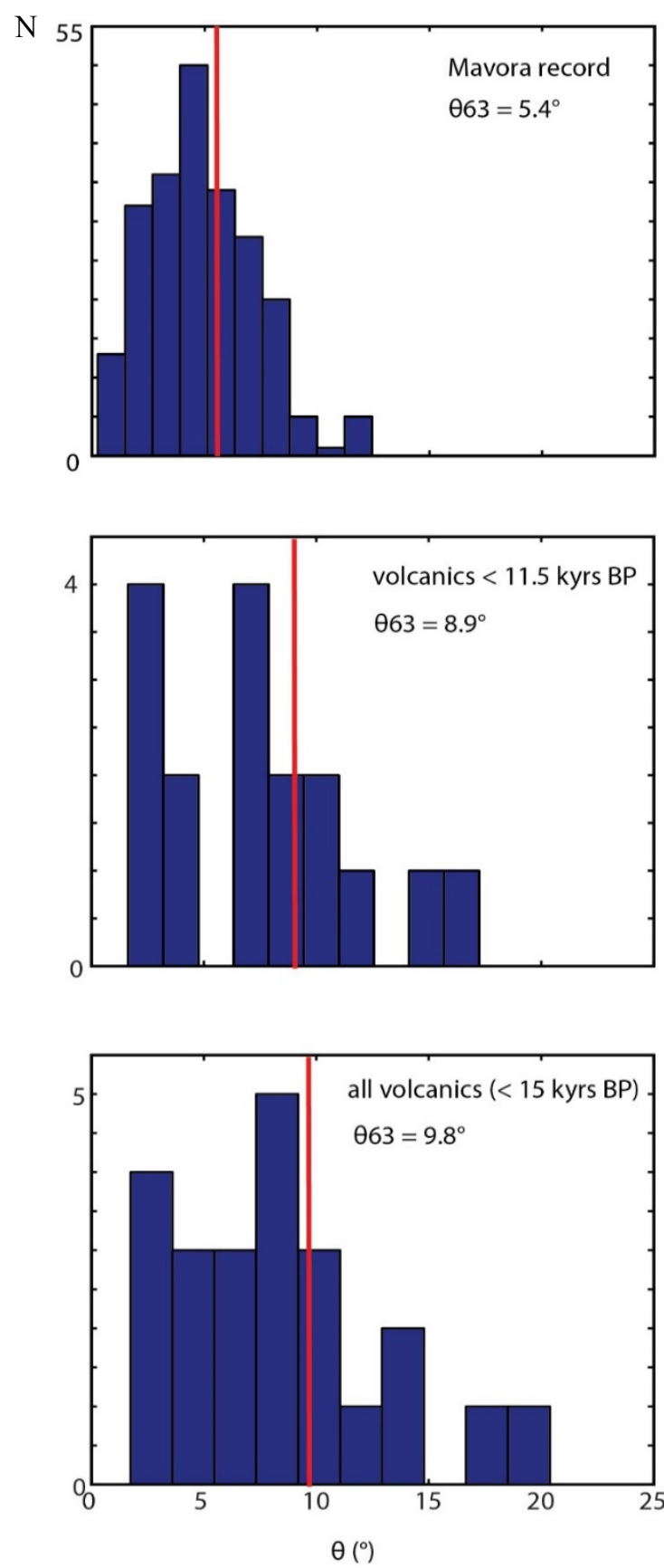

Figure 6-3: Distribution of the palaeomagnetic directions. a) Distribution of the Mavora data about their mean, b) distribution of all discrete PSV data $<11.5$ kyrs about their mean c) Distribution of all discrete PSV data $(<15 \mathrm{kyrs}$ BP) about their mean. The red lines represent the angular bandwidth about the mean that contains $63 \%$ of all data $(\theta 63)$. 


\subsubsection{The Lake Pounui record ( 2400 yrs BP -250 yrs BP?)}

Not discussed in this thesis so far was the earliest continuous PSV record from Lake Pounui near Wellington in the lower North Island (Turner and Lillis, 1994), a directional curve at the time of publication thought to cover the past 2500 yrs BP. The Lake Pounui record describes a broad swing towards westerly declinations and back to the current easterly declination and from relatively shallow to steep inclinations in the late Holocene, features also described by the Mavora Curve. However in comparison to the Lake Mavora Curve the Pounui record appears shifted further back in time (Figure 6-5). Turner et al. (2015b) suggested that the age model of the Pounui record, which was based on four uncalibrated radiocarbon ages, is too old by several hundreds of years. This was probably caused by inclusion of older organic material, with an inbuilt ${ }^{14} \mathrm{C} /{ }^{12} \mathrm{C}$ age, in the sediment samples used for radiocarbon dating. In recent efforts to integrate the Mavora, Pounui and a to-date unpublished sedimentary record into a New Master Curve for New Zealand (Corkill, 2015; Turner et al., 2015a) a revised age model for the Pounui sedimentary record was put forward. In the following we demonstrate that an age model can also be provided by correlation with the volcanic records younger than $2500 \mathrm{yrs} \mathrm{BP}$, for which radiometric age controls are available (section 6.4). Independence in the age models of the continuous records is a requirement for stacking exercises, for example during the creation of a Master Curve.

In a preliminary approach and, starting from the most recent, we match each palaeomagnetic direction from the volcanic dataset with a point on the Pounui Curve. At its youngest end the Pounui record is dated to $250{ }^{14} \mathrm{C}$ yrs BP and the easterly directions from the Tarawera Basalt (NK19) and Central Crater (CC) flow are probably placed at or above its upper limit. The youngest matches were identified for the Rangitoto basalt (RT) and Kaharoa rhyolite (KH) which correlated best with the mean directions of the Pounui record at 825 and $1075{ }^{14} \mathrm{C}$ yrs BP in its original age model, respectively. 
Going backwards in time, the Pounui record describes a rapid swing towards westerly directions and shallow inclinations and the declinations peak at around 1500 and $170014 \mathrm{C}$ yrs BP (Pounui age model). From this point the declinations return to easterly directions at the lower end ( $240014 \mathrm{C}$ yrs BP, Pounui age model) of the record. If this age model was accurate this would not allow for the inclusion of the easterly palaeomagnetic direction of the Taupo Ignimbrite $\left(\mathrm{Dec}=3.9, \mathrm{Inc}=-52.2^{\circ}\right.$, $\alpha 95=2.4^{\circ}$ ), which has a radiocarbon age of $1720 \pm 10$ cal. yrs BP (Table 6-1, Figure 6-5).

We thus suggest that the direction of the Taupo Ignimbrite is placed below the earliest Pounui record. This may explain the absence of Taupo Ignimbrite in the Pounui sediments, as it forms a distinct marker bed in many sedimentary sequences from the North Island. Taking the positions of the Rangitoto basalt and Kaharoa rhyolite and assuming that the direction of the Taupo Ignimbrite lies close to the bottom of the Pounui record (here: extrapolated to ca. $2600{ }^{14} \mathrm{C}$ yrs BP in Pounui's age model), we calculate a linear fit between the original ${ }^{14} \mathrm{C}$ age model and the calibrated age model provided by the volcanic data. The age calibration suggests that at its lowest end the original age model is up to 900 years too old (Figure 6-4). Figure 6-5 displays the Pounui record in comparison to the Mavora Curve prior to calibration of its age model and thereafter. The calibrated version of the record produces Mavora's features much better, although Pounui's record suggests a declination swing of slightly longer duration and higher amplitude than it is displayed in the Mavora Curve.

This simple correction demonstrates the potential of providing independent age constraints on a sedimentary curve using discrete palaeomagnetic datasets. A more robust correction of the Pounui record requires a detailed analysis of the errors in the palaeomagnetic directions of the sedimentary and volcanic dataset and by taking the original depth model of Turner and Lillis (1994) into account. It may be further improved by inclusion of additional discrete datasets, for example obtained from archaeomagnetic materials in a parallel $\mathrm{PhD}$ thesis by Kinger (in prep). 


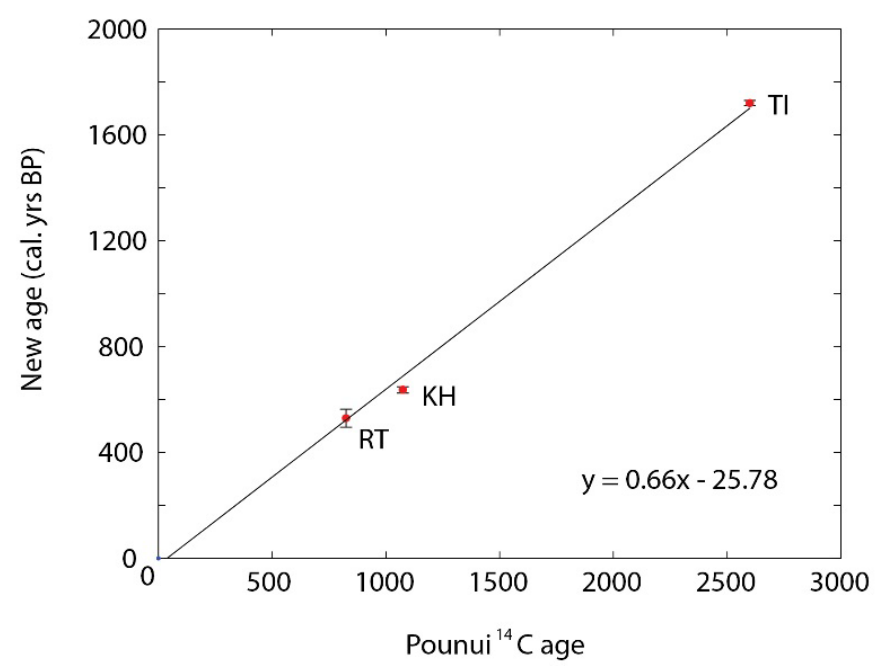

Figure 6-4: Calibrated age model for the Pounui record based on a correlation of the palaeomagnetic record with discrete data points from two volcanic lavas for which age constraints are available (section 6.4) and inference that the Taupo eruption preceded the earliest record. The $\mathrm{x}$-axis displays the original ${ }^{14} \mathrm{C}$ ages of the Pounui record, on the $y$ axis we display the calibrated ages. 

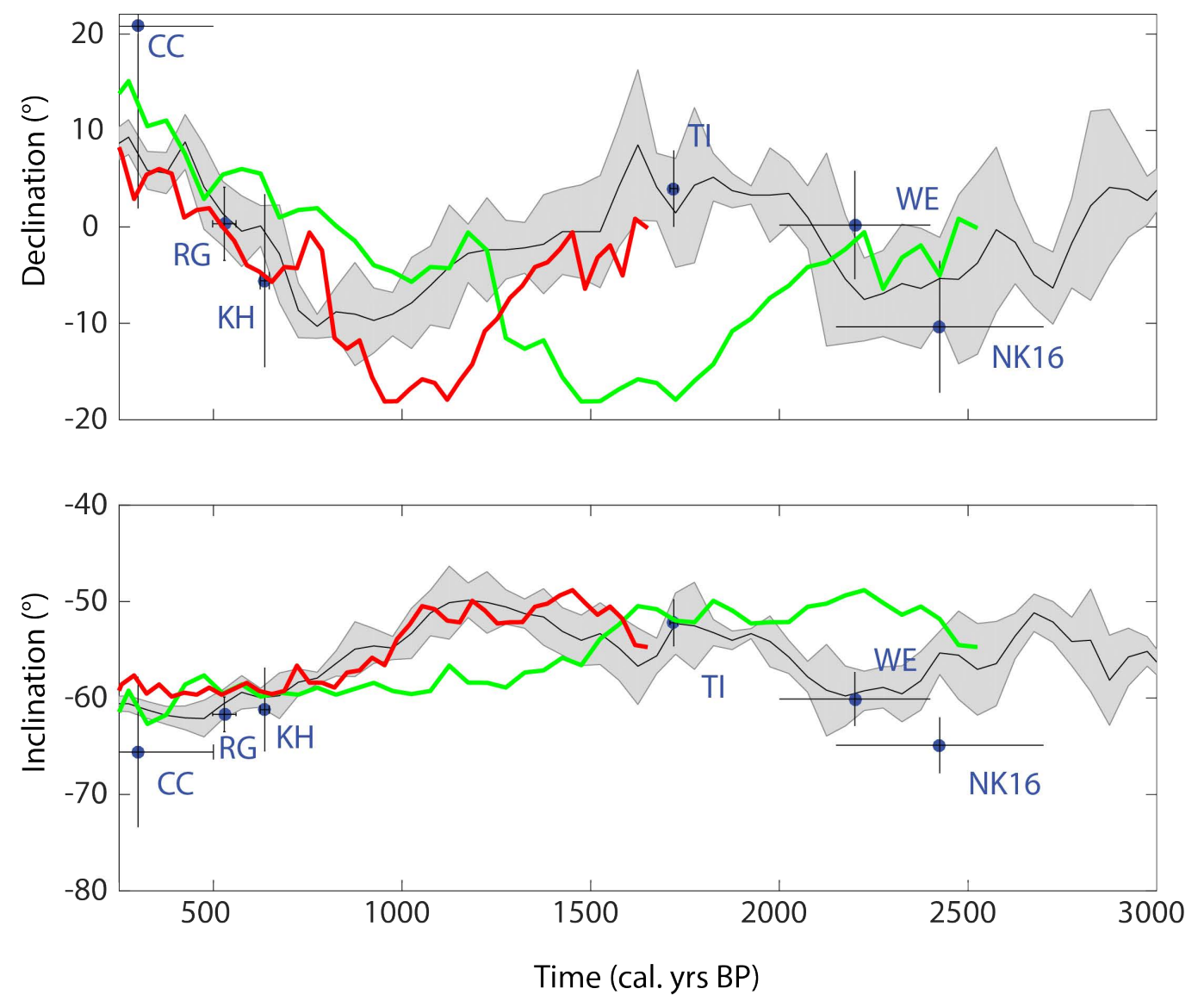

$\begin{array}{llll}- & \text { Pounui uncorrected } & - & \text { Mavora } \\ - & \text { Pounui corrected } & - & \text { NZ volcanics }\end{array}$

Figure 6-5: Comparison between the Mavora Curve and the Pounui record prior to the correction of its age model, the Pounui record after its correction and the discrete data discussed in the text. All data was relocated to $39.2^{\circ} \mathrm{S}, 175.5^{\circ} \mathrm{E}$. The revised Pounui Curve reproduces the features of the Mavora Curve between ca. 1700 cal. yrs BP and present. 


\subsubsection{Effects of the new data on global field model 'pfm9k.1a'}

With the aim of testing the impact of the new discrete data on the most recent global field model pfm9k.1a, which incorporates sedimentary and absolute directional and intensity records (Nilsson et al., 2014), Andreas Nilsson kindly re-ran the modelling procedure including the discrete data presented in this chapter. Figure 6-6 compares between model pfm9k.1a a) as it was published in 2014 (green), including Turner and Lillis (1994) continuous record from Lake Pounui and the discrete data of previous studies by Tanaka et al. (1994; 2009) and Robertson (1986) b) after replacing the Pounui record with the Mavora Curve (red), c) after replacing all previously included datasets from New Zealand with the Mavora Curve and the revised or new data presented in this thesis (blue). In this preliminary approach we used the palaeomagnetic ages from chapter 3 as age control for the TgVC lavas (Table 6-1). We use these refined ages to improve the usability of the data for the modelling approach, where age uncertainties are translated to palaeomagnetic uncertainties (e.g. Korte et al., 2005).

When the Mavora record is included in the calculation of pfm9k.1a the overall model reproduces its details very well, as would be expected as the only other data from the SW Pacific region are five lake sediment records from Australia (Barton and McElhinny, 1881; Constable, 1985; Constable and Mc Elhinny, 1985), more than 2500 $\mathrm{km}$ north-east of New Zealand. The most prominent changes to the original model are visible in the late Holocene (2000 yrs BP - 1000 yrs BP), where the original model pfm9k.1a was primarily constrained by the Lake Pounui record (Turner and Lillis, 1994), which has an age model that is probably too old (section 6.5.3). A prominent swing towards easterly declination and shallow inclinations described by the Mavora Curve in the early parts of its record ( $\sim 9000$ yrs BP), has a significant effect on the model as well. However most of this high amplitude signal is earlier than the lower end of model pfm9k.1a. As discussed earlier, the discrete data suggest even higher amplitude swings than described by the Mavora Curve. It is therefore not surprising that inclusion of the additional discrete data to the modelling procedure results in an even stronger bias of the model towards easterly directions at its earliest end. However, 
overall we note that in comparison to the Mavora Curve the discrete data has only minor impact on the model, most probably due to the smaller data volume, its wide temporal and spatial distribution (pers. comm. Nilsson), the overall good agreement with the Mavora Curve and the also the fact that the ages of the TgVC lavas are not independent of the Mavora Curve. Single and extreme data points often result in short wavelength biases of the model towards the respective data. This outcome has a number of implications:

- A larger dataset from the region is required to ensure that outliers are not overly weighted during the modelling procedure.

- To decrease the impact of single data points but to place higher emphasis on the overall scale of PSV described by the absolute records we suggest the implementation of some form a pre-scaling procedure for the amplitudes (e.g. section 6.5.1) for the continuous records.

A pre-scaling procedure may also allow for the inclusion of palaeomagnetic data from the TgVC lavas with their independent and large uncertainties. Removal of these datasets from the modelling procedure would be unfortunate as following the data analysis presented in chapters 3,4 and 5 we place overall higher confidence in the palaeomagnetic data obtained from the andesitic lavas from the $\mathrm{TgVC}$ than in that of many of the rhyolitic domes or flows. This is because the TgVC lavas were usually clearly in-situ, showed coherence of palaeodirections over wide site-spreads and were rarely affected by VRM or CRM overprints. In contrast on some of the rhyolitic lava flows or domes coherence could only be established through wide spread sampling campaigns. 

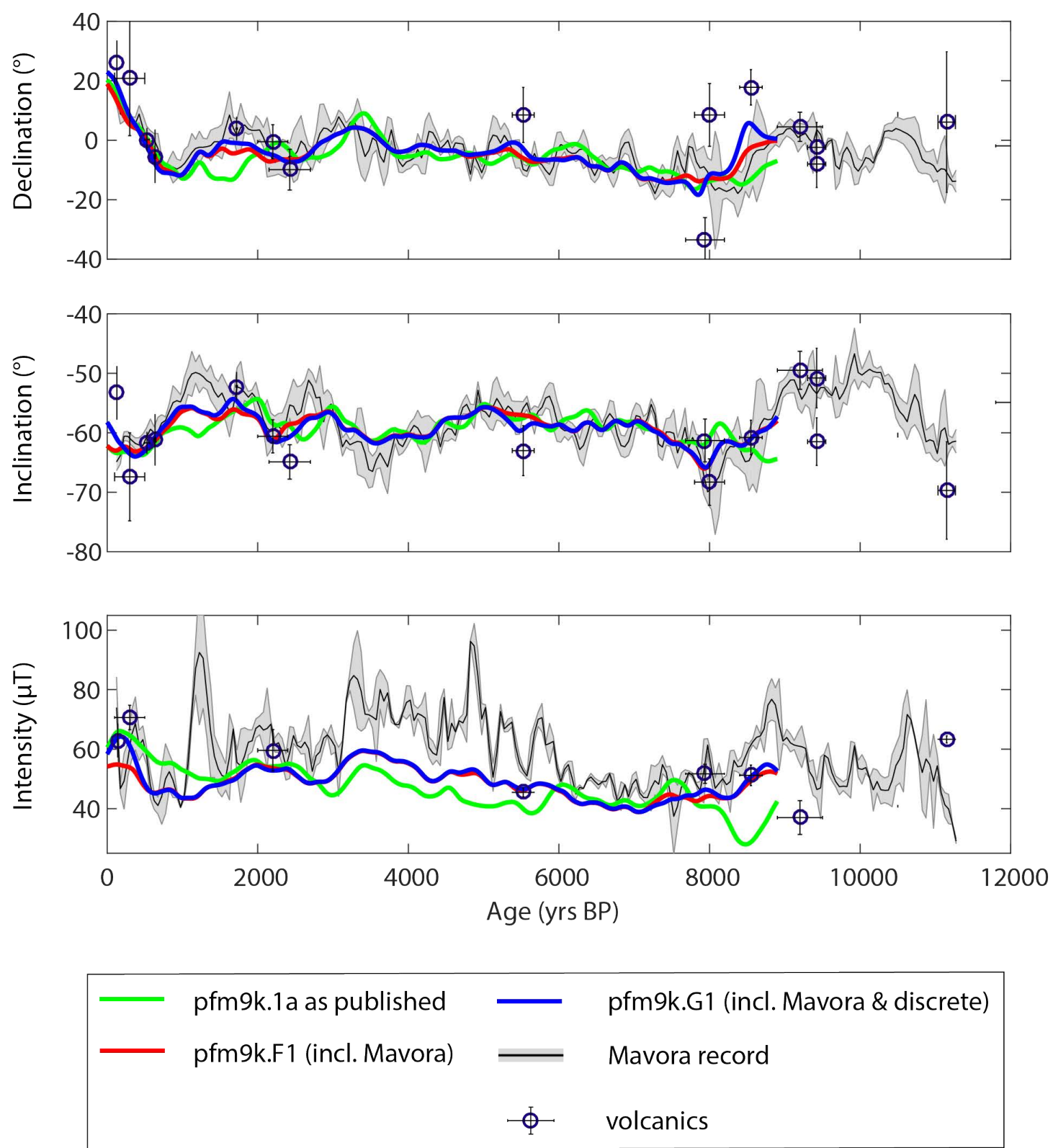

Figure 6-6: Declination, inclination and intensity records for $39.2^{\circ} \mathrm{S}, 175.5^{\circ} \mathrm{E}$ calculated from the global field model pfm9k.1a in its original and published form (Nilsson et al., 2014), after inclusion of the Mavora Curve and after addition of the discrete data discussed in this chapter. 


\subsubsection{VADM reconstruction}

Comparison of palaeointensity data from New Zealand with global datasets is possible by comparison of virtual axial dipole moments (VADMs) or virtual dipole moments (VDMs) with global averages. A VADM describes the moment of the geocentric axial dipole that would produce the observed palaeointensity at the latitude of the site. It is calculated using:

$$
V A D M=\frac{4 \pi R^{3}}{\mu_{0} \sqrt{1+3 \cos ^{2} \theta_{s}}} F
$$

where $\mathrm{F}(\mathrm{T})$ is the palaeointensity measured, $\mathrm{R}(\mathrm{m})$ Earth's mean radius, $\mu_{0}\left(\mathrm{~m} * \mathrm{~kg}^{*} \mathrm{~s}^{-2}\right.$ $\left.* \mathrm{~A}^{-2}\right)$ the permeability of free space and $\theta_{\mathrm{s}}$ the co-latitude of the site.

Temporal and global averages of VADM aim to average out variations in the nondipolar field (e.g. Yang et al., 2000) and thus present a record of the evolution of Earth's dipole moment. Deviations from the global average, observed in single studies may bear information about the effects of the non-axial and non-dipole components of the field in a particular region. Figure 6-7a displays the virtual axial dipole moments (VADM) calculated from the discrete palaeointensity records presented in Table 6-1 and those from archaeointensity data from the SW Pacific Islands (Stark et al., 2010) in comparison to a global VADM reconstruction by Knudsen et al. (2008). The latter is based on discrete palaeointensity data from the GEOMAGIA50 database (Donadini et al., 2006). Knudsen et al.'s (2008) curve describes a long wavelength swing prior to 7,000 years BP, from when it increases towards a prominent high at around 3,000 years BP. From 1,000 yrs BP the VADM reconstruction describes a rapid decrease towards the present day axial dipole moment of $7.72 * 10^{22} \mathrm{Am}^{2}$ (Thébault et al., 2015)

With one exception (Acacia Heights dome) our pre-5 ka data compare well with the VADM reconstruction. Considerable differences are however seen between the global reconstruction and the discrete data from the Pacific region in the late Holocene. For instance, Stark et al.'s (2010) archaeomagnetic data (2500 - 4000 years BP) generally displays significantly below the VADM average. In contrast, the palaeointensity results on the young flows from New Zealand, for example Central Crater flow (palaeomagnetic age $300 \pm 200$ yrs BP) and the 1886 AD basalt from Tarawera 
(Tanaka et al., 2009) yield VADMs significantly above the global VADM reconstruction. The high palaeointensity recorded at Central Crater (CC) flow is accompanied by a steep inclination, which suggests an offset of the south magnetic pole towards New Zealand. From around 1700 AD global models show high magnetic flux at the core-mantle boundary (CMB) in the South Pacific (Nilsson et al., 2014) with tilting of the magnetic poles towards the pacific hemisphere. South magnetic pole movement towards lower latitude has continued during the last $100 \mathrm{yrs} \mathrm{BP}$, as recorded in observational data (e.g. Finlay et al., 2010).

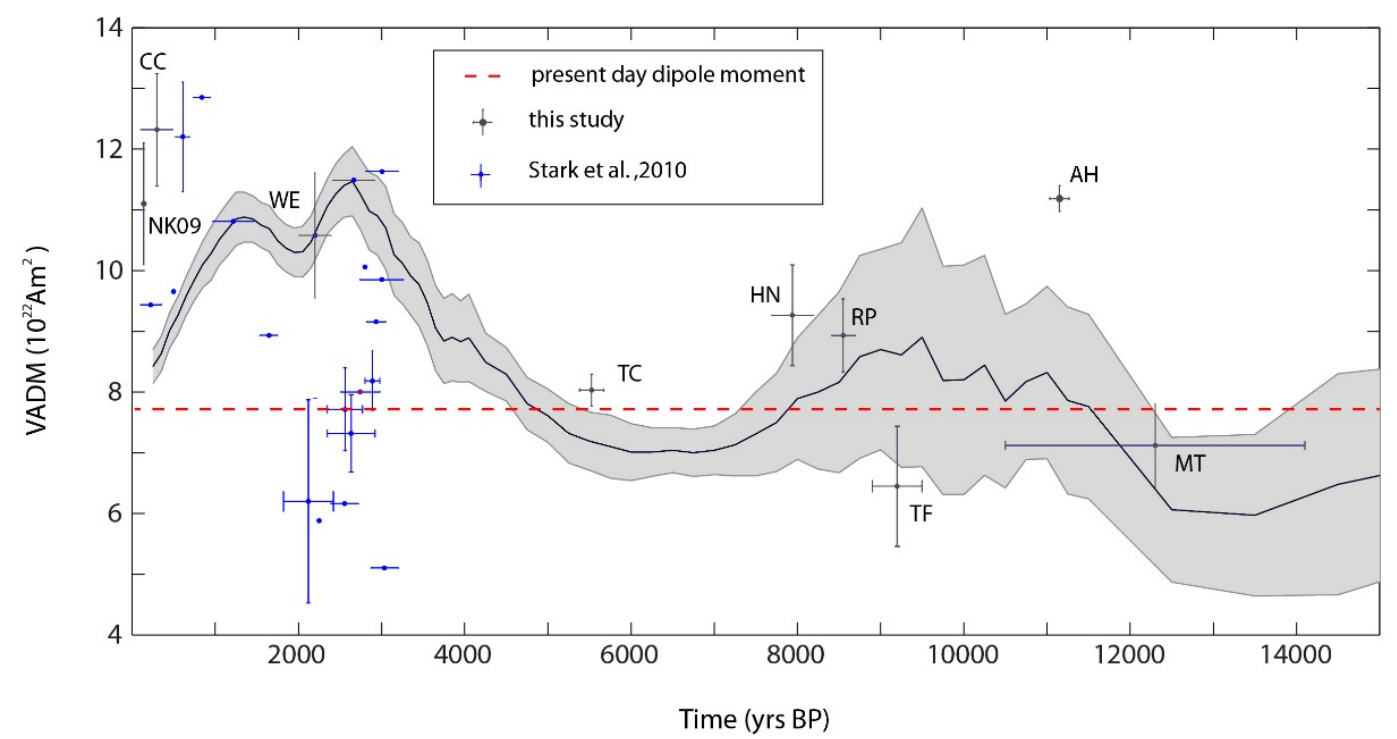

Figure 6-7: VADM's calculated from all intensity data from NZ volcanics and Pacific Island pottery (Stark et al., 2011) in comparison to the global VADM reconstruction of Knudsen et al. (2008). 


\subsection{Future Work}

A spatial and temporal extension of the present dataset would enhance our understanding of the evolution of the palaeomagnetic field in New Zealand and the SW Pacific region. The discrete dataset presented in this thesis lacks data in the timeperiod between 5000 and $2500 \mathrm{yrs} \mathrm{BP}$, due to the relative quiescence the Okataina Volcanic Centre and a dearth of well-dated materials from the Tongariro Volcanic Centre in that time-period. A priority of further studies on Holocene volcanic materials in New Zealand should therefore be an extension of the sampling campaign to other volcanic areas. For that purpose the inclusion of other materials than lavas, such as welded ignimbrites may be explored. Likewise, discrete and continuous datasets from the wider Pacific region are required in order to produce more robust field models and to understand the non-dipolar contributions to the field particularly in the late Holocene.

A major goal of future studies lies in the combination of the new datasets, including discrete data from volcanic and archaeomagnetic materials, and continuous records from New Zealand into regional field models (e.g. Alfheid, 2014; Ingham, 2009) and a PSV Master Curve for New Zealand (e.g. Corkill, 2015; Kinger, in prep; Turner et al., 2015b). A PSV Master Curve will be beneficial not only to an understanding of Earth's magnetic field but will provide important constraints for later palaeomagnetic dating studies. The potential of palaeomagnetic dating to refine age controls on lavas that are associated with large uncertainties was demonstrated on seven flows from Mts Ruapehu and Tongariro in chapter 3. Additional palaeomagnetic studies in particular in the northern part of the Tongariro Volcanic Centre, where the cone-building stratigraphic sequences are only loosely defined from under- and/or overlying tephra marker beds (Hobden, 1997) may be able provide additional age constraints and highlight individual effusive episodes. 


\section{Chapter 7}

Conclusions 
This study presents the results of a comprehensive palaeomagnetic study on Holocene lavas from the Taupo Volcanic Zone, with a focus on the Tongariro and Okataina Volcanic Centres. The new dataset includes:

- New palaeomagnetic directions from twelve units from the Tongariro Volcanic Centre, six flows from the Okataina Volcanic Centre and a direction from a rhyolitic dome near Taupo in the central North Island in New Zealand.

- Ten new palaeointensity estimates on flows from all three volcanic complexes are obtained using the thermal Thellier-type palaeointensity method and, for the andesitic lavas, also the microwave palaeointensity technique.

- The new data, and data previously published from the region are integrated into a new discrete PSV data compilation for New Zealand, including 24 high quality directional data and ten palaeointensity estimates. Each data carries independent high resolution ${ }^{40} \mathrm{Ar} /{ }^{39} \mathrm{Ar}$ age constraints from a parallel PhD study by Conway (2015) on Mt Ruapehu in the Tongariro Volcanic Centre, or tephra ages summarized in Lowe et al. (2013) of associated plinian fall deposits.

Integration with continuous sedimentary records from New Zealand or the most recent global field model pfm9k.1 a leads to the following conclusions/suggestions:

- The new data compare well to the recently published sedimentary record from Lake Mavora (Fiordland, New Zealand) (Turner et al., 2015b) and support the features described therein. The overall data dispersion $(\theta 63)$ of the data from volcanic materials is significantly larger than that of the Lake Mavora Curve, suggesting that the Mavora Curve is subject to amplitude smoothing. A comparison of the earliest secular variation record from Lake Pounui in the lower North Island, New Zealand (Turner and Lillis, 1994) with the Mavora Curve suggests that the age model of the earlier record is too old (Turner et al., 2015b). A tentative age model is presented in this study, based on a comparison with the independently dated volcanic dataset. The new model suggests that, at its lower end, the Pounui Curve is up to 900 years too old. 
- The virtual axial dipole moments of the absolute palaeointensity data of this study and archaeomagnetic data from the south west Pacific Islands (Stark et al., 2010) are compared with a global VADM reconstruction by Knudsen et al. (2008). The datasets from New Zealand compare well to the VADM reconstruction in the early Holocene, but significant differences are visible in the late Holocene (ca. 3000 yrs BP until present). Above average VADM values recorded by our new data younger than 1000 yrs BP are in accordance with a tilting of the magnetic poles towards the Pacific region, visible in global field model pfm9k.1a (Nilsson et al., 2014) and from observational data (Thébault et al., 2015).

- Inclusion of all new datasets into the global field model pfm9k.1a, which was re-run by Andreas Nilsson, has a strong impact on the model, most probably due to the small volume of data previously available from the region. In comparison to the Mavora Curve the volcanic data has only minor effect, probably due to the smaller number of data available and the good agreement with the Mavora Curve. Suggestions as to how volcanic PSV records could be addressed differently during modelling procedures are made.

- A Bayesian based statistical Matlab tool (Pavón-Carrasco et al., 2011) is used to refine the independent radiometric age constraints on five lava flows from the Tongariro Volcanic Centre by comparison with the Mavora directional record. The new age estimates reduce the age uncertainties from between 2-3000 years to as little as 500 years. 


\section{References}

Alfheid, M. A. (2014). Modelling Secular Variation in the Southwest Pacific for the last 400 years. (MSc), Victoria University of Wellington, New Zealand.

Barker, S. J., Wilson, C. J. N., Smith, E. G. C., Charlier, B. L. A., Wooden, J. L., Hiess, J., \& Ireland, T. R. 2014. Post-supereruption magmatic reconstruction of Taupo Volcano (New Zealand), as reflected in zircon ages and trace elements. Journal of Petrology, 55(8), 1511-1533.

Barton, C. E., \& McElhinny, M. W. 1881. A 10000 yr geomagnetic secular variation record from three Australian maars. Geophysical Journal International, 67(2). doi: 10.1111/j.1365-246X.1981.tb02761.x

Barton, C. E., \& Mc Elhinny, M. W. 1982. Time-series analysis of the $10000 \mathrm{yr}$ geomagnetic secular variation record from SE Australia. Geophysical Journal, Royal Astronomical Society, 68, 709-724.

Bibby, H. M., Caldwell, T. G., Davey, F. J., \& Webb, T. H. 1995. Geophysical evidence on the structure of the Taupo Volcanic Zone and its hydrothermal circulation. Journal of Volcanology and Geothermal Research, 68(1-3), 29-58.

Biggin, A. J., Perrin, M., \& Dekkers, M. J. 2007. A reliable absolute palaeointensity determination obtained from a non-ideal recorder. Earth and Planetary Science Letters, 257(3), 545-563. doi:10.1016/j.eps1.2007.03.017

Biggin, A. J., Strik, G. H. M. A., \& Langereis, C. G. 2009. The intensity of the geomagnetic field in the late-Archaen: new measurements and an analysis of the updated IAGA palaeointensity database. Earth Planets Space, 61(1), 9-22.

Biggin, A. J., McCormack, A., \& Roberts, A. 2010. Paleointensity database updated and upgraded. EOS, Transaction American Geophysical Union, 91(2), 15-15.

Biggin, A. J., Badejo, S., Hodgson, E., Muxworthy, a. R., Shaw, J., \& Dekkers, M. J. 2013. The effect of cooling rate on the intensity of thermoremanent magnetization (TRM) acquired by assemblages of pseudo-single domain, multidomain and interacting single-domain grains. Geophysical Journal International, 193, 1239-1249. doi: 10.1093/gji/ggt078

Bowles, J., Gee, J. S., Kent, D. V., Bergmanis, E., \& Sinton, J. 2005. Cooling rate effects on paleointensity estimates in submarine basaltic glass and implications for dating young flows. Geochemistry, Geophysics, Geosystems, 6, 1-24. doi: 10.1029/2004GC000900

Brown, M. C., Donadini, F., Nilsson, A., Panovska, S., Frank, U., Korhonen, K., . . . Constable, C. G. 2015. GEOMAGIA50.v3: 2. A new paleomagnetic database for lake and marine sediments. Earth, Planets and Space, 67(1), 1-19. doi: 10.1186/s40623-015-0233-Z 
Buck, M. D., Briggs, R. M., \& Nelson, C. S. 1981. Pyroclastic deposits and volcanic history of Mayor Island, N.Z. New Zealand Journal of Geology and Geophysics, 24, 449-4667.

Butler, R. F. 1998. Paleomagnetism: Magnetic domains to geologic terranes. Electronic edition, 1-238.

Cairns, E. A. (2014). Paleomagnetic Rotation Study of Woodlark-Australia plate motions in the Woodlark Rift, SE Papua New Guinea. (MSc), Victoria University of Wellington, Wellington.

Chadima, M., \& Hrouda, F. 2006. Remasoft 3.0 a user-friendly paleomagnetic data browser and analyzer. Travaux Géophysiques, 27, 20-21.

Chadima, M., \& Hrouda, F., 2012. Cureval 8.0.2: Thermomagnetic curve analyser for Windows: Agico, Inc.

Coe, R. S. 1967. Paleointensities of the Earth's magnetic field determined from Tertiary and Quaternary rocks. Journal of Geophysical Research, 72(12), 3247-3262. doi: 10.1029/JZ072i012p03247

Cole, J. W. 1978. Andesites of the Tongariro Volcanic Centre, North Island, New Zealand. Journal of Volcanology and Geothermal Research, 3(1), 121-153.

Cole, J. W., Spinks, K. D., Deering, C. D., Nairn, I. A., \& Leonard, G. S. 2010. Volcanic and structural evolution of the Okataina Volcanic Centre; dominantly silicic volcanism associated with the Taupo Rift, New Zealand. Journal of Volcanology and Geothermal Research, 190, 123-135. doi: 10.1016/j.jvolgeores.2009.08.011

Constable, C., Kopper, A., Tauxe, L., \& Minnet, R. (2006). The Five Dimensions of MagIC. Paper presented at the AGU Fall Meeting, San Francisco.

Constable, C., \& Korte, M. 2006. Is Earth's magnetic field reversing? Earth and Planetary Science Letters, 246, 1-16. doi: 10.1016/j.epsl.2006.03.038

Constable, C. G. 1985. Eastern australian geomagnetic field intensity over the past 14 000 yr. Geophysical Journal International, 81(1), 112-130. doi: 10.1111/j.1365-246X.1985.tb01354.x

Constable, C. G., \& Mc Elhinny, M. W. 1985. Holocene geomagnetic secular variation records from northeastern australian lake sediments. Geophysical Journal, Royal Astronomical Society, 81(1), 103-120. doi: 10.1111/j.1365246X.1985.tb01353.x

Constable, C. G., Johnson, C. L., \& Lund, S. P. 2000. Global geomagnetic field models for the past 3000 years: transient or permanent flux lobes? Philosophical Transactions of the Royal Society London, Series A, 358, 991-1008. doi: 10.1098/rsta.2000.0570

Conway, C., Leonard, G. S., Townsend, D. B., Calvert, A.T., Wilson, C. J. N Gamble, J. A., \& Eaves, S. R. 2016. A high-resolution ${ }^{40} \mathrm{Ar} /{ }^{39} \mathrm{Ar}$ lava

chronology and edificie history for Ruapehu volcano, New Zealand. Journal of Volcanology and Geothermal Research.

Conway, C. E., D. B. Townsend, G. S. Leonard, C. J. N. Wilson, A. T. Calvert, \& Gamble, J. A. 2015. Lava-ice interaction on a large composite volcano: a case study from Ruapehu, New Zealand. Bulletin of Volcanology, 21(77). doi: 10.1007/s00445-015-0906-2

Corkill, R. (2015). Holocene Palaeosecular Variation in New Zealand and the South West Pacific: Records and Models. (Master of Science), Victoria University of Wellington, Wellington, New Zealand. 
Cox, A. 1969. A paleomagnetic study of secular variation in New Zealand. Earth and Planetary Science Letters, 6(4), 257-267.

Day, R., Fuller, M., \& Schmidt, V. A. 1977. Hysteresis properties of titanomagnetites: grain-size and compositional dependence. Physics of the Earth and Planetary Interiors, 13, 260-267.

De Groot, L. V. d., Dekkers, M. J., Visscher, M., \& Maat, G. W. 2014. Magnetic properties and paleointensities as function of depth in a Hawaiian lava flow. Geochemistry, Geophysics, Geosystems, 15(4), 1096-1112. doi: 10.1002/2013GC005094

Donadini, F., Korhonen, K., Riisager, P., \& Pesonen, L. 2006. Database for Holocene Geomagnetic Intensity Information. Eos Transactions American Geophysical Union, 87, 137-143. doi: 10.1029/2003JB002672.

Donadini, F., Korte, M., \& Constable, C. G. 2009. Geomagnetic field for 0-3 ka: 1. New data sets for global modeling. Geochemistry, Geophysics, Geosystems, 10(6). doi: 10.1029/2008GC002295

Donoghue, S., Neall, V., \& Palmer, A. 1995. Stratigraphy and chronology of late Quaternary andesitic tephra deposits, Tongariro Volcanic Centre, New Zealand. Journal of the Royal Society of New Zealand, 25(2), 115-206.

Donoghue, S. L., \& Neall, V. E. 2001. Late Quaternary constructional history of the southeastern Ruapehu ring plain, New Zealand. New Zealand Journal of Geology and Geophysics, 44(3), 439-466. doi: 10.1080/00288306.2001.9514949

Downey, W. S., Kellett, R. J., Smith, I. E. M., Price, R. C., \& Stewart, R. B. 1994. New palaeomagnetic evidence for the recent eruptive activity of Mt. Taranaki, New Zealand. Journal of Volcanology and Geothermal Research, 60, 15-27.

Draeger, U., Prévot, M., Poidras, T., \& Riisager, J. 2006. Single-domain chemical, thermochemical and thermal remanences in a basaltic rock. Geophysical Journal International, 166, 12-32. doi: 10.1111/j.1365-246X.2006.02862.x

Dunlop, D., \& Özdemir, O. 1997. Rock Magnetism: Fundamentals and Frontiers, Cambridge University Press.

Dunlop, D. J. 2002. Theory and application of the Day plot $\left(\mathrm{M}_{\mathrm{rs}} / \mathrm{M}_{\mathrm{s}}\right.$ versus $\left.\mathrm{H}_{\mathrm{cr}} / \mathrm{H}_{\mathrm{c}}\right) 1$. Theoretical curves and tests using titanomagnetite data. Journal of Geophysical Research: Solid Earth, 107(B3), EPM 4-1-EPM 4-22. doi: 10.1029/2001JB000487.

Eaves, S. (2015). The glacial history of Tongariro and Ruapehu volcanoes, New Zealand. (PhD), Victoria University of Wellington, Wellington.

Eaves, S. R., Winckler, G., Schaefer, J. M., Vandergoes, M. J., Alloway, B. V., Mackintosh, A. N., . . Li, X. 2015. A test of the cosmogenic $\mathrm{He}^{3}$ production rate in the south-west Pacific (39 ${ }^{\circ}$ S). Journal of Quaternary Science, 30, 7987. doi: $10.1002 /$ jqs. 2760

Fabian, K. 2001. A theoretical treatment of paleointensity determination experiments on rocks containing pseudo-single or multi domain magnetic particles. Earth and Planetary Science Letters, 188, 45-58. doi: 10.1016/S0012821X(01)00313-2

Ferk, A., Leonhardt, R., Hess, K. U., \& Dingwell, D. B. 2011. Paleointensities on an 8 ka obsidian from Mayor Island, New Zealand. Solid Earth, 2, 259-270. doi: $10.5194 / \mathrm{se}-2-259-2011$ 
Finlay, C. C., Maus, S., Beggan, C. D., Bondar, T. N., Chambodut, A., Chernova, T. A., . . . Zvereva, T. I. 2010. International Geomagnetic Reference Field: the eleventh generation. Geophysical Journal International, 183, 1216-1230.

Fisher, R. 1953. Dispersion on a Sphere. Proceedings of the Royal Society A: Mathematical, Physical and Engineering Sciences, 217(1130), 295-305. doi: 10.1098/rspa.1953.0064

Froggatt, P. C. 1981. Karapiti Tephra Formation : a 10000 years B . P . rhyolitic tephra from Taupo. New Zealand Journal of Geology and Geophysics, 24, 95-98.

Froggatt, P. C., \& Lowe, D. J. 1990. A review of late Quaternary silicic and some other tephra formations from New Zealand: Their stratigraphy, nomenclature, distribution, volume, and age. New Zealand Journal of Geology and Geophysics, 33, 89-109. doi: 10.1080/00288306.1990.10427576

Gamble, J. A., Price, R. C., Smith, I. E. M., McIntosh, W. C., \& Dunbar, N. W. 2003. ${ }^{40} \mathrm{Ar} /{ }^{39} \mathrm{Ar}$ geochronology of magmatic activity, magma flux and hazards at Ruapehu volcano, Taupo Volcanic Zone, New Zealand. Journal of Volcanology and Geothermal Research, 120(3), 271-287.

Glatzmaier, G. A., \& Roberts, P. H. 1995. A three-dimensional convective dynamo solution with rotating and finitely conducting inner core and mantle. Physics of the Earth and Planetary Interiors, 91(1-3), 63-75.

Hackett, W. R. (1985). Geology and petrology of Ruapehu volcano and related vents. $(\mathrm{PhD})$, Victoria University of Wellington.

Hill, M. J., \& Shaw, J. 1999. Palaeointensity results for historic lavas from Mt.

Etna using microwave demagnetization/remagnetization in a modified Thellier-type experiment. Geophysical Journal International, 139, 583-590. doi: 10.1046/j.1365-246X.1999.00980.x

Hill, M. J., \& Shaw, J. 2000. Magnetic field intensity study of the 1960 Kilauea lava flow, Hawaii, using the microwave palaeointensity technique. Geophysical Journal International, 142, 487-504.

Hill, M. J., Gratton, M. N., \& Shaw, J. 2002. A comparison of thermal and microwave palaeomagnetic techniques using lava containing laboratory induced remanence. Geophysical Journal International, 151(1), 157-163. doi: 10.1046j.1365-246x.2002.01745.x

Hobden, B., Houghton, B., Lanphere, M., \& Nairn, I. 1996. Growth of the Tongariro volcanic complex: New evidence from K-Ar age determinations. New Zealand Journal of Geology and Geophysics, 39(1), 151-154. doi: 10.1080/00288306.1996.9514701

Hobden, B. J. (1997). Modelling magmatic trends in time and space: Eruptive and magmatic history of Tongariro Volcanic Complex, New Zealand. (PhD), University of Canterbury, Christchurch.

Hogg, A. G., Hua, Q., Blackwell, P. G., Niu, M., Buck, C. E., Guilderson, T. P., \& al., e. 2013. SHCAL13 southern hemisphere calibration, 0-50,000 years cal BP. Radiocarbon, 55(4), 1889-1903.

Houghton, B. F., Carey, R. J., Cashman, K. V., Wilson, C. J. N., Hobden, B. J., \& Hammer, J. E. 2010. Diverse patterns of ascent, degassing, and eruption of rhyolite magma during the $1.8 \mathrm{ka}$ Taupo eruption, New Zealand: Evidence from clast vesicularity. Journal of Volcanology and Geothermal Research, 195, 31-47. 
Ingham, L. (2009). The geomagnetic field in the South Pacific during the 19th Century New Zealand. (BSc Hons), Victoria University of Wellington, New Zealand.

Jackson, A., Jonkers, A. R., \& Walker, M. R. 2000. Four centuries of geomagnetic secular variation from historical records. Philosophical Transactions of the Royal Society of London A: Mathematical, Physical and Engineering Sciences, 358(1768), 957-990. doi: 10.1098/rsta.2000.0569

Jicha, B. R., Coombs, M. L., Calvert, A. T., \& Singer, B. S. 2012. Geology and ${ }^{40} \mathrm{Ar} /{ }^{39} \mathrm{Ar}$ geochronology of the medium- to high-K Tanaga volcanic cluster, western Aleutians. Bulletin of the Geological Society of America, 124, 842856. doi: 10.1130/B30472.1

Johnson, C. L., \& Constable, C. G. 1998. Persistently anomalous Pacific geomagnetic fields. Geophysical Research Letters, 25, 1011. doi: 10.1029/98GL50666

Kinger, R. (2016). An Archaeomagnetic Study of Hangi stones in New Zealand. $(\mathrm{PhD})$, Victoria University of Wellington, New Zealand.

Kirschvink, J. L. 1980. The least-squares line and plane and the analysis of palaeomagnetic data. Geophysical Journal, Royal Astronomical Society, 62(3), $699-718$.

Kissel, C., \& Laj, C. 2004. Improvements in procedure and paleointensity selection criteria (PICRIT-03) for Thellier and Thellier determinations: application to hawaiian basaltic long cores. Physics of the Earth and Planetary Interiors, 147(2-3), 155 - 169.

Knudsen, M. F., Riisager, P., Donadini, F., Snowball, I., Muscheler, R., Korhonen, K., \& Pesonen, L. J. 2008. Variations in the geomagnetic dipole moment during the Holocene and the past $50 \mathrm{kyr}$. Earth and Planetary Science Letters, 272, 319-329. doi: 10.1016/j.eps1.2008.04.048

Korhonen, K., Donadini, F., Riisager, P., \& Pesonen, L. J. 2008. GEOMAGIA50: An archeointensity database with PHP and MySQL. Geochemistry, Geophysics, Geosystems, 9, 1-14. doi: 10.1029/2007GC001893

Korte, M., Genevey, A., Constable, C. G., Frank, U., \& Schnepp, E. 2005. Continuous geomagnetic field models for the past 7 millenia: 1. A new global data compilation. Geochemistry, Geophysics, Geosystems, 6(2). doi: 10.1029/2004GC000800

Korte, M., Donadini, F., \& Constable, C. G. 2009. Geomagnetic field for 0-3 ka: 2. A new series of time-varying global models. Geochemistry Geophysics Geosystems, 10(6). doi: 10.1029/2008GC002297

Korte, M., \& Holme, R. 2010. On the persistence of geomagnetic flux lobes in global Holocene field models. Physics of the Earth and Planetary Interiors, 182(3), 179-186. doi: 10.1016/j.pepi.2010.08.006

Korte, M., Constable, C., Donadini, F., \& Holme, R. 2011. Reconstructing the Holocene geomagnetic field. Earth and Planetary Science Letters, 312, 497505. doi: 10.1016/j.epsl.2011.10.031

Lanos, P. 2004. Bayesian inference of calibration curves: application to archaeomagnetism. In C. B. A. Millard (Ed.), Tools for Constructing Chronologies: Crossing Disciplinary Boundaries., 177, 43 - 82, Springer Verlag.

Lattard, D., Engelmann, R., Kotny, A., \& Sauerzapf, U. 2006. Curie temperatures of synthetic titanomagnetites in the Fe-Ti-O system: Effects of 
composition, crystal chemistry, and thermomagnetic methods. Journal

of Geophysical Research, 111(B12S28). doi: 10.1029/2006JB004591

Leonhardt, R., Heunemann, C., \& Krasa, D. 2004a. Analyzing absolute paleointensity determinations: Acceptance criteria and the softwarde ThellierTool4.0. Geochemistry, Geophysics, Geosystems, 5(12). doi: 10.1029/2004GC000807

Leonhardt, R., Krasa, D., \& Coe, R. S. 2004b. Multidomain behavior during Thellier paleointensity experiments: a phenomenological model. Physics of the Earth and Planetary Interiors, 147(2-3), 127-140.

Leonhardt, R. 2006. Analyzing rock magnetic measurements: The RockMagAnalyzer 1.0 software. Computers \& Geosciences, 32, 1420-1431. doi: 10.1016/j.cageo.2006.01.006

Leonhardt, R., Matzka, J., Nichols, a. R. L., \& Dingwell, D. B. 2006. Cooling rate correction of paleointensity determination for volcanic glasses by relaxation geospeedometry. Earth and Planetary Science Letters, 243, 282-292. doi: 10.1016/j.epsl.2005.12.038

Lescinsky, D. T., \& Fink, J. H. 2000. Lava and ice interaction at stratovolcanoes: use of characteristic features to determine past glacial extents and future volcanic hazards. Journal of Geophysical Research, 105, 23711-23726.

Levi, S. 1977. The effect of magnetite particle size on paleointensity determinations of the geomagnetic field. Physics of the Earth and Planetary Interiors, 13, 245259. doi: 10.1016/0031-9201(77)90107-8

Lowe, D. J., Blaauw, M., Hogg, A. G., \& Newnham, R. M. 2013. Ages of 24 widespread tephras erupted since 30,000 years ago in New Zealand, with reevaluation of the timing and palaeoclimatic implications of the Lateglacial cool episode recorded at Kaipo bog. Quaternary Science Reviews, 74, 170-194. doi: 10.1016/j.quascirev.2012.11.022

McClelland, E. 1996. Theory of CRM acquired by grain growth, and its implications for TRM discrimination and palaeointensity determination in igneous rocks. Geophysical Journal International, 126, 271-280.

McClelland, E., \& Erwin, P. S. 2003. Was a dacite dome implicated in the 9,500 BP collapse of Mt Ruapehu? A palaeomagnetic investigation. Bulletin of Volcanology, 65(4), 294-305.

McClelland, E., Wilson, C. N., \& Bardot, L. 2004. Palaeotemperature determinations for the 1.8-ka Taupo ignimbrite, New Zealand, and implications for the emplacement history of a high-velocity pyroclastic flow. Bulletin of Volcanology, 66, 492-513. doi: 10.1007/s00445-003-0335-5

McCormack, F. G., Hogg, A. G., Blackwell, P. G., Buck, C. E., Higham, T. F. G., \& Reimer, P. J. 2004. SHCAL04 Southern Hemisphere calibration, 0-11.0 cal kyr BP. Radiocarbon, 46(3), 1087-1092.

McElhinny, M., \& McFadden, P. 1997. Palaeosecular variation over the past $5 \mathrm{Myr}$ based on a new generalized database. Geophysical Journal International, 131, 240-252.

McFadden, P. L., \& McElhinny, M. W. 1988. The combined analysis of remagnetization circles and direct observations in palaeomagnetism. Earth and Planetary Science Letters, 87, 163-189.

Merill, R. T., McElhinny, M. W., \& McFadden, P. I. 1998. The magnetic field of the Earth: Paleomagnetism, the Core and the Deep Mantle, Academic Press. 
Moebis, A., Cronin, S. J., Neall, V. E., \& Smith, I. E. 2011. Unravelling a complex volcanic history from fine-grained, intricate Holocene ash sequences at the Tongariro Volcanic Centre, New Zealand. Quaternary International, 246(1-2), 352-363. doi: 10.1016/j.quaint.2011.05.035

Nairn, I. A. 2002. Geology of the Okataina Volcanic Centre, Scale 1:50,000 geological map. Institute of Geology and Nuclear Sciences, Lower Hutt, Wellington.

Nakagawa, M., Nairn, I. A., \& Kobayashi, T. 1998. The 10 ka multiple vent pyroclastic eruption sequence at Tongariro Volcanic Centre, Taupo Volcanic Zone, New Zealand: Part 2. Petrological insights into magma storage and transport during regional extension. Journal of Volcanology and Geothermal Research, 86, 45-65. doi: 10.1016/S0377-0273(98)00086-9

Needham, A. J., Lindsay, J. M., Smith, I. E. M., Augustinus, P., \& Shane, P. A. 2010. Sequential eruption of alkaline and sub-alkaline magmas from a small monogenetic volcano in the Auckland Volcanic Field, New Zealand. Journal of Volcanology and Geothermal Research, 201, 126-142. doi: 10.1016/j.jvolgeores.2010.07.017

Néel, L. 1955. Some theoretical aspects of rock magnetism. Advances in Physics, 4, $191-243$.

Nilsson, A., Holme, R., Korte, M., Suttie, N., \& Hill, M. 2014. Reconstructing Holocene geomagnetic field variation: new methods, models and implications. Geophysical Journal International. doi: 10.1093/gji/ggu120

Noel, M., \& Batt, C. M. 1990. A method for correcting geographically separated remanence directions for the purpose of archaeomagnetic dating. Geophysical Journal International, 102, 753-756.

Olson, P. 2002. The disappearing dipole. Nature, 416, 591-594. doi: 10.1038/416591a

Paterson, G. A., Roberts, A. P., Mac Niocaill, C., Muxworthy, A. R., Gurioli, L., Viramonté, J. G., . . . Weider, S. 2010. Paleomagnetic determination of emplacement temperatures of pyroclastic deposits: An under-utilized tool. Bulletin of Volcanology, 72, 309-330. doi: 10.1007/s00445-009-0324-4

Paterson, G. A., Tauxe, L., Biggin, A. J., Shaar, R., \& Jonestrask, L. C. 2014. On improving the selection of Thellier-type paleointensity data. Geochemistry, Geophysics, Geosystems, 15(4), 1180-1192. doi: 10.1002/2013GC005135

Pavón-Carrasco, F. J., Rodríguez-González, J., Osete, M. L., \& Torta, J. M. 2011. A Matlab tool for archaeomagnetic dating. Journal of Archaeological Science, 38(2), 408-419. doi: 10.1016/j.jas.2010.09.021

Petrovsky, E., \& Kapicka, A. 2006. On determination of the Curie point from thermomagnetic curves. Journal of Geophysical Research, 111(B12). doi: 10.1029/2006JB004507

Price, R. C., Gamble, J. A., Smith, I. E. M., Maas, R., Waight, T., Stewart, R. B., \& Woodhead, J. 2012. The Anatomy of an Andesite Volcano: a TimeStratigraphic Study of Andesite Petrogenesis and Crustal Evolution at Ruapehu Volcano, New Zealand. Journal of Petrology, 53, 2139-2189. doi: 10.1093/petrology/egs050

Riisager, P., \& Riisager, J. 2001. Detecting multidomain magnetic grains in Thellier palaeointensity experiments. Physics of the Earth and Planetary Interiors, 125, 111-117. doi: 10.1016/S0031-9201(01)00236-9 
Roberts, A. P. 2008. Geomagnetic excursion: Knowns and unknowns. Geophysical Research Letters, 35(L17307). doi: 10.1029/2008GL034719

Roberts, A. P., Pike, Christopher P., Verosub, Kenneth L. 2000. First-order reversal curve diagrams: A new tool for characterizing the magnetic properties of natural samples. Journal of Geophysical Research, 105, 28,461-418,457.

Robertson, D. J. 1986. A paleomagnetic study of Rangitoto Island, Auckland, New Zealand. New Zealand Journal of Geology and Geophysics, 29(4), 405-411. doi: 10.1080/00288306.1986.10422162

Robertson, D. J. 2007. Paleomagnetism of c. AD 1314 Kaharoa rhyolite and the New Zealand paleosecular variation master curve NZPSV2007. New Zealand Journal of Geology and Geophysics, 50(1), 39-50. doi: 10.1080/00288300709509819

Sauerzapf, U., Lattard, D., Burchard, M., \& Engelmann, R. 2008. The Titanomagnetite-Ilmenite Equilibrium: New experimental data and thermooxybarometric application to the crystallization of basic to intermediate rocks. Journal of Petrology, 49, 1161-1185. doi: 10.1093/petrology/egn021

Selkin, P. A., Gee, J. S., Tauxe, L., Meurer, W. P., \& Newell, A. J. 2000. The effect of remanence anisotropy on paleointensity estimates: a case study from the Archean Stillwater Complex. Earth and Planetary Science Letters, 183, 403 416.

Selkin, P. A., \& Tauxe, L. 2000. Long-Term Variations in Palaeointensity. Philosophical Transactions, Royal Society, London, 358, 1065-1088.

Shcherbakov, V. P., Shcherbakova, V. V., Vinogradov, Y. K., \& Heider, F. 2001. Thermal stability of pTRMs created from different magnetic states. Physics of the Earth and Planetary Interiors, 126, 59-73. doi: 10.1016/S00319201(01)00244-8

Sigurdsson, H. 2000. Encyclopedia of Volcanoes. San Diego, Academic Press.

Smith, V. C., Shane, P., Nairn, I. A., \& Williams, C. M. 2006. Geochemistry and magmatic properties of eruption episodes from Haroharo linear vent zone, Okataina Volcanic Centre, New Zealand during the last $10 \mathrm{kyr}$. Bulletin of Volcanology, 69, 57-88. doi: 10.1007/s00445-006-0056-7

Speranza, F., Pompilio, M., D'Ajello Caracciolo, F., \& Sagnotti, L. 2008. Holocene eruptive history of the Stromboli volcano: Constraints from paleomagnetic dating. Journal of Geophysical Research, 113(B9). doi: 10.1029/2007JB005139

Stark, F., Cassidi, J., Hill, M., Shaw, J., \& Sheppard, P. 2010. Establishing a first archaeointensity record for the SW Pacific. Earth and Planetary Science Letters, 198, 113-124.

Stark, F. (2011). Secular variation of the Earth's magnetic field in the South West Pacific. (PhD), University of Liverpool.

Stormer, J. C. 1983. The effects of recalculation on estimates of temperature and oxygen fugacity from analyses of multicomponent iron-titanium oxides. American Mineralogist, 68, 586-594. 
Suttie, N., Shaw, J., \& Hill, M. J. 2010. Direct demonstration of microwave demagnetization of a whole rock sample with minimal heating. Earth and Planetary Science Letters, 292(3-4), 357-362. doi: 10.1016/j.epsl.2010.02.002

Tanaka, H., \& Kono, M. 1984. Analysis of the Thellier method of paleointensity determination 2: applicability to high and low magnetic fields. Journal of geomagnetism and geoelectricity, 36, 285-297.

Tanaka, H., Otsuka, A., Tachibana, T., \& Kono, M. 1994. Paleointensities for 10-22 ka from volcanic rocks in Japan and New Zealand. Earth and Planetary Science Letters, 122(1-2), 29-42.

Tanaka, H., Turner, G. M., Houghton, B. F., Tachibana, T., Kono, M., \& McWilliams, M. O. 1996. Palaeomagnetism and chronology of the central Taupo Volcanic Zone, New Zealand. Geophysical Journal International, 124(3), 919-934.

Tanaka, H., Kawamura, K., Nagao, K., \& Houghton, B. F. 1997. K-Ar ages and paleosecular variation of direction and intensity from quaternary lava sequences in the Ruapehu Volcano, New Zealand. Journal of geomagnetism and geoelectricity, 49, 587-599.

Tanaka, H., Komuro, N., \& Turner, G. M. 2009. Palaeosecular variation for 0 . $1-21$ ka from the Okataina Volcanic Centre, New Zealand. Earth, Planets and Space, 61(1), 213-225. doi: 10.1186/BF03352901

Tauxe, L., Mullender, T. A. T., \& Pick, T. 1996. Potbellies, wasp-waists, and superparamagnetism in magnetic hysteresis. Journal of Geophysical Research, 101, 571-583.

Tauxe, L. 1998. Paleomagnetic Principles and Practice, Kluwer Academic Publishers.

Tauxe, L., \& Staudigel, H. 2004. Strength of the geomagnetic field in the cretaceous normal superchron : new data from submarine basaltic glass of the Troodos Ophiolite. Geochemistry, Geophysics, Geosystems, 5(2). doi: 10.1029/2003GC000635

Tauxe, L., \& Yamazaki, T. 2007. Paleointensities. Treatise on Geophysics, 5, 509-563.

Tauxe, L. 2015. Essentials of Paleomagnetism: Third Web Edition.

Thébault, E., Finlay, C. C., Beggan, C. D., Alken, P., Aubert, J., Barrois, O., . . . Zvereva, T. 2015. International Geomagnetic Reference Field: the 12th generation. Earth, Planets and Space, 67, 79. doi: 10.1186/s40623-015-02289

Thellier, E., \& Thellier, O. 1959. Sur l'intensité du champ magnétique terrestre dans le passé historique et géologique. Ann. Geophys., 15, 285-376.

Topping, W. W. (1974). Some Aspects of Quaternary History of Tongariro Volcanic Centre. (PhD), Victoria University of Wellington, Wellington.

Tost, M., \& Cronin, S. J. 2015. Linking distal volcaniclastic sedimentation and stratigraphy with the development of Ruapehu volcano, New Zealand. Bulletin of Volcanology, 77(11), 1-17. doi: 10.1007/s00445-015-0977-0

Townsend, D., Leonard, G., Conway, C., \& Eaves, S. 1: 60000 Geological Map of the Tongariro Volcanic Centre. GNS Science, Lower Hutt. in prep

Turner, G., de Gelder, G. I. N. O., Howarth, J., Greve, A., Kinger, R., Corkill, R. \& Nilsson, A. (2015a). NZPSV1k and NZPSV10k: New palaeosecular V variation master records for New Zealand: Applications for dating and field modeling. 
Oral presentation at the American Geophysical Union Joint Assembly. Montreal.

Turner, G. M., \& Thompson, R. 1982. Detransformation of the British geomagnetic secular variation record for Holocene times. Geophysical Journal International, 70, 789-792.

Turner, G. M., \& Lillis, D. A. 1994. A palaeomagnetic secular variation record for New Zealand during the past 2500 years. Physics of the Earth and Planetary Interiors, 83(3-4), 265-282.

Turner, G. M., Howarth, J. D., de Gelder, G. I. N. O., \& Fitzsimons, S. J. 2015b. A new high-resolution record of Holocene geomagnetic secular variation from New Zealand. Earth and Planetary Science Letters, 430, 296-307. doi: 10.1016/j.eps1.2015.08.021

Valet, J.-P., Brassart, J., Meur, I. L., Soler, V., Quidelleur, X., Tric, E., \& Gillot, P. Y. 1996. Absolute paleointensity and magnetomineralogical changes. Journal of Geophysical Research, 101(B11), 25,029 - 025,044.

Van Bemmelen, W. 1898. Observations made with the Compass on Tasman's Voyage. In Abel Janszoon Tasman's Journal. Produced in facsimile, Frederick Muller and Co., Amserdam. Reprinted by N.A. Kovach, Los Angeles, 1965. Also availabe at Gutenberg.net.au/ebooks06/0600571h.html.

Van Eaton, A. R., \& Wilson, C. J. N. 2012. The nature, origins and distribution of ash aggregates in a large-scale wet eruption deposit: Oruanui, New Zealand. Journal of Volcanology and Geothermal Research, 250, 129-154.

Vandergoes, M. J., Hogg, A. G., Lowe, D. J., Newnham, R. M., Denton, G. H., ., . . \& Blaauw, M., 2013. A revised age for the Kawakawa/Oruanui tephra, a key marker for the Last Glacial Maximum in New Zealand. Quartenary Science Reviews, 74, 195-201.

Walker, A. D., \& Backus, G. E. 1996. On the difference between the average values of $\mathrm{B}_{\mathrm{r}}^{2}$ in the Atlantic and Pacific hemispheres. Geophysical Research Letters, 23, 1965-1968.

Walton, D., Snape, S., Rolph, T. C., Shaw, J., \& Share, J. 1996. Application of ferrimagnetic resonance heating to palaeointensity determinations. Physics of the Earth and Planetary Interiors, 94, 183 - 186.

Watkins, N. D., \& Haggerty, S. E. 1968. Oxidation and magnetic polarity in single icelandic lavas and dikes. Geophysical Journal International, 15, 305-315. doi: 10.1111/j.1365-246X.1968.tb00187.x

Wilson, C., Houghton, B., McWilliams, M., Lanphere, M., Weaver, S., \& Briggs, R. 1995. Volcanic and structural evolution of Taupo Volcanic Zone, New Zealand: a review. Journal of Volcanology and Geothermal Research, 68(1), 1-28. doi: doi:10.1016/0377-0273(95)00006-G

Wilson, C. J. N. 1993. Stratigraphy, chronology, styles and dynamics of late quaternary eruptions from Taupo Volcano, New Zealand. Philosophical Transactions of the Royal Society A: Mathematical, Physical and Engineering Sciences, 343, 205-306. doi: 10.1098/rsta.1993.0050

Yamamoto, Y., Tsunakawa, H., \& Shibuya, H. 2003. Palaeointensity study of the Hawaiian 1960 lava: implications for possible causes of erroneously high intensities. Geophysical Journal International, 153, 263-276. 
Yang, S., Odah, H., \& Shaw, J. 2000. Variations in the geomagnetic dipole moment over the last 12000 years. Geophysical Journal International, 140(1), 158162. doi: 10.1046/j.1365-246x.2000.00011.x

Yu, Y., Tauxe, L., \& Genevey, A. 2004. Toward an optimal geomagnetic field intensity determination technique. Geochemistry, Geophysics, Geosystems, 5(2). doi: 10.1029/2003GC000630

Zijderveld, J. 1967. AC demagnetization of rocks: analysis of results. Methods in paleomagnetism, 254-268. 